QATAR UNIVERSITY

COLLEGE OF ENGINEERING

FLEXURAL BEHAVIOR OF BASALT FIBER REINFORCED CONCRETE BEAMS

WITH RECYCLED CONCRETE COARSE AGGREGATES

\author{
BY \\ OMAR RAAD NAJI ALJIDDA
}

\author{
A Thesis Submitted to the Faculty of \\ The College of Engineering \\ In Partial Fulfillment \\ of the Requirements \\ for the Degree of \\ Master of Science in Civil Engineering
}

January 2017

(C) 2017. Omar Raad Naji Aljidda. All Rights Reserved 


\section{COMMITTEE PAGE}

The members of the Committee approve the Thesis of Omar Raad Naji Aljidda defended on $26 / 02 / 2017$.

\begin{tabular}{r} 
Dr. Wael Alnahhal \\
Thesis Supervisor \\
\hline $\begin{array}{r}\text { Dr. Usama Ebead } \\
\text { Committee Member }\end{array}$ \\
\hline Dr. Mohammed Al-Ansari \\
Committee Member \\
Dr. Shahria Alam \\
Committee Member \\
\\
Dr. Arslan Ayari \\
Committee Member
\end{tabular}

Dr. Wael Alnahhal

Dr. Usama Ebead

Committee Member

Approved:

Khalifa Al-Khalifa, Dean, College of Engineering 


\begin{abstract}
Aljidda Omar, Masters: January: 2017, Masters of Science in Civil Engineering.

Title: Flexural Behavior of Basalt Fiber Reinforced Concrete Beams with Recycled Concrete Coarse Aggregates.

Supervisor of Thesis: Dr. Wael Alnahhal
\end{abstract}

The State of Qatar has experienced tremendous economic development in the last decades. As a result, massive quantities of building materials have been used to accommodate the great pace in construction. However, Qatar suffers from the shortage of natural resources needed for concrete production. Therefore, it is essential to investigate the feasibility of reusing construction and demolition waste as aggregates to maintain the concrete construction industry. Recycled concrete aggregate (RCA) has been produced in Qatar since 2009 as a result of the extensive construction and demolition activities.

The purpose of this study is to study the effect of using RCA combined with a newly developed basalt macro fibers (BMF) on the flexural behavior and ultimate capacity of beams with different replacement ratios of RCA experimentally and analytically.

A total of 16 concrete beam specimens were flexural tested until failure. The parameters investigated included the RCA replacement ratio $(0 \%, 25 \%, 50 \%$, and $100 \%)$ and the BMF volume fraction $(0 \%, 0.5 \%, 1 \%$ and $1.5 \%)$. The deflection, concrete compressive strain and steel tensile strain at mid-span of the tested beams were measured and recorded. The testing results of the specimens were compared to the control beam specimen with natural aggregate (Gabbro), without BMF. In addition, a critical comparison study was carried out between the experimental findings of this research and the analytical formulations based on the existing code-based analytical models. The test results showed an improvement in the flexural capacity of the beam specimens with the addition of BMF, while there are no remarkable effects of RCA on flexural strength of the tested beams. Test results clearly showed that both RCA and BMF in Qatar can be used as sustainable and eco-friendly alternative materials in concrete structures. 


\section{ACKNOWLEDGMENTS}

I am sincerely grateful to all who supported me in completing this project effectively and on time. I put forward my profound appreciation to my thesis supervisor, Dr. Wael Alnahhal for his counseling and advice throughout the study. Dr. Alnahhal has always been a source of inspiration for me. The way of his thinking and very well decisionmaking at critical situations have really been a good support for me. I thank him again for all the assistance and technical support he has provided for me, never at all failing me at any stage.

It is also an honor and privilege to have Dr. Usama Ebead and Dr. Mohammed Al-Ansari serving on my Master thesis committee. For all pieces of advice and insightful suggestions and directions received from them, they are highly appreciated. My gratitude also goes to Dr. Shahria Alam of the University of British Columbia, for serving as the outside reader. His thorough review and insightful comments are very much appreciated.

This work was funded by Qatar University; their financial support through the internal research grant QUUS-CENG-SPR14/15-21 is greatly appreciated and acknowledged. I am grateful to the Construction Materials Co L.L.C. (Qatar Quarry CompanyLafarge Middle East) for providing the RCA. In particular, special thanks are due to Mr. Salim Kutty who was very supportive of the research work. In addition, the support provided by ReforceTech, AS (Norway) is gratefully acknowledged.

Any words would not be enough to express my gratitude to my dearest parents, whose continued encouragement, constant prayers and unlimited supported to me have never refrained throughout my life. Whatever I am and whatever I shall be, I owe it all to them. 


\section{TABLE OF CONTENTS}

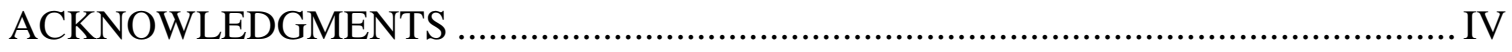

LIST OF FIGURES …....................................................................................

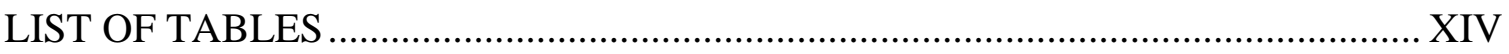

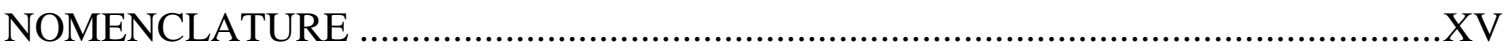

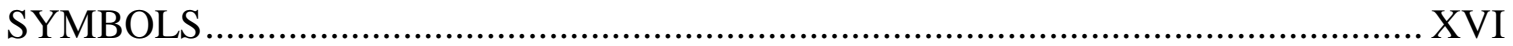

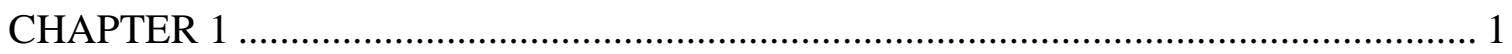

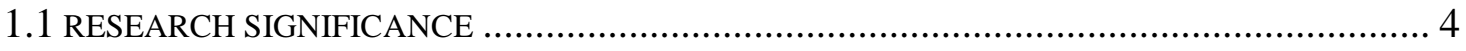

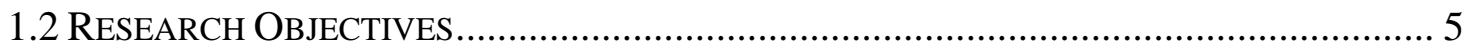

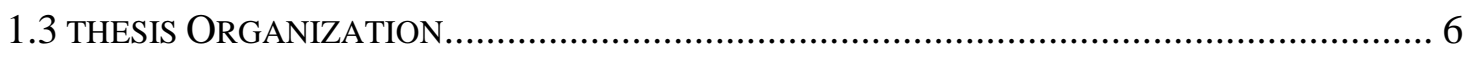

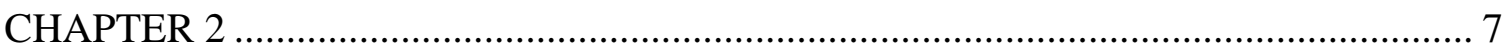

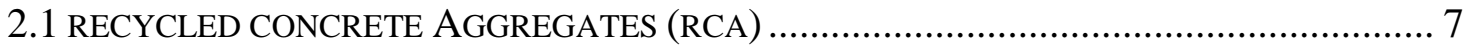

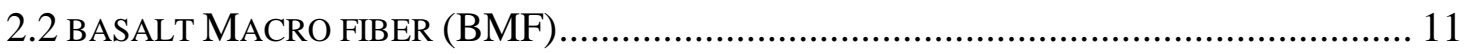

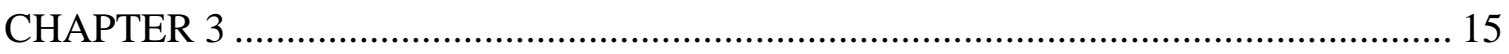

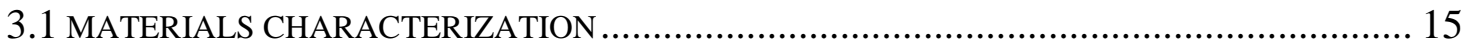

3.1.1 Recycled Concrete Aggregates (RCA) and Natural Coarse Aggregates (NCA)

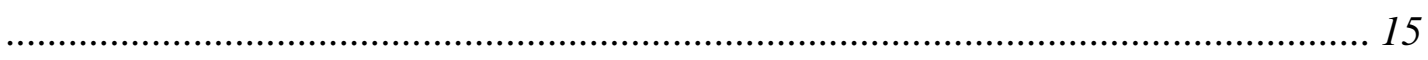

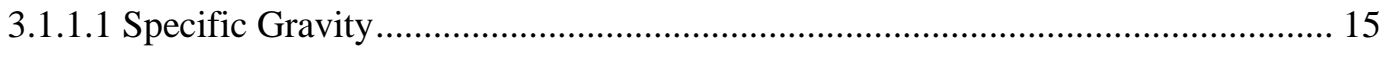

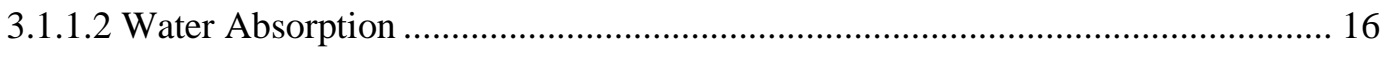

3.1.1.3 L.A. Abrasion Test ..................................................................................... 17

3.1.1.4 Sieve Analysis and Fineness Modulus …......................................................... 18

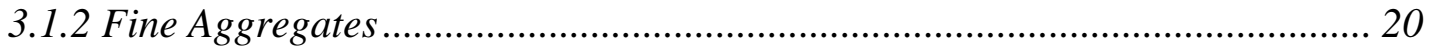

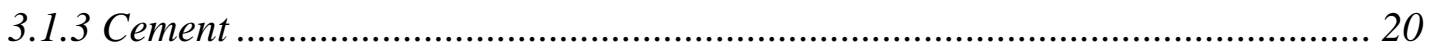

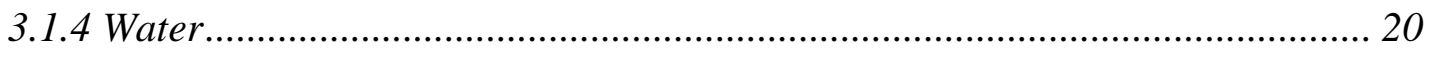

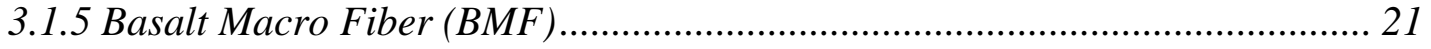

3.1.6 Steel Reinforcement Properties............................................................... 22 


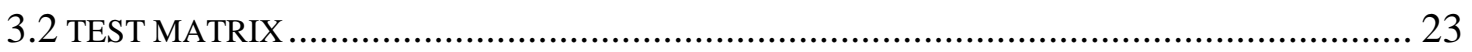

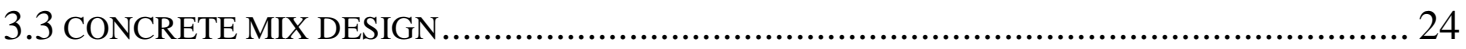

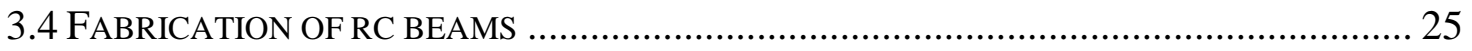

3.4.1 Grinding of The Steel Rebar Surface ………………................................. 25

3.4.2 Steel Fabrication and Formwork........................................................... 26

3.4.3 Installation of Strain Gauges ................................................................... 29

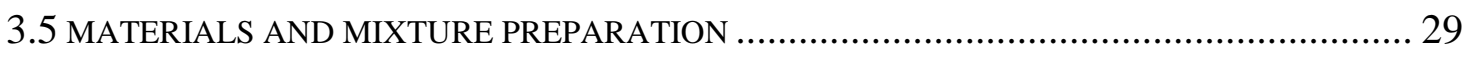

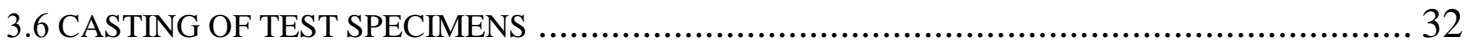

3.6.1 Curing of Test Specimens........................................................................... 34

3.6.2 Transportation of Test Specimens............................................................. 35

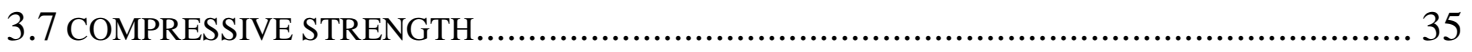

3.8 FLEXURAL TENSILE STRENGTH (MODULUS OF RAPTURE) ....................................... 36

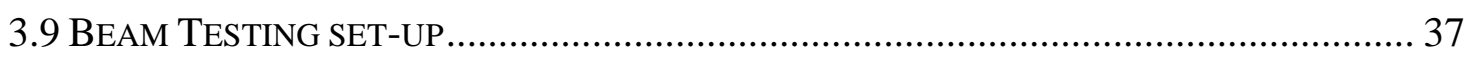

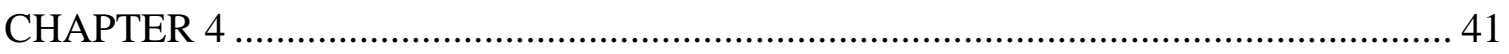

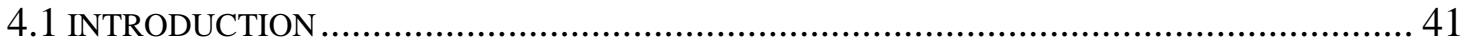

4.2 PROPERTIES OF HARDENED CONCRETE ……........................................................ 42

4.2.1 Flexural Tensile Strength (Modulus of Rapture) Testing Results.................... 42

4.2.1.1 Effect of Volume Fraction of BMF ................................................................... 43

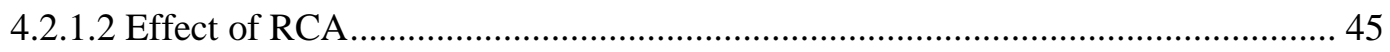

4.2.2 Compressive Strength Testing Results ......................................................... 47

4.2.2.1 Effect of Volume Fraction of BMF ................................................................ 49

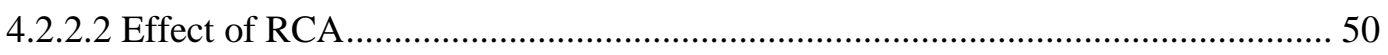

4.3 LARGE SCALE BEAM TESTING RESULTS ………………..................................... 52

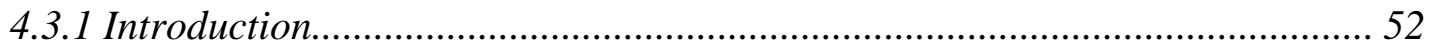

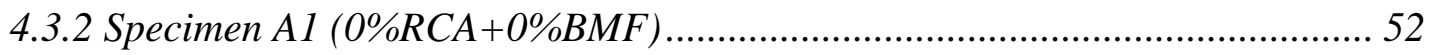

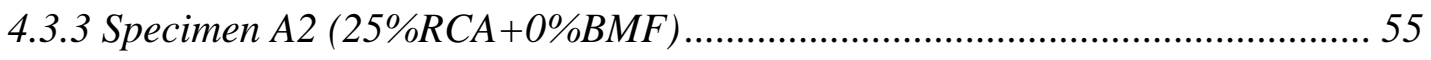

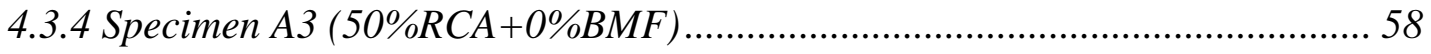

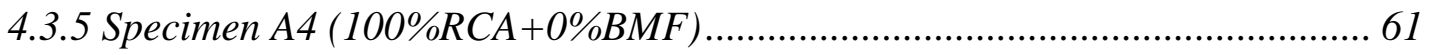

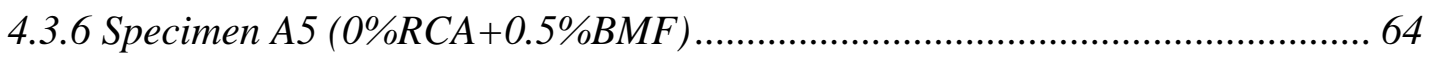

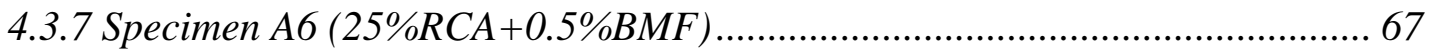

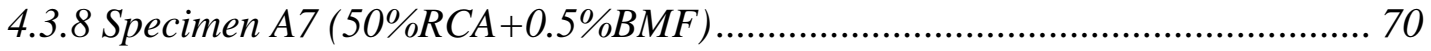




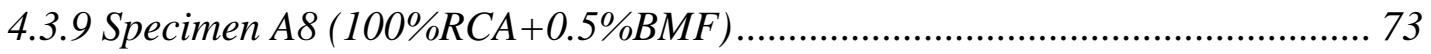

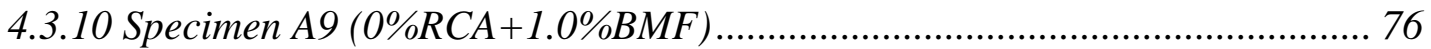

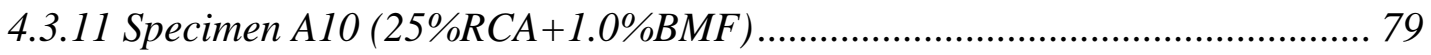

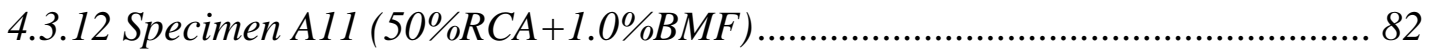

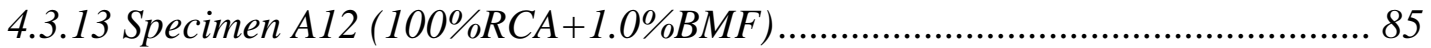

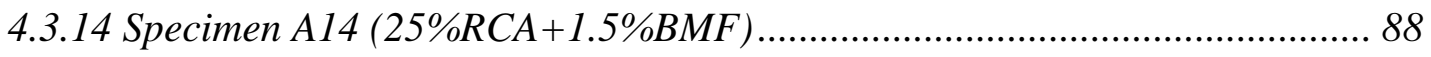

4.3.15 Specimen A15 (50\%RCA+1.5\%BMF) ................................................. 91

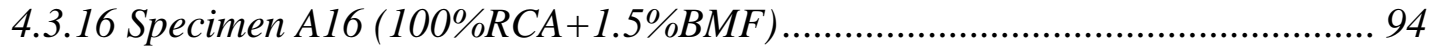

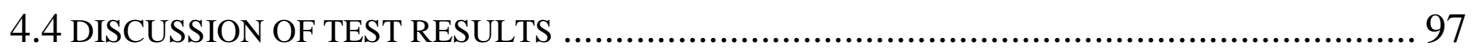

4.4.1 Effect of Fiber Volume Fraction Ratio ....................................................... 98

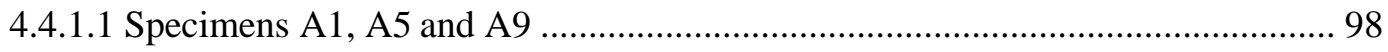

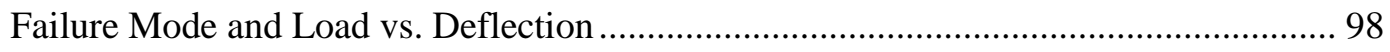

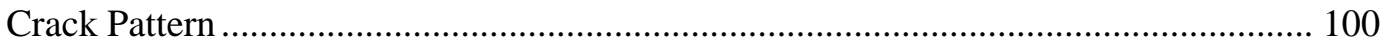

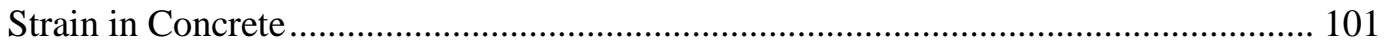

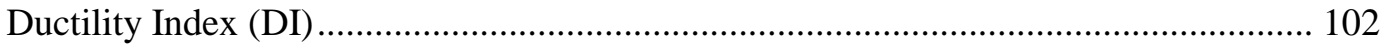

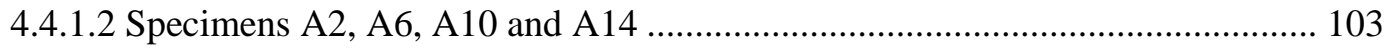

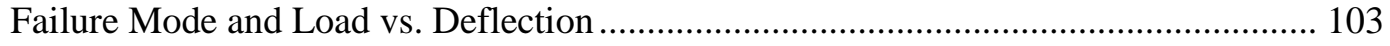

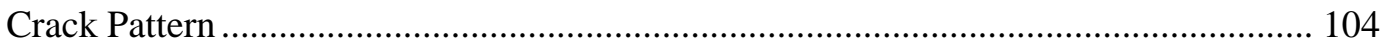

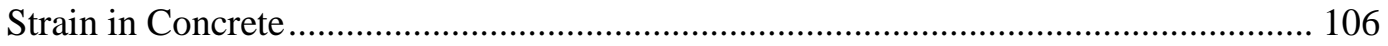

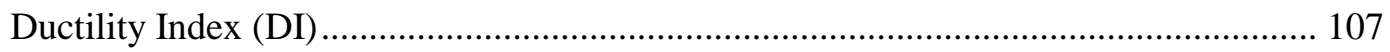

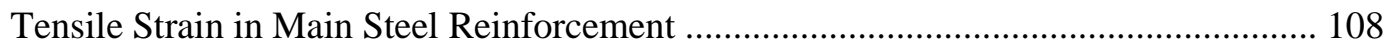

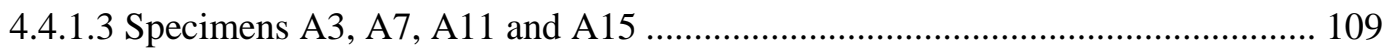

Failure Mode and Load vs. Deflection ....................................................................... 109

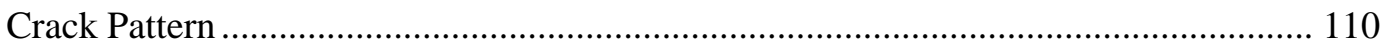

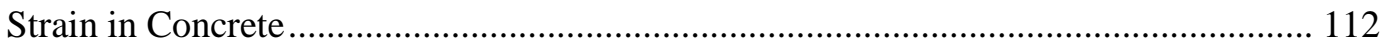

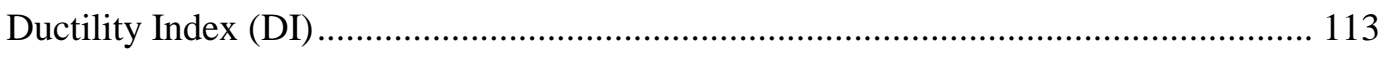

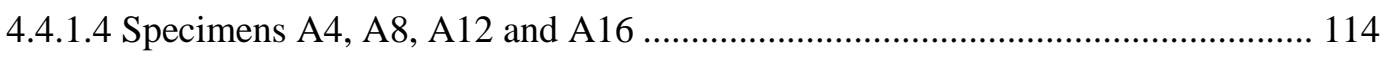

Failure Mode and Load vs. Deflection ...................................................................... 114

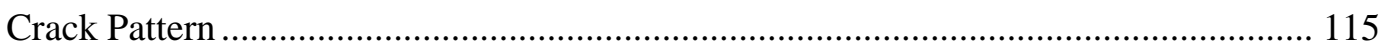

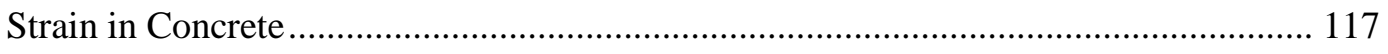

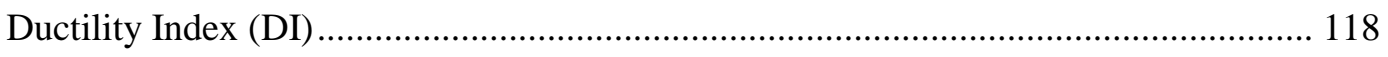

4.4.2 Effect of Aggregate Replacement Ratio of the RCA..................................... 119

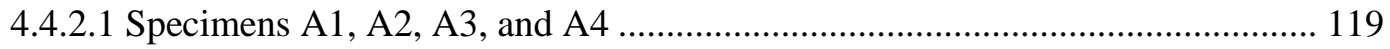




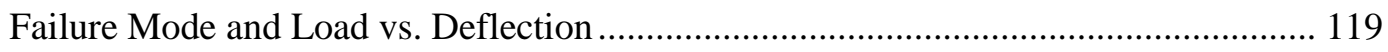

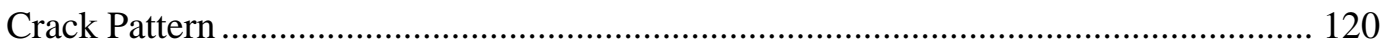

Strain in Concrete

Tensile Strain in Main Steel Reinforcement ................................................................ 123

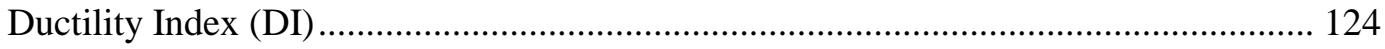

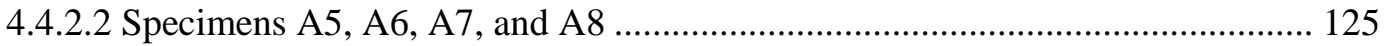

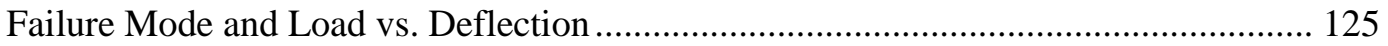

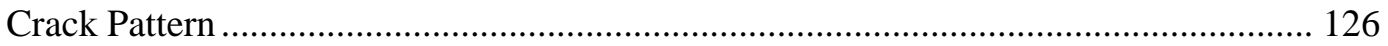

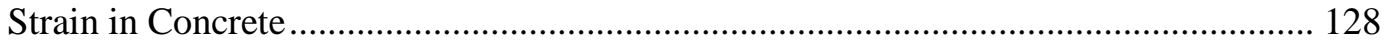

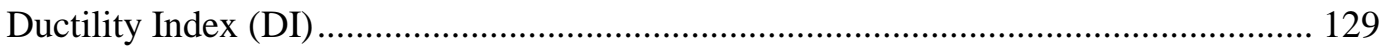

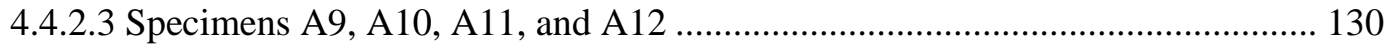

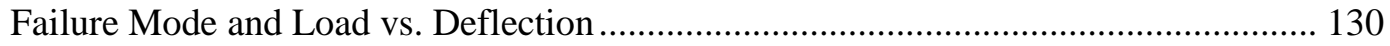

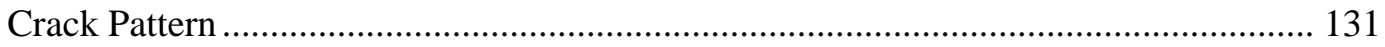

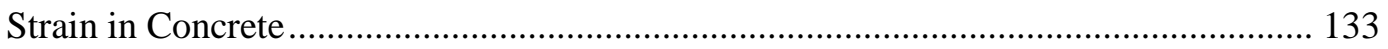

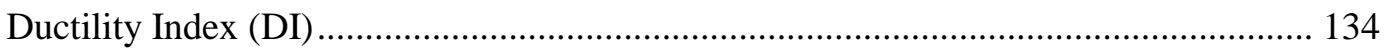

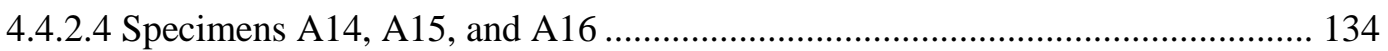

Failure Mode and Load vs. Deflection ............................................................................. 134

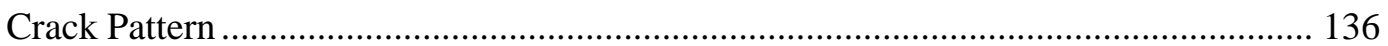

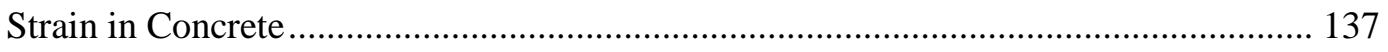

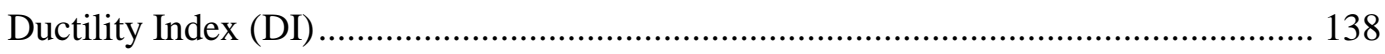

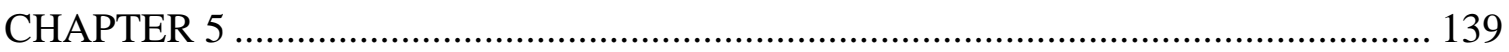

5.1 FLEXURAL CALCULATIONS ……………………......................................... 140

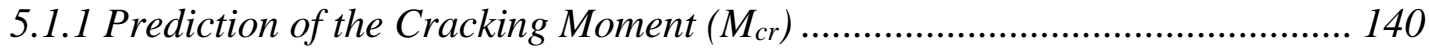

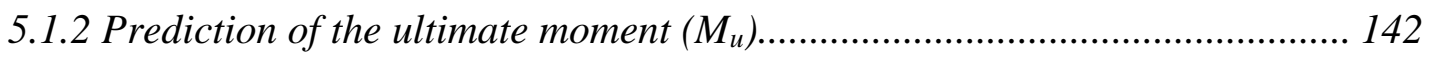

5.2 ANALYTICAL MODELS FOR DEFLECTION CALCULATION .................................... 144

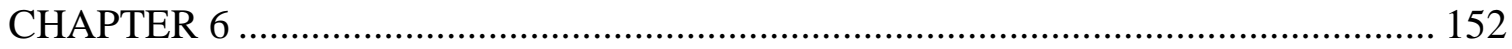

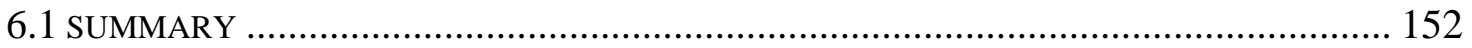

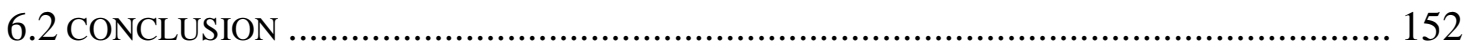

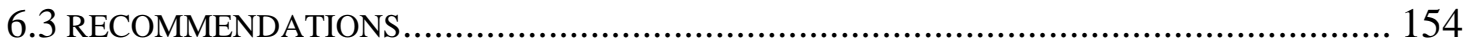

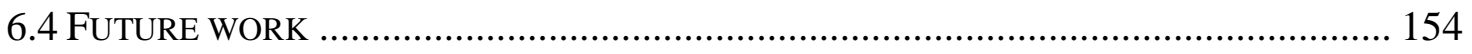

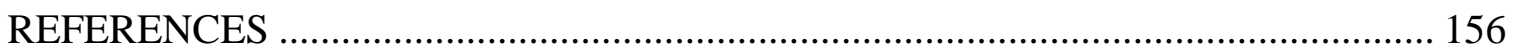




\section{LIST OF FIGURES}

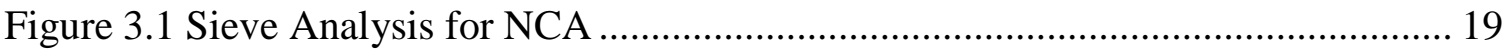

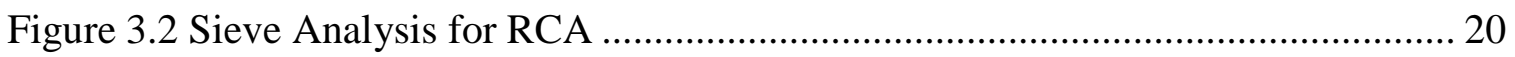

Figure 3.3 Basalt Macro Fiber (BMF) ……………….......................................... 21

Figure 3.4 Grinded Steel Bars....................................................................... 26

Figure 3.5 Reinforcement Details and Cross Section (Dimensions are in $\mathrm{mm}$ ) ............... 27

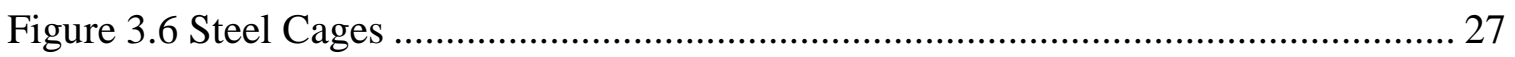

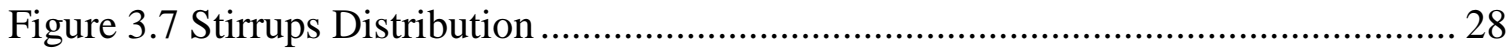

Figure 3.8 Framework and Steel Cage with Cover Spacer ............................................ 28

Figure 3.9 Fixing of Steel Strain Gauges................................................................ 29

Figure 3.10 Moisturizing the Aggregates in Water Tanks............................................. 30

Figure 3.11 Drying the Aggregates to Achieve the SSD Condition ................................. 30

Figure 3.12 Mixing Water with Admixture ............................................................ 31

Figure 3.13 Adding BMF Inside the Concrete Mechanical Mixer .................................... 31

Figure 3.14 Coded Beam Ready for Casting ................................................................. 33

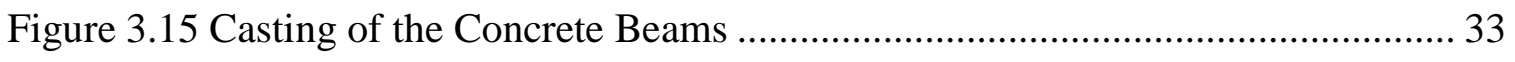

Figure 3.16 Curing of Beam Specimens ………………........................................ 34

Figure 3.17 Curing of Concrete Cylinders and Prisms ..................................................... 34

Figure 3.18 Compressive Strength Test Setup............................................................... 36

Figure 3.19 Tensile Strength Test Setup ....................................................................... 37

Figure 3.20 Detail of loading pattern (Dimensions are in $\mathrm{mm}$ ) ……….......................... 38

Figure 3.21 Beam test setup and measuring sensors (Dimensions are in $\mathrm{mm}$ )................. 38

Figure 3.22 Left and Right Side Linear Variable Deflection Transducers (LVDT)......... 39

Figure 3.23 Concrete Strain Gauge (Top Side) ........................................................... 39

Figure 3.24 Data logger (TML Data Logger Multi-Channel Digital Strain meter DRA-

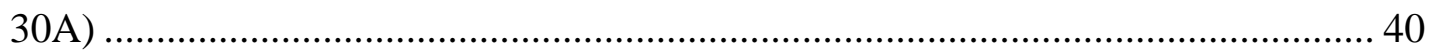

Figure 3.25 Instron 1500HDX Static Hydraulic Universal Testing machine with the deflection transducers and data acquisition system ................................................ 40

Figure 4.1 Failure Mode of Typical Concrete Prism ..................................................... 42

Figure 4.2 Flexural Tensile Strength Test Results for Different RCA Replacement Ratios 
Figure 4.3 Flexural Tensile Strength Test Results for Different Fiber Volume Fraction

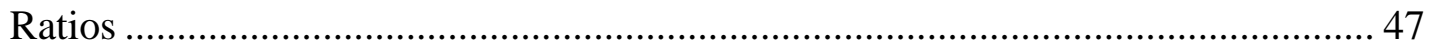

Figure 4.4 Failure Mode of Typical Cylinder Specimen ............................................ 48

Figure 4.5 Compressive Strength Test Results for Different RCA Replacement Ratios . 50 Figure 4.6 Compressive Strength Test Results for Different Fiber Volume Fraction Ratios

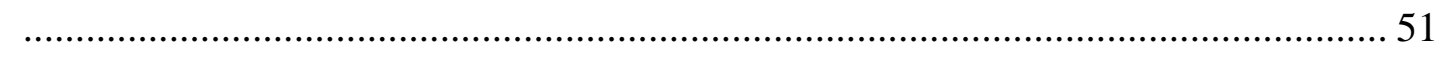

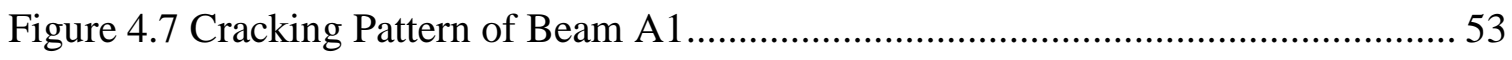

Figure 4.8 Test Results for Beam A1. a) Load vs. Deflection, b) Load vs. Concrete Strain

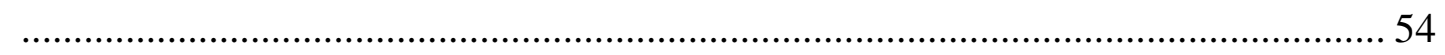

Figure 4.9 Deformed Shapes at Different Load Levels at the Bottom Surface ............... 55

Figure 4.10 Cracking Pattern of Beam A2 .............................................................. 56

Figure 4.11 Test Results for Beam A2. a) Load vs. Deflection, b) Load vs. Concrete Strain 57

Figure 4.12 Deformed Shapes at Different Load Levels at the Bottom Surface ............. 58

Figure 4.13 Cracking Pattern of Beam A3 ................................................................. 59

Figure 4.14 Test Results for Beam A3. a) Load vs. Deflection, b) Load vs. Concrete

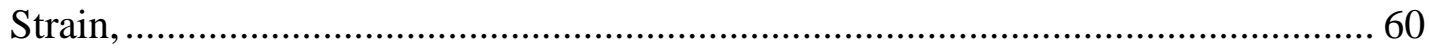

Figure 4.15 Deformed Shapes at Different Load Levels at the Bottom Surface ............. 61

Figure 4.16 Cracking Pattern of Beam A4 ................................................................ 62

Figure 4.17 Test Results for Beam A4. a) Load vs. Deflection, b) Load vs. Concrete Strain 63

Figure 4.18 Deformed Shapes at Different Load Levels at The Bottom Surface ............ 64

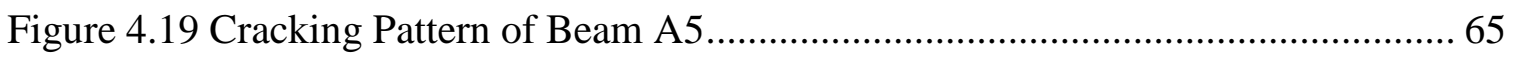

Figure 4.20 Test Results for Beam A5. a) Load vs. Deflection, b) Load vs. Concrete Strain 66

Figure 4.21 Deformed Shapes at Different Load Levels at the Bottom Surface ............. 67

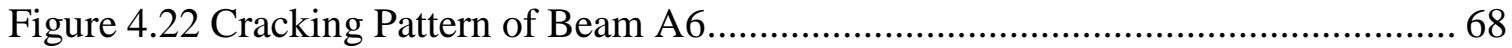

Figure 4.23 Test Results for Beam A6. a) Load vs. Deflection, b) Load vs. Concrete

Strain 69

Figure 4.24 Deformed Shapes at Different Load Levels at the Bottom Surface ............. 70

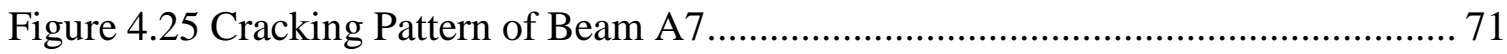


Figure 4.26 Test Results for Beam A7. a) Load vs. Deflection, b) Load vs. Concrete Strain, 72

Figure 4.27 Deformed Shapes at Different Load Levels at the Bottom Surface ............. 73

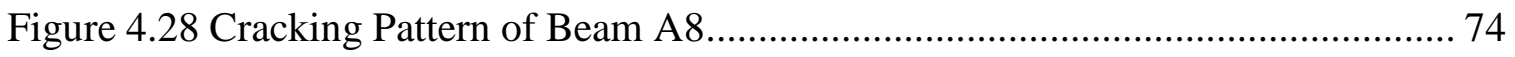

Figure 4.29 Test Results for Beam A8. a) Load vs. Deflection, b) Load vs. Concrete Strain 75

Figure 4.30 Deformed Shapes at Different Load Levels at the Bottom Surface ............. 76

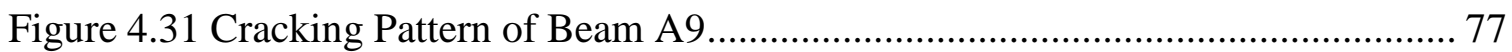

Figure 4.32 Test Results for Beam A9. a) Load vs. Deflection, b) Load vs. Concrete Strain 78

Figure 4.33 Deformed Shapes at Different Load Levels at the Bottom Surface . 79

Figure 4.34 Cracking Pattern of Beam A10. 80

Figure 4.35 Test Results for Beam A10. a) Load vs. Deflection, b) Load vs. Concrete Strain 81

Figure 4.36 Deformed Shapes at Different Load Levels at the Bottom Surface 82

Figure 4.37 Cracking Pattern of Beam A11. 83

Figure 4.38 Test Results for Beam A11. a) Load vs. Deflection, b) Load vs. Concrete Strain 84

Figure 4.39 Deformed Shapes at Different Load Levels at the Bottom Surface ............. 85

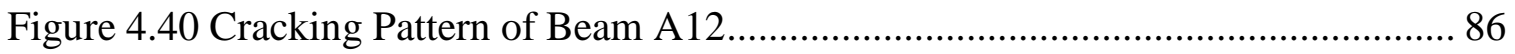

Figure 4.41 Test Results for Beam A12. a) Load vs. Deflection, b) Load vs. Concrete Strain 87

Figure 4.42 Deformed Shapes at Different Load Levels at the Bottom Surface ............. 88

Figure 4.43 Cracking Pattern of Beam A14

Figure 4.44 Test Results for Beam A14. a) Load vs. Deflection, b) Load vs. Concrete

Strain 90

Figure 4.45 Deformed Shapes at Different Load Levels at the Bottom Surface. 91

Figure 4.46 Cracking Pattern of Beam A15.

Figure 4.47 Test Results for Beam A15. a) Load vs. Deflection, b) Load vs. Concrete Strain 93

Figure 4.48 Deformed Shapes at Different Load Levels at the Bottom Surface 94 
Figure 4.49 Cracking Pattern of Beam A16.

Figure 4.50 Test Results for Beam A16. a) Load vs. Deflection, b) Load vs. Concrete Strain

Figure 4.51 Deformed Shapes at Different Load Levels at the Bottom Surface. 97

Figure 4.52 Load vs. Deflection for Specimens A1, A5 and A9 99

Figure 4.53 Crack Pattern in Test Beams A1, A5 and A9 .......................................... 100

Figure 4.54 Concrete strain for test beams A1, A5 and A9 ....................................... 102

Figure 4.55 Ductility Index vs. Volume Fraction of Fiber for Beams A1, A5 and A9 .. 103

Figure 4.56 Load vs. Deflection for Specimens A2, A6, A10 and A14 …................... 104

Figure 4.57 Crack Pattern in Test Beams A2, A6, A10 and A14 …............................ 105

Figure 4.58 Concrete strain for test beams A2, A6, A10 and A14 ............................. 107

Figure 4.59 Ductility Index vs. Volume Fraction of Fiber for Beams A2, A6, A10 and

A14. 108

Figure 4.60 Steel Strain for test beams A2, A6, A10 and A14 ................................... 109

Figure 4.61 Load vs. Deflection for Specimens A3, A7, A11 and A15 ....................... 110

Figure 4.62 Crack Pattern in Test Beams A3, A7, A11 and A15 ............................... 111

Figure 4.63 Concrete strain for test beams A3, A7, A11 and A15 .............................. 113

Figure 4.64 Ductility Index vs. Volume Fraction of Fiber for Beams A3, A7, A11 and

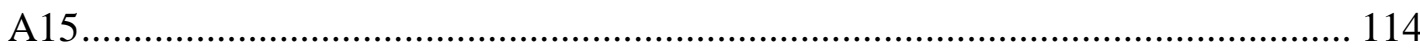

Figure 4.65 Load Vs. Deflection for Specimens A4, A9, A12 and A16 ...................... 115

Figure 4.66 Crack Pattern in Test Beams A4, A9, A12 and A16 ................................ 116

Figure 4.67 Concrete strain for test beams A4, A9, A12 and A16 .............................. 118

Figure 4.68 Ductility Index vs. Volume Fraction of Fiber for Beams A4, A8, A12and

A16. 119

Figure 4.69 Load Vs. Deflection for Specimens A1, A2, A3 and A4 ........................ 120

Figure 4.70 Crack Pattern in Test Beams A1, A2, A3 and A4 .................................. 121

Figure 4.71 Concrete strain for test beams A1, A2, A3 and A4 ................................ 122

Figure 4.72 Steel Strain for test beams A1, A2, A3 and A4 .................................... 123

Figure 4.73 Ductility Index vs. Replacement Ratio of RCA for Specimens A1, A2, A3 and A4 124

Figure 4.74 Load Vs. Deflection for Specimens A5, A6, A7 and A8 ......................... 126 
Figure 4.75 Crack Pattern in Test Beams A5, A6, A7 and A8 ................................... 127

Figure 4.76 Concrete strain for test beams A5, A6, A7 and A8 _................................ 128

Figure 4.77 Ductility Index vs. Replacement Ratio of RCA for Specimens A5, A6, A7

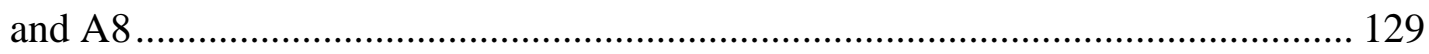

Figure 4.78 Load Vs. Deflection for Specimens A9, A10, A11 and A12 .................... 131

Figure 4.79 Crack Pattern in Test Beams A9, A10, A11 and A12 .............................. 132

Figure 4.80 Concrete strain for test beams A9, A10, A11 and A12 ............................ 133

Figure 4.81 Ductility Index vs. Replacement Ratio of RCA for Specimens A9, A10, A11

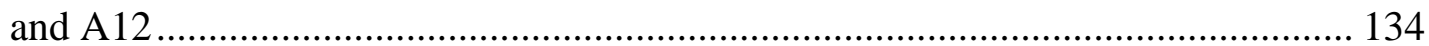

Figure 4.82 Load Vs. Deflection for Specimens A14, A15 and A16 .......................... 135

Figure 4.83 Crack Pattern in Test Beams A14, A15 and A16 .................................... 136

Figure 4.84 Concrete strain for test beams A14, A15 and A16 .................................. 137

Figure 4.85 Ductility Index vs. Replacement Ratio of RCA for Specimens A14, A15 and A16. 138

Figure 5.1Stress and Strain for RC beam with BMF 142

Figure 5.2 The simply-supported beam subjected to two equal concentrated loads symmetrically placed about the beam centerline 144

Figure 5.3 Comparison of Predicted and Experimental Deflection 150 


\section{LIST OF TABLES}

Table 3.1 Specific Gravity and Absorption ratio of NCA and RCA ….......................... 16

Table 3.2 Abrasion Resistance Results of NCA and RCA .......................................... 17

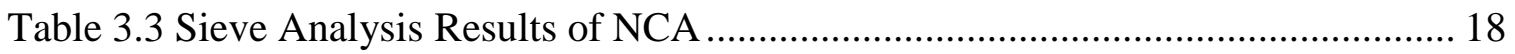

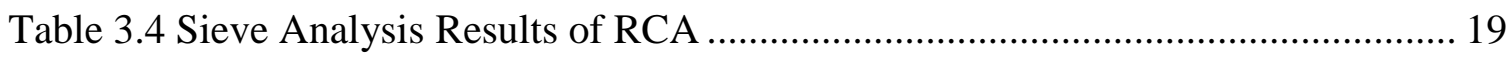

Table 3.5 Characterization of Basalt Macro Fiber (BMF) ......................................... 22

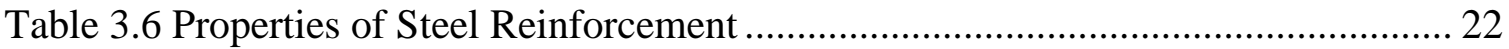

Table 3.7 Test Matrix for Beam Samples ...................................................................... 23

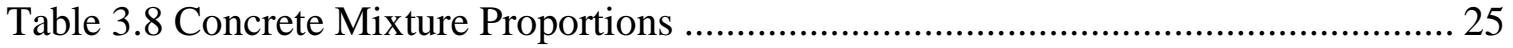

Table 4.1 Average Flexural Tensile Strength of Concrete Prisms................................. 43

Table 4.2 Average Compressive Strength Test Results............................................. 48

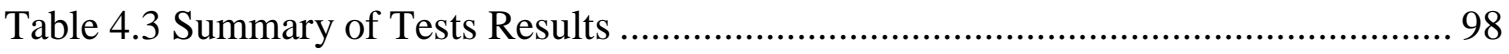

Table 4.4 Summary of Number of Cracks .............................................................. 101

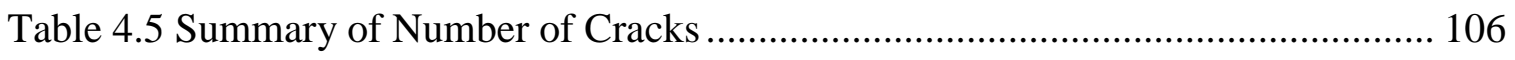

Table 4.6 Summary of Number of Cracks ............................................................. 112

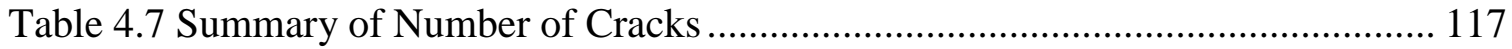

Table 4.8 Summary of Number of Cracks ............................................................ 122

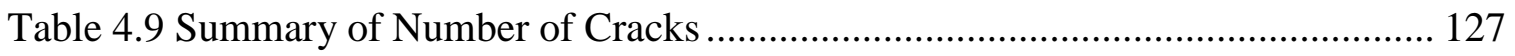

Table 4.10 Summary of Number of Cracks .......................................................... 132

Table 4.11Summary of Number of Cracks ........................................................... 137

Table 5.1 Theoretical and Experimental cracking moments ..................................... 141

Table 5.2 Theoretical and Experimental Ultimate Flexural Moments ......................... 143

Table 5.3 Theoretical and Experimental Mid-Span Deflection of the Tested Beams .... 146 


\section{NOMENCLATURE}

Abbreviations

RCA

NCA

LVDT

$\mathrm{RC}$

$\mathrm{BMF}$

$\mathrm{CC}$

$\mathrm{W} / \mathrm{C}$

SCC

ITZ

LVDT

FRP

BFRP

FRC

SFRP

SF

GGBFS
Recycled Concrete Aggregates

Natural Coarse Aggregates

Liner Variable Differential Transducer

Reinforced Concrete

Basalt Macro Fiber

Conventional Concrete

Water to Cement ratio

Self Compacted Concrete

Interfacial Transition Zone

Liner Variable Differential Transducers

Fiber Reinforced Polymer

Basalt Fiber Reinforced Polymer

Fiber Reinforced Concrete

Steel Fiber Reinforced Concrete

Silica Fume

Ground Granulated Blast Furnace Slag 


\section{Symbols}

\begin{tabular}{ll}
$I_{e}$ & Moment of inertia of gross section \\
$I_{c r}$ & Moment of inertia of the cracked transformed section \\
$P_{u}$ & Ultimate load \\
$A$ & Mass of Oven Dray Test Sample \\
$B$ & Mass of Saturated Surface Dry Test Sample \\
$Y$ & Final mass of test sample \\
$P$ & Total concentrated load \\
$D I$ & Ductility index \\
$\Delta I$ & Instantaneous deflection \\
$f_{r}$ & Modulus of rapture \\
$f_{c}^{\prime}$ & Compressive strength \\
$b$ & Width of beam \\
$h$ & Height of beam \\
$d$ & Effective depth of beam \\
$L$ & Span of beam \\
$a$ & Depth of compressive stress block \\
$x$ & Distance from compression surface to the beam to the natural axis \\
$n$ & Modular ratio \\
$y_{t}$ & Centroidal axis for uncracked section \\
$A_{s}$ & Area of steel bar \\
$A_{f}$ & Area of BMF in tensile zone \\
$A_{f} f_{y}$ & Area of BMF in compression zone \\
$f_{y}$ & Yield strength of steel \\
$\sigma_{t}$ & Tensile stress in fibrous concrete \\
$e$ & Distance from extreme compressive fiber to top of tensile stress block \\
$\epsilon_{f}$ & Tensile strain of fiber \\
$c$ & Distance from extreme compression fiber to natural axis \\
$V_{f}$ & Volume fraction of BMF \\
$F_{b e}$ & Bond efficiency of BMF \\
& \\
\hline &
\end{tabular}




$\begin{array}{ll}\eta_{l} & \text { Length efficiency factor of BMF } \\ \eta_{0} & \text { Orientation factor before cracking of the composite material } \\ \eta^{\prime}{ }_{0} & \text { Orientation factor after cracking of the composite material } \\ E_{c} & \text { Modulus of elasticity of concrete } \\ E_{f} & \text { Modulus of elasticity of BMF } \\ E_{c f} & \text { Modulus of elasticity of concrete with BMF } \\ M_{a} & \text { Applied moment } \\ M_{c r} & \text { Cracking moment } \\ M_{u} & \text { Ultimate moment }\end{array}$




\section{CHAPTER 1}

\section{INTRODUCTION}

The State of Qatar has experienced tremendous economic development during the last decades. Thus, massive quantities of building materials have been used to accommodate the great pace in construction. Qatar is anticipated to spend USD 17 billion on its infrastructure as part of its preparation to host the Soccer World Cup in 2022. Most of these expenses will go towards the construction of new hotels, stadiums, facilities, and tourism attractions (Qatar 2022).Major projects such as the stadiums for the World Cup 2022, Doha Metro, an international harbor and huge real-estate projects, have nominated Qatar as the fastest growing construction market within the Gulf Cooperation Council (GCC). Concrete is the main material used in construction in Qatar and in most of the Gulf Cooperation Council (GCC) countries. However, most of these countries suffer from the shortage of natural resources required for concrete production. For example, the quantities of imported aggregates in the State of Qatar have increased from 9.5 million tons in 2006 to 21.5 million tons in 2008 (Qatar Customs 2010). Therefore, it is essential to investigate the feasibility of using recycled materials in concrete production.

Several types of recyclable materials are currently used in concrete. One of the potential resources of recycled concrete is the construction and demolition waste. Construction and demolition waste is one of the largest and most massive waste streams produced in the State of Qatar. The GCC countries produce about 120 million tons per year of waste (Emmanuelle Landais 2008). Recycled concrete aggregate (RCA) has been produced in Qatar since 2009 as a result of the extensive construction and demolition activities (AlAnsary \& Iyengar 2013).Little data is available on the quantity or scale of the construction and demolition wastes in Qatar. Nevertheless, construction and demolition wastes have been generated from various extensive construction activities undertaken all over the State of Qatar since early 2000 to date. The use of RCA in concrete applications has major economic and environmental benefits to Qatar. RCA can partially replace the relatively expensive imported Gabbro aggregates commonly used in Qatar, thus saving on the total 
cost of the concrete projects. Gabbro is a natural coarse aggregate, which is unavailable in Qatar but imported from the United Arab Emirates. Several economic and environmental advantages are connected with using RCA. Recycling construction and demolition waste will have a significant environmental impact due to the reduction in demand of virgin aggregates. Moreover, using waste materials would partially solve a significant environmental concern about land-filling the large quantities of waste construction materials produced every year. In addition, using recycled aggregates can reduce the carbon footprint of a building. Moreover, the unit cost of RCA is less than natural aggregate resulting from a significant reduction in material prices.

Recycled aggregates can be crushed into several forms and dimensions. Recycled aggregates can be used as fine and coarse aggregates in concrete. However, RCA have different properties and characteristics from natural coarse aggregates (NCA). As a result, the hardened and fresh concrete properties can vary considerably, depending on the type of coarse aggregate that used. However, reinforced concrete (RC) structures using RCA exhibit high deflections and large crack widths due to the weaker interfacial transition zone (ITZ) between RCA and new cement mortar. Previous investigations have shown that using discrete steel fibers in concrete increases its ductility and reduces the crack width due to the large compressive strains exhibited at failure (Holschemacher et al. 2010) (Mohammadi et al. 2009) and (Katzer \& Domski 2012). The fibers can act as a bridge between the two adjacent cracked sections of the concrete, which will reduce the crack width. Though, the main disadvantage of using steel fibers is corrosion, especially in the harsh environment that characterizes the Gulf area. Research studies, carried out on the effect of using discrete fibers on the structural performance of concrete structures reinforced with FRP are limited (Urbanski et al. 2013), not to mention the use of basalt macro fibers (BMF), which could be attributed to their recent presence in the construction field.

Basalt fiber is a natural material that is found in volcanic basalt rocks formed in a melting temperature comprised between 1500 to $1700 \mathrm{C}$. Basalt fiber products are available around the world in various forms such as bars, mesh, spirals, fabric and chopped. Basalt fibers are environmentally safe, non-toxic, resisting high temperatures, strength, and durable. Researchers show the advantages of the use of BMF in concrete elements; basalt fiber will 
modify the cracking mechanism, increases flexural tensile strength and average residual strength, reduce the crack width and high tensile strength and bond with concrete.(Sudeep Adhikari 2013),(Anil et al. 2013) and (Banibayat \& Patnaik 2014).

For all construction material, stiffness and strength are of greatest importance in most of structural applications. Depending upon the purpose of the structure, there is always a need for reciprocal trade-off between these two parameters. Composite materials such as fiber reinforced concrete, both concrete and BMF were introduced to serve that specific purpose. BMF contributes to the improvement of the toughness characteristics of normal concrete. Toughness of a material is the physical measure of the energy that is required to deform the material to a particular strain.

Basalt macro fiber is a non-corrosive structural macro fiber, made from basalt fiber reinforced polymer (BFRP) bars. The method for manufacturing BMF is a simplified automated method called wet-ley up process, which is the same method of the manufacture of BFRP bar. BMF possesses higher tensile strength and stiffness compared to other standard synthetic fibers and at the meantime it is non-corrosive (Sudeep Adhikari 2013). BMF acts as the proactive reinforcement that provides the immediate tensile load, carrying capacity when micro cracks develop in concrete. Numerous applied applications have been successfully demonstrated in Europe, showing the functional and economic benefits of FRC with BMF for constructing façade walls, pontoons and inner walls (Banibayat \& Patnaik 2014). The crack width of plain concrete is higher than the crack width of polypropylene fiber concrete, which is also higher than the crack width for MRC (Bajaj 2012). In addition, BMF has a higher density closet to concrete than the density of synthetic or steel fiber (Anil et al. 2013). This gives minibar an advantage over other fibers during mixing of concrete. 


\subsection{RESEARCH SIGNIFICANCE}

Having in mind that the state of Qatar suffers from the shortage of natural resources needed for concrete production, it is imperative for the country to investigate the feasibility of reusing construction and demolition waste as aggregates to maintain the concrete construction industry. The use of RCA in concrete applications has major economic and environmental benefits to Qatar. RCA can partially replace the relatively expensive imported Gabbro aggregates commonly used in Qatar, thus saving on the total cost of the concrete projects. Recycling construction and demolition waste will also have a significant environmental impact, due to the reduction in demand of virgin aggregates. Moreover, using waste materials would partially solve a significant environmental concern about landfilling the large quantities of waste construction materials produced every year. This will lead also to a drop in the carbon emissions from concrete structures. Thus, this research effort is aligned with Qatar National Vision 2030 to promote environmental related research as a top priority in Qatar.

In addition, most of the construction work in Qatar is built from RC structures. Therefore, they are vulnerable to damage from environmental factors. Corrosion, in particular, has led to the premature deterioration of $\mathrm{RC}$ structures. As a result, it may instead be beneficial to seek alternative materials and construction practices. With recent advances in the development of high-performance composite materials and the escalation of the cost of conventional materials, the time may now be right for the development of new alternative construction materials such as basalt macro fiber in combination with concrete is a possible solution to enhance the structural performance of concrete structures made with RCA. The test results shed light on the feasibility of using BMF to enhance the flexural performance of concrete beams made with RCA. It also provides researchers and practicing engineers with better understanding of the ultimate capacity and the failure mechanisms of the FRC beams made with RCA. The success of the project will have a significant influence on the use of fiber reinforced concrete in the gulf area, especially in Qatar, where harsh environment is dominating. In this aspect, the implementation of anti-corrosive basalt fibers in the structural field will overcome the corrosion problem usually associated with steel reinforcement/fibers. 
To the best of the authors' knowledge, this research on the behavior of FRC beams with RCA produced in Qatar will be the first conducted in the GCC region. The test results shed light on the feasibility of using sustainable FRC structures made from recycled materials produced in Qatar. It also provides researchers and practicing engineers with better understanding of the ultimate capacity and the serviceability performance of the FRC beams made with RCA.

\subsection{RESEARCH OBJECTIVES}

The primary aim of this study is to use recycled concrete aggregates and basalt macro fiber in concrete structural elements and verify the feasibility of these proposed materials experimentally and analytically. The following points summarize the major objectives of this project:

- Investigating the feasibility of using RCA and Basalt Macro Fiber (BMF) as alternative materials in RC structural system.

- Examining experimentally the material characterization of the RCA, and the Basalt FRC made with RCA.

- Evaluating the effect of the volume fraction of BMF, and the replacement ratio of RCA on the hardened properties of concrete.

- Studying and quantifying experimentally the deflection and the load-carrying capacity of RC beams made with different replacement ratios of RCA and various percentage of BMF. Crack patterns, failure mechanisms, and mode of failures are among the scope of the study.

- Conducting an analytical study on the flexural behavior and the predicted deflection of the RC beams made with different replacement ratios of RCA and various percentage of BMF. 


\subsection{THESIS ORGANIZATION}

This thesis contains six chapters arranged as follows:

Chapter 1: An introduction, research significance and research objectives.

Chapter 2: Background and Literature review: This chapter contains a detailed review of previous works related to the current research.

Chapter 3: Experimental program: This chapter introduces the material characterization of all materials. Further, describes the procedure followed in preparation, casting and testing the test specimens.

Chapter 4: Result and discussion: covers the detailed test results of each specimen, the test results include the graphs of cracking pattern, load vs deflection, compressive concrete strain, and deformed shape. The latter section covers a summary of the test results and the effect of different parameters in order to understand the behavior of RCA and BMF to make comparisons among all groups.

Chapter 5: Theoretical deflection and flexural calculations: this chapter describes the stepby-step formulations adopted for calculating the deflection and flexural strength of RC beams with and without BMF.

Chapter 6: Summary, conclusion and recommendations: This chapter contains the summary, conclusions of the study, recommendations and future work. 


\section{CHAPTER 2}

\section{BACKGROUND AND LITERATURE REVIEW}

Qatar 2022 bidding committee official website stated that the State of Qatar has recently experienced great economic developments. As a result, massive amounts of construction materials have been used to accommodate the excessive pace in construction. The State is expected to spend USD 17 billion on its infrastructure as part of its preparation to host the Football World Cup in 2022. Most of these expenses will go to the construction of new, stadiums, hotels, facilities, and tourism attractions.

Concrete is the main material used in construction in Qatar and all Gulf countries. However, most of these countries suffer from the lack of natural resources required for concrete production. Qatar Customs Database announced that the quantities of imported aggregates into the State of Qatar have increased from 9.5 million tons in 2006 to 21.5 million tons in 2008 . Therefore, it is essential to investigate the possibility of using recycled materials like fine and coarse aggregates in concrete production.

Gulf News (2008) stated that numerous kinds of recyclable materials were currently used in concrete. One of the potential resources of recycled concrete is the construction and demolition waste. The gulf countries produce about 120 million tons per year of waste. In the past, a wide range of experimental studies were made on the overall durability and strength of recycled concrete aggregates (RCA). Special considerations were also attributed to the effect of Basalt macro fiber (BMF) on concrete properties. Some of these researches are highlighted below.

\subsection{RECYCLED CONCRETE AGGREGATES (RCA)}

Qatar Construction Specification (QCS, 2014) define the recycled aggregates as the aggregates resulting from the processing of inorganic material previously used in construction. It shall be free from any deleterious matter and conform to the requirements of physical and chemical properties as a minimum of QCS requirements and shall meet with ASTM standards. (Al-Ansary \& Iyengar 2013) investigated the resources, production, properties and experimental evaluation of RCA in the State of Qatar, finding out that the RCA has been produced in Qatar since 2009 as a result of the extensive construction and 
demolition activities. Approximately 20000 tons of concrete debris have to be discarded every day, and half of that quantity converted to RCA.This study shows the initial physiochemical characterization of the NCA and compares them with RCA as per Qatar construction specifications limits. The use of RCA in concrete applications has major economic and environmental benefits to Qatar. RCA can partially replace the relatively expensive imported Gabbro aggregates, commonly used in Qatar, thus saving on the total cost of the concrete projects. Recycling construction and demolition waste will also have a significant environmental impact, due to the reduction in demand of natural aggregates. Moreover, using waste materials would partially solve a significant environmental concern over land-filling the large quantities of waste construction materials produced every year. (Poon \& Chan 2007) of Hong Kong estimated that around 20 million tons of construction and demolished waste were produced in 2004 , although $12 \%$ of the waste could be disposed of at landfills and $88 \%$ was used as backfilling materials. The main objective was to investigate the possibility of using construction and demolition wastes in concrete. Their research work provided some preliminary results on the effects of using recycled aggregates on the hardened concrete properties. (Abbas et al. 2007) and (Zhang \& Ingham 2010), have presented the economic and environmental benefits of using RCA in the construction sector in Canada and New Zealand. Most of the RCA have used as highway construction, and only a slight portion of the solid waste is reused as an aggregate in new concrete construction. The comparable results between RCA and NCA indicated that RCA is a viable alternative to NCA. (Silva et al. 2014) have presented the main factors affecting the physical, chemical, mechanical, permeation and compositional properties of recycled aggregates originated form construction and demolition waste that is mainly used for construction field. The investigation results show the classifications based on the quality of recycled aggregates can be re-used to produce concrete with predictable performance. (Abdulla 2012). presented the test results of the mechanical properties of eight different types of recycled aggregates in Iraq and evaluated the influences and performance of these types of the properties on concrete mix produced by using recycled aggregates.(Huda \& Alam 2014) investigated the fresh and the hardened properties of three different generations of repeated recycled concrete, which were produced using $100 \%$ of RCA as a replacement of NCA. RCA was recycled three times over its life span. The results showed 
that the bulk density and specific gravity of different generations of repeated of RCA decreased with the increased number of repetitions, the air content of fresh concrete mix increased with the increased number of repetitions. In addition, the results showed a slight decrease in the concrete compressive strength compared with the control specimen. However, all concrete mixes successfully achieved their target strength at $56^{\text {th }}$ days expect the third generation concrete this is due to the reduced bulk density, adhered mortar and weak interfacial transition zone (ITZ). Though all concrete mixes exceeded the target strength at 120 days. The peak axial strain values were higher for repeated RCA. In addition, the values of the splitting tensile strength of first and second generations were higher than the control specimen. (McNeil \& Kang 2013) discussed and reviewed the properties of RCA and their impact on the structural concrete elements. Testing results showed that using RCA resulted in a decrease in the compressive strength. They found out that the modulus of rupture for RCA concrete was less than the normal concrete and the modulus of elasticity was also less than expected. A number of studies showed that RC beams made with RCA did experience larger deflection and lesser cracking moment and the ultimate moment compared with RC made with RCA. (Panda \& Bal 2013), (Grdic et al. 2010) and (Kou \& Poon 2009). Several researchers have studied and evaluated both the hardened and fresh properties of self-compacted concrete (SCC) mixtures produced by different percentage of RCA instead of NCA. (Katz 2004) found that RCA is commenly covered with loose particles and attached mortar, which prevent the high bonding between the new cement matrix and RCA, and different methods of RCA's treatments by impregnation of silica fume solution and by ultrasonic cleaning could increase the compressive strength by $15 \%$ and 7\%, respectively. (Liang et al. 2013), (Purushothaman et al. 2000) and (Güneyisi et al. 2014), have investigated experiementaly various surface pretreatment methods for RCA and their effect on the quality, hardened and fresh properties of concrete mix produce by using a surface treated RCA. (Çakir 2014) studied the influence of mineral additives like silica fume (SF) and ground granulated blast furnace slag (GGBFS) at several percentages with RCA on the hardened properties of concrete. The results showed that the compressive strength of the concrete gradually decreases as the amount of RCA increases. The test results showed that at $100 \%$ of replacing RCA, the compressive strength at 28 day decreased by $24 \%$ and strength reduction is more significant 
with 50\% RCA content.The ratios between the tensile splitting strength to the compressive strength are higher in the RCA concretes with GGBFS than the RCA concretes with SF. (Dilbas et al. 2014) investigated the mechanical and physical properties of concrete containing different ratios of SF with RCA. The properties of RCA can vary depending on their source. RCA affects more on the splitting tensile strength rather than the compressive strength. The results demonstrated that the compressive strength decreased for specimen produced by concrete mix contain RCA. As well. the results showed significant improvement in tensile splitting strength but the modulus of elasticity was decreased with increasing the RCA content. (Choi \& Yun 2013) Presented experimental results on the flexural behavior and long-term deflection of beams made with RCA under sustained loads for a period of 380 days. The principal objective was to evaluate and compare the experimental result with the code-based equations calculated using the ACI 318 Code. They found that the maximum flexural strength of the beams without NCA was $20 \%$ higher than that of the beams with RCA. Similar crack patterns were observed regrdless of the aggregates type.Though, more cracks were present in the beams composed of RCA, and the instant deflection values of the beam with RCA were smaller than the beams with NCA. (Knaack \& Kurama 2014) conducted an experimental program to assess shear and flexural behavior of reinforced concrete beams, produced by concrete mix made with RCA. The study found the results were reasonable and did not cause any noticeable alteration on the shear and flexural strength of the beams. (Arezoumandi et al. 2015) conducted an experimental study on the flexural strength of concrete beams constructed with RCA as well as with NCA.The experiemntal results showed that the deflection corresponding to the ultimate flexural strength of a beam made with RCA about $13 \%$ higher than the comparable beam made with NCA.(Pereira-De-Oliveira et al. 2014) investigated the influence of RCA on perpeability properties of SCC. They have used four different types of concrete mixes. One of them was taken as a reference with 100\% NCA. It was compared with the remaining concrete mix with $20 \%, 40 \%$, and $100 \%$ of RCA respectively.A larger amount of superplasticizer for concrete mix with RCA was required because of the high water absorption presented by RCA. As a result, the density of concrete was less when increasing RCA. The results from fresh and hardened concrete properties lead to the conclusion that it is viable to replace NCA by RCA since this research did not show any 
detrimental to the SCC permeability properties. (Kutalmis et al. 2015) investigated the usability of polypropylene fiber in recycled aggregates concrete in order to be used primarily in construction field. The results of using RCA with different amount of fiber showed reduction in concrete workability with no significant influence observed on the compressive strength. However, both of the flexural and splitting tensile strength were increased with adding the fibers.(Dong et al. 2017) focussed on the mechanical properties of the concrete made with RCA and basalt fiber, the major parameters were the replacement ratio of $\operatorname{RCA}(0 \%, 50 \%$ and $100 \%)$ and basalt fiber $\left(0,2\right.$ and $\left.4 \mathrm{~kg} / \mathrm{m}^{3}\right)$. The results obtaind from this study showed that the mechanical properties of concrete made with RCA are decreased with increasing the RCA replacement ratio. However they could be enhanced by using basalt fiber. The scanning electron microscope observations of the concrete revealed that the basalt fiber accumulated in pores and on the surface of the attached morter can not only strengthen the RCA, but also improve the microstructure of the interfacial transition zone, which further enhances the strength and ductility of the concrete.

\subsection{BASALT MACRO FIBER (BMF)}

Fiber composites have been developed to improve mechanical properties and longterm severability of the structure in respect of serviceability, which can be enhanced by using the fibers to control the cracking as well as to prevent the occurrence of large crack width (ACI 544.1R-96 2002). Fiber reinforced concrete (FRC) is concrete made primarily of hydraulic cement containing coarse aggregates, fine aggregates and discontinuous discrete reinforcing fibers. Fibers suitable for reinforcing concrete are produced from steel, glass, polymers (synthetic fibers) and other materials. The concrete matrices may be mortars, normally proportioned mixes, or mixes specifically formulated for a particular application. Generally, the length and diameter of the fibers used for FRC do not exceed $76 \mathrm{~mm}$ and $1 \mathrm{~mm}$, respectively. Basalt is a rock with higher percentage of iron and magnesium than granite. The ocean floor is almost completely made up of basalt. Most of the basalt found on earth was produced in three rock-forming environments: 1) oceanic divergent boundaries, 2) oceanic hotspots, and 3) mantle plumes and hotspots beneath continents. Basalt rock has long been known for its thermal properties, strength, and durability. The density of basalt rock is between $2.8 \mathrm{~g} / \mathrm{cm} 3$, and $2.9 \mathrm{~g} / \mathrm{cm} 3$. Crushed basalt 
is used in road base, concrete aggregates, asphalt pavement aggregates, railroad ballast, and filter stone in drain fields. Polished, thin basalt slabs are used as floor tiles and building veneer (Subramanian 2010).

Basalt filaments are made by melting crushed volcanic basalt rock to about $1400^{\circ} \mathrm{C}$ to $1700^{\circ} \mathrm{C}$ for about 6 hours. The molten material is then extruded through special platinum bushings to produce continuous filaments of basalt fiber. The three main manufacturing techniques of basalt filaments are 1) centrifugal-blowing, 2) centrifugal-multiroll, 3) die blowing. The fibers cool into hexagonal chains resulting in a resilient structure substantially stronger than steel or glass fibers. Its production creates no environmental waste and it is non-toxic in use or recycling. Basalt fibers are manufactured in a singlestage process by melting pure raw crushed volcanic basalt rock (Brik 1997). They are environmentally harmless, non-toxic, possess high heat stability and insulating characteristics. Basalt fiber is extremely strong and durable and hence, it is a perfect material for structural applications. It provides unique mechanical properties when used in composite materials. The mechanical characteristics depend on the diameter of the elemental fibers. Fibers with smaller diameter show higher tensile strength and modulus of elasticity than those fibers with larger diameter. Continuous roving basalt fiber can be used to produce a wide range of composite materials with high reliability.(Jiang et al. 2014) evaluated and analyzed the effects of the length and volume fraction of basalt fiber on the engineering properties of fiber reinforced concrete. The results obtained showed that there was a steady increase in tensile strength, toughness index, flexural strength and an excellent bond between basalt fiber surface and cement contents, comparing with plain concrete. Also, these corresponding strengths will profoundly influence if the length of basalt fiber is increasing, but the compressive strength increases slightly and that addition of basalt fiber to the concrete mix leads to decrease concrete workability.( Zielinski \& Olszewski 2005) investigated the mechanical and physical properties of basalt fiber reinforced concrete at 28 days' concrete age. The test results show the addition of basalt fiber causes a smaller shrinkage, decrease in bending strength and concrete workability, and this recommended study allows an optimum percentage of basalt fiber in concrete from $0.5 \%$ to $0.8 \%$ of cement weight to achieve the best concrete properties.(Dias \& Thaumaturgo 2005 ) investigated the influence of the volumetric fraction of the fibers on the fracture 
toughness of geopolymeric cement concrete reinforced with basalt fiber. The results indicated that the concrete have better fracture properties than conventional concrete, with less number of crack. (Tumadhir 2013) studied the mechanical and thermal properties of basalt fiber reinforced concrete, with fiber volume fraction ranging $(0.1 \%, 0.2 \%, 0.3 \%$, and $0.5 \%$ ) by total mix volume. The final test results indicated that increasing the basalt fiber content slightly increased the splitting tensile strength but did not affect the compressive strength up to $0.3 \%$ of basalt fiber which then decreased with $0.5 \%$ of basalt fiber. The compressive strength increases with the increase of fiber content till $0.3 \%$ of Basalt fiber, then there is a slightly decrease when Basalt fiber increases when $0.5 \%$ fiber was used. This study also reported a reduction in fresh concrete properties as the basalt fiber volume content was increased. (High et al. 2015) investigated the effect of using two different types of chopped basalt fibers to enhance the mechanical properties of concrete. The results indicate that the use of basalt fiber had increased the modulus of rupture and slightly increased the compressive strength of concrete, however the increase in the flexural strength of concrete was more pronounced. (Byung \& Oh 1993) Investigated the flexural behavior of reinforced concrete beams containing steel fiber. An experimental program was included two series of singly reinforced concrete beams and one series of doubly reinforced concrete beams, the fiber contents for each series were $0 \%, 1 \%$, and $2 \%$ by total mix volume. The result indicated that the ultimate strength of FRC beams is increased with an increase of fiber content, and the ductility and energy absorption capacity are considerably enhanced with the addition of steel fiber. In addition, the crack width increases almost linearly with increase of steel stress and that the crack width is remarkably reduced as the fiber amount in the beam increases. The FRC beams exhibited considerably less cracking and have remarkable resistance to tensile cracking.(Mertol et al. 2015) investigated the flexural behavior of large-scale steel fiber reinforced concrete beams (SFRC), with lightly and heavily reinforcement. The main parameters in this study were the type of concrete and the amount of longitudinal reinforcement. The results indicate that the use of SFRC increases the ultimate load and service stiffness of the beams slightly compared to the conventional concrete (CC). As reinforcement ratio increases, the ultimate deflection of SFRC beams become significantly greater than that of CC beams, the flexural 
toughness of SFRC specimens is greater than that of CC specimens with the difference being significantly larger for over-reinforced sections. 


\section{CHAPTER 3}

\section{EXPERIMENTAL PROGRAM}

In this chapter, the material characterizations for all materials are presented and discussed. In addition, the testing set-up, and testing protocol including the preparation of beams specimens for the four-point load flexural testing is highlighted.

\subsection{MATERIALS CHARACTERIZATION}

\subsubsection{Recycled Concrete Aggregates (RCA) and Natural Coarse Aggregates (NCA)}

The construction sector requires a supply of aggregates, but a state of Qatar does not possess any sources of hard rock aggregates. The aggregate that use to produce concrete (Gabbro) is imported from the United Arab Emirates. The redevelopment of Qatar has also generated massive quantities of construction and demolition waste. This waste is taken to the duping site in Rawdat Rashid area and it is divided depend on the source of waste. Since 2013 a large-scale recycled aggregate plant has been operating at the site by Lafarge Qatar Quarry Company and had supplied the required RCA for this project.

\subsubsection{Specific Gravity}

Relative density or specific gravity is expressed by the ASTM as the ratio of the density of aggregates particles to the density of distilled water at a specified temperature. It was calculated in this study according to ASTM C127-15 (ASTM C127 2015). Here below the procedure used for obtaining specific gravity.

$$
\begin{aligned}
& \text { Specific Gravity }(\mathrm{OD})=\frac{\mathrm{A}}{\mathrm{B}-\mathrm{C}} \\
& \text { Specific Gravity (SSD) }=\frac{\mathrm{B}}{\mathrm{B}-\mathrm{C}}
\end{aligned}
$$

Where OD is specific gravity of oven-dry coarse aggregates, SSD is specific gravity of saturated-surface-dry, $A$ is the mass of oven-dry test sample in air, $B$ is the mass of 
saturated-surface-dry test sample in air and $C$ is the apparent mass of saturated test sample in water.

The specific gravity of RCA is usually lower than the specific gravity of NCA because of attached mortar to the surface of RCA. The results show in Table 3.1.

\subsubsection{Water Absorption}

The absorption is defined as the in the mass of an aggregates due to water absorbed in the pore spaces within the constituent particles, compared to the dry condition, when it is deemed that the aggregate has been in contact with water long enough to satisfy most of the absorption potential. Using ASTM C127-15 (ASTM C127 2015) the procedure to calculate the percentage of absorption is as follow:

$$
\text { Absorption } \%=\left[\frac{B-A}{A}\right] X 100
$$

Where $A$ is the mass of oven-dry test sample in air and $B$ is the mass of saturated-surfacedry test sample in air.

The natural coarse aggregate has significantly lower absorption compared with RCA. The absorption of NCA is $0.65 \%$ while the RCA has absorption of $4.06 \%$. This difference in water absorption between both types of aggregates is due to the old grout contained in the RCA.

Table 3.1 Specific Gravity and Absorption ratio of NCA and RCA

\begin{tabular}{lcccc}
\hline $\begin{array}{c}\text { Aggregates } \\
\text { Type }\end{array}$ & $\begin{array}{c}\text { Bulk Specific Gravity } \\
\text { (Dry) }\end{array}$ & $\begin{array}{c}\text { Bulk Specific } \\
\text { Gravity (SSD*) }\end{array}$ & $\begin{array}{c}\text { Bulk Specific Gravity } \\
(\text { APP**) }\end{array}$ & $\begin{array}{c}\text { Absorption } \\
(\%)\end{array}$ \\
NCA & 2.88 & 2.89 & 2.93 & 0.65 \\
RCA & 1.96 & 2.04 & 2.13 & 4.06 \\
$* \begin{array}{l}\text { *SSD= Saturated Surface Dry) } \\
\text { * (APP= Apparent })\end{array}$
\end{tabular}




\subsubsection{L.A. Abrasion Test}

Abrasion is another aggregates property, which demonstrate its wear percentage and thus the concrete. It is desired to have the lowest possible percentage of wear because the concrete is usually subjected to heavy loads and repeated use. If percentage of wear is high, then it increases the amount of fines in concrete mixture, thus increasing the required water percentage for the mixture. If more water is needed, it decreases the strength of the concrete. Then, it is important to realize that wear percentage is actually an index of strength and toughness of the concrete. The ASTM C131-15 (ASTM C131 2015) was used to evaluate the coarse aggregates with a maximum size smaller than $37.5 \mathrm{~mm}$ resistance to abrasion using the Los Angeles testing machine. This test is used to evaluate the resistance of coarse aggregates for possible degradation. Percent loss is calculated as the difference between the final and initial mass of the tested sample as a percentage of the initial mass as shown in equation 3-4, and the results shows in Table 3.2, the increasing in the material loss for RCA has been attributed to the weak bond between the aggregate and cement mortar, while NCA has a stronger inner structure.

$$
\text { Percent Loss }=\left[\frac{C-Y}{C}\right] X 100
$$

Where $C$ is the mass of initial mass test sample (g), and $Y$ is the final mass of the test sample (g).

Table 3.2 Abrasion Resistance Results of NCA and RCA

\begin{tabular}{cccc}
\hline $\begin{array}{c}\text { Aggregates } \\
\text { type }\end{array}$ & Total Weight & Weight of Aggregates Retained on 1.7 mm & Loss \\
NCA & $($ g) & sieve & $(\%)$ \\
RCA & 5000 & 3775.2 & 75.5 \\
\hline
\end{tabular}




\subsubsection{Sieve Analysis and Fineness Modulus}

The aggregate in general makes about of $60-80 \%$ of total concrete volume, so it has a significant effect on concrete properties, and aggregate should be durable and vigorous and uniformly graded to meet the desired concrete mix. The ASTM C136-15 (ASTM C136 2015) was used to determine the particle size distribution of fine and coarse aggregates by sieving. A weighed sample of dry aggregate is separated through a series of sieves of progressively smaller openings for determination of particle size distribution. Fineness Modulus is defined as the total percentage of cumulative percentages retained on each of specified series of sieves and dividing the sum by100. The NCA is relatively coarser than the RCA. Hence the fineness modulus of $100 \%$ RCA is 3.916, which is slightly lower than NCA of 4.388. Table 3.3 and 3.4 shows the results of the sieve analysis for NCA and RCA respectively. Figure 3.1 and Figure 3.2 show the sieve analysis obtained for both types aggregates with respect to the upper and lower ASTM limits.

Table 3.3 Sieve Analysis Results of NCA

\begin{tabular}{ccccccc}
\hline $\begin{array}{c}\text { Sieve } \\
\text { Opening Size }\end{array}$ & $\begin{array}{c}\text { Mass } \\
\text { Sieve (g) }\end{array}$ & $\begin{array}{c}\text { Mass Sieve } \\
\text { +Retained (g) }\end{array}$ & $\begin{array}{c}\text { Mass } \\
\text { Retained (g) }\end{array}$ & $\begin{array}{c}\text { Retained } \\
\text { \% }\end{array}$ & $\begin{array}{c}\text { Cumulative } \\
\text { \% Retained }\end{array}$ & $\begin{array}{c}\text { Cumulative } \\
\text { \%Passing }\end{array}$ \\
$\mathbf{2 5} \mathbf{~ m m}$ & 1337.500 & 1337.500 & 0.00 & 0.00 & 0.00 & 100.00 \\
$\mathbf{1 9} \mathbf{~ m m}$ & 1311.000 & 1574.500 & 263.50 & 6.53 & 6.53 & 93.47 \\
$\mathbf{1 2 . 5} \mathbf{~ m m}$ & 1280.500 & 3378.000 & 2097.50 & 51.98 & 58.51 & 41.49 \\
$\mathbf{9 . 5} \mathbf{~ m m}$ & 1288.500 & 2479.500 & 1191.00 & 29.52 & 88.03 & 11.97 \\
$\mathbf{4 . 7 5} \mathbf{~ m m}$ & 1241.500 & 1706.500 & 465.00 & 11.52 & 99.55 & 0.45 \\
$\mathbf{2 . 3 6} \mathbf{~ m m}$ & 1101.000 & 1113.000 & 12.00 & 0.30 & 99.85 & 0.15 \\
$\mathbf{P a n}$ & 788.00 & 794.00 & 6.00 & 0.15 & 100.00 & 0.00 \\
& & & 4035.00 & & & \\
\hline
\end{tabular}




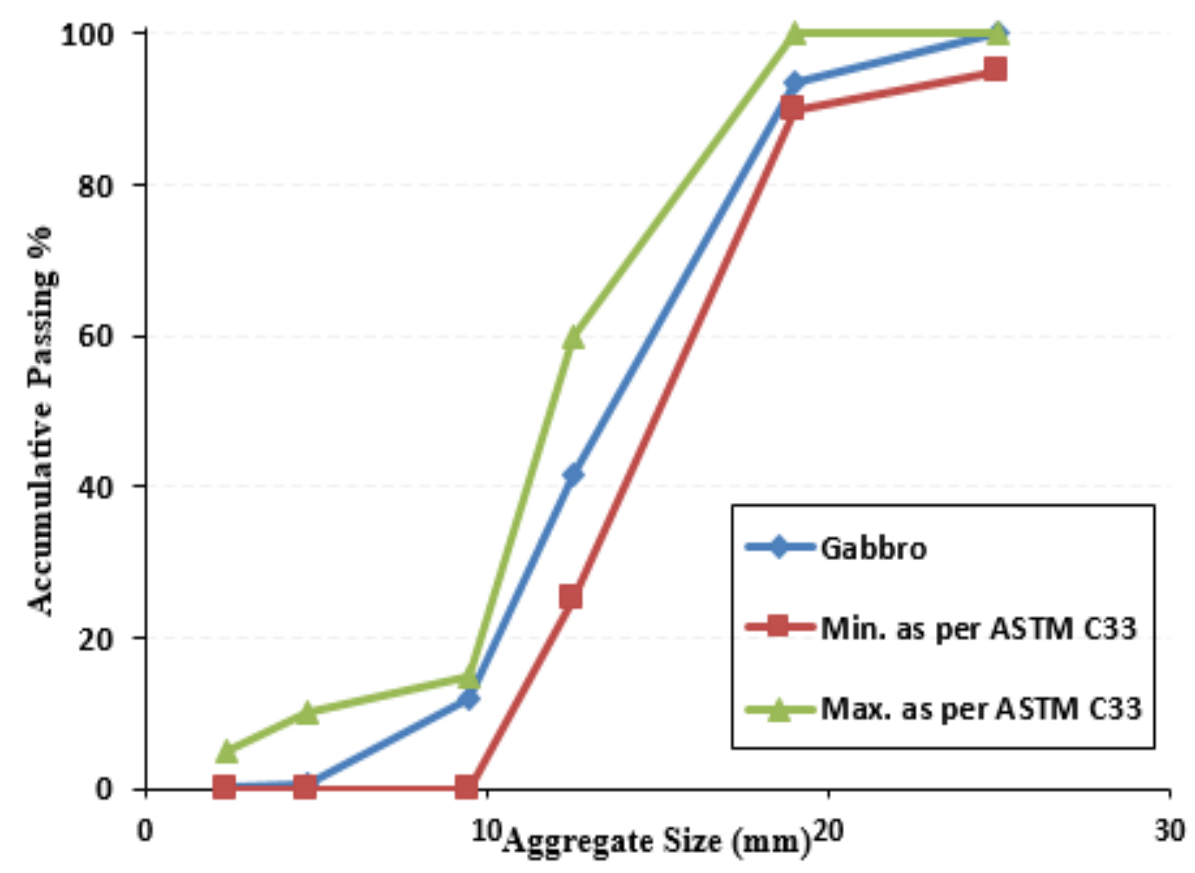

Figure 3.1 Sieve Analysis for NCA

Table 3.4 Sieve Analysis Results of RCA

\begin{tabular}{ccccccc}
\hline $\begin{array}{c}\text { Sieve } \\
\text { Opening Size }\end{array}$ & $\begin{array}{c}\text { Mass } \\
\text { Sieve (g) }\end{array}$ & $\begin{array}{c}\text { Mass Sieve } \\
\text { +Retained in }(\mathbf{g})\end{array}$ & $\begin{array}{c}\text { Mass Retained } \\
\text { in (g) }\end{array}$ & $\begin{array}{c}\text { Retained } \\
\text { \% }\end{array}$ & $\begin{array}{c}\text { Cumulative } \\
\text { \%Retained }\end{array}$ & $\begin{array}{c}\text { Cumulative } \\
\text { \%Passing }\end{array}$ \\
$\mathbf{2 5} \mathbf{~ m m}$ & 1337.500 & 1337.500 & 0.00 & 0.00 & 0.00 & 100.00 \\
$\mathbf{1 9} \mathbf{~ m m}$ & 1311.000 & 1344.000 & 33.00 & 1.10 & 1.10 & 98.90 \\
$\mathbf{1 2 . 5} \mathbf{~ m m}$ & 1280.500 & 2473.000 & 1192.50 & 39.78 & 40.88 & 59.12 \\
$\mathbf{9 . 5} \mathbf{~ m m}$ & 1288.500 & 2623.000 & 1334.50 & 44.51 & 85.39 & 14.61 \\
$\mathbf{4 . 7 5} \mathbf{~ m m}$ & 1241.500 & 1611.000 & 369.50 & 12.32 & 97.72 & 2.28 \\
$\mathbf{2 . 3 6} \mathbf{~ m m}$ & 1100.500 & 1158.500 & 58.00 & 1.93 & 99.65 & 0.35 \\
$\mathbf{P a n}$ & 788.50 & 799.00 & 10.50 & 0.35 & 100.00 & 0.00 \\
& & & 2998.00 & & & \\
\hline
\end{tabular}




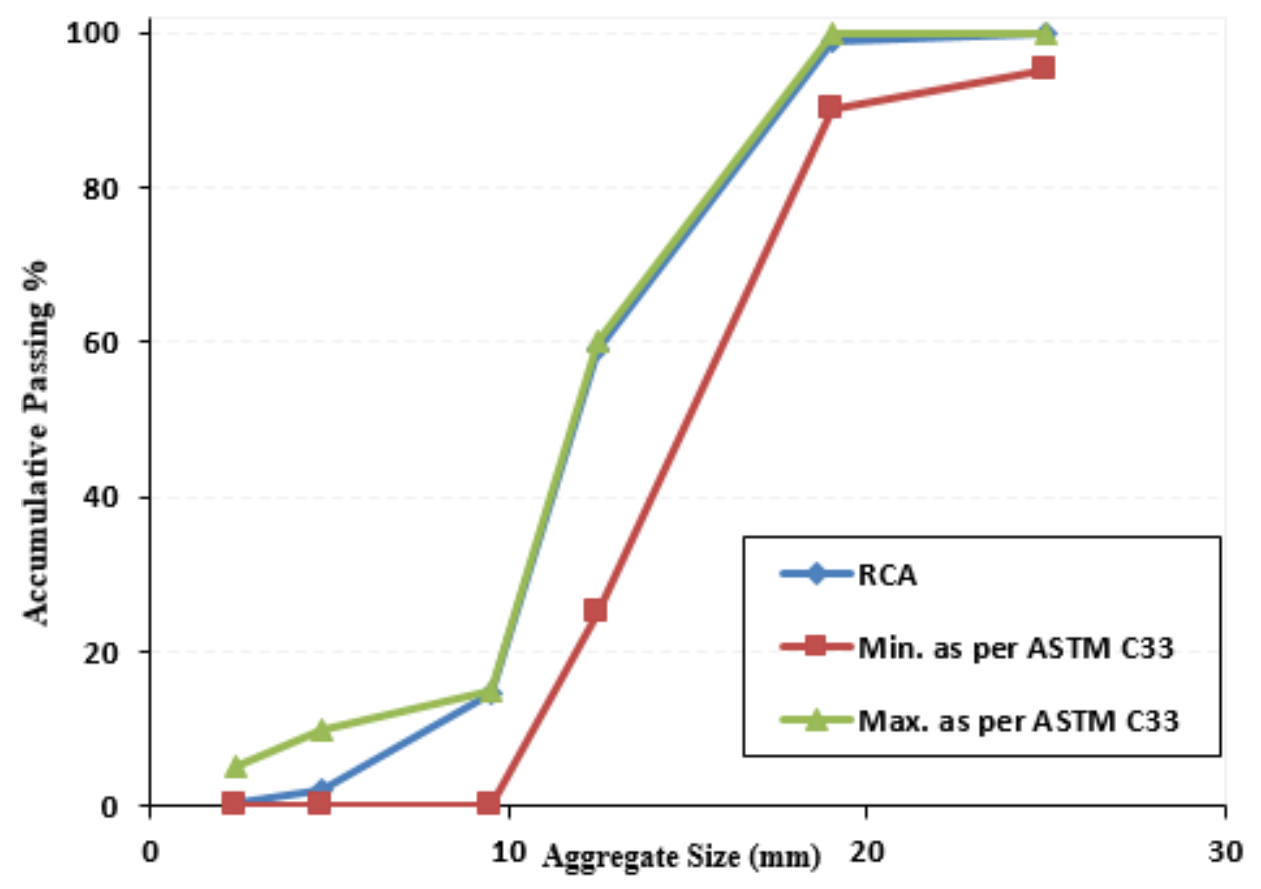

Figure 3.2 Sieve Analysis for RCA

\subsubsection{Fine Aggregates}

Fine Aggregates consists of natural clean washed sand, which is free from clay and any other inert impurities. The sand was purchased from a local supplier in Qatar, It is conforming to the requirements of physical and chemical properties as specified in the Qatar Construction Specification 2014 (QCS 2014).

\subsubsection{Cement}

Cement used in this study was normal Portland cement where its properties were conforming to ASTM C150-07 (ASTM C150 2007). The cement purchased from Qatar National Cement Company (QNCC). The cement was delivered to the site in sealed and branded bags and stored in dry and shade area until the mixing day.

\subsubsection{Water}

The water used for the concrete mixes was the normal tap water supplied by Qatar General Electricity and Water Corporation (Kahramaa) and water quality were complying with Qatar Construction Specification 2014 (QCS 2014). 


\subsubsection{Basalt Macro Fiber (BMF)}

Basalt macro fiber is designed to improve concrete structural strength, control crack, and deliver high flexural toughness with high integrity, high thermal resistance and alkali resistance. Recently, ReforceTech AS, Norway has developed an innovative chopped basalt fiber, with trademark brand name of MiniBar (ReforceTech ). This BMF was used in this study. It is a non-corrosive discrete thin fiber made from basalt stone, and coated with solution suitable for use in concrete, with an average diameter from 13-20 $\mu \mathrm{m}$ and a length of $45 \mathrm{~mm}$ as seen in Figure 3.3. It possesses higher tensile strength and stiffness compared to other standard synthetic fibers (Sudeep Adhikari 2013).It acts as the proactive reinforcement that provides the immediate tensile load carrying capacity when micro cracks develop in concrete. It has a tensile strength of $3200 \mathrm{MPa}$ and a modulus of elasticity of $90 \mathrm{GPa}$. In addition, it has a density closet to concrete than the density of synthetic or steel fiber (Banibayat \& Patnaik 2014). This allows mixing of concrete with BMF at dosages up to $3 \%$ by volume without impairing the workability. The main properties of the basalt macro fiber used in this study are shown in Table 3.5.
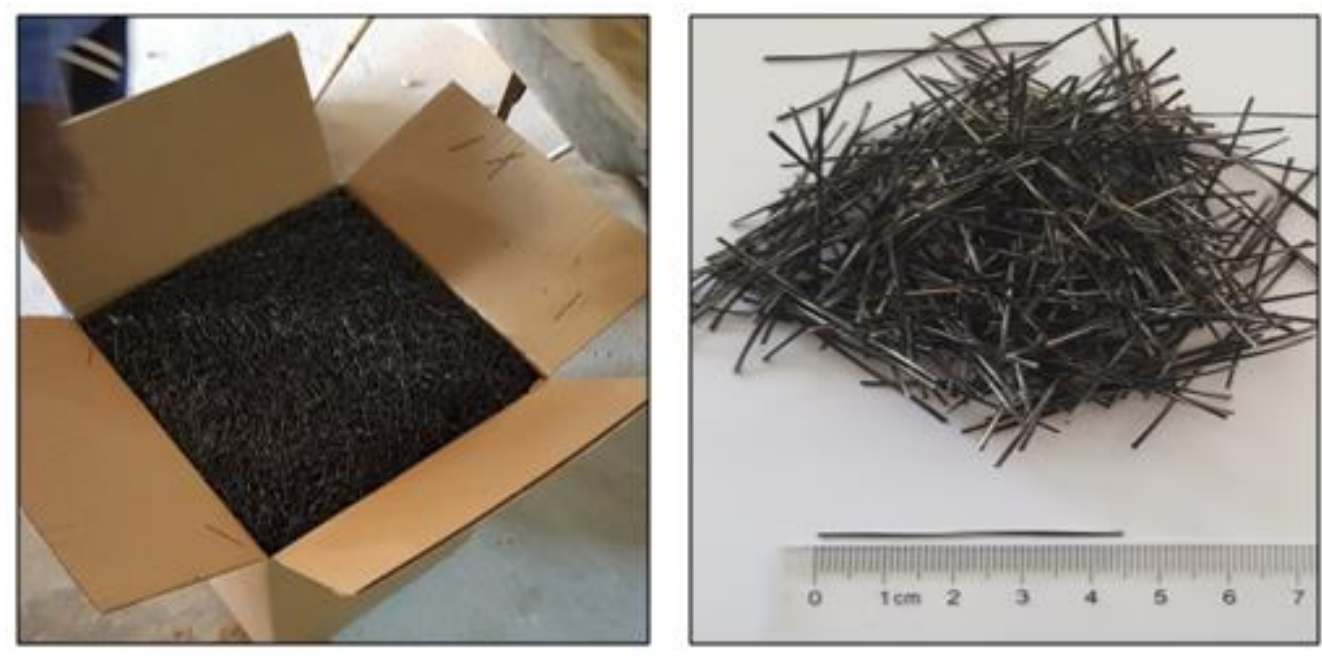

Figure 3.3 Basalt Macro Fiber (BMF) 
Table 3.5 Characterization of Basalt Macro Fiber (BMF)

\begin{tabular}{cc}
\hline Diameter $(\boldsymbol{\mu m})$ & $13-20$ \\
Length $(\mathbf{m m})$ & 45 \\
Specific Gravity $\left(\mathbf{g} / \mathbf{c m}^{\mathbf{3}}\right)$ & 2.68 \\
Water Absorption & None \\
Tensile Strength $(\mathbf{M P a})$ & 3200 \\
E modulus $(\mathbf{G P a})$ & 90 \\
Alkaline Resistance & Excellent \\
Thermal Operating Range $(\mathbf{C})$ & -260 to +700 \\
Electrical Conductivity & None \\
Resistance to Corrosion & Non-Corrosive \\
\hline
\end{tabular}

\subsubsection{Steel Reinforcement Properties}

Steel bars with diameter of 8 and $16 \mathrm{~mm}$ were used as steel reinforcement of beam specimens, the bars with diameter of $8 \mathrm{~mm}$ were used for all transverse steel reinforcement (stirrups) and also used in the compression reinforcement (Top steel), while bars with dimeter of $16 \mathrm{~mm}$ were used for the main flexural reinforcement (Bottom steel). The mechanical properties of the test steel bars are presented in Table 3.6.as provided by the manufacturer (Qatar Steel).

Table 3.6 Properties of Steel Reinforcement

\begin{tabular}{cccccc}
\hline $\begin{array}{c}\text { Bar Dia. } \\
(\mathbf{m m})\end{array}$ & $\begin{array}{c}\text { Area } \\
\left(\mathbf{m m}^{\mathbf{2}}\right)\end{array}$ & $\begin{array}{c}\text { Yield } \\
\text { Strain }\end{array}$ & $\begin{array}{c}\text { Yield Stress } \\
\left(\mathbf{N} / \mathbf{m m}^{\mathbf{2}}\right)\end{array}$ & $\begin{array}{c}\text { Ultimate Stress } \\
\left(\mathbf{N} / \mathbf{m m}^{\mathbf{2}}\right)\end{array}$ & $\begin{array}{c}\text { Modulus of } \\
\text { Elasticity }(\mathbf{G P a})\end{array}$ \\
$\mathbf{8}$ & 50 & 0.00268 & 512 & 551 & 191 \\
$\mathbf{1 6}$ & 201 & 0.00266 & 525 & 560 & 197 \\
\hline
\end{tabular}




\subsection{TEST MATRIX}

It was intended in this project to reach for experimentally-driven conclusive remarks about the effect of following parameters on the flexural behavior of RC beams: i.) Aggregate replacement ratio of the RCA: three different coarse aggregate replacement ratios of RCA were investigated (i. e. $0 \%, 25 \%, 50 \%$, and 100\%); and ii.) Volume fraction of the BMF: three different volume fractions of BMF were used in this research (i. e. $0 \%$, $0.5 \%, 1 \%$, and $1.5 \%$ ). The testing specimens were included 16 beams with different RCA replacement ratios, and volume fractions of basalt fibers ratios, as shown in Table 3.7.

Table 3.7 Test Matrix for Beam Samples

\begin{tabular}{ccc}
\hline Beam ID & RCA \% & BMF\% \\
A1 & 0 & 0 \\
A2 & 25 & 0 \\
A3 & 50 & 0 \\
A4 & 100 & 0 \\
A5 & 0 & 0.5 \\
A6 & 25 & 0.5 \\
A7 & 50 & 0.5 \\
A8 & 100 & 0.5 \\
A9 & 0 & 1 \\
A10 & 25 & 1 \\
A11 & 50 & 1 \\
A12 & 100 & 1 \\
A13 & 0 & 1.5 \\
A14 & 25 & 1.5 \\
A15 & 50 & 1.5 \\
A16 & 100 & 1.5 \\
\hline
\end{tabular}




\subsection{CONCRETE MIX DESIGN}

Once both types of the aggregate were tested and characterized, concrete mixtures were proportioned to achieve target compressive strength of $35 \mathrm{MPa}$ at 28 day. In total, of sixteen concrete mixtures with different replacement ratios of RCA and volume fractions of BMF were developed as part of this study. All concrete mixtures were prepared with a constant water-to-cement ratio of 0.45 and cement content of $349.5 \mathrm{Kg} / \mathrm{m}^{3}$. Four series of concrete mixtures were prepared and each series content four mixtures, where the fist mixture of each groups has treated as a control mixture. Where the BMF were used at rates of $0 \%, 0.5 \%, 1 \%$ and $1.5 \%$ of total volume of concrete mix for each series respectively. The RCA were used at rates of $0 \%, 25 \%, 50 \%$ and $100 \%$ of coarse aggregate total volume for each mix respectively. Due to using different BMF dosages, admixture has used to achieve the acceptable concrete workability. As the RCA were characterized by higher water absorption due to attached mortar content compared with NCA, the total amount of water plays a key rule on the evolution of the hardened properties for resulting concrete, for this reason, the RCA as well the NCA were in saturated surface dry condition and appropriate moisture adjustments were made to cater for the different water absorption properties of the aggregates before batching, the saturated surface dry aggregates were prepared by removing the surface moisture from the aggregates with a moistened cloth after immersing the aggregates in water for 24 hours. Using this method will ensure that all water has been absorbed by the both types of aggregate especially the RCA and the moisture condition from sample to sample does not differ significantly, the volume of water absorbed by the saturated aggregates is not include in the calculation of the water to cement content. The absolute volume method was adopted to design the concrete mixture proportions, which uses the relative densities of various constituents to calculate the absolute volume of each that will occupy one cubic meter of concrete, as shown in Table3.8. 
Table 3.8 Concrete Mixture Proportions

\begin{tabular}{ccccccccc}
\hline Mix & RCA & BMF & Cement & Fine Aggregates & Water & NCA & RCA & BMF \\
ID & \% & \% & $\mathrm{kg} / \mathrm{m}^{3}$ & $\mathrm{~kg} / \mathrm{m}^{3}$ & $\mathrm{~kg} / \mathrm{m}^{3}$ & $\mathrm{~kg} / \mathrm{m}^{3}$ & $\mathrm{~kg} / \mathrm{m}^{3}$ & $\mathrm{~kg} / \mathrm{m}^{3}$ \\
A1 & 0 & 0 & 349.5 & 709 & 156 & 1076 & 0 & 0 \\
A2 & 25 & 0 & 349.5 & 709 & 156 & 807 & 189.5 & 0 \\
A3 & 50 & 0 & 349.5 & 709 & 156 & 538 & 379.5 & 0 \\
A4 & 100 & 0 & 349.5 & 709 & 156 & 0 & 759 & 0 \\
A5 & 0 & 0.5 & 349.5 & 709 & 156 & 1076 & 0 & 9 \\
A6 & 25 & 0.5 & 349.5 & 709 & 156 & 807 & 189.5 & 9 \\
A7 & 50 & 0.5 & 349.5 & 709 & 156 & 538 & 379.5 & 9 \\
A8 & 100 & 0.5 & 349.5 & 709 & 156 & 0 & 759 & 9 \\
A9 & 0 & 1 & 349.5 & 709 & 156 & 1076 & 0 & 18 \\
A10 & 25 & 1 & 349.5 & 709 & 156 & 807 & 189.5 & 18 \\
A11 & 50 & 1 & 349.5 & 709 & 156 & 538 & 379.5 & 18 \\
A12 & 100 & 1 & 349.5 & 709 & 156 & 0 & 759 & 18 \\
A13 & 0 & 1.5 & 349.5 & 709 & 156 & 1076 & 0 & 27 \\
A14 & 25 & 1.5 & 349.5 & 709 & 156 & 807 & 189.5 & 27 \\
A15 & 50 & 1.5 & 349.5 & 709 & 156 & 538 & 379.5 & 27 \\
A16 & 100 & 1.5 & 349.5 & 709 & 156 & 0 & 759 & 27 \\
\hline & & & & & & & &
\end{tabular}

\subsection{FABRICATION OF RC BEAMS}

This section describes the preparation of RC beams, cylinders and prisms specimens.

\subsubsection{Grinding of The Steel Rebar Surface}

Before casting the beams, the strain gauges were installed on the steel bars. In order to install strain gauges on steel rebar, the surface of rebar should be smooth and flat enough so that the strain gauge will have the maximum contact area to the steel bar. Grinder was used for grinding the steel bar surface, as shown in Figure 3.4. 


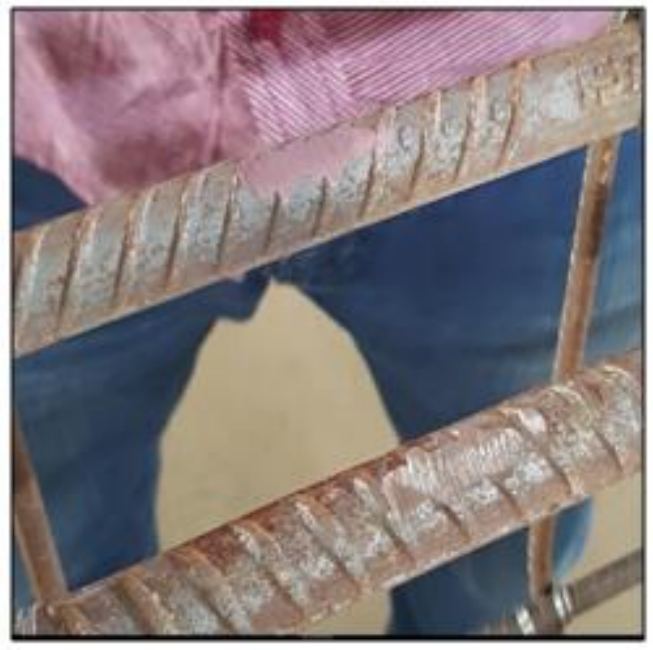

Figure 3.4 Grinded Steel Bars

\subsubsection{Steel Fabrication and Formwork}

The beam formwork was quite simple to construct and there was no difference between the 16 beams. The basic beam geometry is length of $2550 \mathrm{~mm}$, width of $150 \mathrm{~mm}$, and depth of $250 \mathrm{~mm}$, as shown in Figure 3.5. All steel bars cut and bent in accordance with beam dimensions and fit within the formwork. Steel bars were used for the reinforcement in the construction of beams as shown in Figure3.6. The bars of diameter 8 $\mathrm{mm}$ were used for all transverse steel reinforcement (stirrups) and also used as compression reinforcement (top steel) for all the beams, while the $16 \mathrm{~mm}$ bars were used for the main flexural reinforcement. In order to get approximately pure flexural behavior at the middle of the beam, the stirrups were uniformly spaced at $70 \mathrm{~mm}, 100 \mathrm{~mm}$ and $150 \mathrm{~mm}$ center to center respectively(ACI 315-99 code has been followed for stirrup bent), as shown in Figure 3.7. Plywood was used to construct the formwork as per required beam's dimensions (2550 $\mathrm{mm}$ length, $150 \mathrm{~mm}$ width and $250 \mathrm{~mm}$ depth). The inner surface of formwork has been sprayed with oil to ensure the formwork will open easily when demolded, then the reinforcement had been placed in the formwork with effective $2.5 \mathrm{~cm}$ spacers for all beam sides to provide the desired clear cover $(25 \mathrm{~mm})$ at the bottom and both sides of beam, as shown in Figure3.8. 

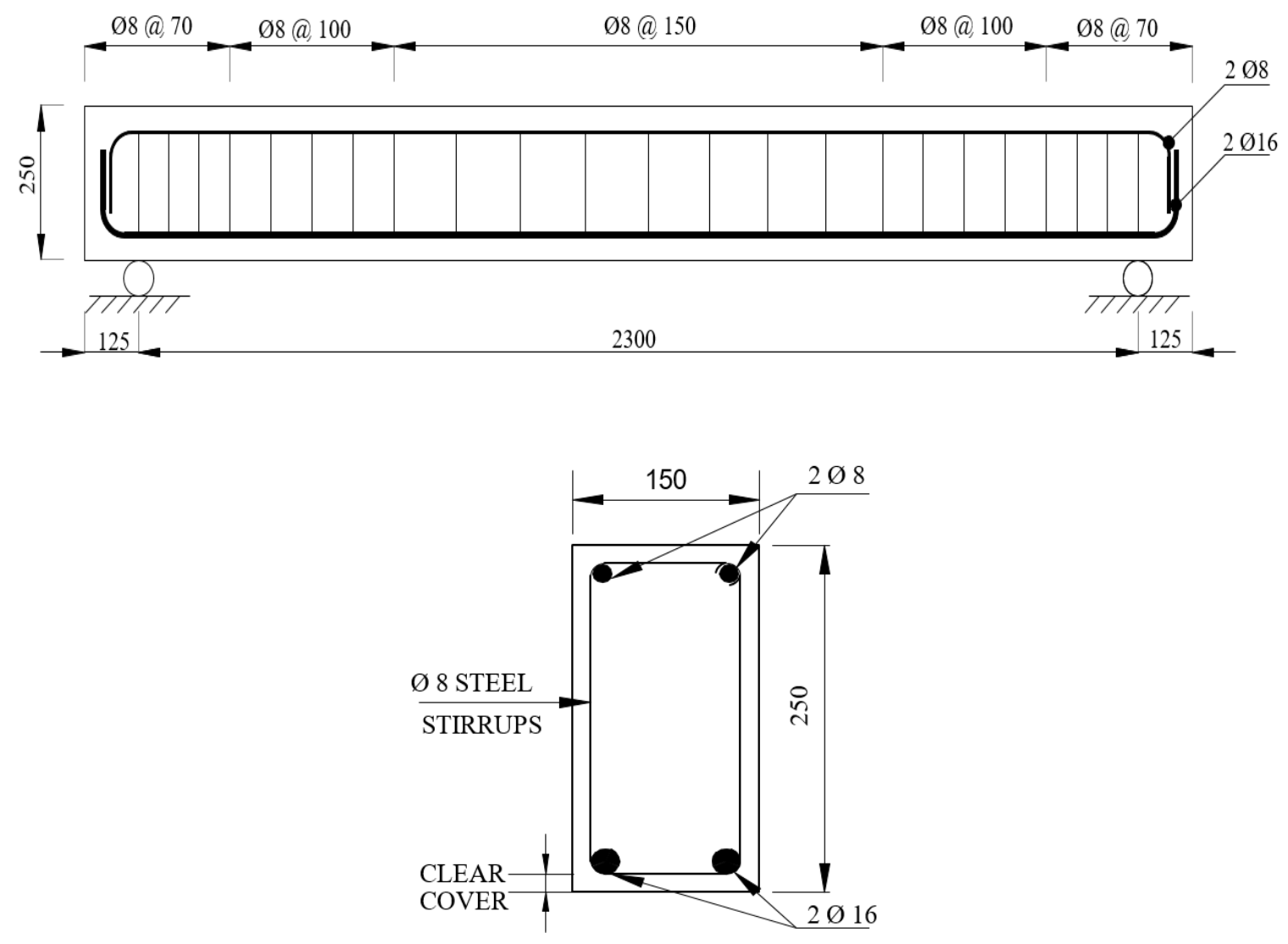

Figure 3.5 Reinforcement Details and Cross Section (Dimensions are in $\mathrm{mm}$ )
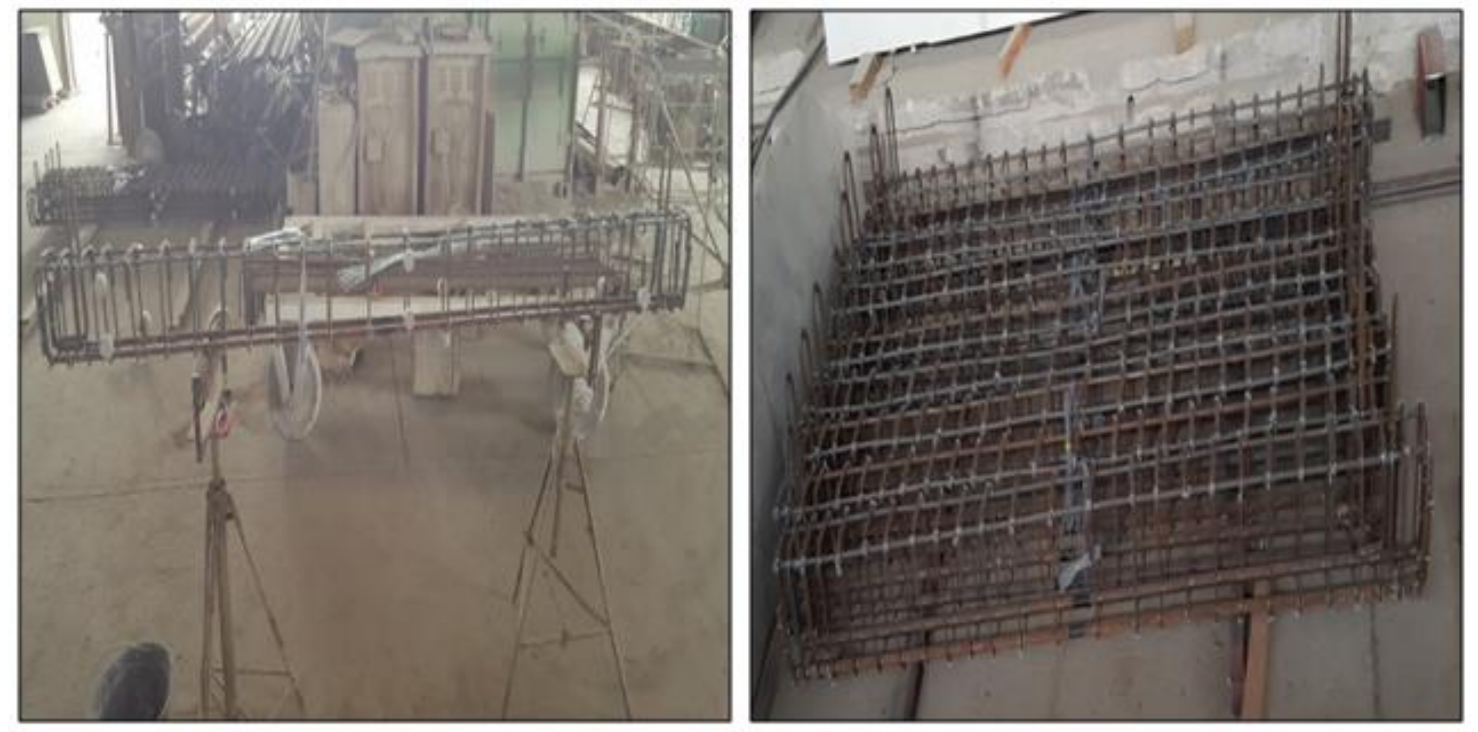

Figure 3.6 Steel Cages 

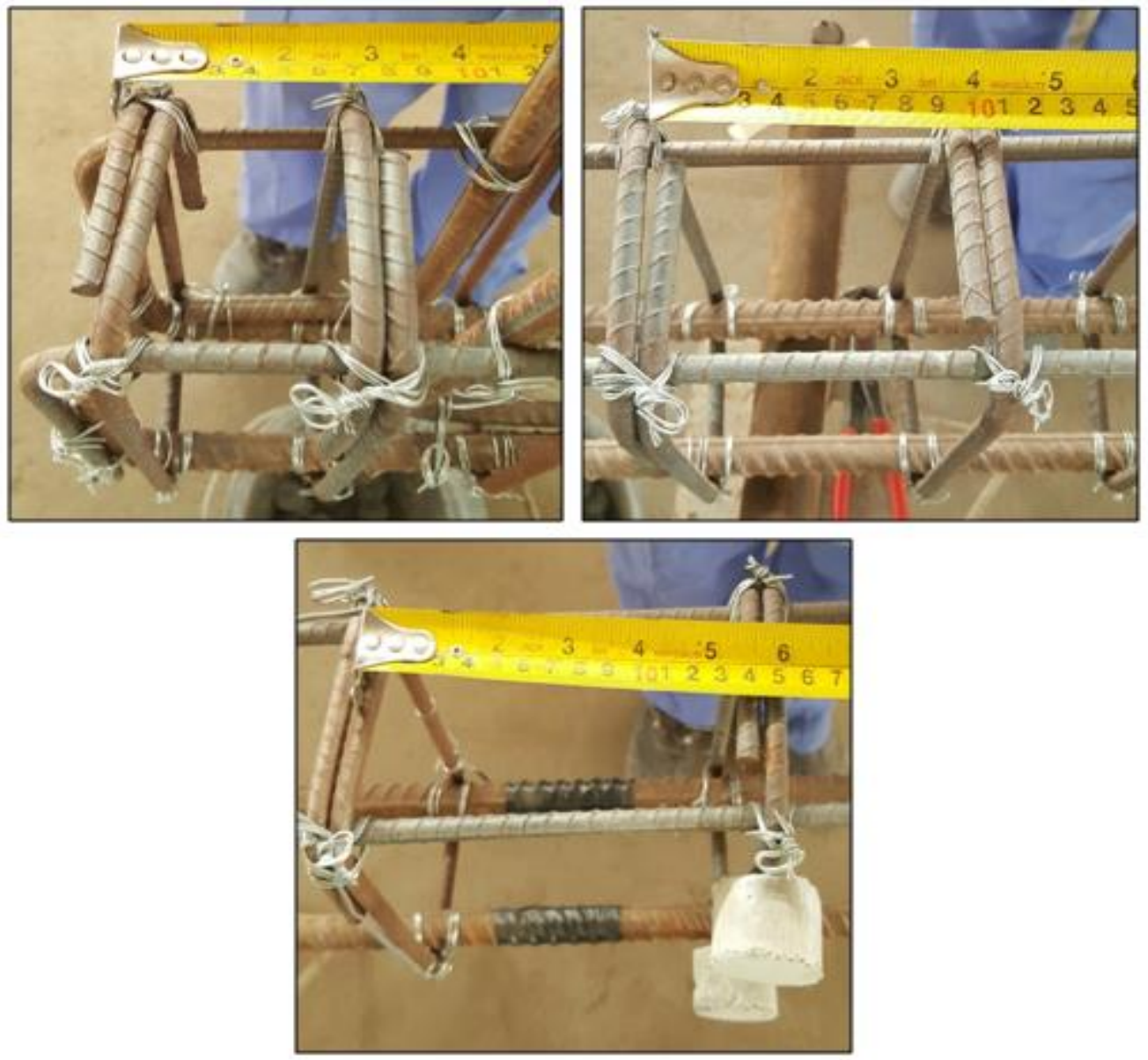

Figure 3.7 Stirrups Distribution

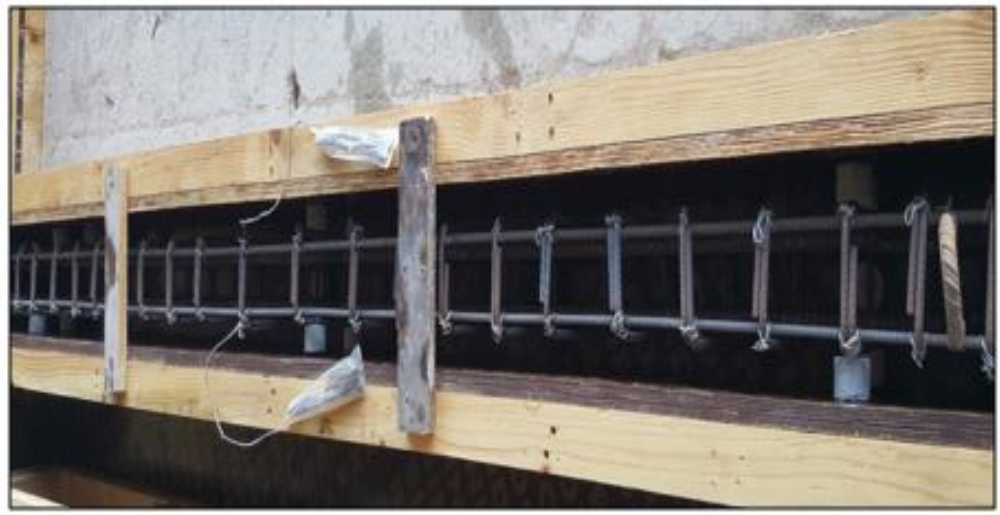

Figure 3.8 Framework and Steel Cage with Cover Spacer 


\subsubsection{Installation of Strain Gauges}

Strain gauges (TML strain gauge type FLA-5-11-5) were installed in the middle of each bottom steel bars to measure the steel tensile strains at mid-span of beams during the test. Two strain gauges were attached to the bottom steel bars. The insulation tape was wrapped around the strain gauge as shown in Figure 3.9 in order to protect the strain gauge while casting of concrete.
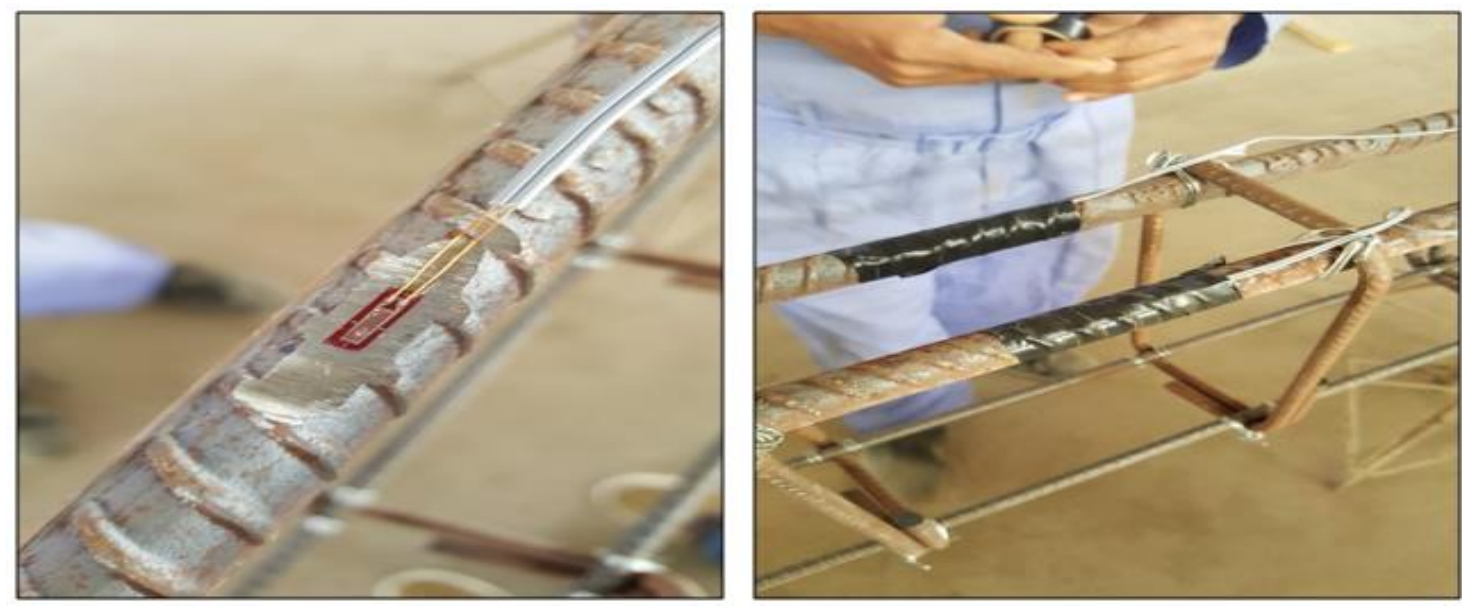

Figure 3.9 Fixing of Steel Strain Gauges

\subsection{MATERIALS AND MIXTURE PREPARATION}

Recycled concrete aggregates (RCA) and natural coarse aggregates (NCA) were washed and immersed in water for 24 hours before mixing to minimize their effects on the workability of the concrete, due to the high-water absorption of the RCA and then dried, as can be seen in Figure 3.10 and 3.11. All materials were balanced using accurate balance. The concrete casting process was done using $0.2 \mathrm{~m}^{3}$ tilting drum mixer.

To begin the mixing process, tap water was used to clean the interior of the mixing drum. Once the drum was fully cleaned, the excess water was dumped out. Next, all coarse aggregates (RCA and/or NCA) and then fine aggregates were placed into the mixer. Once all of the aggregates were inside, the mixer was turned on and small portion of the water mixed with admixture $(0 \mathrm{ml}, 200 \mathrm{ml}, 300 \mathrm{ml}$ and $400 \mathrm{ml}$ for $0 \%, 0.5 \%, 1 \%$ and $1.5 \%$ of BMF respectively to increase the workability) was added as shown in Figure 3.12, the mixer was 
allowed to run for two minutes to let the aggregates to achieve a homogeneous blend, the next step was to add the Cement, BMF and then remaining mixed water add gradually, as shown in Figure 3.13. After approximately ten minutes of mixing, the mixer was stopped and the concrete was ready for pouring in the specimen's molds.

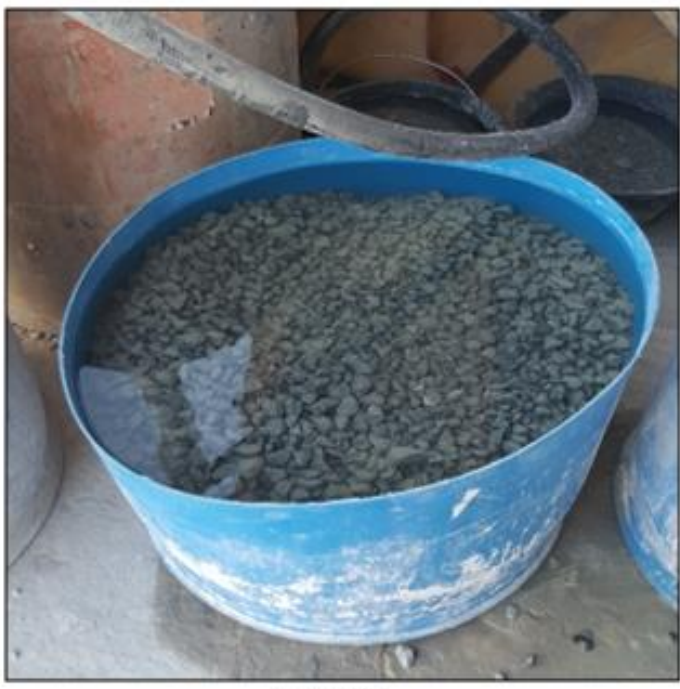

(a) NCA

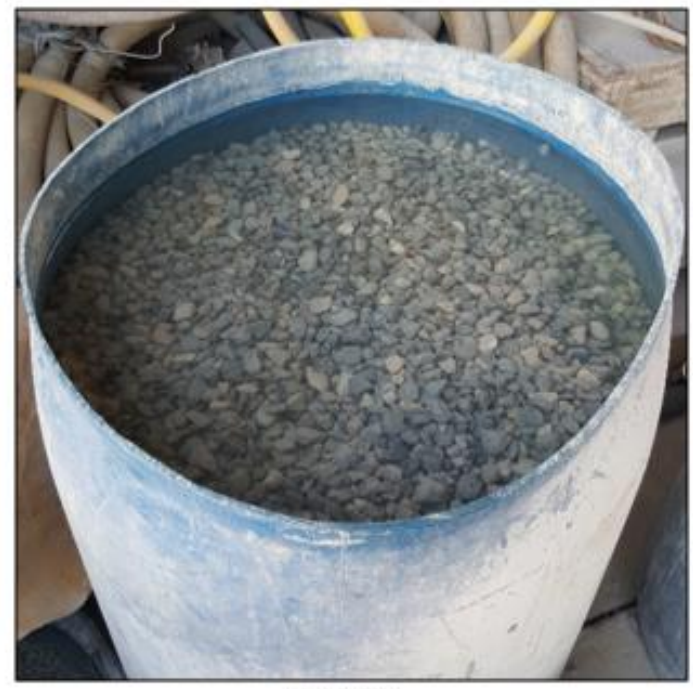

(b) RCA

Figure 3.10 Moisturizing the Aggregates in Water Tanks

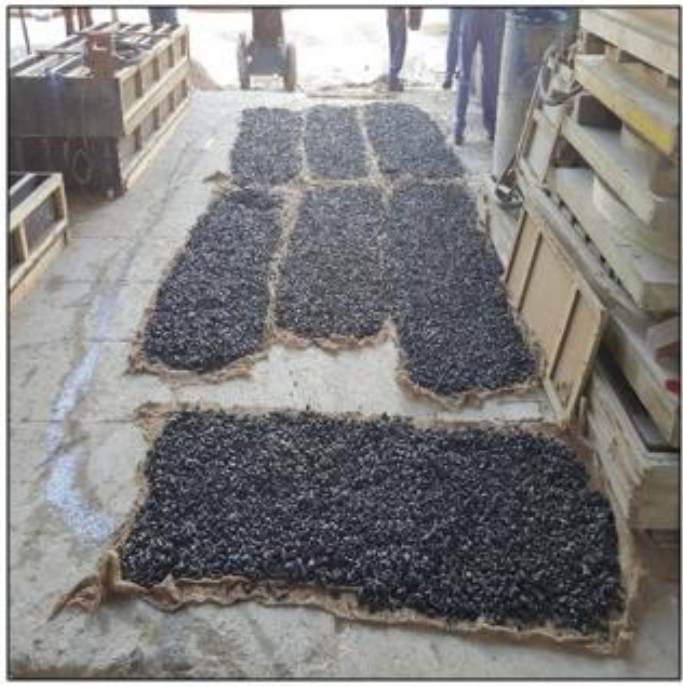

(a) NCA

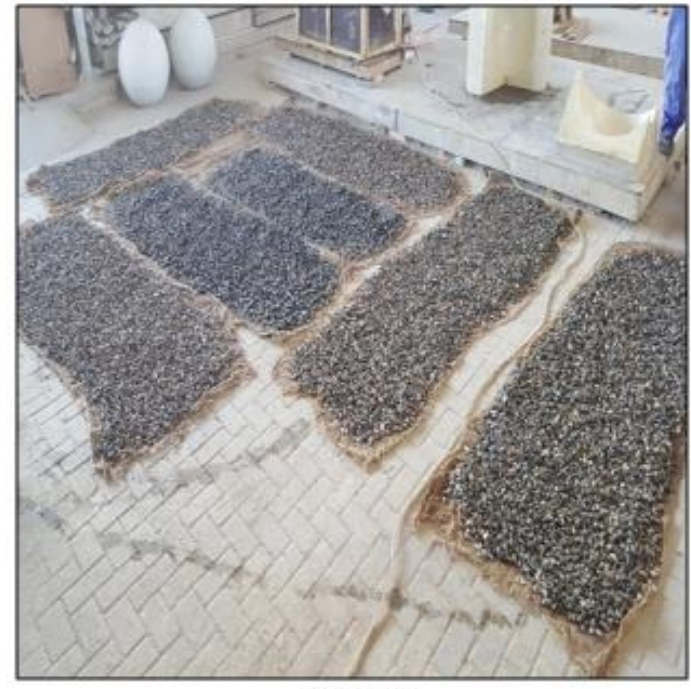

(b) RCA

Figure 3.11 Drying the Aggregates to Achieve the SSD Condition 

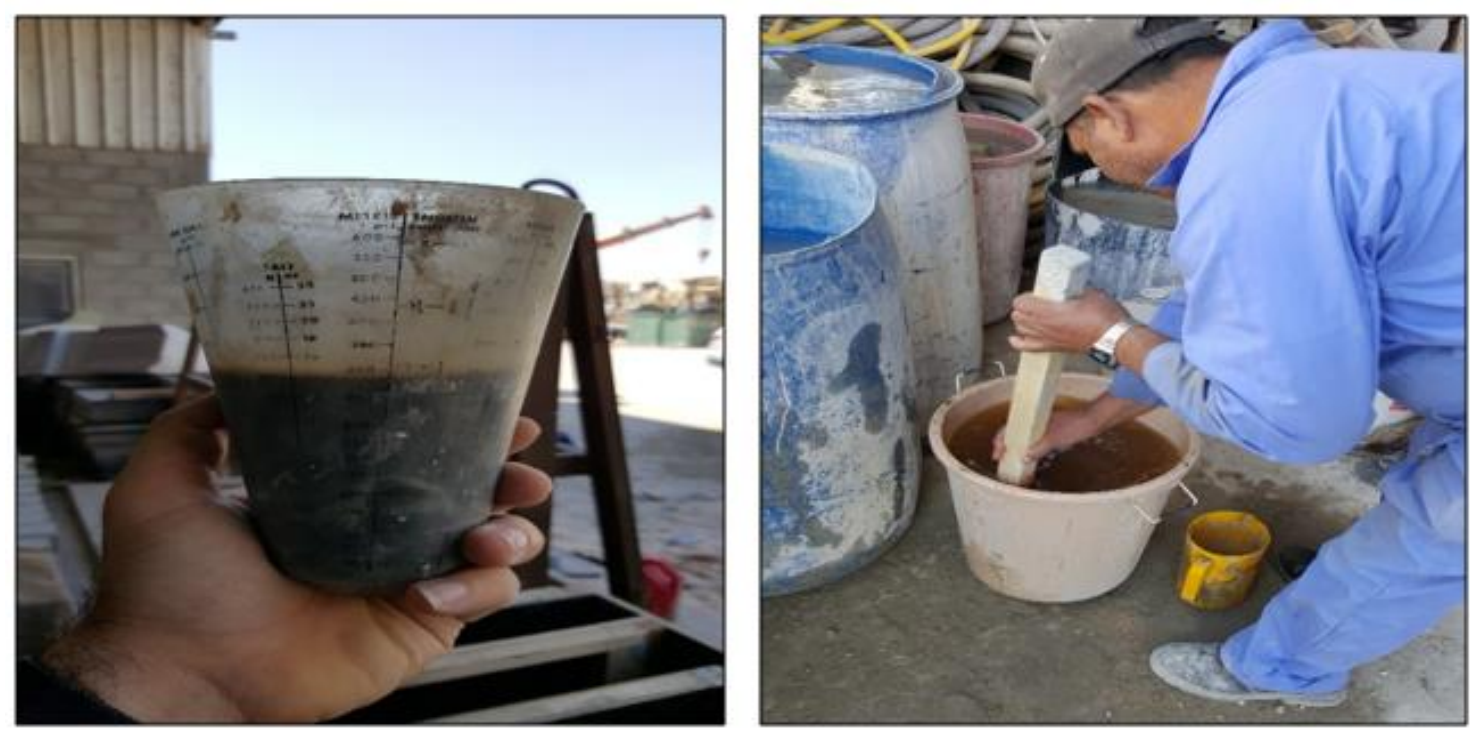

Figure 3.12 Mixing Water with Admixture
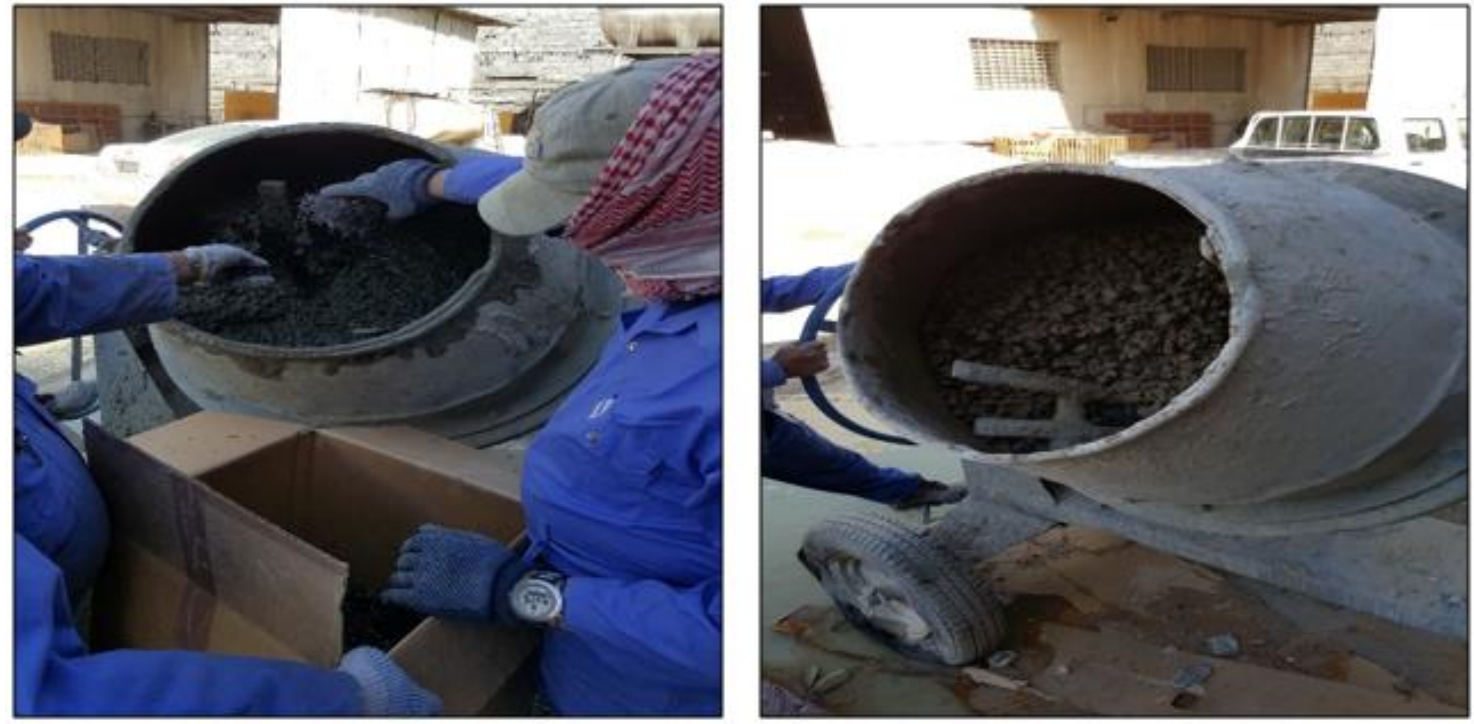

Figure 3.13 Adding BMF Inside the Concrete Mechanical Mixer 


\subsection{CASTING OF TEST SPECIMENS}

The steel cages were placed into the formwork and coded as per concrete design mix, as seen in Figure3.14. It was confirmed wires of strain gauges were not damaged during casting of the concrete. Each beam had a concrete volume of $0.096 \mathrm{~m}^{3}$ and it was casted in addition to the cylinders and prisms in one batch from the concrete mixer. Before casting the concrete specimens, the formwork was cleaned by compressed air to make sure that there was no dust. Then a brush was used to oiling the inner surface of formwork with two perpendicular coats to prevent any contact between the concrete and the formwork. Then the formwork was filled with concrete in two layers, each layer was compacted properly using electrical vibrator to avoid having any air bubbles inside the concrete and achieve full compaction and then the beam's top surface was finished accurately. At the same time three cylinders and three prisms were casted for each beam mixture for compressive strength and tensile strength tests, respectively as shown in Figure3.15 The concrete casting process took about one week for all specimens. The BMF were placed in the concrete mix during casting at the assigned volume fractions. The BMF were dispersed in both the compression and the tension zones of the beam specimens. Physical inspection of the fresh concrete showed that satisfactory workability was achieved with the addition of BMF for all samples except sample "A13". The BMF was found to be uniformly distributed within the concrete for all samples except sample "A13". That is because sample "A13" was the first casted one with a higher percentage of BMF (1.5\%), which resulted in having balling and segregation in that sample. However, a modified mixing procedure were used in casting samples (A14 to A16), which satisfied the workability requirements. 


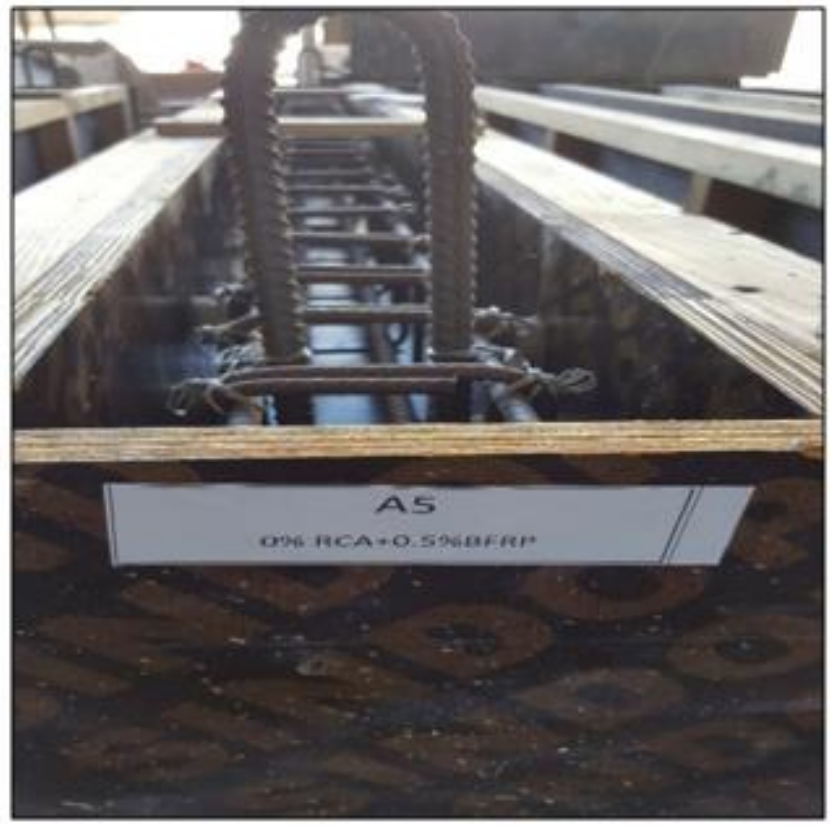

Figure 3.14 Coded Beam Ready for Casting
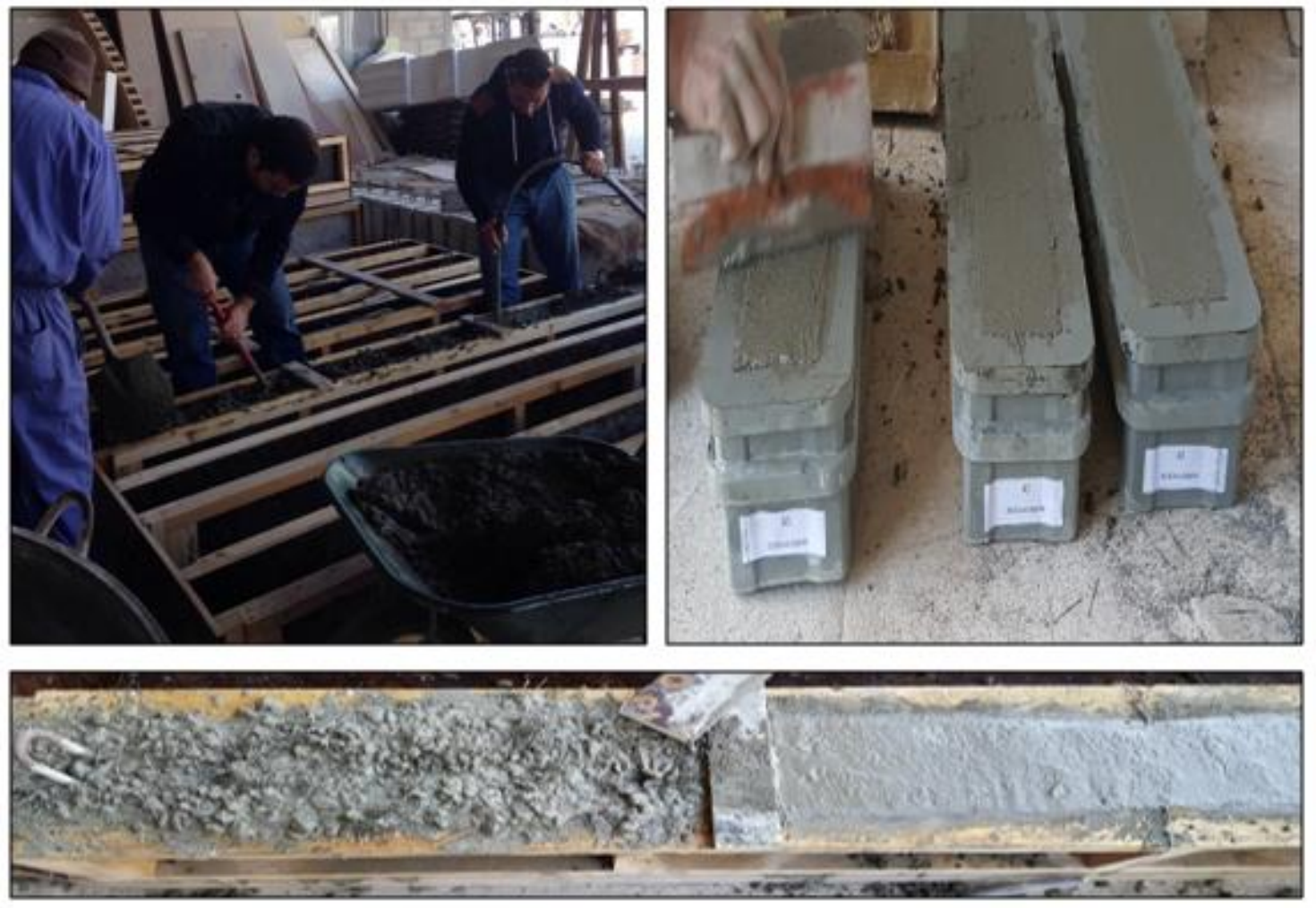

Figure 3.15 Casting of the Concrete Beams 


\subsubsection{Curing of Test Specimens}

The specimens were coded and de-shuttered 24 hours after concrete casting when they had reached sufficient strength to carry their own weight. Curing is the process in which the concrete is protected from loss of moisture and kept within a reasonable temperature range. Tap water was used to cured all 16 beams three times per day for 28 days under shaded area and covered by wet burlap sacks in order to achieve the required compressive strength of concrete, as can be seen in Figure3.16. All cylinders and prisms were immersed in water tank for 28 days, and then kept in shaded area before the test day, as shown in Figure3.17.

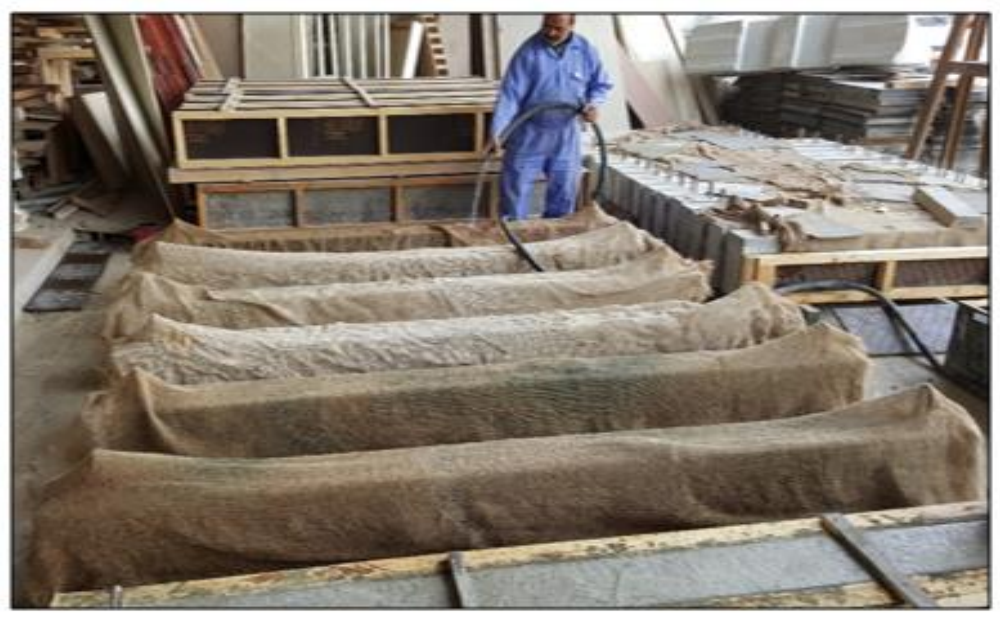

Figure 3.16 Curing of Beam Specimens
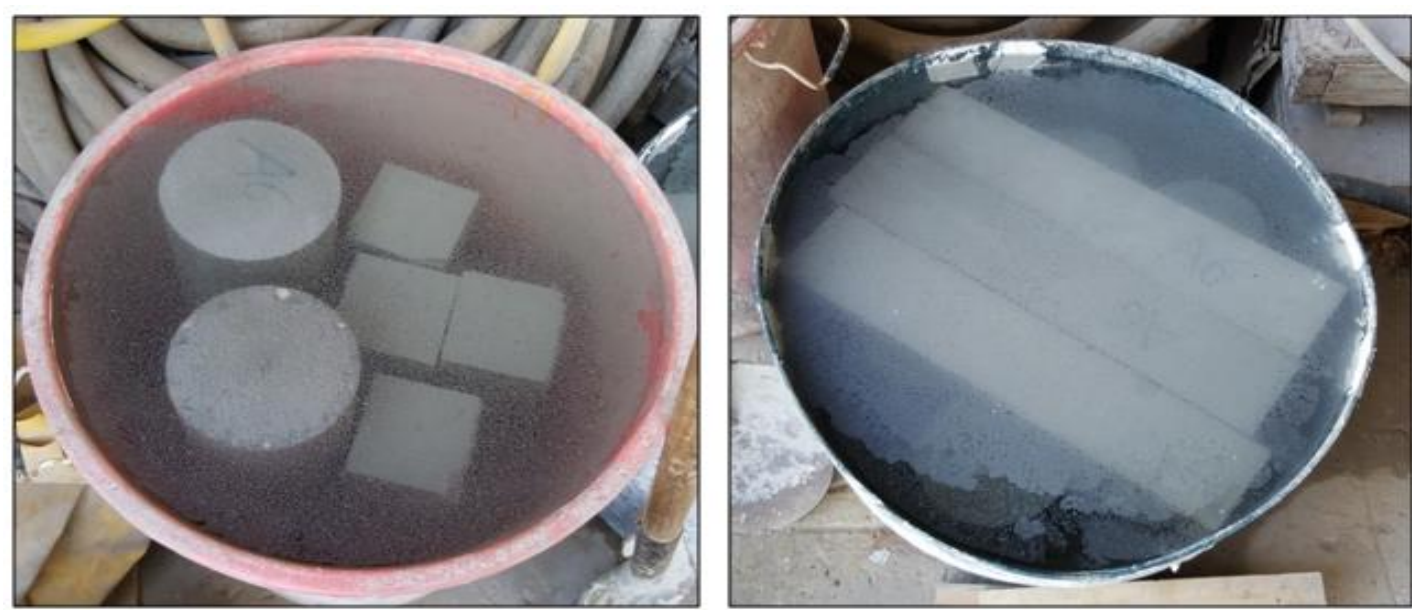

Figure 3.17 Curing of Concrete Cylinders and Prisms 


\subsubsection{Transportation of Test Specimens}

The beams, cylinders and prisms were transported to testing laboratory located at Qatar University using a trailer. All test specimens ( 16 beams, 48 cylinders and 48 prisms) were transported in two trips and the beams were unloaded using crane where a hydraulic forklift were used to transfer and place them inside the laboratory.

\subsection{COMPRESSIVE STRENGTH}

The compressive strength of all concrete mixes was measured using standard cylinders of $150 \times 300 \mathrm{~mm}$ according to the provisions of ASTM C192-16 (ASTM C192 2016). The cylinders were moist-cured for 28 days after mixing. Three test cylinders were performed for each mix after 28 days according to ASTM C39-16 (ASTM C39 2016). Concrete cylinders were tested using automatic compression machine for cylinders (with Advantest software) with $250 \mathrm{kN}$ maximum compression load capacity, as seen in Figure3.18. Cylinder cappers were used for both ends to assure plane end surfaces perpendicular to the axis of the cylinder to improve the smoothness and reduce the possibility of eccentric loading. The highest load reached by the specimen before it failed was divided by the cross section area to determine the ultimate compressive strength. The compressive strength of each concrete mixture is determined based on the average compressive strength of three concrete cylinders made from the same concrete batch. 


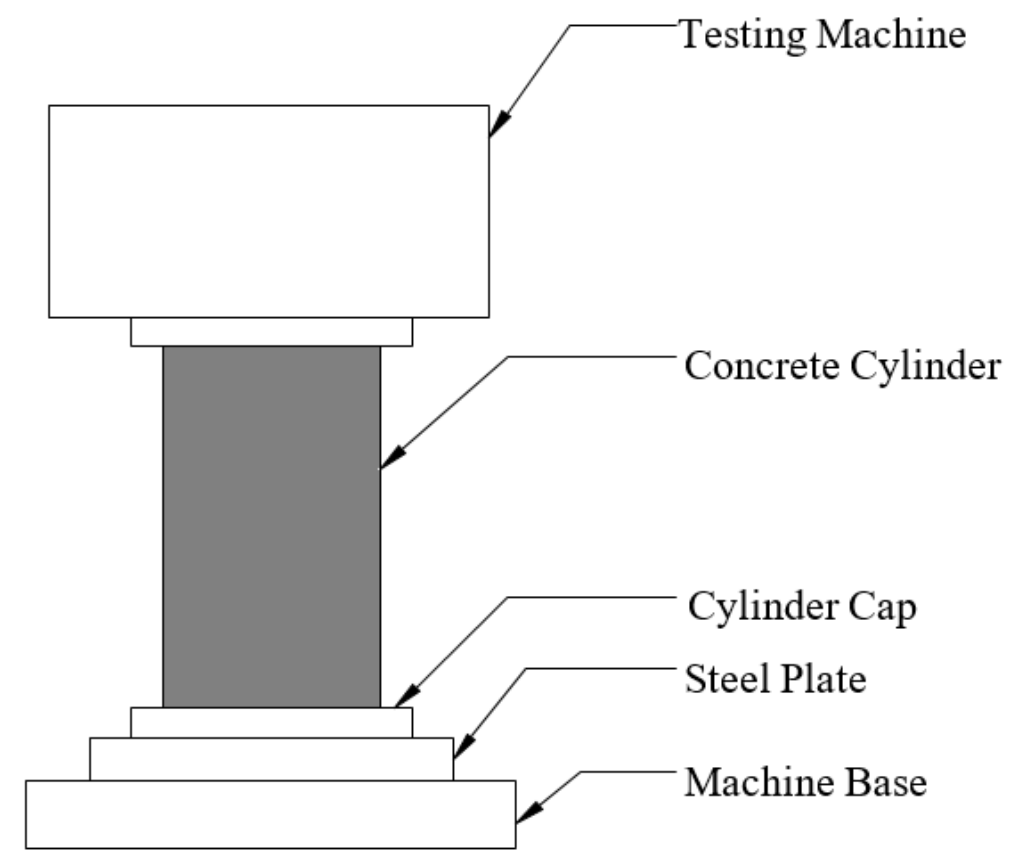

Figure 3.18 Compressive Strength Test Setup

\subsection{FLEXURAL TENSILE STRENGTH (MODULUS OF RAPTURE)}

Fibers seem to affect the flexural strength in concrete to a much greater extent than it affects the compressive. Three test prisms from each concrete mix with dimension of 100 $\mathrm{mm}$. in width, $100 \mathrm{~mm}$. in depth and 500. $\mathrm{mm}$ in length were tested. Testing of these prisms was done according to ASTM C78-10 (ASTM C78 2010). Hydraulic jack of automatic flexural testing machine mounted inside a structural steel test frame applied the load. The applied load was measured using load cell. Below the load cell, there was a spherical head and a roller assembly to distribute the load consistently to two loading points on top of the prism. The spacing between supports and the nearest loading point was $100 \mathrm{~mm}$ as well as the spacing between the two loading points was $100 \mathrm{~mm}$, as seen in Figure 3.19. Load readings from the load cell were recorded using a data acquisition system. 


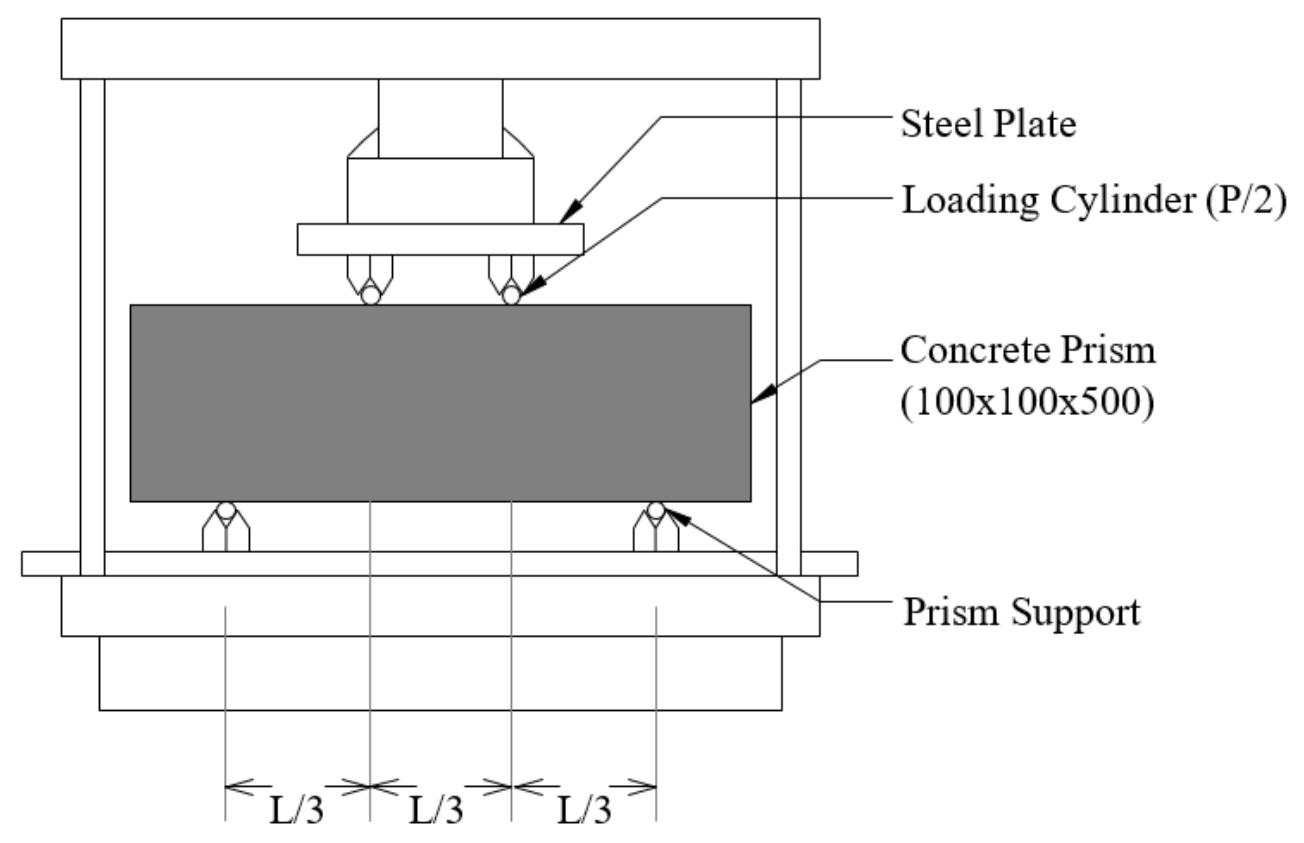

Figure 3.19 Tensile Strength Test Setup

\subsection{BEAM TESTING SET-UP}

All 16 beams were four-point flexural loaded up to failure with a loading span of 2550 $\mathrm{mm}$. The details of the test setup for all the beams are demonstrated in Figure3.20. The test was performed under deflection control mode with loading rate of $1 \mathrm{~mm} / \mathrm{min}$. Each beam specimen was fitted with a total of six linear variable differential transducers (LVDTs) on both exterior sides to measure the deflection. Two LVDTs were placed at mid-span and two underneath each loading point on the beam, as seen in Figure3.21 and Figure3.22. Concrete strain gauge (TML strain gauge type PL-60-11-3L) was attached at the top of the concrete beam at mid-span location, as shown in Figure 3.23. Two strain gauges (TML strain gauge type FLA-5-11-5L) were attached at the top of tensile steel reinforcement at the beam mid-span to measure the strain on the tension bar. The electrical strain and the LVDT were connected through a master panel to a data acquisition system (TML Data Logger Multi-Channel Digital Strain meter DRA-30A), as seen in Figure 3.24. The analog electrical signals of deflections and strains were converted through the data acquisition system to digital signals and then were displayed and recorded for each load increment. All the specimens were four-point loaded until it reaches failure by using Instron 1500HDX 
static hydraulic universal testing machine in the structural laboratory at Qatar University, as shown in Figure 3.25. The actuator has a maximum stroke of $150 \mathrm{~mm}$. and a maximum load capacity of $1500 \mathrm{KN}$

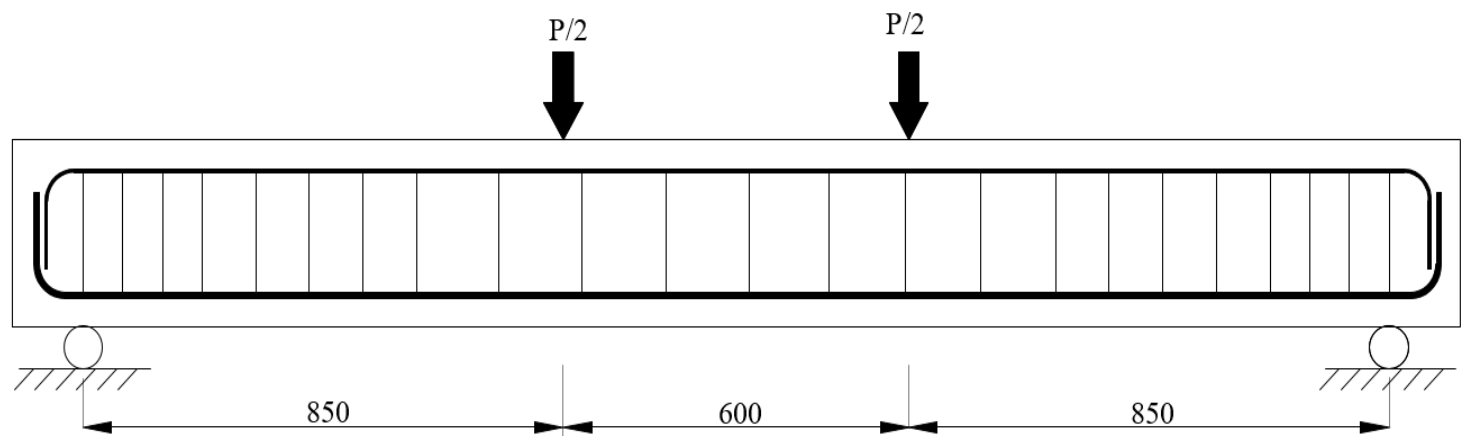

Figure 3.20 Detail of loading pattern (Dimensions are in $\mathrm{mm}$ )

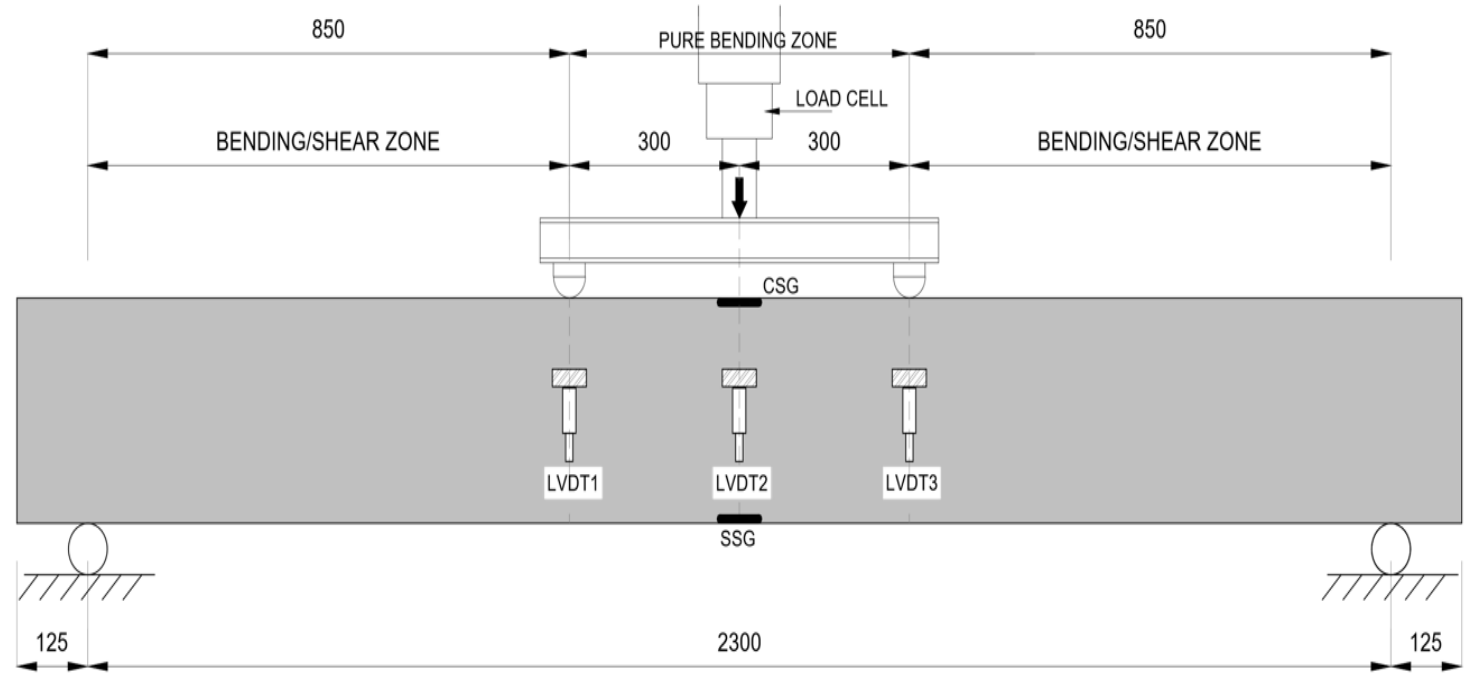

Figure 3.21 Beam test setup and measuring sensors (Dimensions are in $\mathrm{mm}$ ) 

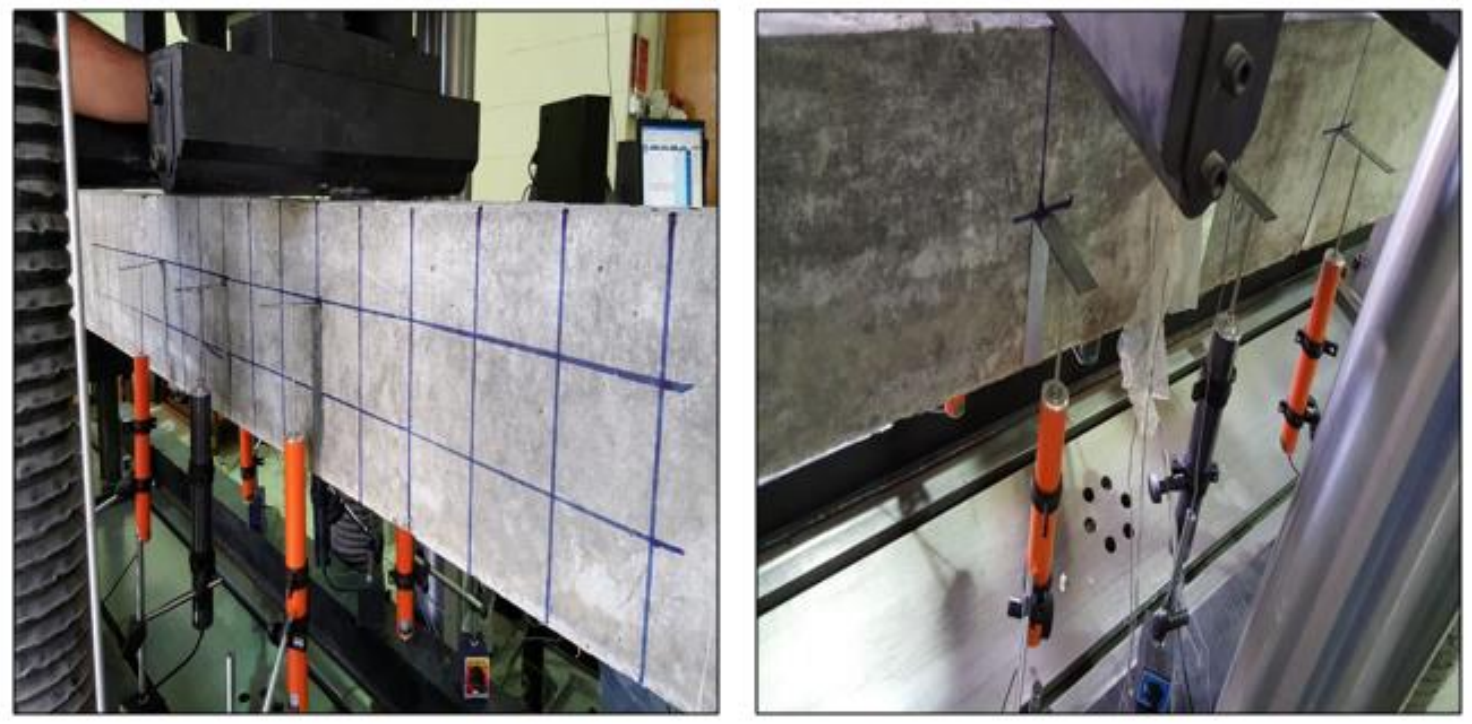

Figure 3.22 Left and Right Side Linear Variable Deflection Transducers (LVDT)

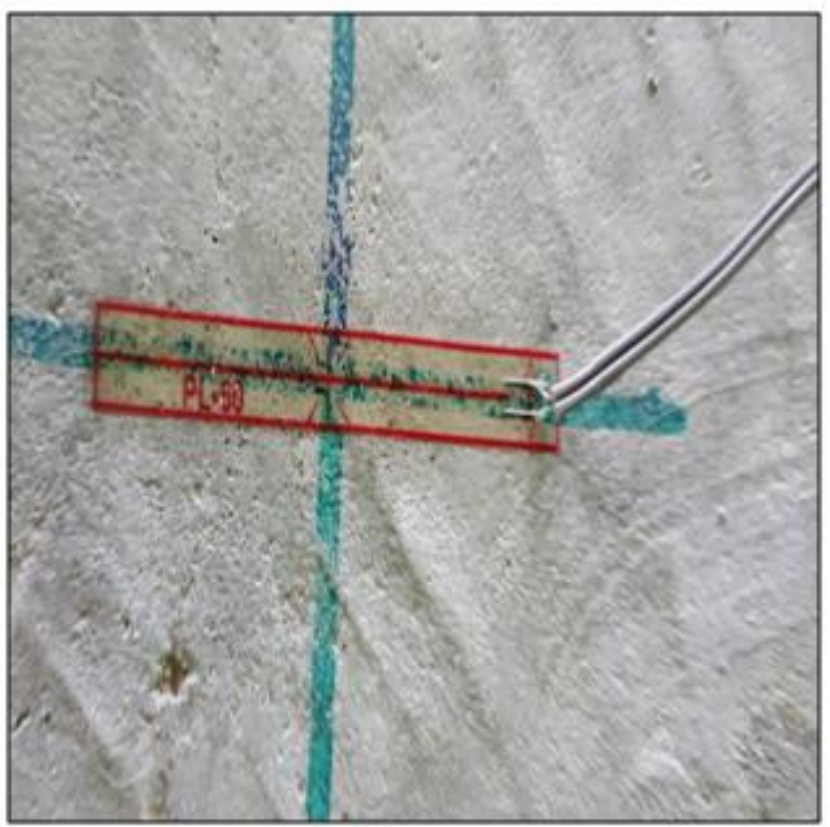

Figure 3.23 Concrete Strain Gauge (Top Side) 


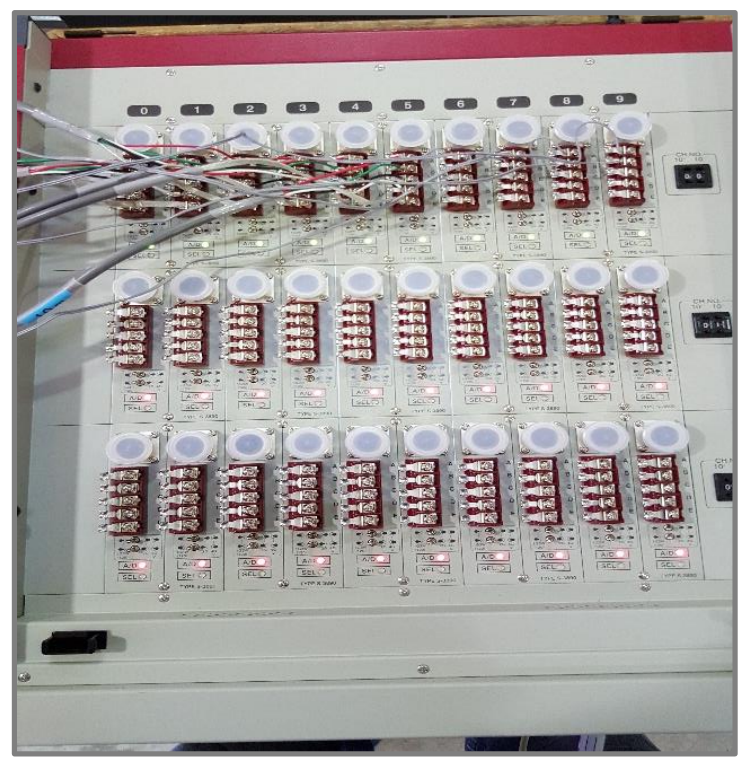

Figure 3.24 Data logger (TML Data Logger Multi-Channel Digital Strain meter DRA$30 \mathrm{~A})$

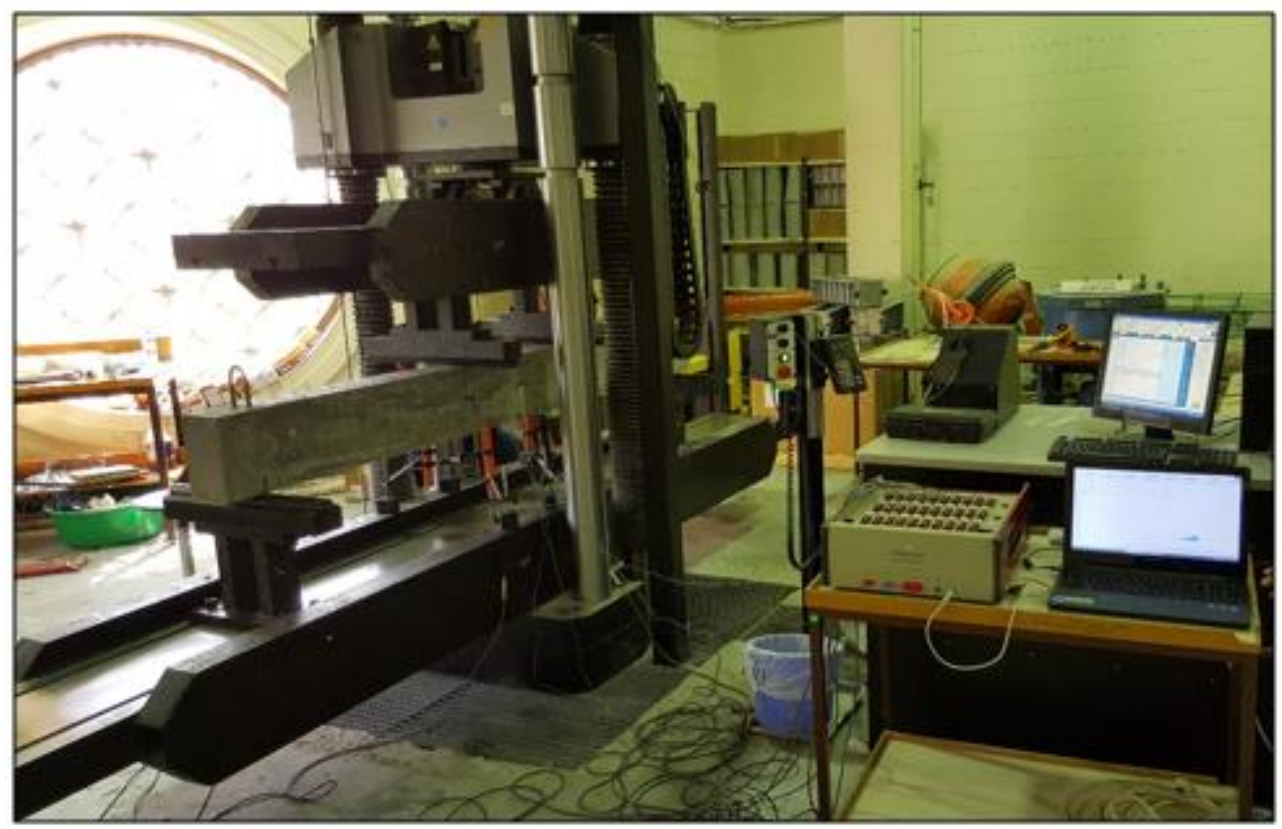

Figure 3.25 Instron 1500HDX Static Hydraulic Universal Testing machine with the deflection transducers and data acquisition system 


\section{CHAPTER 4}

\section{RESULT AND DISCUSSIONS}

\subsection{INTRODUCTION}

In this chapter, the testing results of experimental phase are presented and discussed. Experimental tests had been performed to investigate the flexural behavior for the basalt macro fiber reinforced concrete beams with RCA. Since the flexural strength is the ability of a beam to resist failure in bending, all 16 flexural beams were four-point loaded until failure. The distance between the two loading points was $600 \mathrm{~mm}$. The two-concentrated loading were applied to create constant moment at the mid span of the beam. All the specimens were tested using Instron 1500HDX static hydraulic universal testing machine in the structural laboratory at Qatar University. Loading values were recorded by the load cell of the Instron 1500HDX static hydraulic universal testing machine. Using LVDTs, the deflections at the mid-span and under each loading point of the RC beams were recorded. Strain gauges were glued to locations on the main steel reinforcement. Concrete strains were measured by using a $50 \mathrm{~mm}$ length specialized strain gauges. The electrical strain and the LVDT were connected through a master panel to a data acquisition system. The analog electrical signals of deflections and strains were converted through the data acquisition system to digital signals and then were displayed and recorded for each load increment. The average of the two LVDTs, steel strain gauges, concrete strain gauges were used to plot two graphs for load vs. deflection, and concrete compressive strain for each beam, respectively. In addition, the deformed shapes at different load levels at the bottom surface for each beam were plotted. The location of cracks and their propagation was clearly marked on concrete surface for each specimen. Based on the processed testing results of sample "A13", it was found that experimental results of A13 is not consistent with the remaining 15 samples. That is because of the poor workability and the balling and segregation of BMF in this sample, as explained earlier in section 3.6. Therefore, all testing results of sample "A13" were excluded from this study, and were considered as outliers. 


\subsection{PROPERTIES OF HARDENED CONCRETE}

This section includes the detailed description and discussion of the results of experimental program to determinate both the flexural tensile strength (modulus of rupture) and the compressive strength of the concrete with different percentages of BMF and RCA. All the tests were performed in accordance with the relevant ASTM standers.

\subsubsection{Flexural Tensile Strength (Modulus of Rapture) Testing Results}

The flexural strength (modulus of rupture) at 28 day, was measured using fourpoint loading test in according with ASTM C78-10 (ASTM C78 2010). Flexural prisms of $100 \times 100 \times 500 \mathrm{~mm}$ were tested using an automatic flexural testing system, as shown in Figure 4.1. The average flexural strength test results of three concrete prisms from each mix are given in Table 4.1.

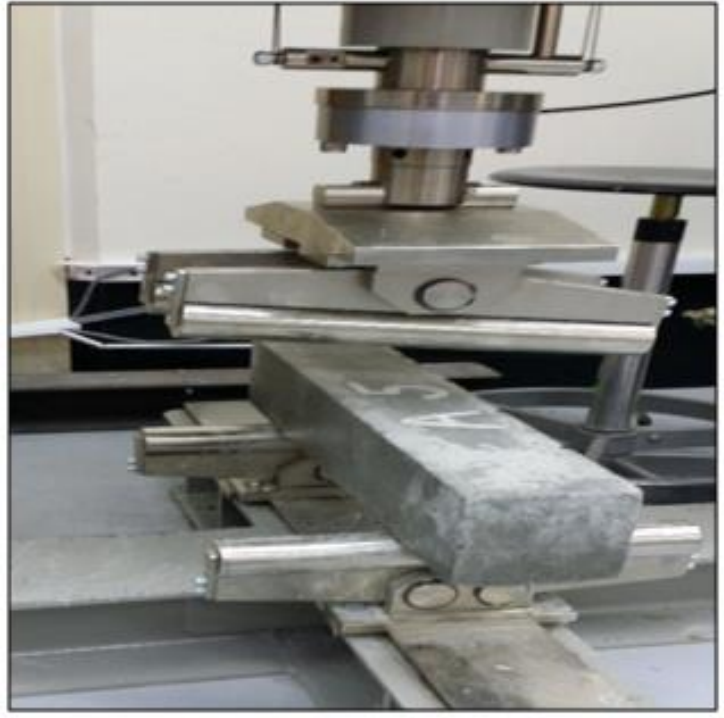

(a)Before

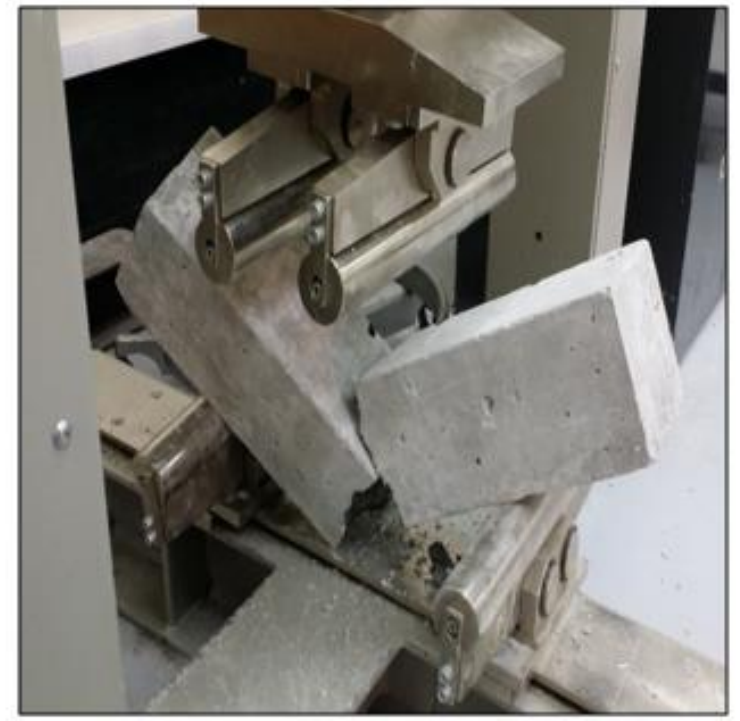

(b)After

Figure 4.1 Failure Mode of Typical Concrete Prism 
Table 4.1 Average Flexural Tensile Strength of Concrete Prisms

\begin{tabular}{|c|c|c|c|}
\hline $\begin{array}{l}\text { Prism } \\
\text { ID }\end{array}$ & $\begin{array}{c}\text { RCA Replacement } \\
\text { Ratio (\%) }\end{array}$ & $\begin{array}{c}\text { BMF Dosage by } \\
\text { Volume (\%) }\end{array}$ & $\begin{array}{c}\text { Average Tensile Strength, } f_{r} \\
(\mathbf{M P a})\end{array}$ \\
\hline A1 & 0 & 0 & 4.37 \\
\hline A2 & 25 & 0 & 4.50 \\
\hline $\mathbf{A 3}$ & 50 & 0 & 4.43 \\
\hline A4 & 100 & 0 & 4.29 \\
\hline A5 & 0 & 0.5 & 4.74 \\
\hline A6 & 25 & 0.5 & 4.94 \\
\hline A7 & 50 & 0.5 & 4.69 \\
\hline A8 & 100 & 0.5 & 5.02 \\
\hline A9 & 0 & 1 & 5.82 \\
\hline $\mathbf{A 1 0}$ & 25 & 1 & 5.72 \\
\hline A11 & 50 & 1 & 5.56 \\
\hline A12 & 100 & 1 & 5.74 \\
\hline A14 & 25 & 1.5 & 6.19 \\
\hline A15 & 50 & 1.5 & 6.04 \\
\hline A16 & 100 & 1.5 & 6.08 \\
\hline
\end{tabular}

\subsubsection{Effect of Volume Fraction of BMF}

Figure 4.2 presents the flexural strength testing results at 28 day with different volume fraction of BMF. As expected, the flexural strength results showed an improvement in the flexural strength with the BMF. It can be observed from test results that using BMF could enhance the flexural strength of the concrete for all mixes due to strong bond with concrete matrix. Figure 4.2a shows the average flexural strength of all mixtures prepared using $0 \%$ RCA with two different percentages of BMF. It can be observed that adding a volume fraction of $0.5 \%$ to the concrete resulted in a slight increase of $7.81 \%$ in the flexural strength. The gain in flexural strength further increased to $24.91 \%$ when the volume fraction of the BMF increased to $1 \%$ compared to control prism. Figure $4.2 \mathrm{~b}$ shows the average flexural strength of all mixtures prepared using 25\% RCA with three different percentages of BMF. It can be observed that adding a volume fraction of $0.5 \%$ to the concrete resulted in a slight increase of $8.91 \%$ in the flexural strength. The gain in flexural 
strength further increased to $20.61 \%$, and $27.3 \%$ when the volume fraction of the BMF increased to $1 \%$. and $1.5 \%$ respectively compared to control prism. Figure $4.2 \mathrm{c}$ shows the average flexural strength of all mixtures prepared using 50\% RCA with three different percentages of BMF. It can be observed that adding a volume fraction of $0.5 \%$ to the concrete resulted in a slight increase of 5.54\% in the flexural strength. The gain in flexural strength further increased to $20.32 \%$, and $26.66 \%$ when the volume fraction of the BMF increased to $1 \%$. and $1.5 \%$ respectively compared to control prism. Figure $4.2 \mathrm{~d}$ shows the average flexural strength of all mixtures prepared using 100\% RCA with three different percentages of BMF. It can be observed that adding a volume fraction of $0.5 \%$ to the concrete resulted in a slight increase of $14.54 \%$ in the flexural strength. The gain in flexural strength further increased to $25.3 \%$, and $29.44 \%$ when the volume fraction of the BMF increased to $1 \%$. and $1.5 \%$ respectively compared to control prism.

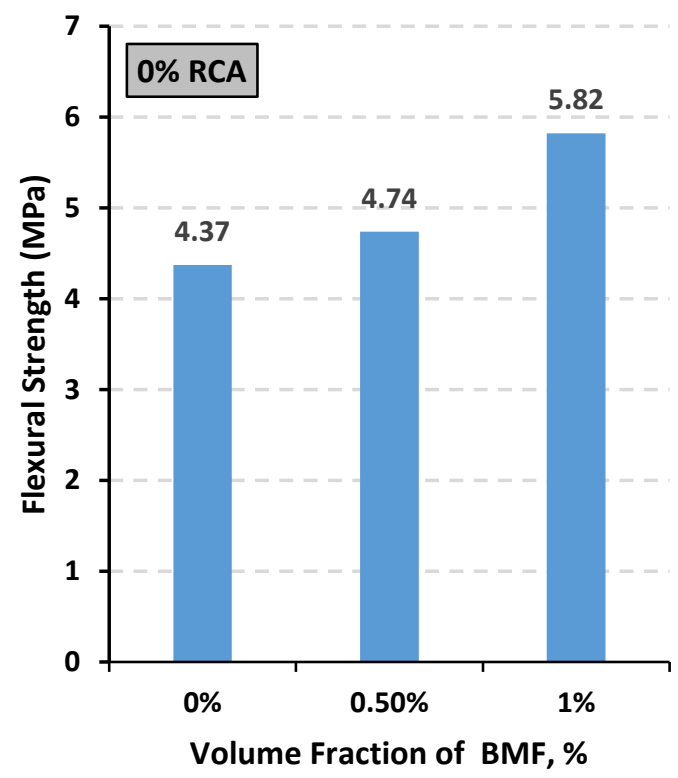

(a) $0 \% \mathrm{RCA}$

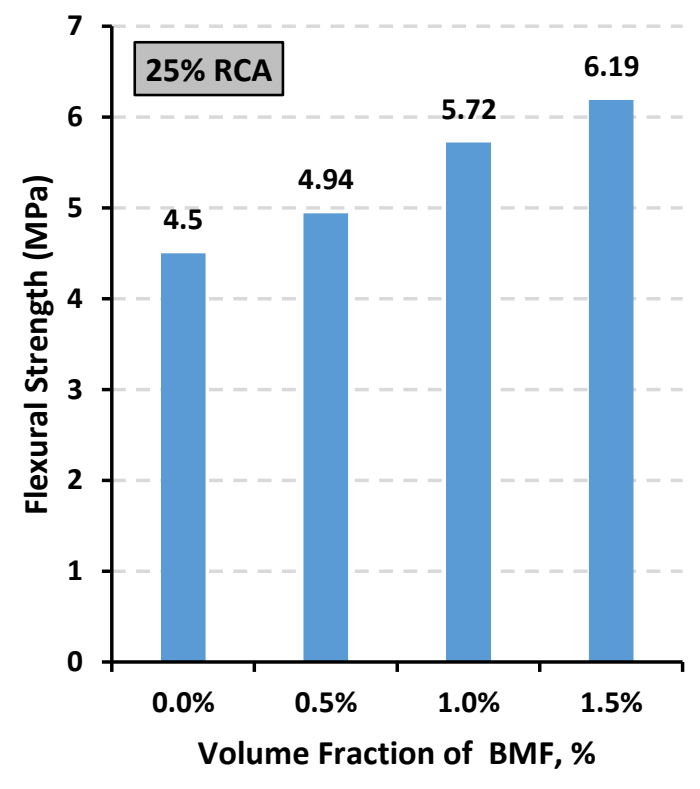

(b) $25 \% \mathrm{RCA}$ 


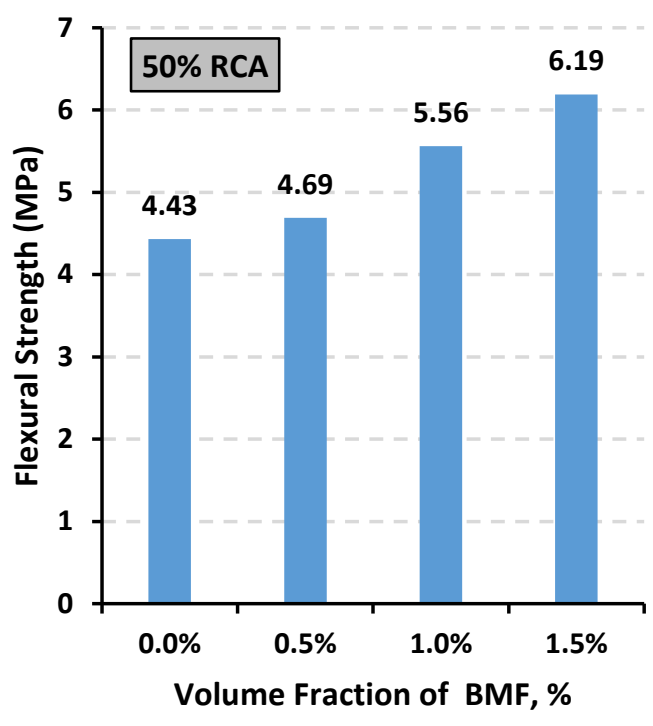

(c) $50 \% \mathrm{RCA}$

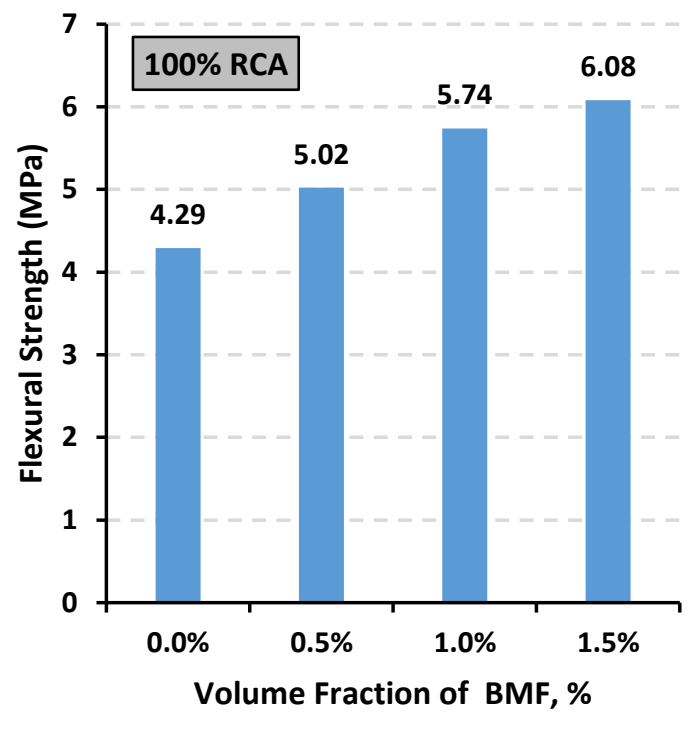

(d) $100 \% \mathrm{RCA}$

Figure 4.2 Flexural Tensile Strength Test Results for Different RCA Replacement Ratios

\subsubsection{Effect of RCA}

Figure 4.3 presents the average flexural tensile strength of all concrete mixtures with different replacement ratios of RCA. The testing results showed that the addition of RCA at different replacement percentage ratios of $25 \%, 50 \%$, and $100 \%$ has a slight effect on the flexural tensile strength of the concrete mixtures. It can be observed that there is no clear correlation between the two parameters. Figure 4.3a shows the average flexural strength of all mixtures prepared using 0\% BMF with three different percentages of RCA. It can be observed that replacing NCA by RCA in concrete resulted in a slight increase of $2.89 \%$ and $1.35 \%$ the flexural strength when the replacement ratios of the RCA increased to $25 \%$ and $50 \%$ respectively compared to control prism and slight decrease of $1.83 \%$ when the replacement ratios of the RCA increased to $100 \%$ compared to control prism. Figure $4.3 \mathrm{~b}$ shows the average flexural strength of all mixtures prepared using 0.5\% BMF with three different percentages of RCA. It can be observed that replacing NCA by RCA in concrete resulted in a slight increase of $4.05 \%$ and $1.05 \%$ the flexural strength when the replacement ratios of the RCA increased to $25 \%$ and $100 \%$ respectively compared to 
control prism and slight decrease of $1.05 \%$ when the replacement ratios of the RCA increased to $50 \%$ compared to control prism. Figure $4.3 \mathrm{c}$ shows the average flexural strength of all mixtures prepared using $1 \%$ BMF with three different percentages of RCA. It can be observed that replacing NCA by RCA in concrete resulted in a slight decrease of $1.72 \%, 4.47 \%$ and $1.4 \%$ the flexural strength when the replacement ratios of the RCA increased to $25 \%, 50 \%$ and $100 \%$ respectively compared to control prism. Figure $4.3 \mathrm{~d}$ shows the average flexural strength of all mixtures prepared using 1.5\% BMF with three different percentages of RCA. It can be observed there was no effect of RCA when using $1.5 \% \mathrm{BMF}$.

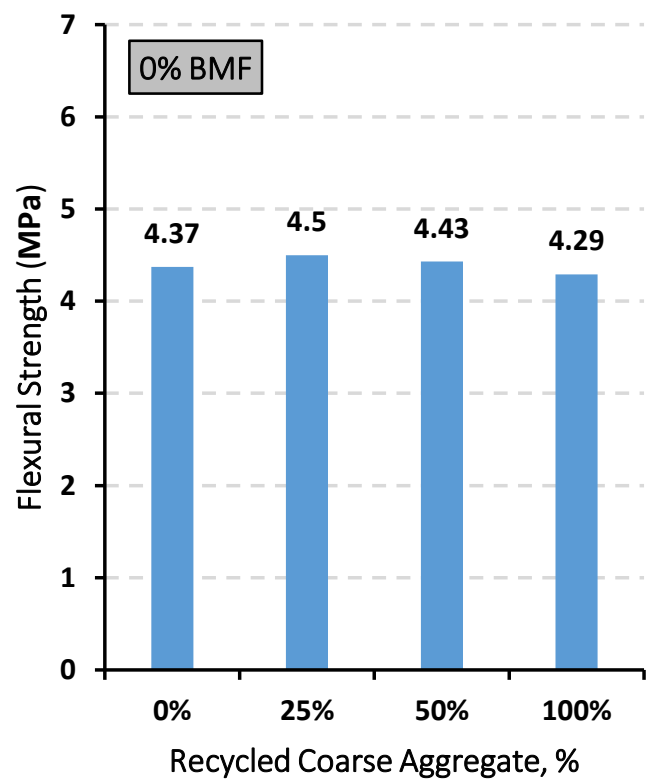

(a) $0 \% \mathrm{BMF}$

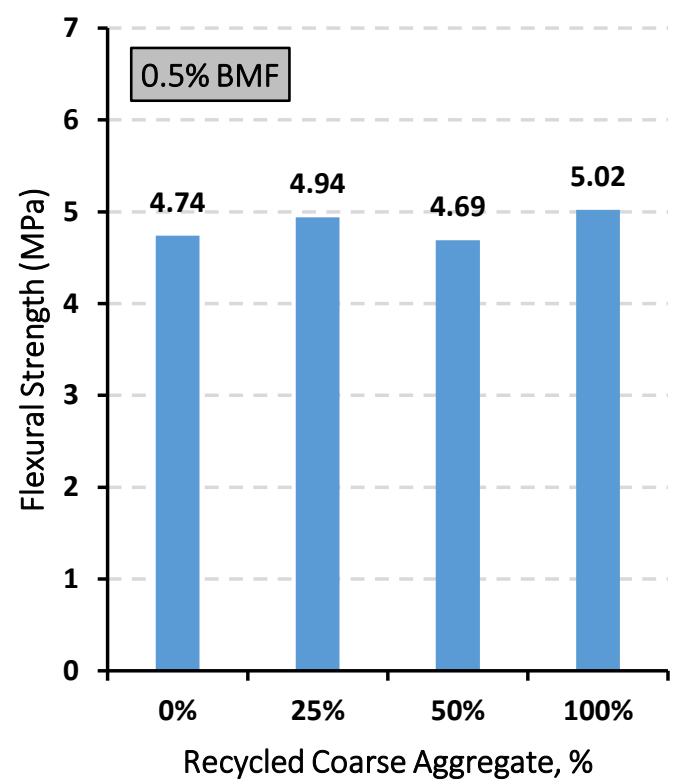

(b) $0.5 \% \mathrm{BMF}$ 


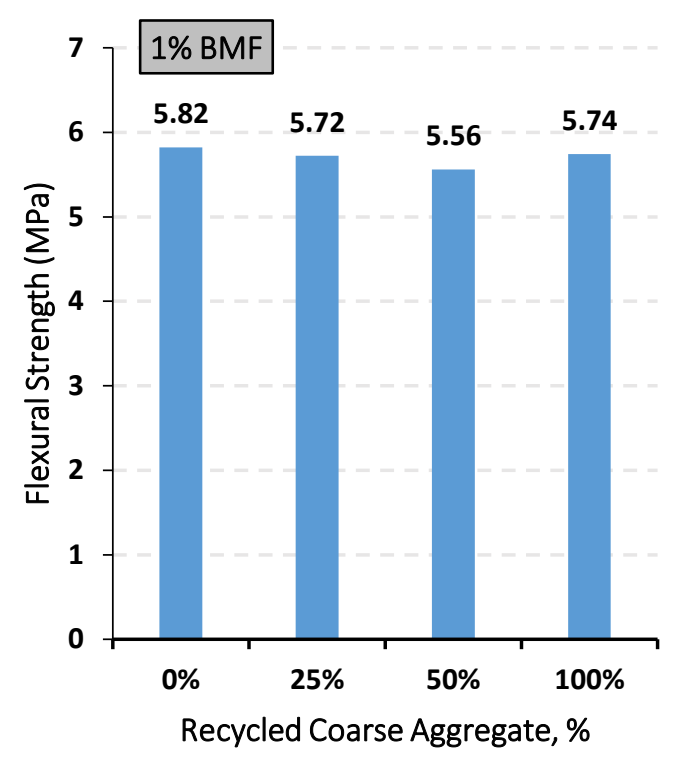

(c) $1.0 \% \mathrm{BMF}$

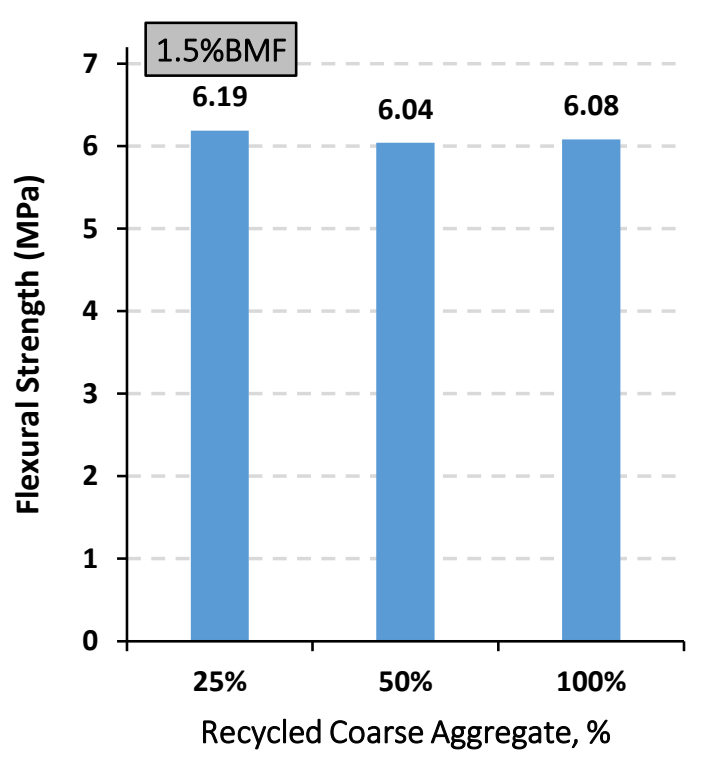

(d) $1.5 \% \mathrm{BMF}$

Figure 4.3 Flexural Tensile Strength Test Results for Different Fiber Volume Fraction Ratios

\subsubsection{Compressive Strength Testing Results}

The compressive strength tests were conducted for each concrete mix at 28 day in accordance with ASTM C39-16 (ASTM C39 2016). Concrete cylinders were tested as shown in Figure 4.4. The average compressive strength results obtained from the tests are shown in Table 4.2. Each result value is based on the average of three concrete cylinders. 


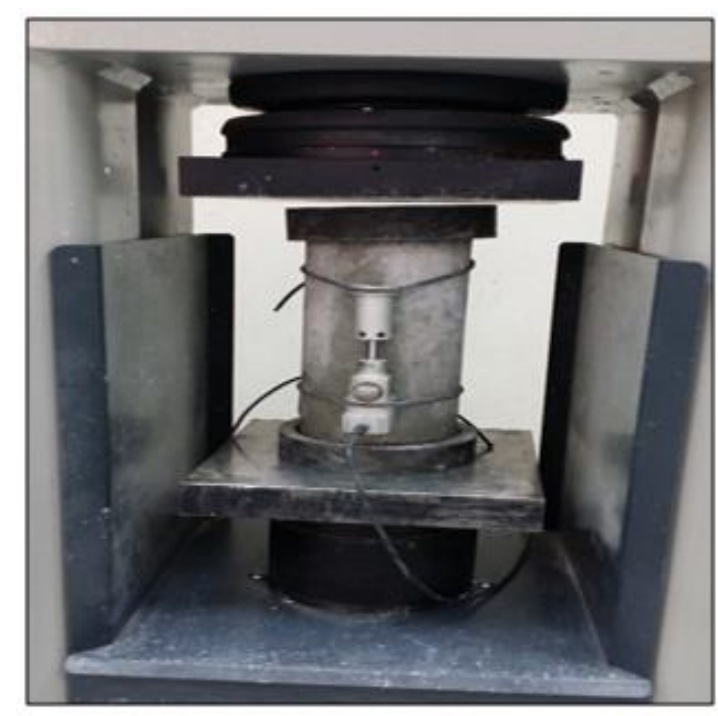

(a)Before

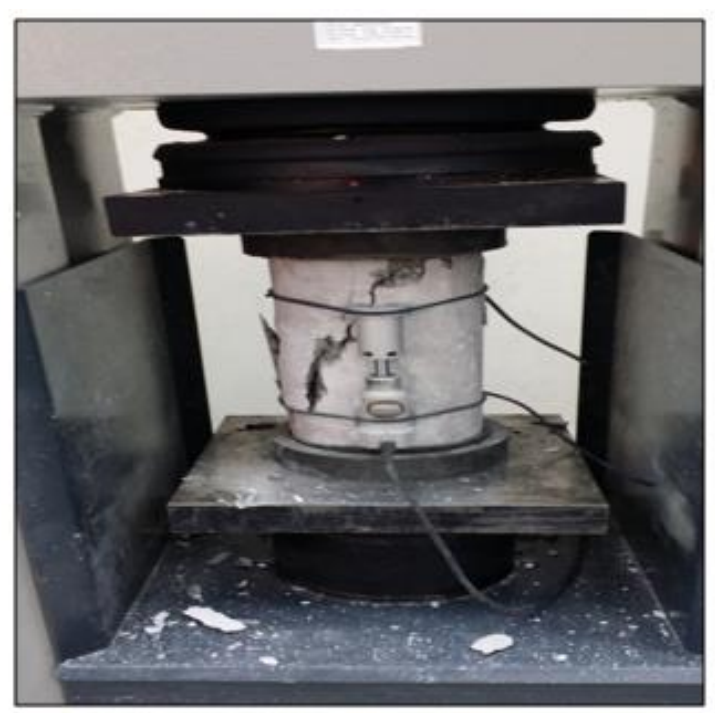

(b)After

Figure 4.4 Failure Mode of Typical Cylinder Specimen

Table 4.2 Average Compressive Strength Test Results

\begin{tabular}{|c|c|c|c|}
\hline $\begin{array}{c}\text { Cylinder } \\
\text { ID }\end{array}$ & $\begin{array}{c}\text { RCA Replacement } \\
\text { Ratio (\%) }\end{array}$ & $\begin{array}{c}\text { BMF Dosage by } \\
\text { Volume (\%) }\end{array}$ & $\begin{array}{l}\text { Average Compressive Strength } \\
\text { (MPa) }\end{array}$ \\
\hline A1 & 0 & 0 & 40.6 \\
\hline A2 & 25 & 0 & 37.5 \\
\hline A3 & 50 & 0 & 36.3 \\
\hline A4 & 100 & 0 & 37.0 \\
\hline A5 & 0 & 0.5 & 42.7 \\
\hline A6 & 25 & 0.5 & 44.0 \\
\hline A7 & 50 & 0.5 & 34.1 \\
\hline A8 & 100 & 0.5 & 43.1 \\
\hline A9 & 0 & 1 & 39.0 \\
\hline A10 & 25 & 1 & 33.7 \\
\hline A11 & 50 & 1 & 36.9 \\
\hline A12 & 100 & 1 & 34.0 \\
\hline A14 & 25 & 1.5 & 38.6 \\
\hline A15 & 50 & 1.5 & 41.0 \\
\hline A16 & 100 & 1.5 & 37.0 \\
\hline
\end{tabular}




\subsubsection{Effect of Volume Fraction of BMF}

The average measured compressive strength of three concrete cylinders for each concrete mix with a different volume fraction of BMF is shown in Figure 4.5, As expected, the compressive strength results did not show a significant difference between the control specimen and the respective BMF concrete mixes. It can be observed from the testing results that there is no clear correlation between the two parameters.

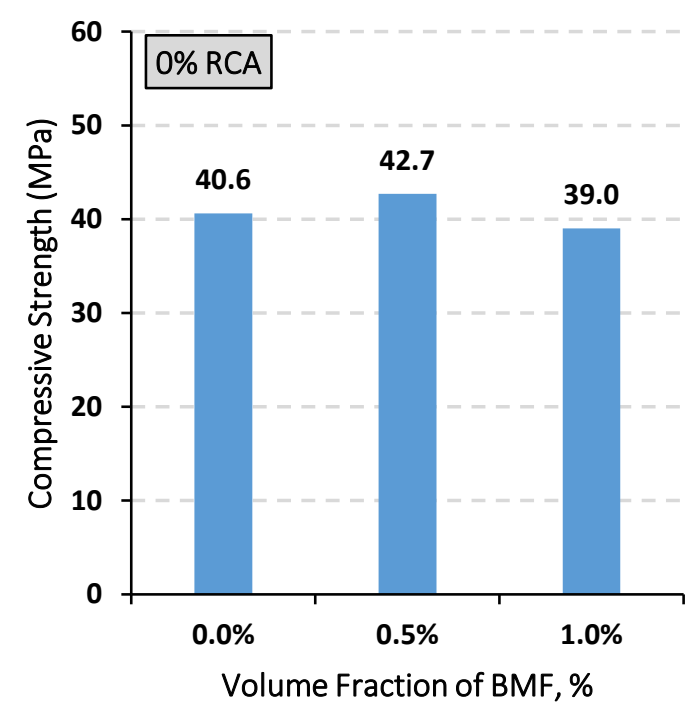

(a) $0 \% \mathrm{RCA}$

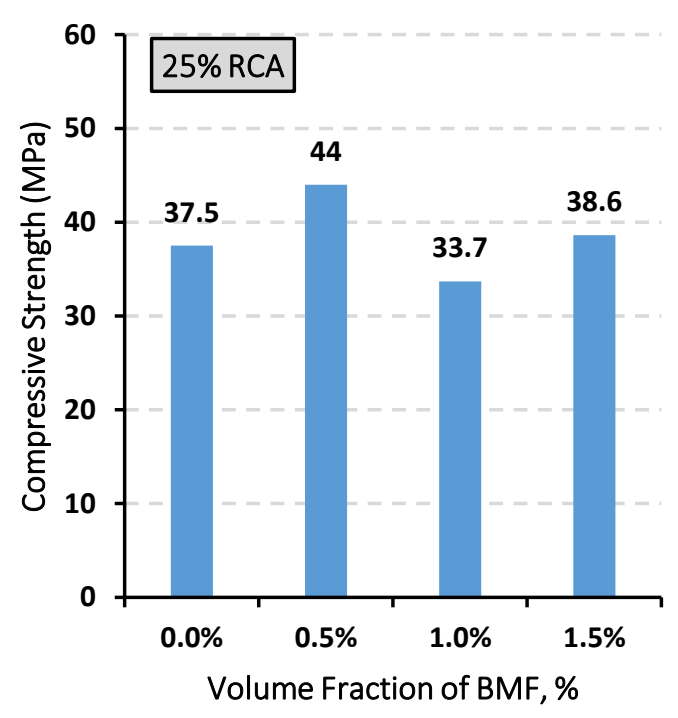

(b) $25 \% \mathrm{RCA}$ 


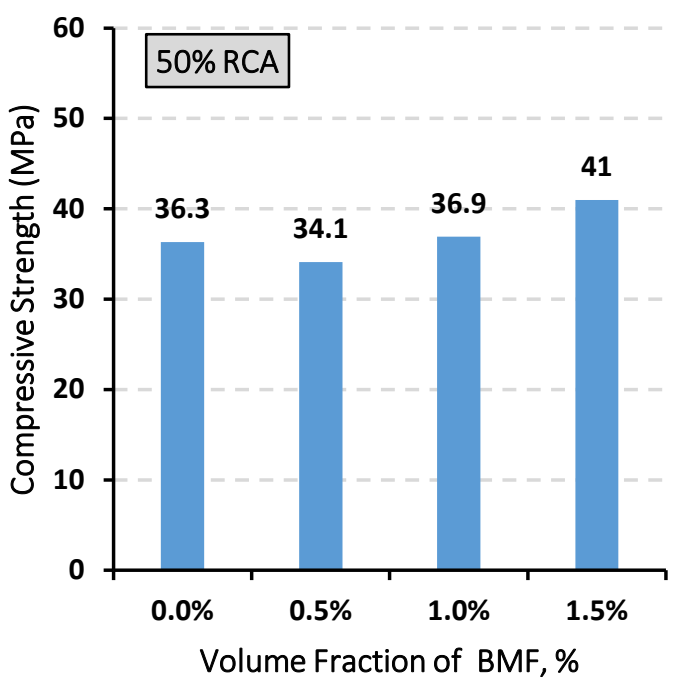

(C) $50 \% \mathrm{RCA}$

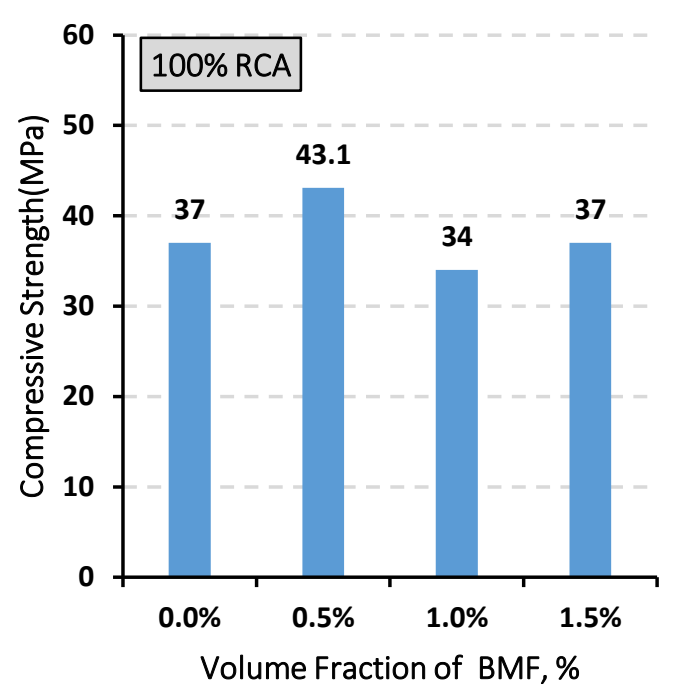

(d) $100 \% \mathrm{RCA}$

Figure 4.5 Compressive Strength Test Results for Different RCA Replacement Ratios

\subsubsection{Effect of RCA}

Figure 4.6 illustrates the average compressive strength of three cylinders tested at 28 day with different replacement ratios of RCA (i. e. $25 \%, 50 \%$, and $100 \%$ ). It can be observed that there is a minor effect on compressive strength by the replacement of RCA even up to a $100 \%$, and the general observed trend is similar to the compressive strength of concrete with NCA. This is mainly due to use the absolute volume concrete mixture method and using RCA in saturated surface dry condition seemed to impose the largest positive effect on the concrete compressive strength due to water presence in RCA. That is because the compressive strength of concrete made with RCA depends on mix proportions, the moisture of RCA, and the method of treatment of RCA. 


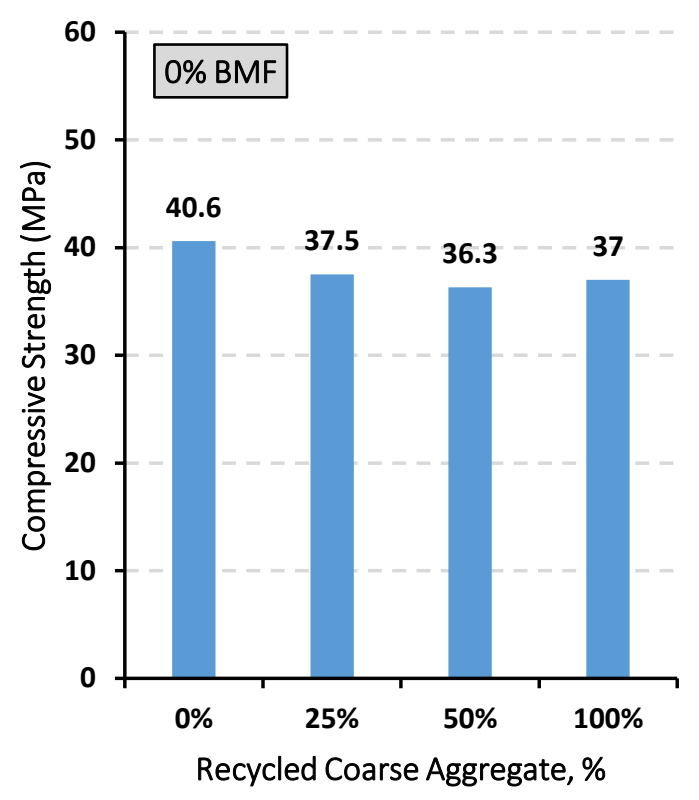

(a) $0 \% \mathrm{BMF}$

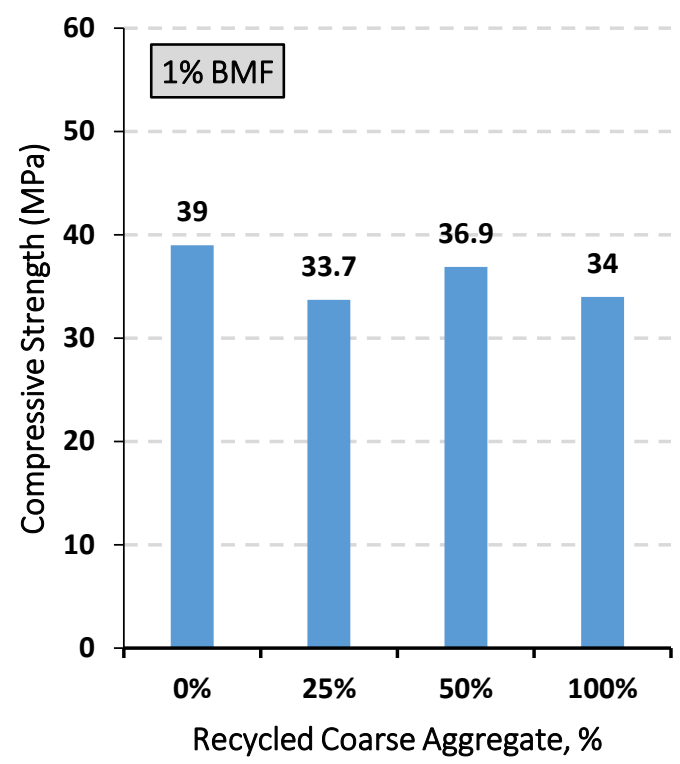

(b) $1 \% \mathrm{BMF}$

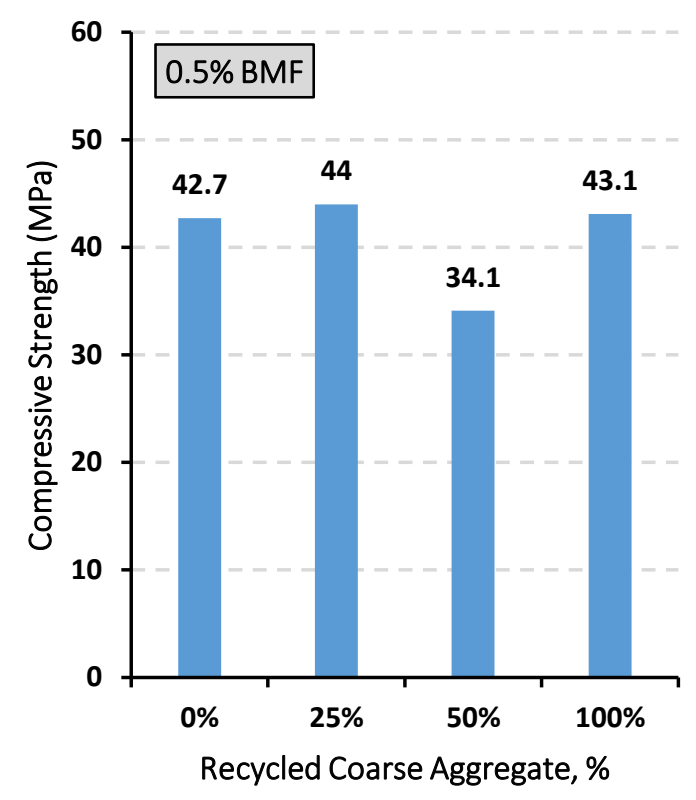

(b) $0.5 \% \mathrm{BMF}$

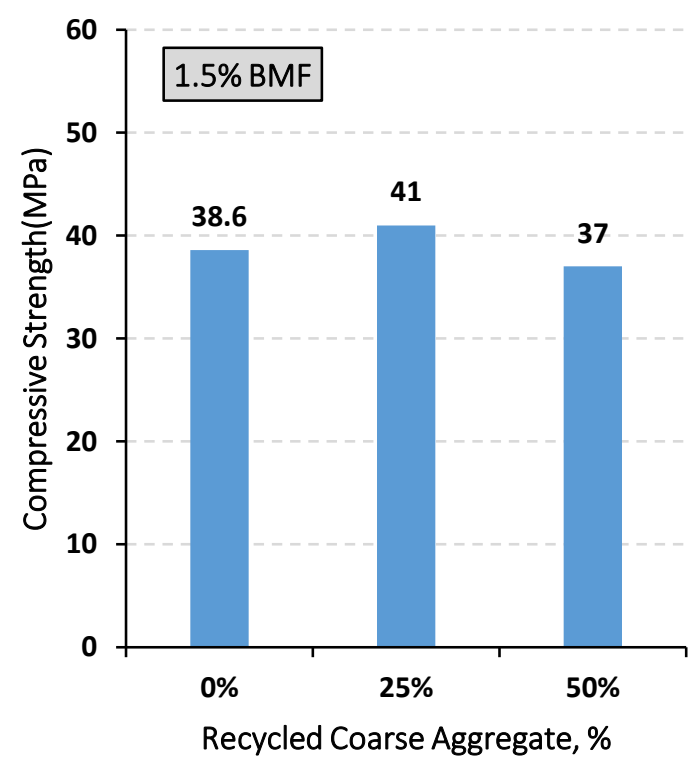

(d) $1.5 \% \mathrm{BMF}$

Figure 4.6 Compressive Strength Test Results for Different Fiber Volume Fraction Ratios 


\subsection{LARGE SCALE BEAM TESTING RESULTS}

\subsubsection{Introduction}

Sixteen beams were loaded gradually and uniformly until reaching the failure load. A data acquisition system was used to record the deflection, concrete compressive strain and steel tensile strain at beam's mid-span. The development of cracks in each RC beams was tracked and noted constantly. The failure mode was documented after the failure occurred in each tested beam. The cracking moment $\left(M_{c}\right)$, the yielding moment $\left(M_{y}\right)$ and the ultimate moment $\left(M_{u}\right)$ were experimentally evaluated per each beam. Testing results obtained from the flexural tests for each beam are presented and discussed in the following paragraphs.

\subsubsection{Specimen A1 (0\% RCA+0\% BMF)}

Beam specimen A1 has 100\% of NCA with $0 \%$ of RCA and no fibers added (0\% $\mathrm{BMF})$. This specimen was tested to serve as a control. The specimen was tested in flexure. After applying the static load gradually, the first crack was observed within the constant moment region of beam specimen at the middle of the beam at a load of $25 \mathrm{kN}$. As the load was increased, additional flexural cracks spread consistently along the beam where the cracks moved further upward, with a visible increase in the deflection. The majority of the flexural cracks developed vertically and after that inclined flexural-shear cracks began to appear. Upon further increasing the applied load, the longitudinal steel yielded, and finally concrete crushed in compression zone and beam failed as it can be seen from Figure 4.7. Figure 4.8-a show the load-deflection relationships measured at the bottom surface at different locations of the specimen (refer to Figure 3.21 for measurement sensors locations). The load-deflection responses at mid-span presented in Figure 4.8-a show a linear elastic behavior before the initiation of the first flexural cracks (point A). When the load was increased beyond the cracking moment, the almost straight line slope was slightly declined because of the crack in the concrete in the tension zone. Then, the longitudinal steel reinforcement reached the yield point (point B) as shown in Figure 4.8-a. The recorded yielding load is $110.2 \mathrm{kN}$ (Yielding moment is $46.84 \mathrm{kN} . \mathrm{m}$ ). Finally, concrete 
crushed in the in compression zone with ultimate load of $113.05 \mathrm{kN}$, and maximum midspan deflection of $35 \mathrm{~mm}$.

Figure 4.8-b shows the load-concrete compressive strain relationship measured at top surface at mid-span of the specimen. The recorded maximum compressive strain was 0.00283 .

A deformed shape of the bottom surface of the specimen is shown in Figure 4.9. In this Figure, the vertical axis represents the vertical downward deflection; therefore, the actual deformed shapes should be up-side-down. It can be observed in Figure 4.9 that the largest deflection was observed at the mid-span of the beam.

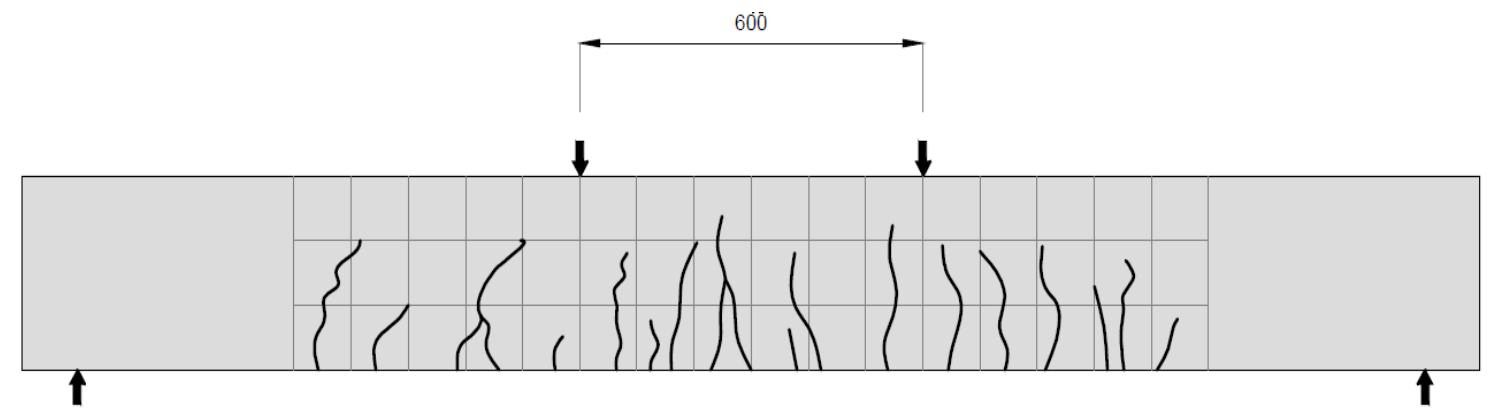

Figure 4.7 Cracking Pattern of Beam A1 


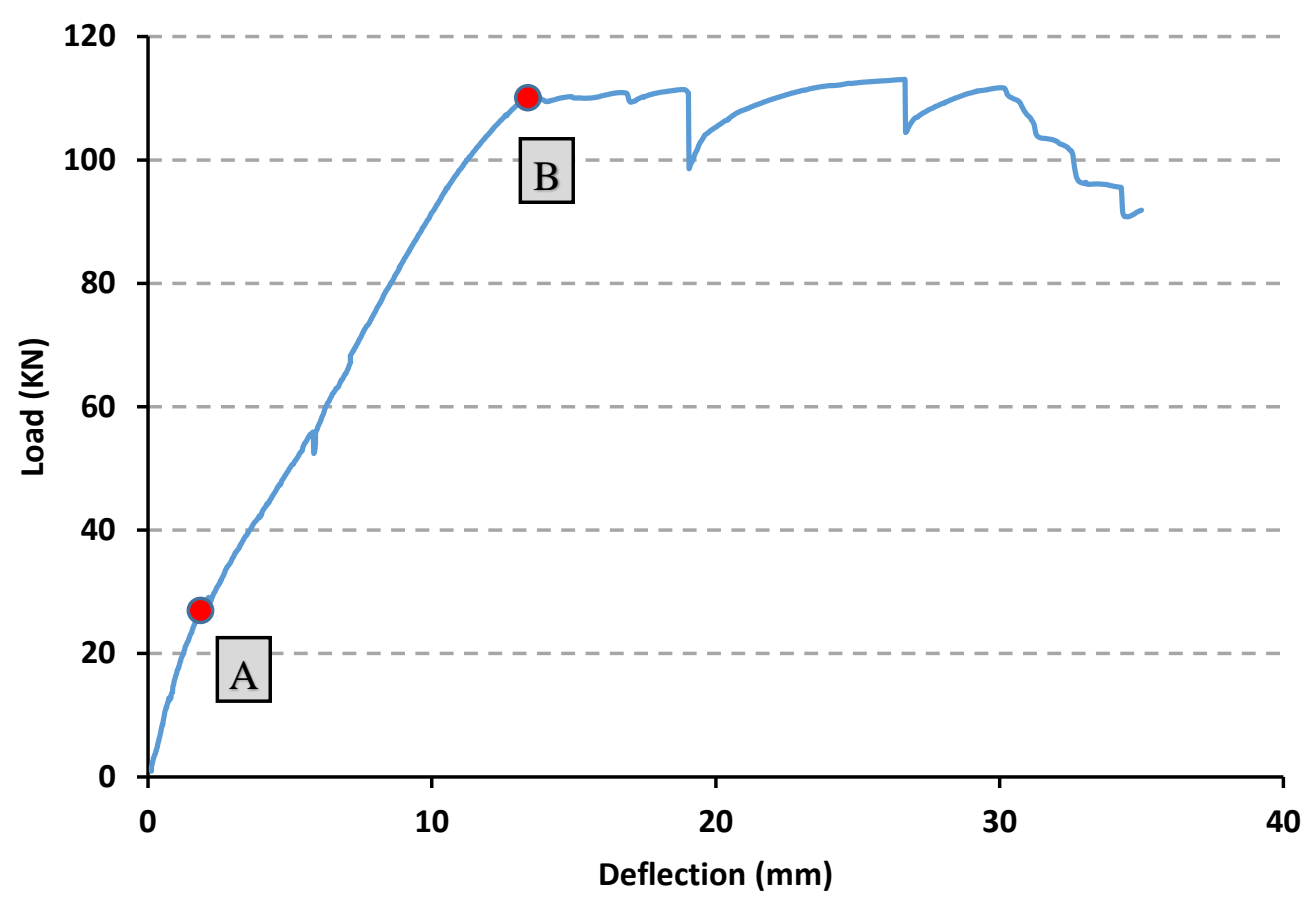

(a)

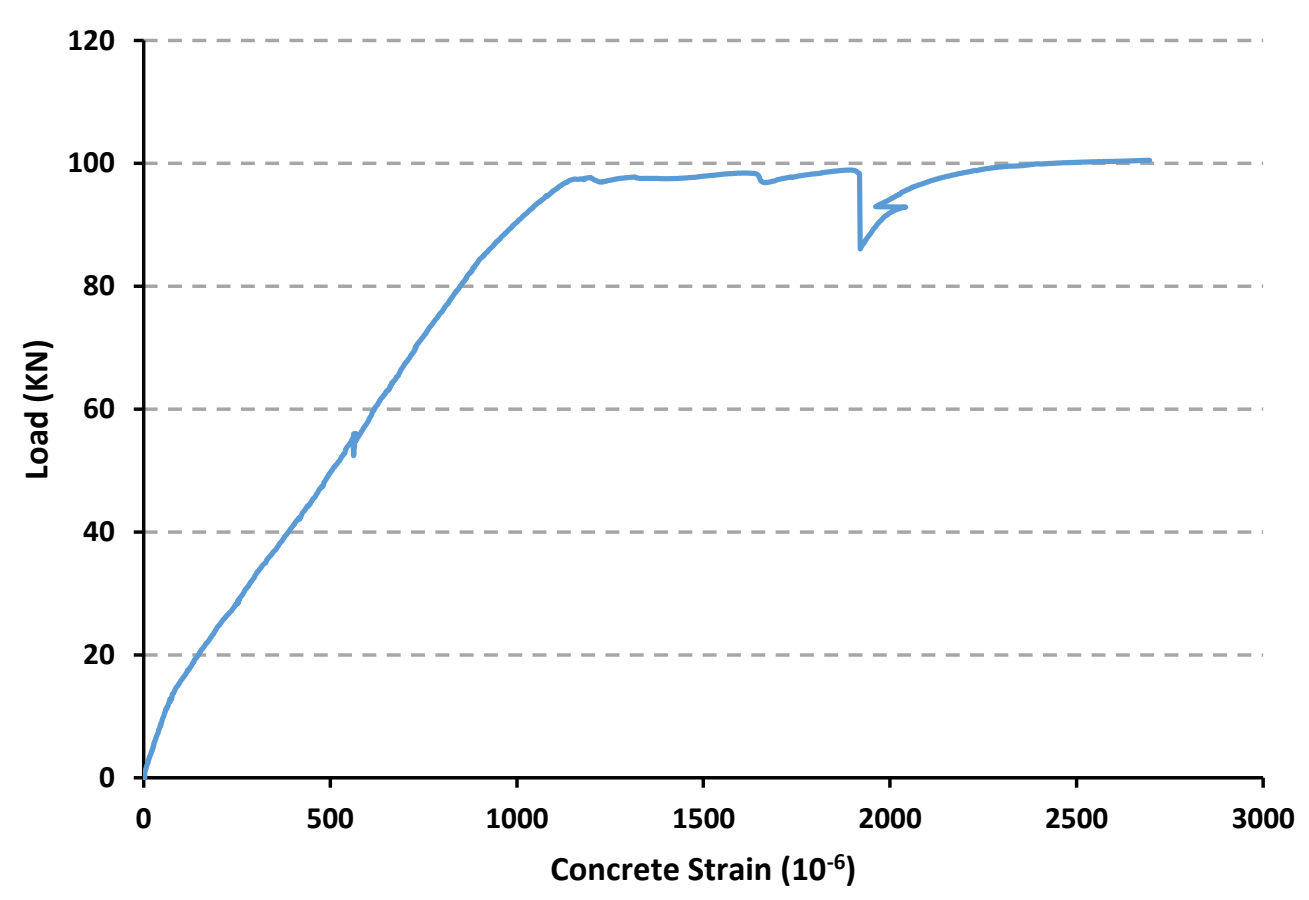

(b)

Figure 4.8 Test Results for Beam A1. a) Load vs. Deflection, b) Load vs. Concrete Strain 


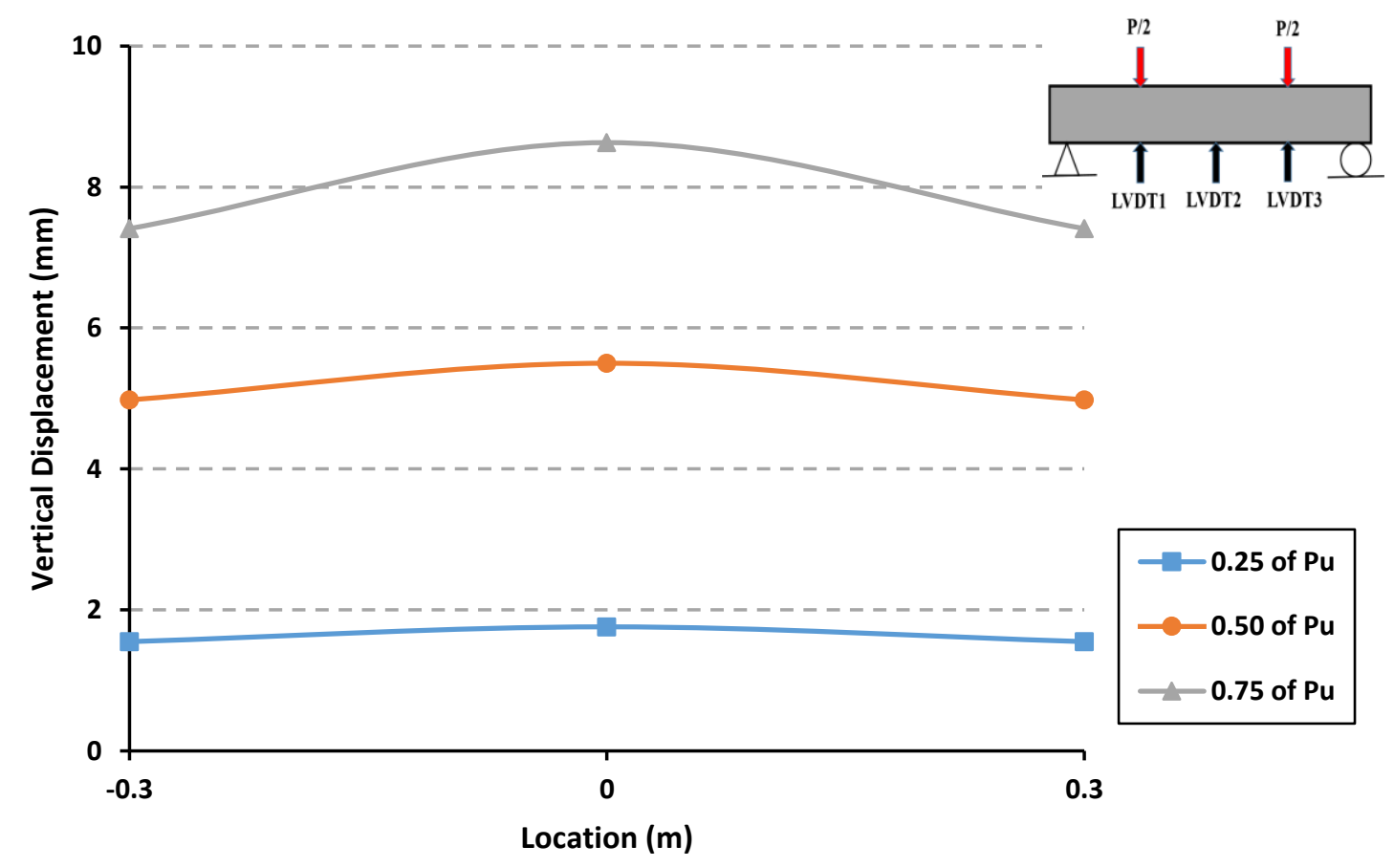

Figure 4.9 Deformed Shapes at Different Load Levels at the Bottom Surface

\subsubsection{Specimen A2 (25\% RCA+0\% BMF)}

Beam specimen A2 has $75 \%$ of NCA with $25 \%$ of RCA and no fibers added $(0 \%$ BMF). The specimen was tested in flexure. After applying the static load gradually, the first crack was observed within the constant moment region of beam specimen at the middle of the beam at a load of $21 \mathrm{kN}$. As the load was increased, additional flexural cracks spread consistently along the beam where the cracks moved further upward, with a visible increase in the deflection. The majority of the flexural cracks developed vertically and after that inclined flexural-shear cracks began to appear. Upon further increasing the applied load, the longitudinal steel yielded, and finally concrete crushed in compression zone and beam failed as it can be seen from Figure 4.10.

Figure 4.11-a show the load-deflection relationships measured at the bottom surface at different locations of the specimen (refer to Figure 3.21 for measurement sensors locations). The load-deflection responses at mid-span presented in Figure 4.11-a show a linear elastic behavior before the initiation of the first flexural cracks (point A). When the 
load was increased beyond the cracking moment, the almost straight line slope was slightly declined because of the crack in the concrete in the tension zone. Then, the longitudinal steel reinforcement reached the yield point (point B) as shown in Figure 4.11-a. The recorded yielding load is $100.17 \mathrm{kN}$ (Yielding moment is $42.57 \mathrm{kN} . \mathrm{m}$ ). Finally, concrete crushed in the in compression zone with ultimate load of $103.08 \mathrm{kN}$, and maximum midspan deflection of $32 \mathrm{~mm}$.

Figure 4.11-b shows the load-concrete compressive strain relationship measured at top surface at mid-span of the specimen, the recorded maximum compressive strain was 0.00285 .

A deformed shape of the bottom surface of the specimen is shown in Figure 4.12. In this Figure, the vertical axis represents the vertical downward deflection; therefore, the actual deformed shapes should be up-side-down. It can be observed in Figure 4.12 that the largest deflection was observed at the mid-span of the beam.

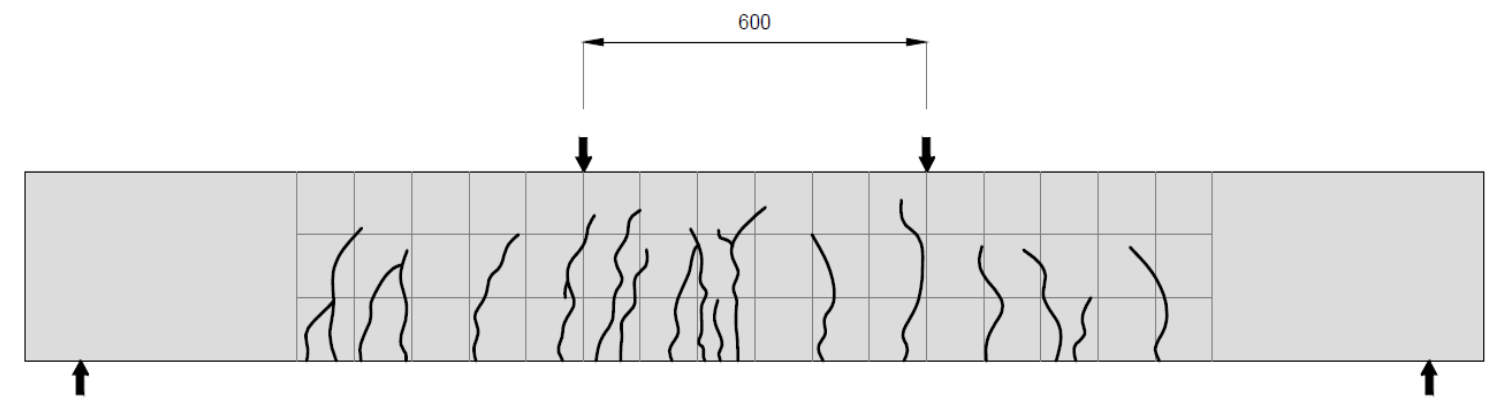

Figure 4.10 Cracking Pattern of Beam A2 


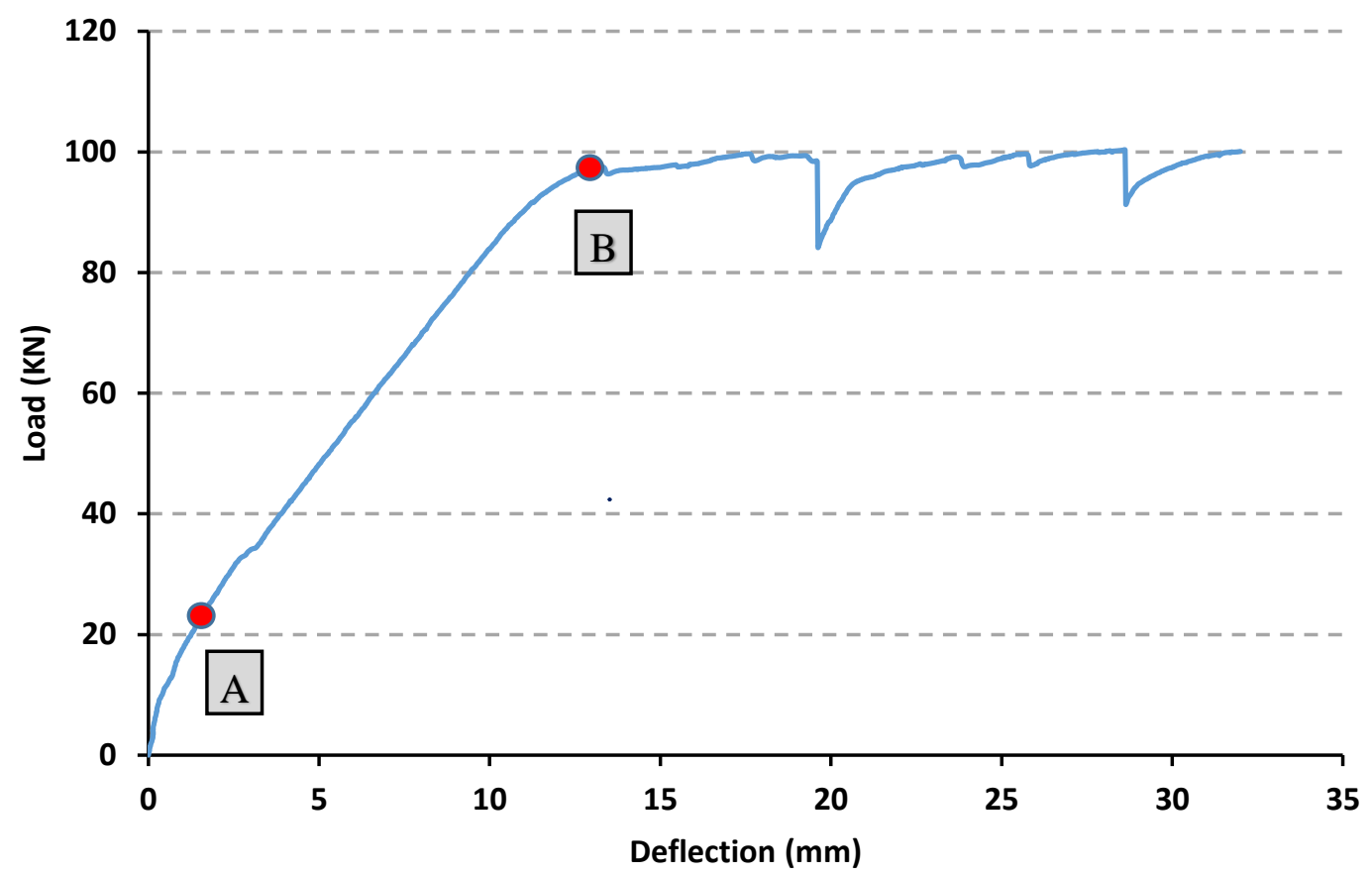

(a)

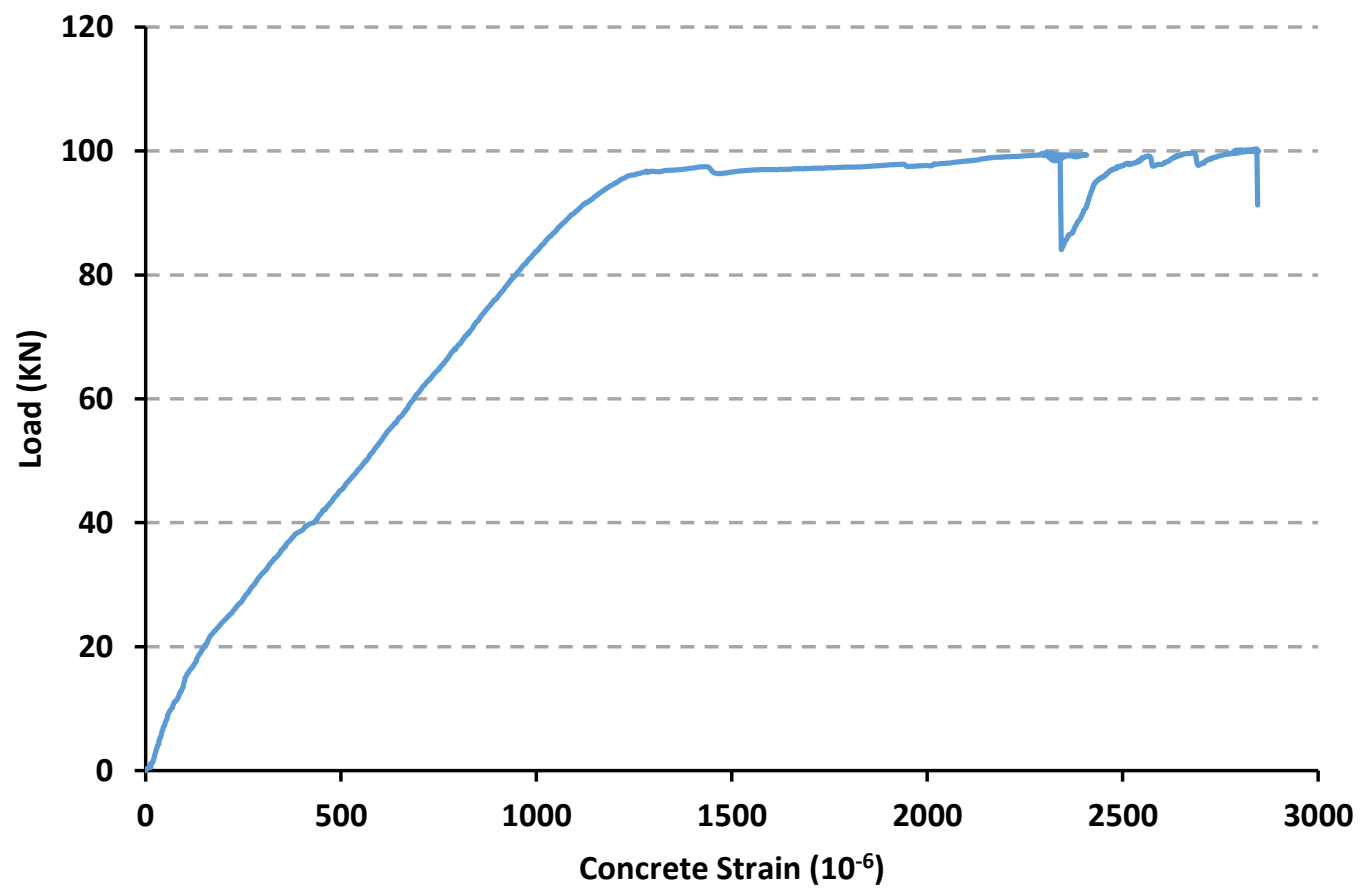

(b)

Figure 4.11 Test Results for Beam A2. a) Load vs. Deflection, b) Load vs. Concrete Strain 


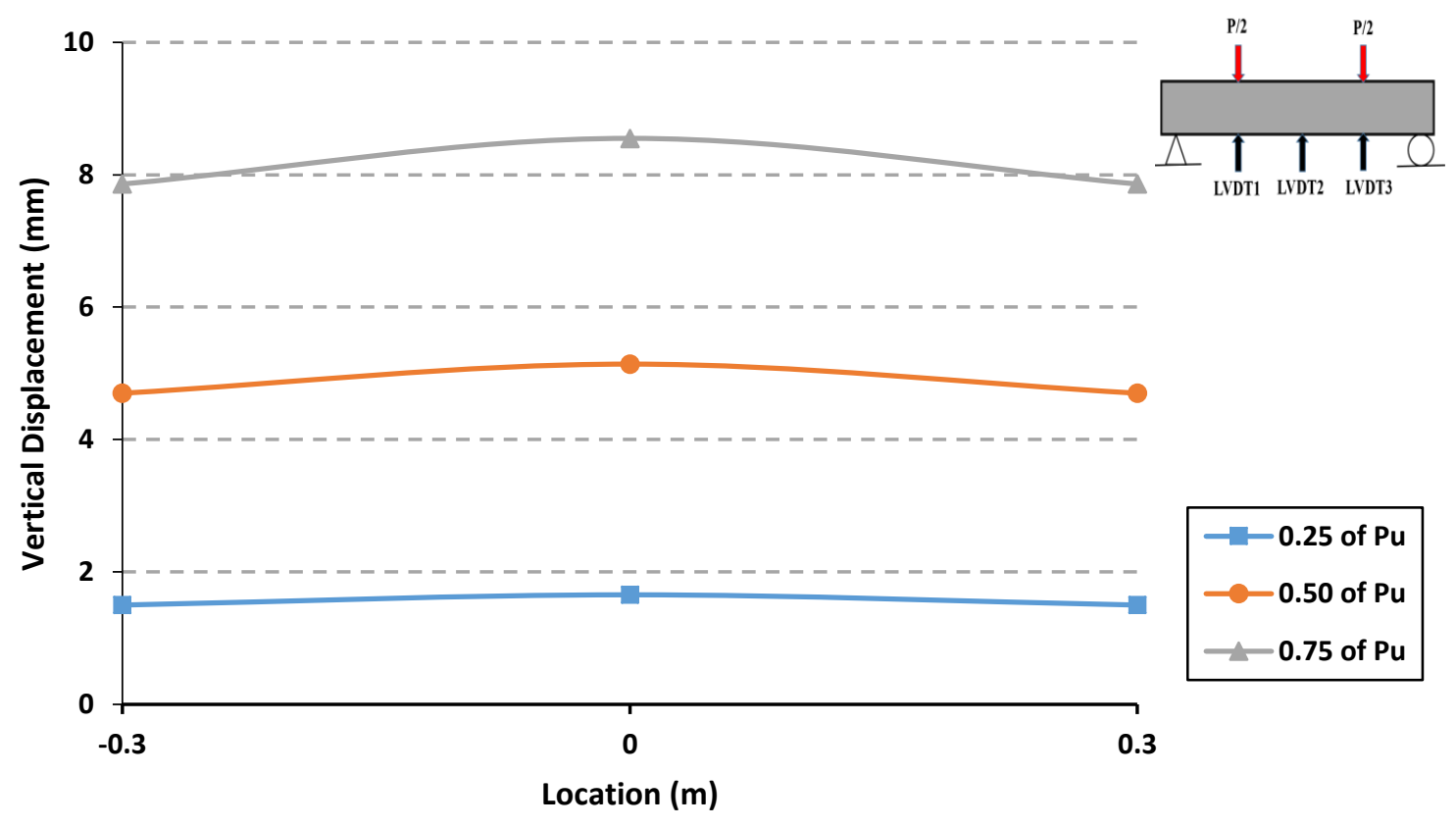

Figure 4.12 Deformed Shapes at Different Load Levels at the Bottom Surface

\subsubsection{Specimen A3 (50\% RCA+0\% BMF)}

Beam specimen A3 has $50 \%$ of NCA with $50 \%$ of RCA and no fibers added ( $0 \%$ BMF). The specimen was tested in flexure. After applying the static load gradually, the first crack was observed within the constant moment region of beam specimen at the middle of the beam at a load of $19 \mathrm{kN}$. As the load was increased, additional flexural cracks spread consistently along the beam where the cracks moved further upward, with a visible increase in the deflection. The majority of the flexural cracks developed vertically and after that inclined flexural-shear cracks began to appear. Upon further increasing the applied load, the longitudinal steel yielded, and finally concrete crushed in compression zone and beam failed as it can be seen from Figure 4.13.

Figure 4.14-a show the load-deflection relationships measured at the bottom surface at different locations of the specimen (refer to Figure 3.21 for measurement sensors locations). The load-deflection responses at mid-span presented in Figure 4.14-a show a linear elastic behavior before the initiation of the first flexural cracks (point A). When the load was increased beyond the cracking moment, the almost straight line slope was slightly 
declined because of the crack in the concrete in the tension zone. Then, the longitudinal steel reinforcement reached the yield point (point B) as shown in Figure 4.14-a. The recorded yielding load is $99.31 \mathrm{kN}$ (Yielding moment is $42.21 \mathrm{kN} . \mathrm{m}$ ). Finally, concrete crushed in the in compression zone with ultimate load of $105.19 \mathrm{kN}$, and maximum midspan deflection of $31 \mathrm{~mm}$.

Figure 4.14-b shows the load-concrete compressive strain relationship measured at top surface at mid-span of the specimen, while Figure 4.12-b shows load-steel tensile strain plot measured at mid-span of the specimen. The recorded maximum compressive strain was 0.00283 .

A deformed shape of the bottom surface of the specimen is shown in Figure 4.15. In this Figure, the vertical axis represents the vertical downward deflection; therefore, the actual deformed shapes should be up-side-down. It can be observed in Figure 4.15 that the largest deflection was observed at the mid-span of the beam.

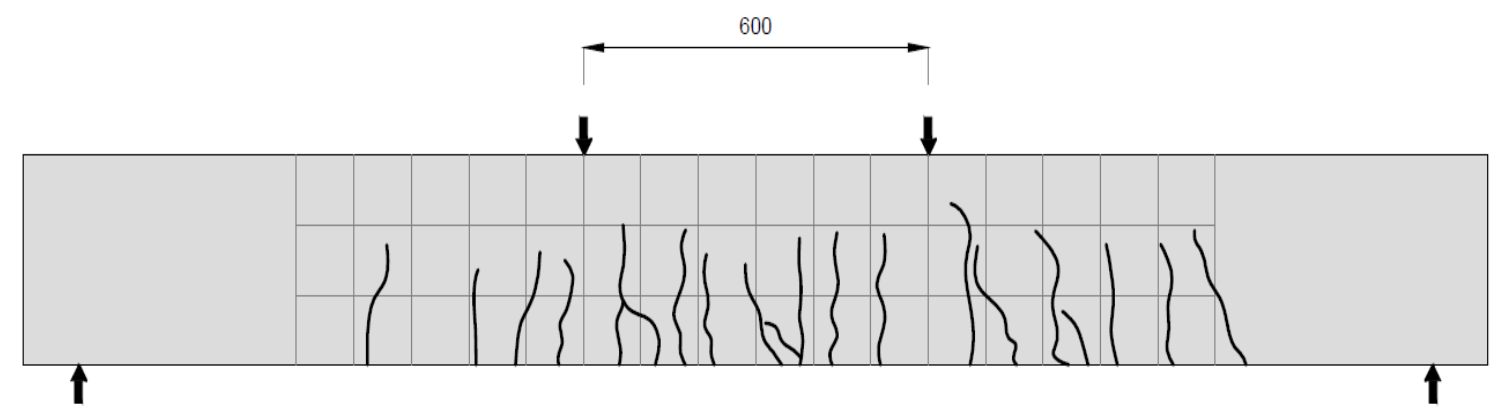

Figure 4.13 Cracking Pattern of Beam A3 


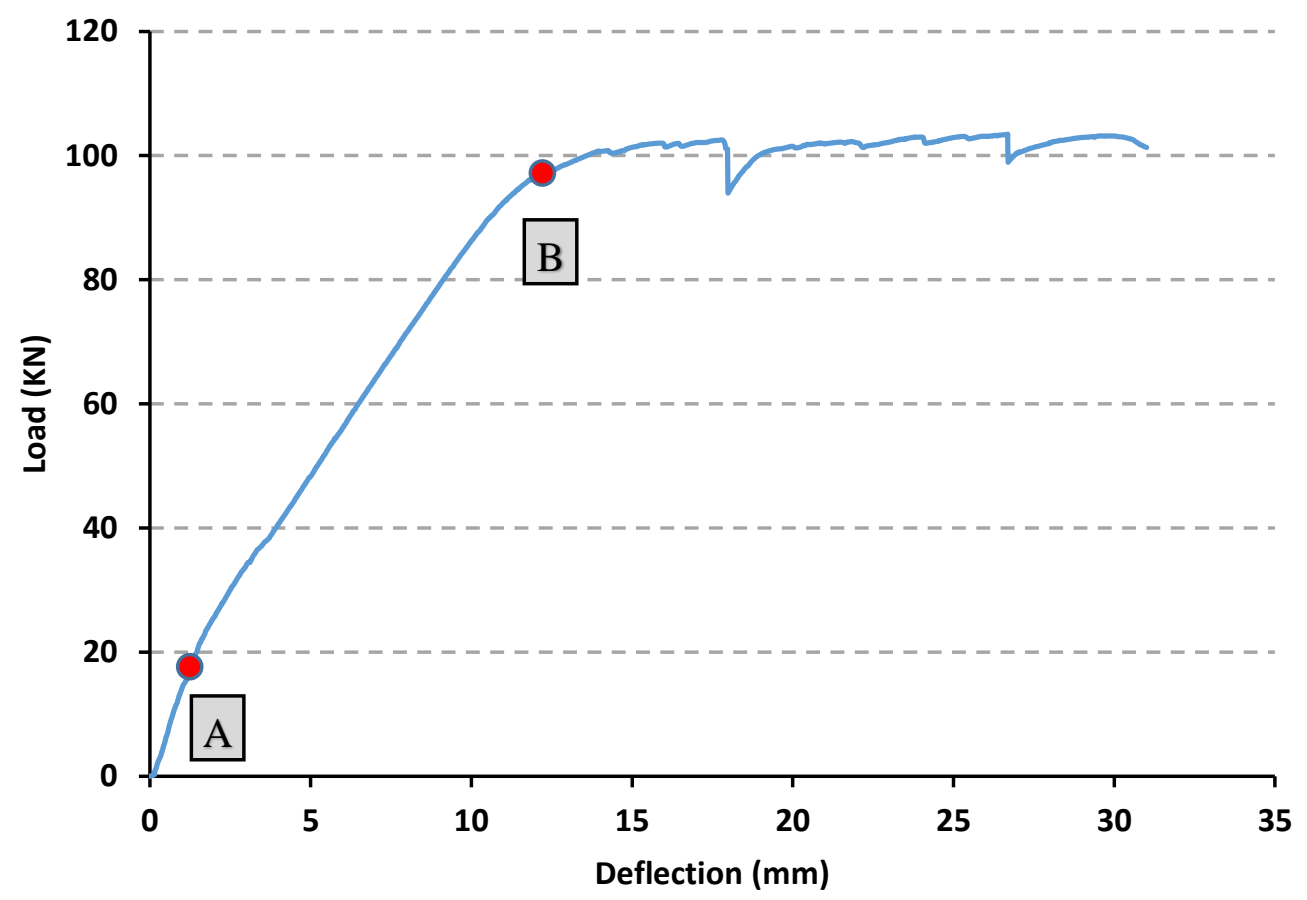

(a)

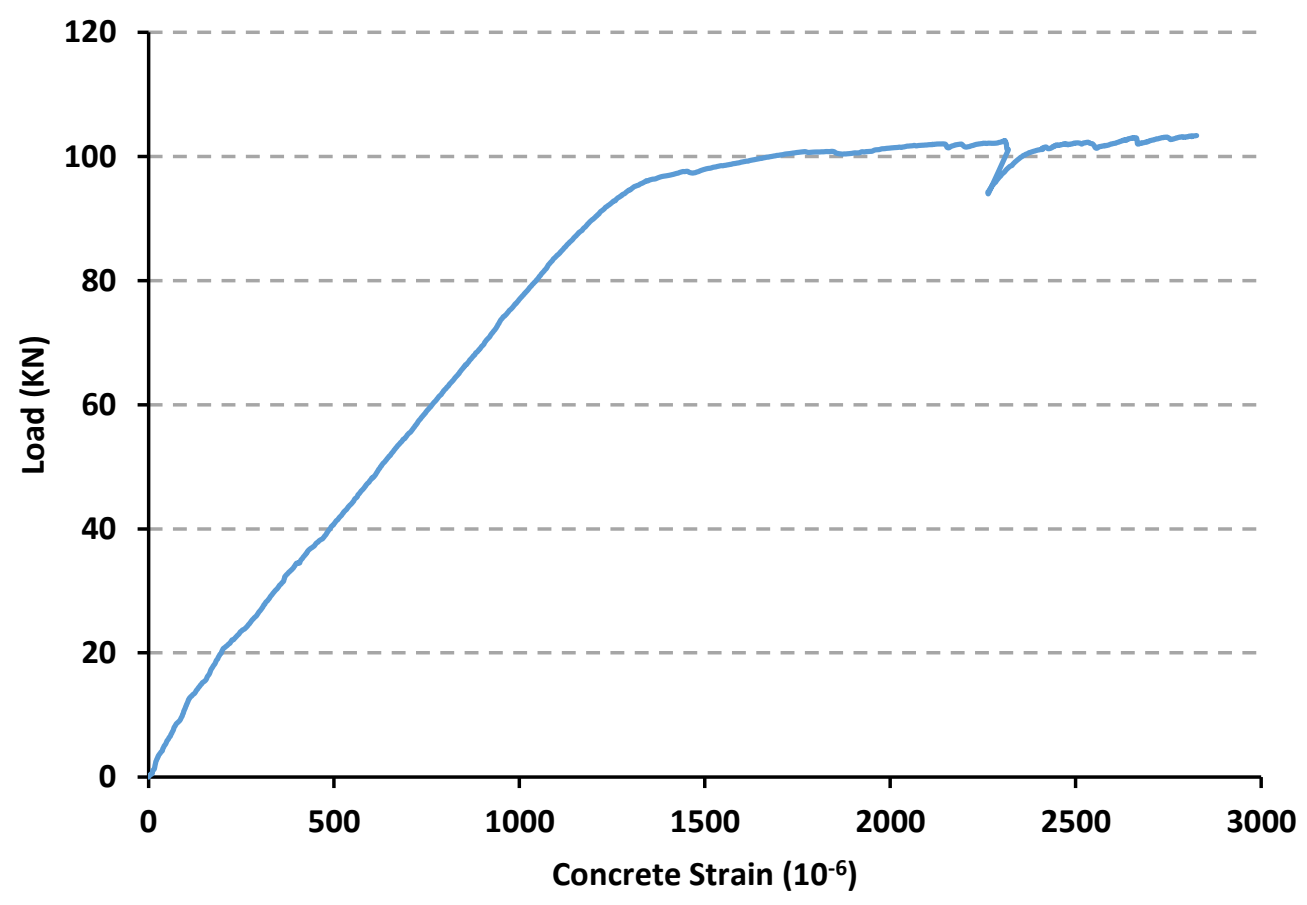

(b)

Figure 4.14 Test Results for Beam A3. a) Load vs. Deflection, b) Load vs. Concrete Strain, 


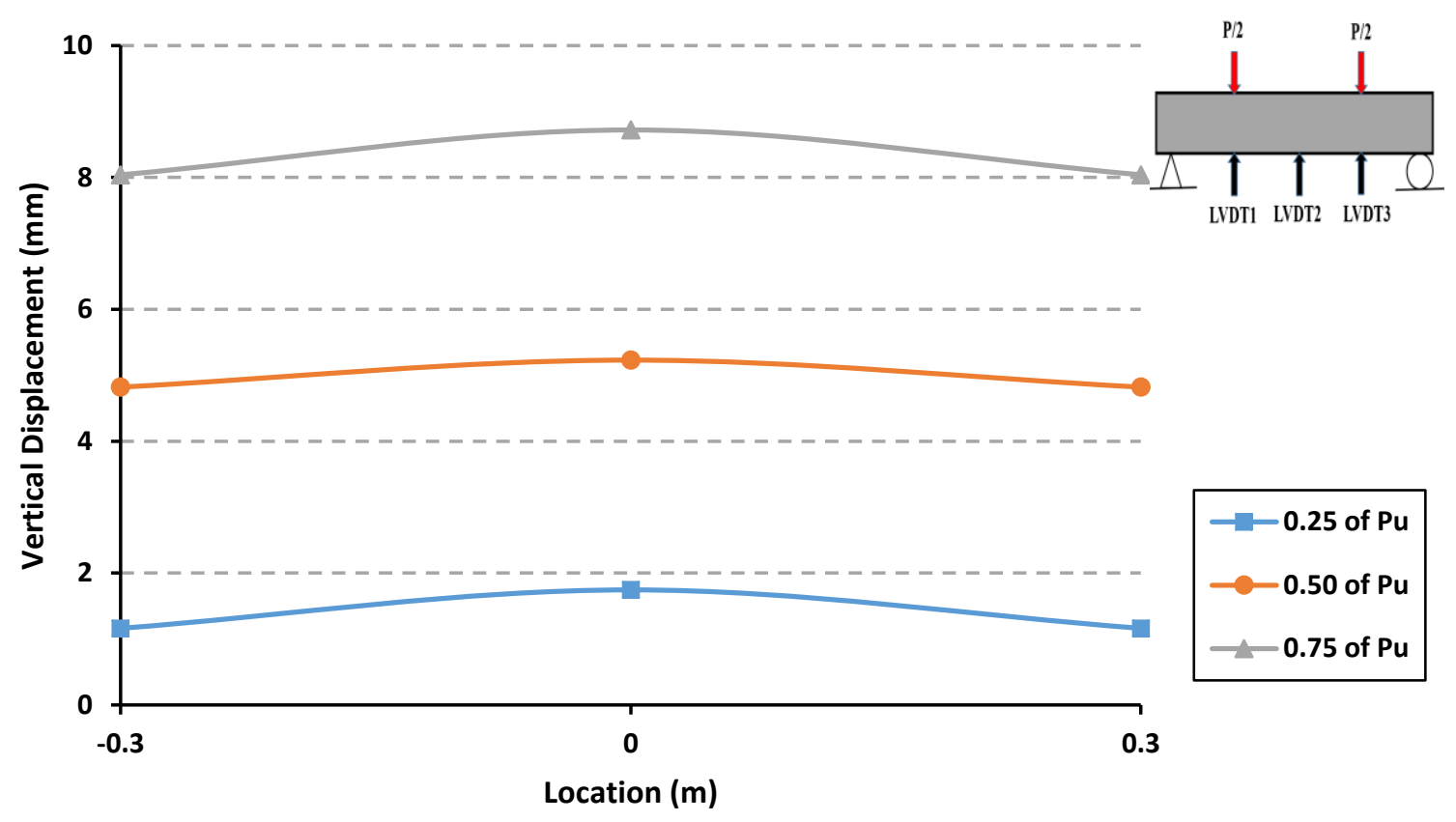

Figure 4.15 Deformed Shapes at Different Load Levels at the Bottom Surface

\subsubsection{Specimen A4 (100\% RCA+0\%BMF)}

Beam specimen A4 has $0 \%$ of NCA with $100 \%$ of RCA and no fibers added $(0 \%$ $\mathrm{BMF})$. The specimen was tested in flexure. After applying the static load gradually, the first crack was observed within the constant moment region of beam specimen at the middle of the beam at a load of $18 \mathrm{kN}$. As the load was increased, additional flexural cracks spread consistently along the beam where the cracks moved further upward, with a visible increase in the deflection. The majority of the flexural cracks developed vertically and after that inclined flexural-shear cracks began to appear. Upon further increasing the applied load, the longitudinal steel yielded, and finally concrete crushed in compression zone and beam failed as it can be seen from Figure 4.16.

Figure 4.17-a show the load-deflection relationships measured at the bottom surface at different locations of the specimen (refer to Figure 3.21 for measurement sensors locations). The load-deflection responses at mid-span presented in Figure 4.17-a show a linear elastic behavior before the initiation of the first flexural cracks (point A). When the load was increased beyond the cracking moment, the almost straight line slope was slightly 
declined because of the crack in the concrete in the tension zone. Then, the longitudinal steel reinforcement reached the yield point (point B) as shown in Figure 4.17-a. The recorded yielding load is $104.6 \mathrm{kN}$ (Yielding moment is $44.46 \mathrm{kN}$.m). Finally, concrete crushed in the in compression zone with ultimate load of $107.58 \mathrm{kN}$, and maximum midspan deflection of $30 \mathrm{~mm}$.

Figure 4.17-b shows the load-concrete compressive strain relationship measured at top surface at mid-span of the specimen, the recorded maximum compressive strain was 0.00292 .

A deformed shape of the bottom surface of the specimen is shown in Figure 4.18. In this Figure, the vertical axis represents the vertical downward deflection; therefore, the actual deformed shapes should be up-side-down. It can be observed in Figure 4.18 that the largest deflection was observed at the mid-span of the beam.

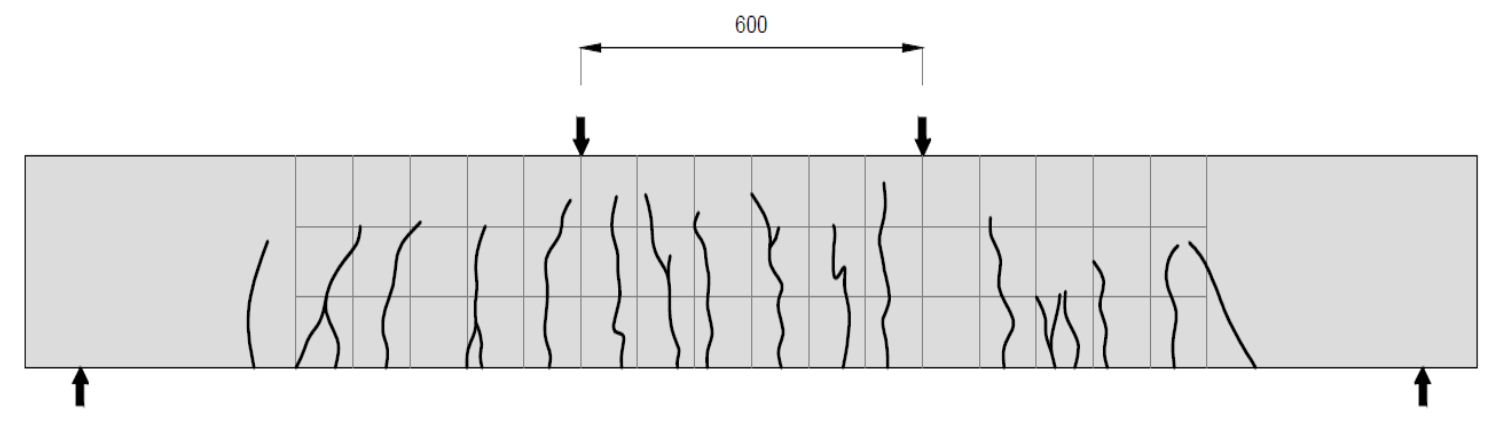

Figure 4.16 Cracking Pattern of Beam A4 


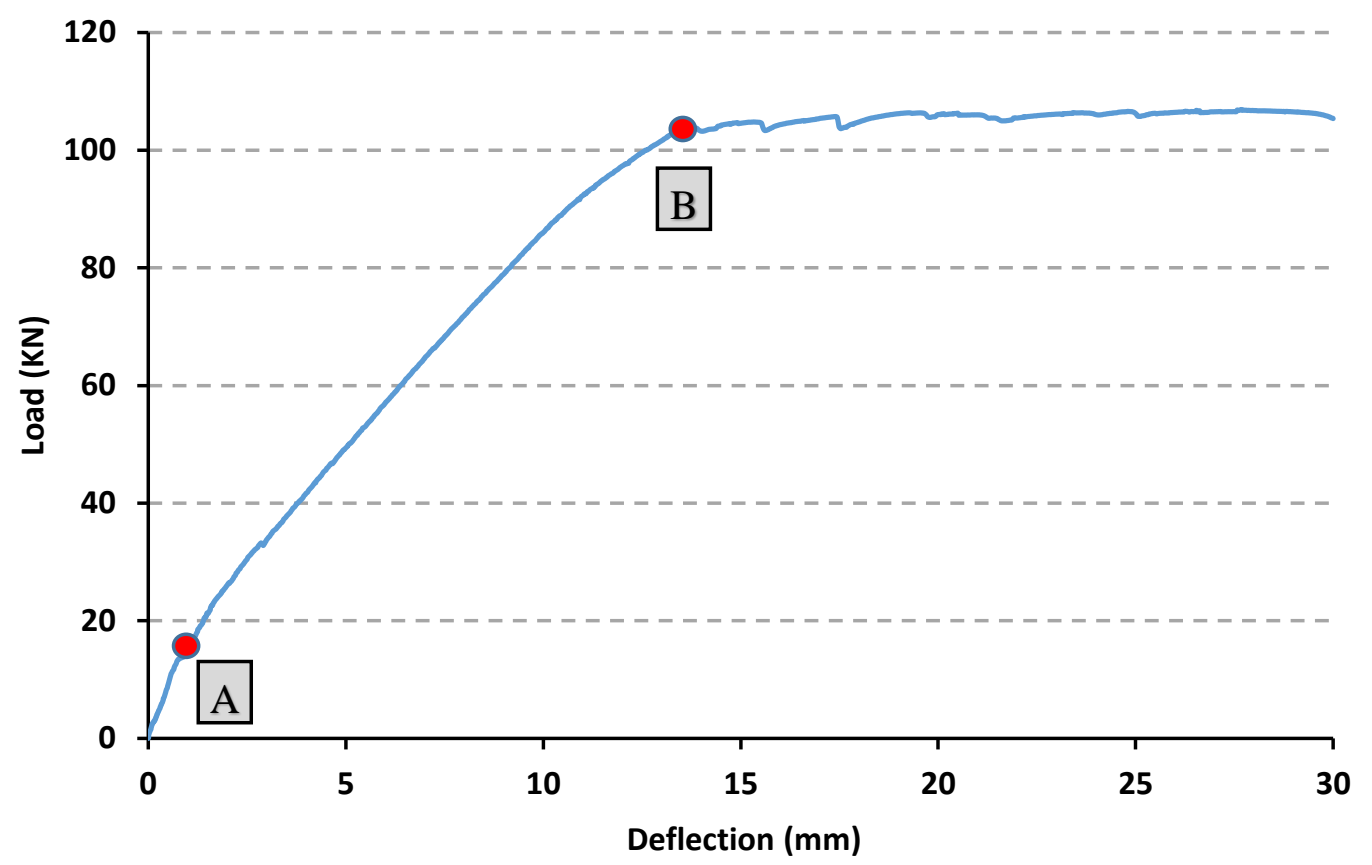

(a)

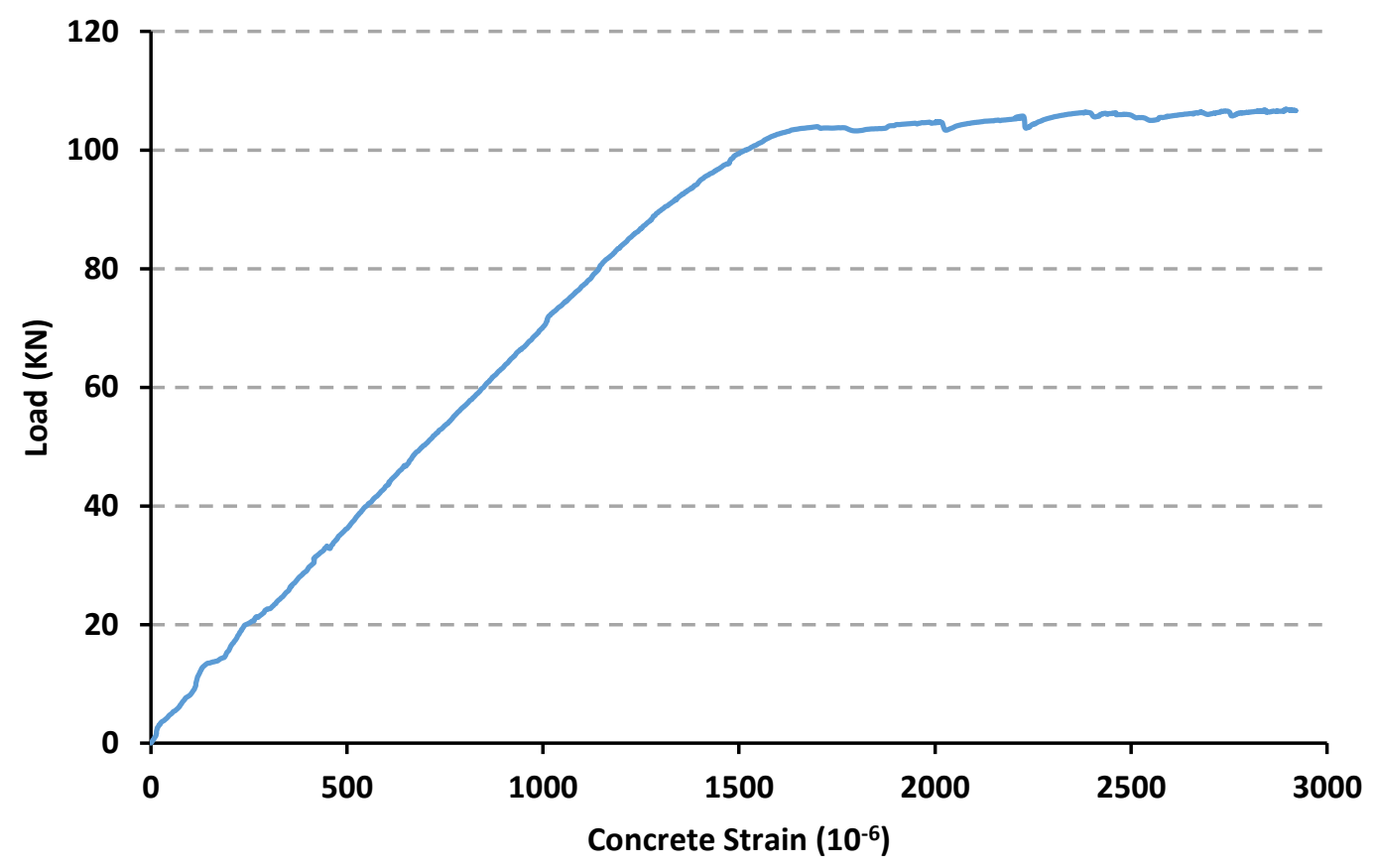

(b)

Figure 4.17 Test Results for Beam A4. a) Load vs. Deflection, b) Load vs. Concrete Strain 


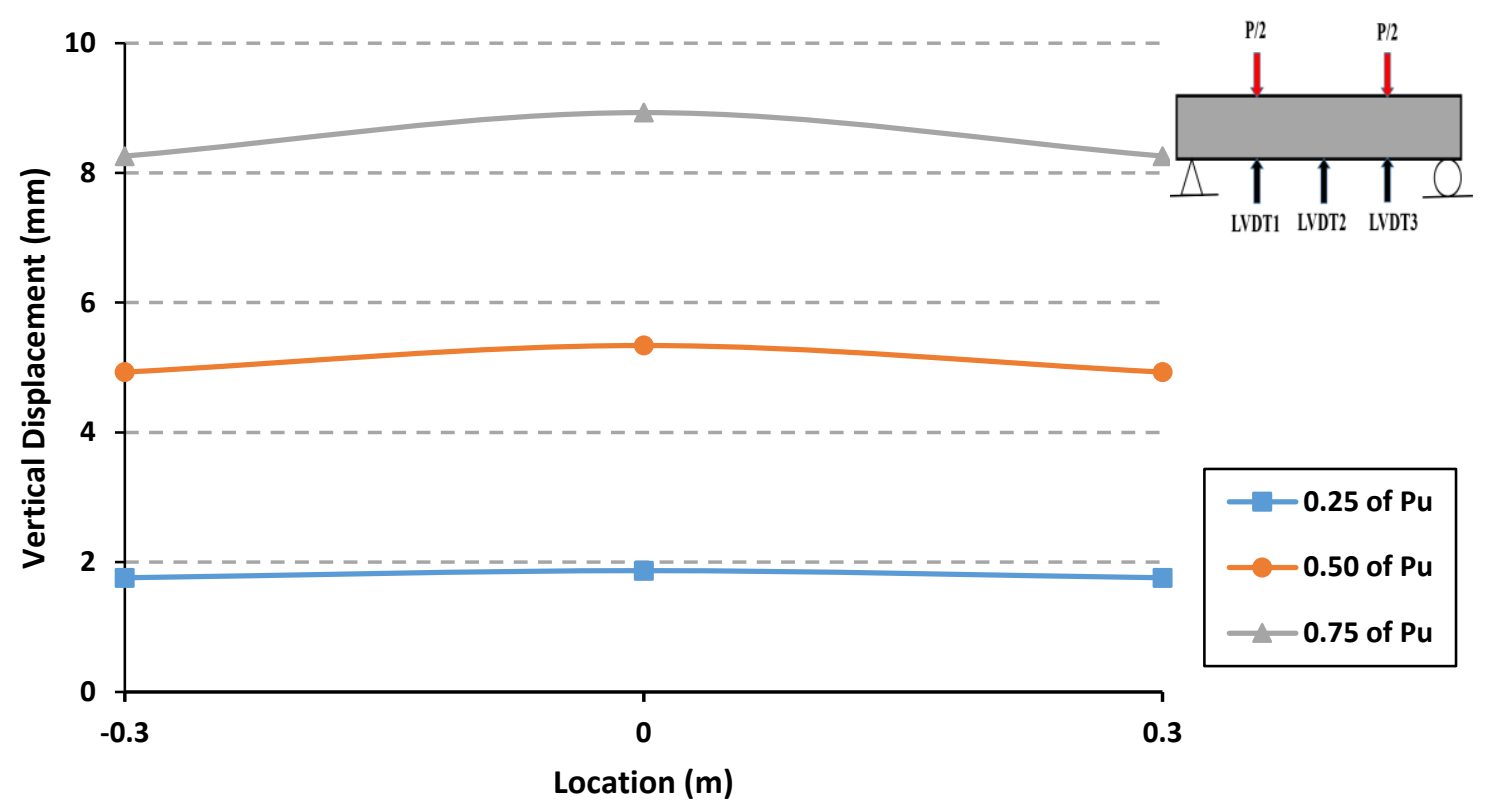

Figure 4.18 Deformed Shapes at Different Load Levels at The Bottom Surface

\subsubsection{Specimen A5 (0\% RCA+0.5\% BMF)}

Beam specimen A5 has $100 \%$ of NCA with $0 \%$ of RCA and added $0.5 \%$ of BMF. This specimen was tested to serve as a control. The specimen was tested in flexure. After applying the static load gradually, the first crack was observed within the constant moment region of beam specimen at the middle of the beam at a load of $27 \mathrm{kN}$. As the load was increased, additional flexural cracks spread consistently along the beam where the cracks moved further upward, with a visible increase in the deflection. The majority of the flexural cracks developed vertically and after that inclined flexural-shear cracks began to appear. Upon further increasing the applied load, the longitudinal steel yielded, and finally concrete crushed in compression zone and beam failed as it can be seen from Figure 4.19.

Figure 4.20-a show the load-deflection relationships measured at the bottom surface at different locations of the specimen (refer to Figure 3.21 for measurement sensors locations). The load-deflection responses at mid-span presented in Figure 4.20-a show a linear elastic behavior before the initiation of the first flexural cracks (point A). When the load was increased beyond the cracking moment, the almost straight line slope was slightly 
declined because of the crack in the concrete in the tension zone. Then, the longitudinal steel reinforcement reached the yield point (point B) as shown in Figure 4.20-b. The recorded yielding load is $113.7 \mathrm{kN}$ (Yielding moment is $48.33 \mathrm{kN}$.m). Finally, concrete crushed in the in compression zone with ultimate load of $115.08 \mathrm{kN}$, and maximum midspan deflection of $42 \mathrm{~mm}$.

Figure 4.20-b shows the load-concrete compressive strain relationship measured at top surface at mid-span of the specimen, the recorded maximum compressive strain was 0.00285 .

A deformed shape of the bottom surface of the specimen is shown in Figure 4.21. In this Figure, the vertical axis represents the vertical downward deflection; therefore, the actual deformed shapes should be up-side-down. It can be observed in Figure 4.21 that the largest deflection was observed at the mid-span of the beam.

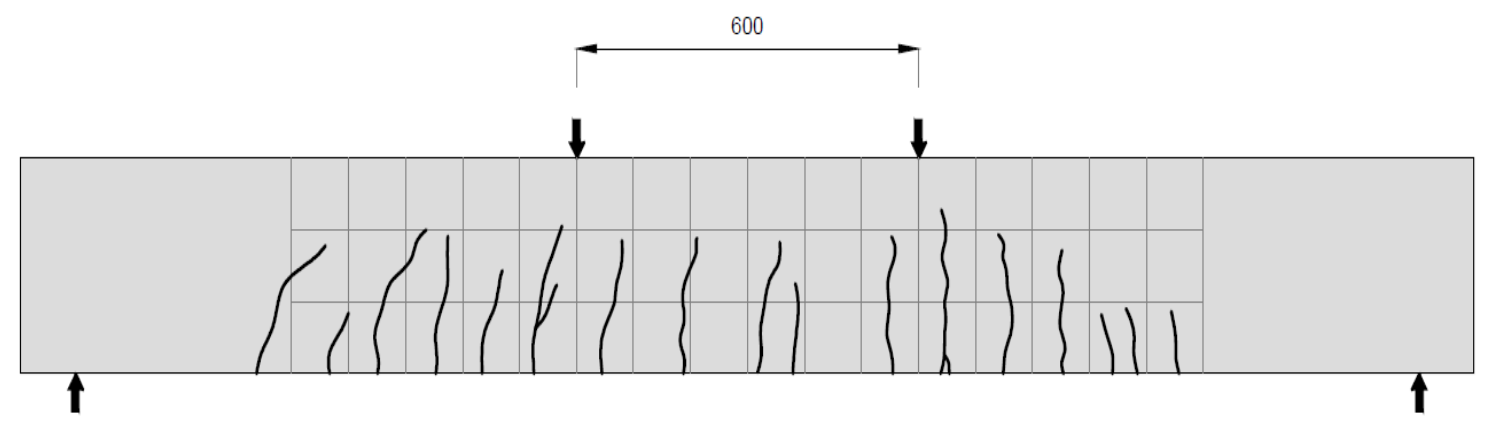

Figure 4.19 Cracking Pattern of Beam A5 


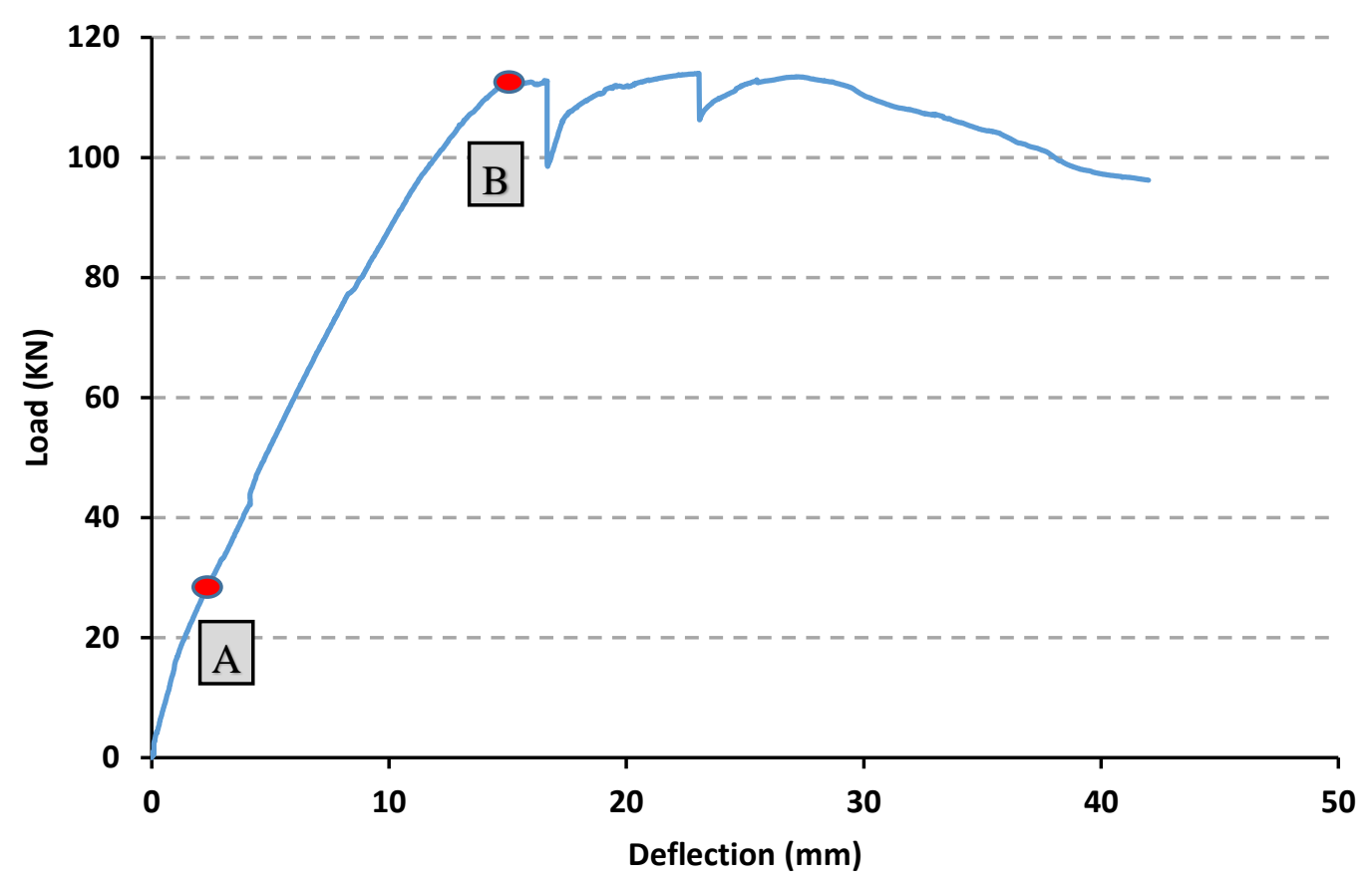

(a)

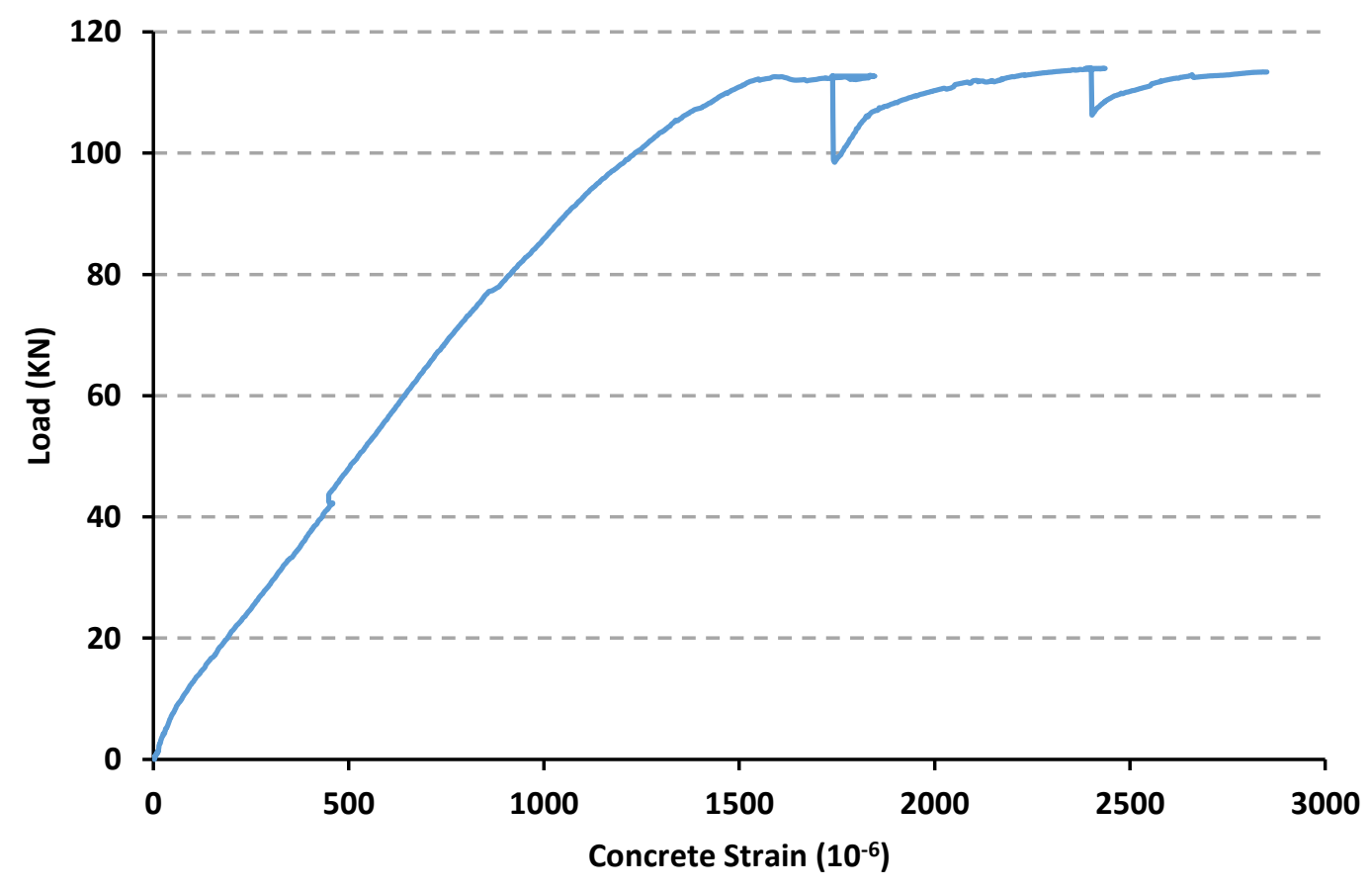

(b)

Figure 4.20 Test Results for Beam A5. a) Load vs. Deflection, b) Load vs. Concrete Strain 


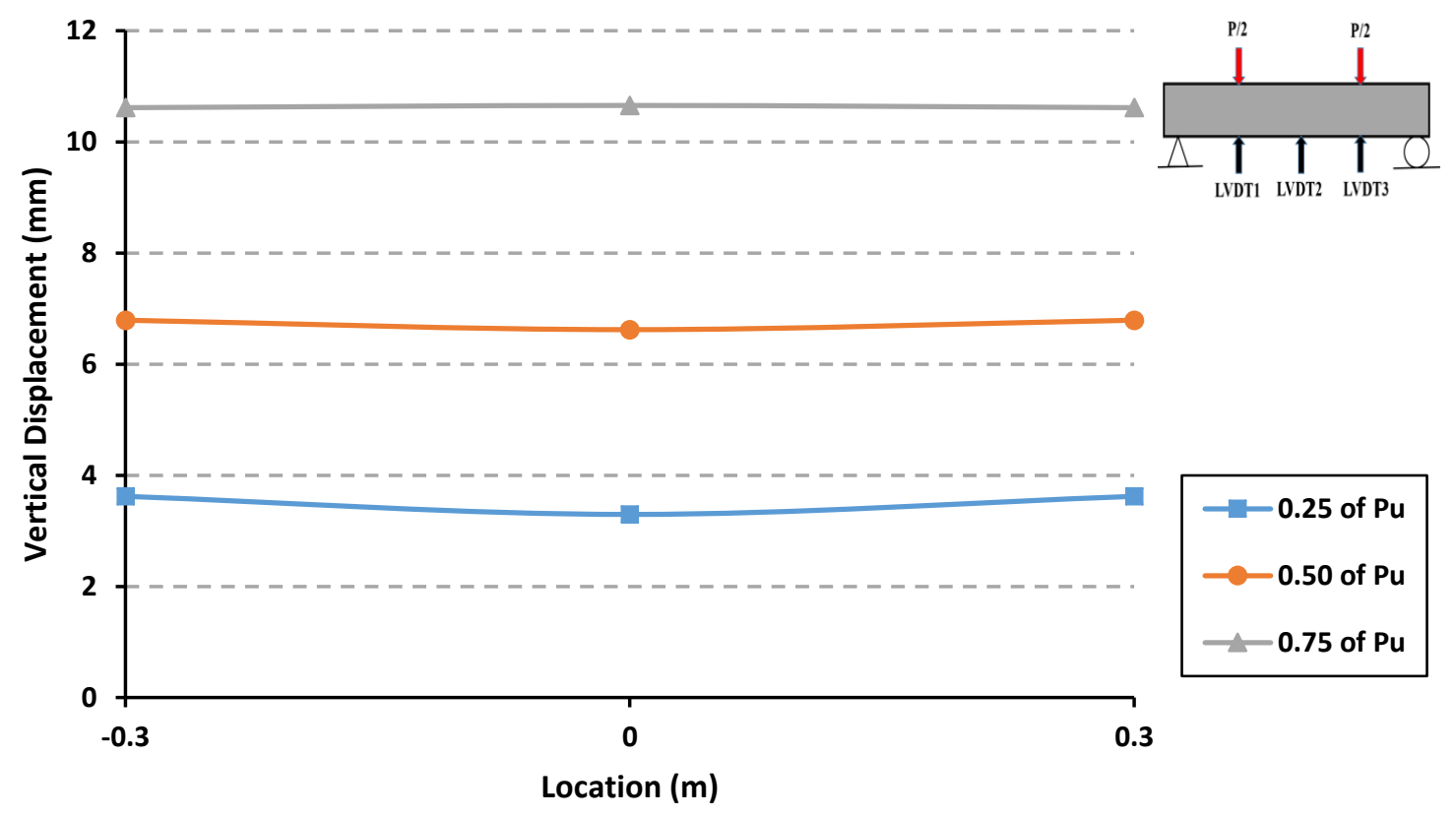

Figure 4.21 Deformed Shapes at Different Load Levels at the Bottom Surface

\subsubsection{Specimen A6 (25\% RCA+0.5\% BMF)}

Beam specimen A6 has $75 \%$ of NCA with $25 \%$ of RCA and added $0.5 \%$ of BMF. The specimen was tested in flexure. After applying the static load gradually, the first crack was observed within the constant moment region of beam specimen at the middle of the beam at a load of $24 \mathrm{kN}$. As the load was increased, additional flexural cracks spread consistently along the beam where the cracks moved further upward, with a visible increase in the deflection. The majority of the flexural cracks developed vertically and after that inclined flexural-shear cracks began to appear. Upon further increasing the applied load, the longitudinal steel yielded, and finally concrete crushed in compression zone and beam failed as it can be seen from Figure 4.22.

Figure 4.23-a show the load-deflection relationships measured at the bottom surface at different locations of the specimen (refer to Figure 3.21 for measurement sensors locations). The load-deflection responses at mid-span presented in Figure 4.23-a show a linear elastic behavior before the initiation of the first flexural cracks (point A). When the load was increased beyond the cracking moment, the almost straight line slope was slightly 
declined because of the crack in the concrete in the tension zone. Then, the longitudinal steel reinforcement reached the yield point (point B) as shown in Figure 4.23-a. The recorded yielding load is $116.75 \mathrm{kN}$ (Yielding moment is $49.62 \mathrm{kN} . \mathrm{m}$ ). Finally, concrete crushed in the in compression zone with ultimate load of $117.77 \mathrm{kN}$, and maximum midspan deflection of $36 \mathrm{~mm}$.

Figure 4.23-b shows the load-concrete compressive strain relationship measured at top surface at mid-span of the specimen, the recorded maximum compressive strain was 0.00228 .

A deformed shape of the bottom surface of the specimen is shown in Figure 4.24. In this Figure, the vertical axis represents the vertical downward deflection; therefore, the actual deformed shapes should be up-side-down. It can be observed in Figure 4.24 that the largest deflection was observed at the mid-span of the beam.

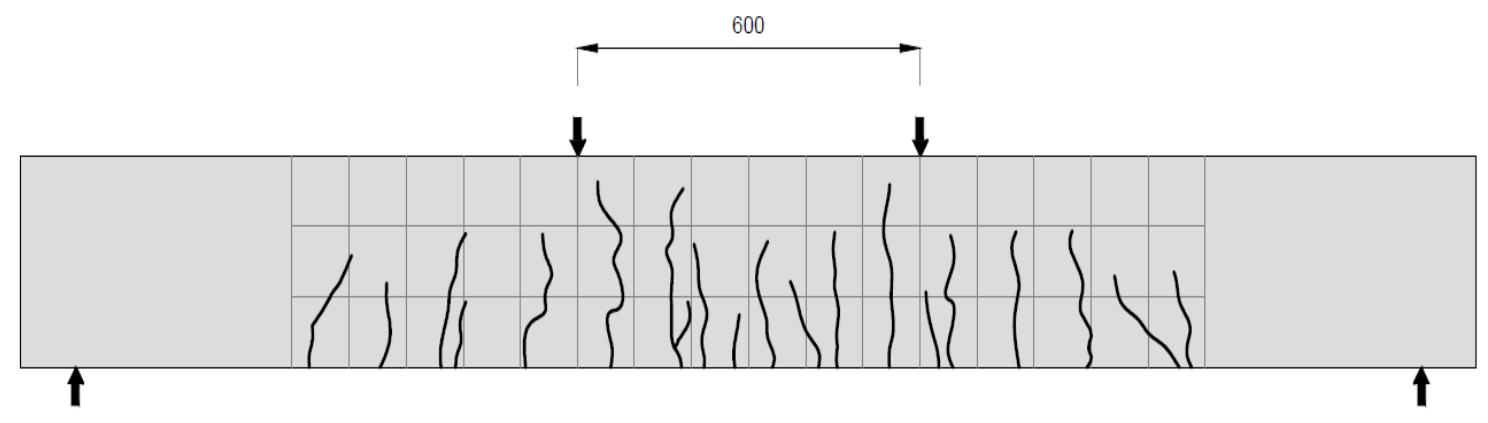

Figure 4.22 Cracking Pattern of Beam A6 


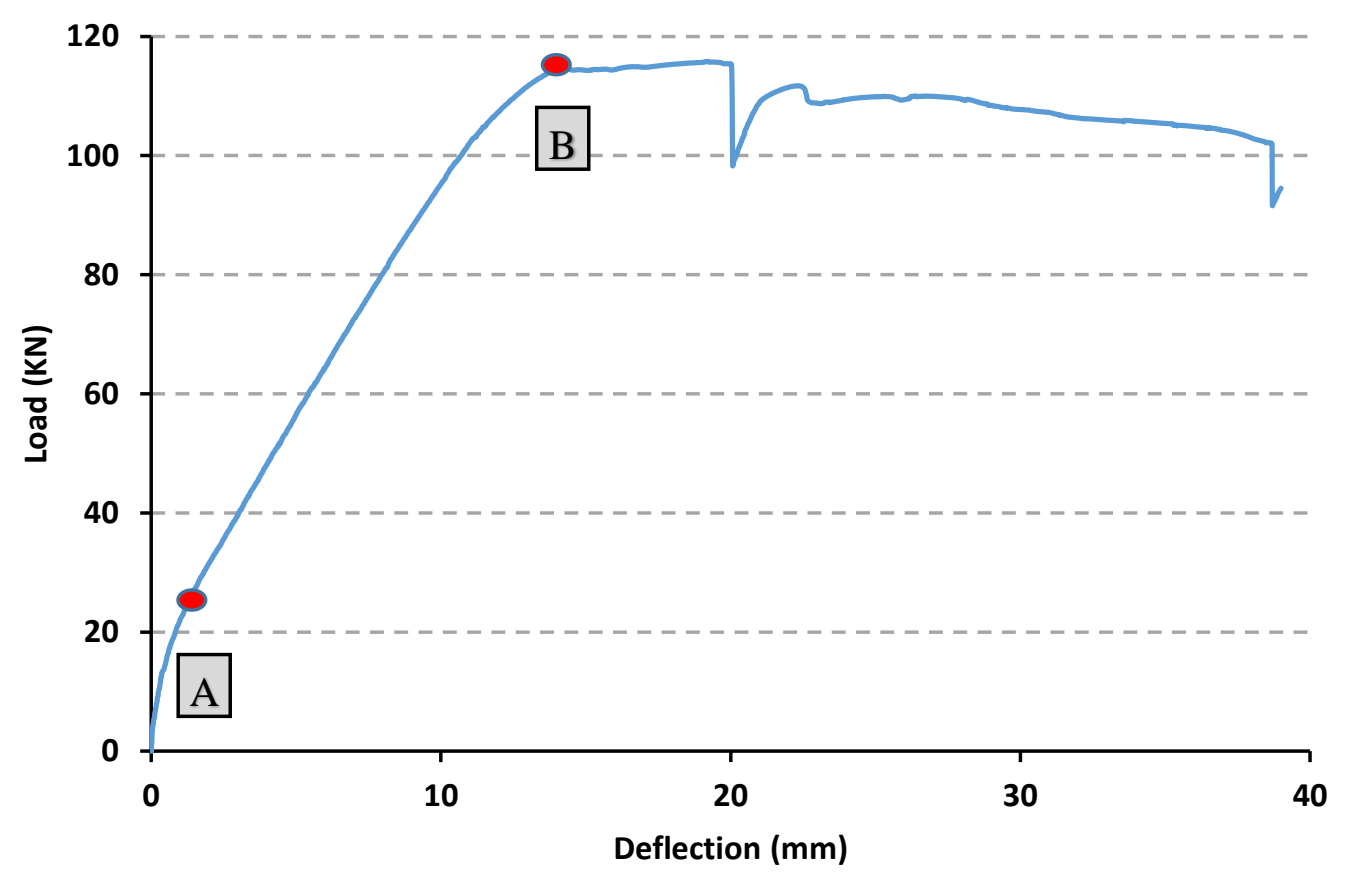

(a)

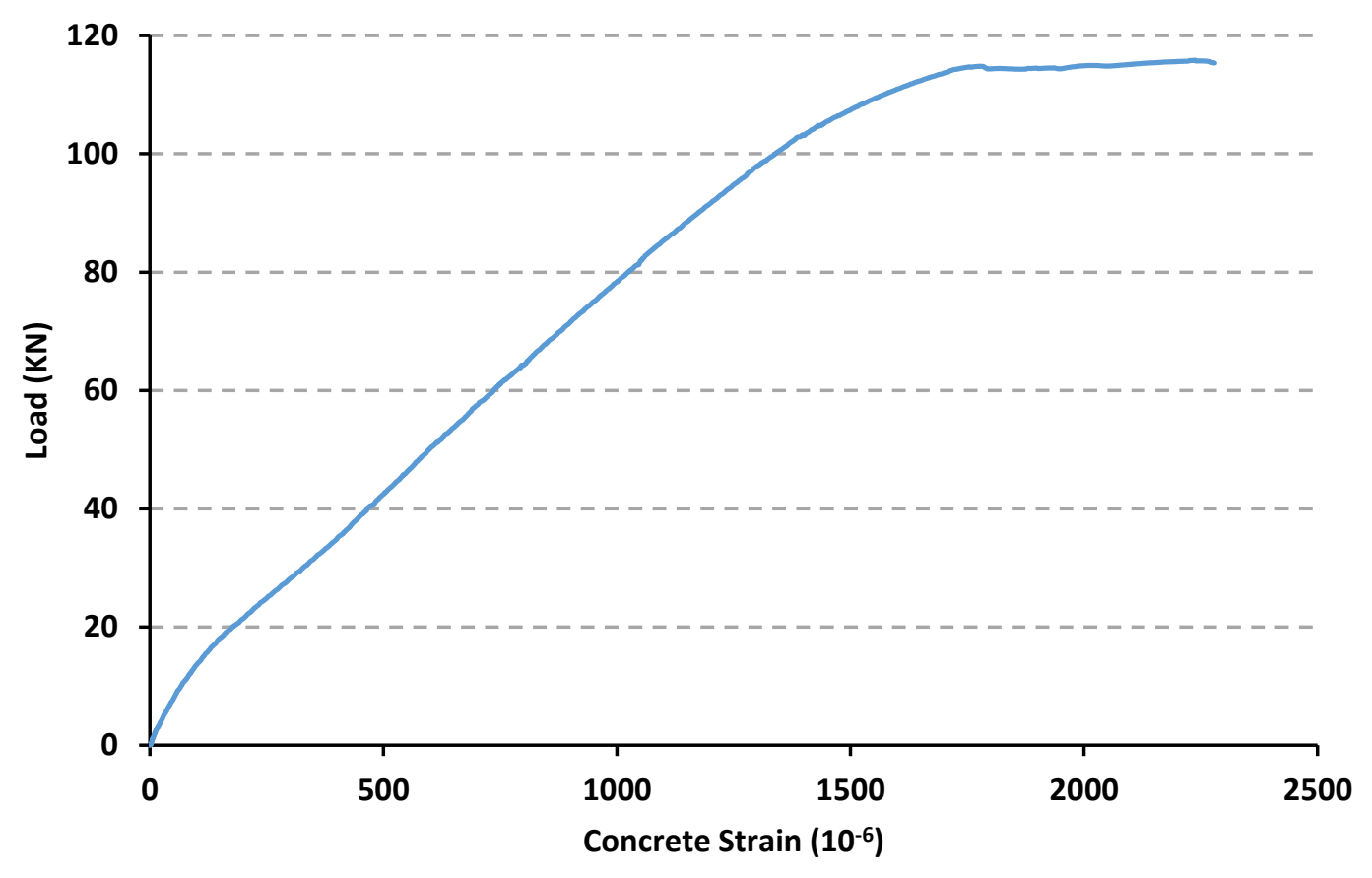

(b)

Figure 4.23 Test Results for Beam A6. a) Load vs. Deflection, b) Load vs. Concrete Strain 


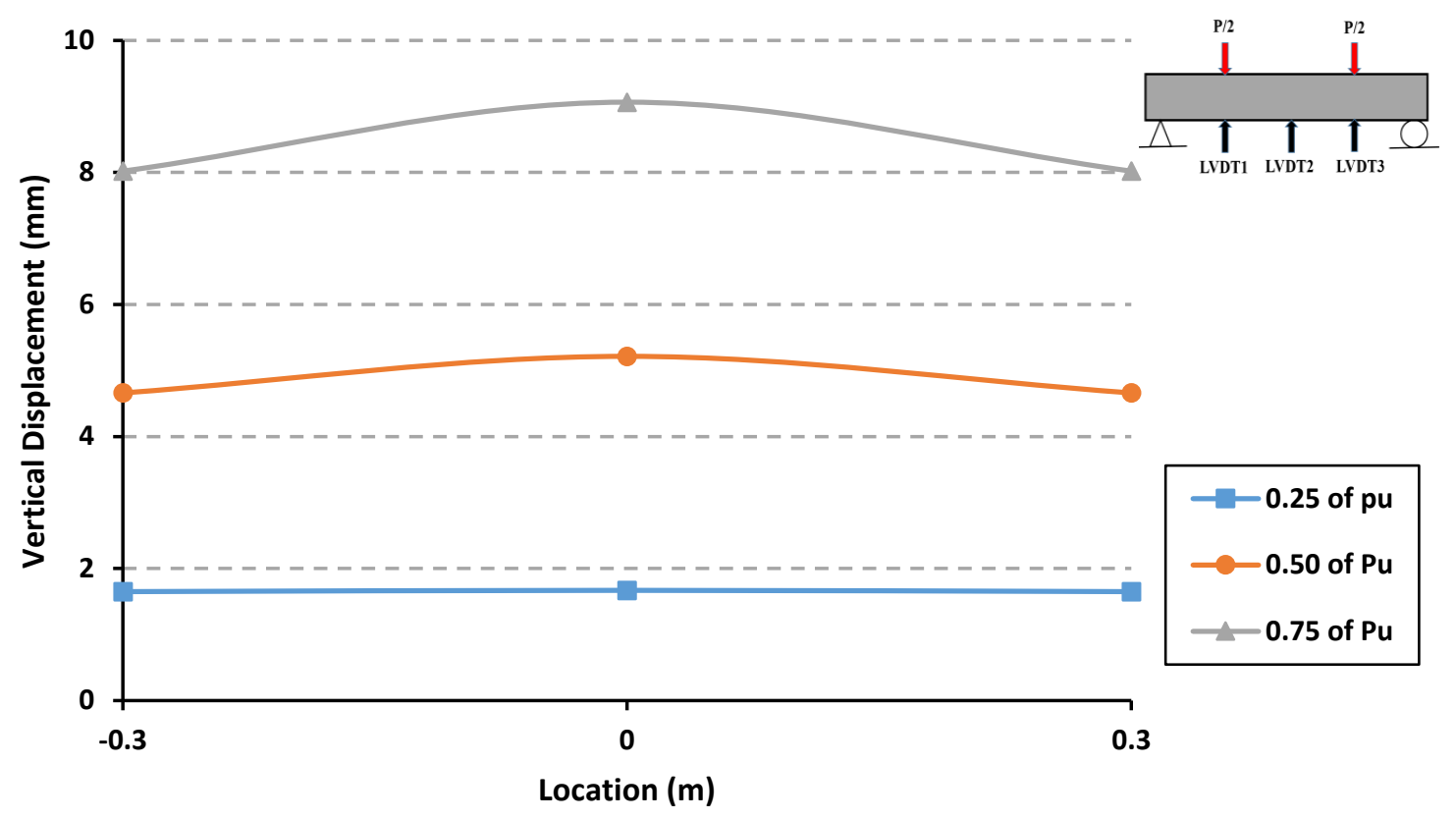

Figure 4.24 Deformed Shapes at Different Load Levels at the Bottom Surface

\subsubsection{Specimen A7 (50\% RCA+0.5\% BMF)}

Beam specimen A7 has $50 \%$ of NCA with $50 \%$ of RCA and added $0.5 \%$ of BMF. After applying the static load gradually, the first crack was observed within the constant moment region of beam specimen at the middle of the beam at a load of $22 \mathrm{kN}$. As the load was increased, additional flexural cracks spread consistently along the beam where the cracks moved further upward, with a visible increase in the deflection. The majority of the flexural cracks developed vertically and after that inclined flexural-shear cracks began to appear. Upon further increasing the applied load, the longitudinal steel yielded, and finally concrete crushed in compression zone and beam failed as it can be seen from Figure 4.25. Figure 4.26-a show the load-deflection relationships measured at the bottom surface at different locations of the specimen (refer to Figure 3.21 for measurement sensors locations). The load-deflection responses at mid-span presented in Figure 4.26-a show a linear elastic behavior before the initiation of the first flexural cracks (point A). When the load was increased beyond the cracking moment, the almost straight line slope was slightly declined because of the crack in the concrete in the tension zone. Then, the longitudinal 
steel reinforcement reached the yield point (point B) as shown in Figure 4.26-a. The recorded yielding load is $107.12 \mathrm{kN}$ (Yielding moment is $45.53 \mathrm{kN} . \mathrm{m}$ ). Finally, concrete crushed in the in compression zone with ultimate load of $108.63 \mathrm{kN}$, and maximum midspan deflection of $36 \mathrm{~mm}$.

Figure 4.26-b shows the load-concrete compressive strain relationship measured at top surface at mid-span of the specimen, the recorded maximum compressive strain was 0.00352 .

A deformed shape of the bottom surface of the specimen is shown in Figure 4.27. In this Figure, the vertical axis represents the vertical downward deflection; therefore, the actual deformed shapes should be up-side-down. It can be observed in Figure 4.27 that the largest deflection was observed at the mid-span of the beam.

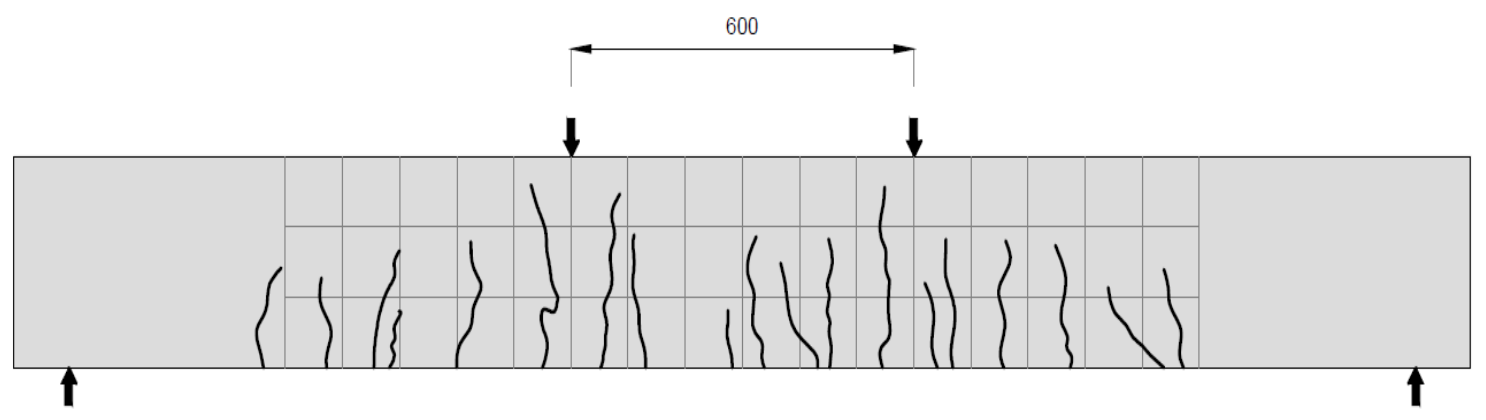

Figure 4.25 Cracking Pattern of Beam A7 


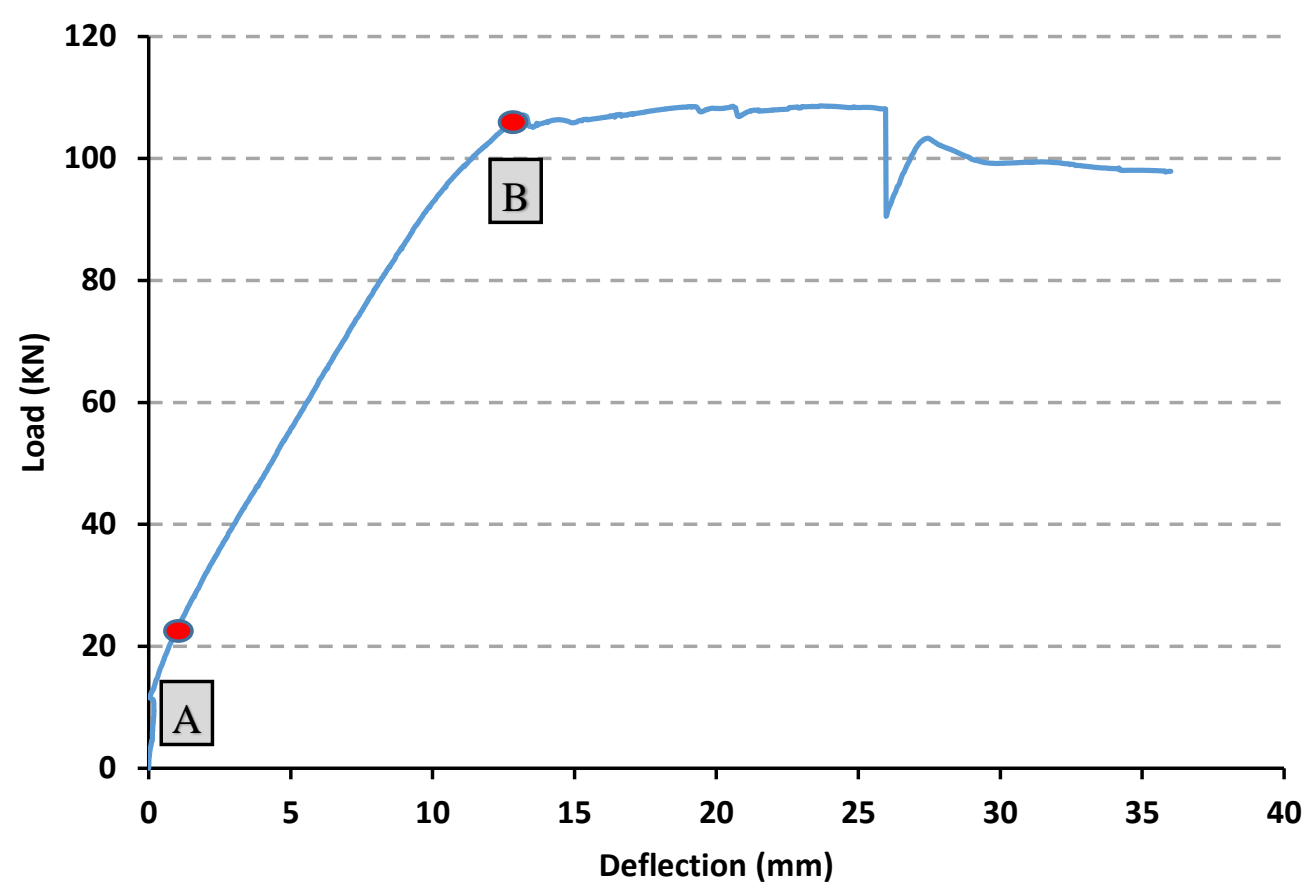

(a)

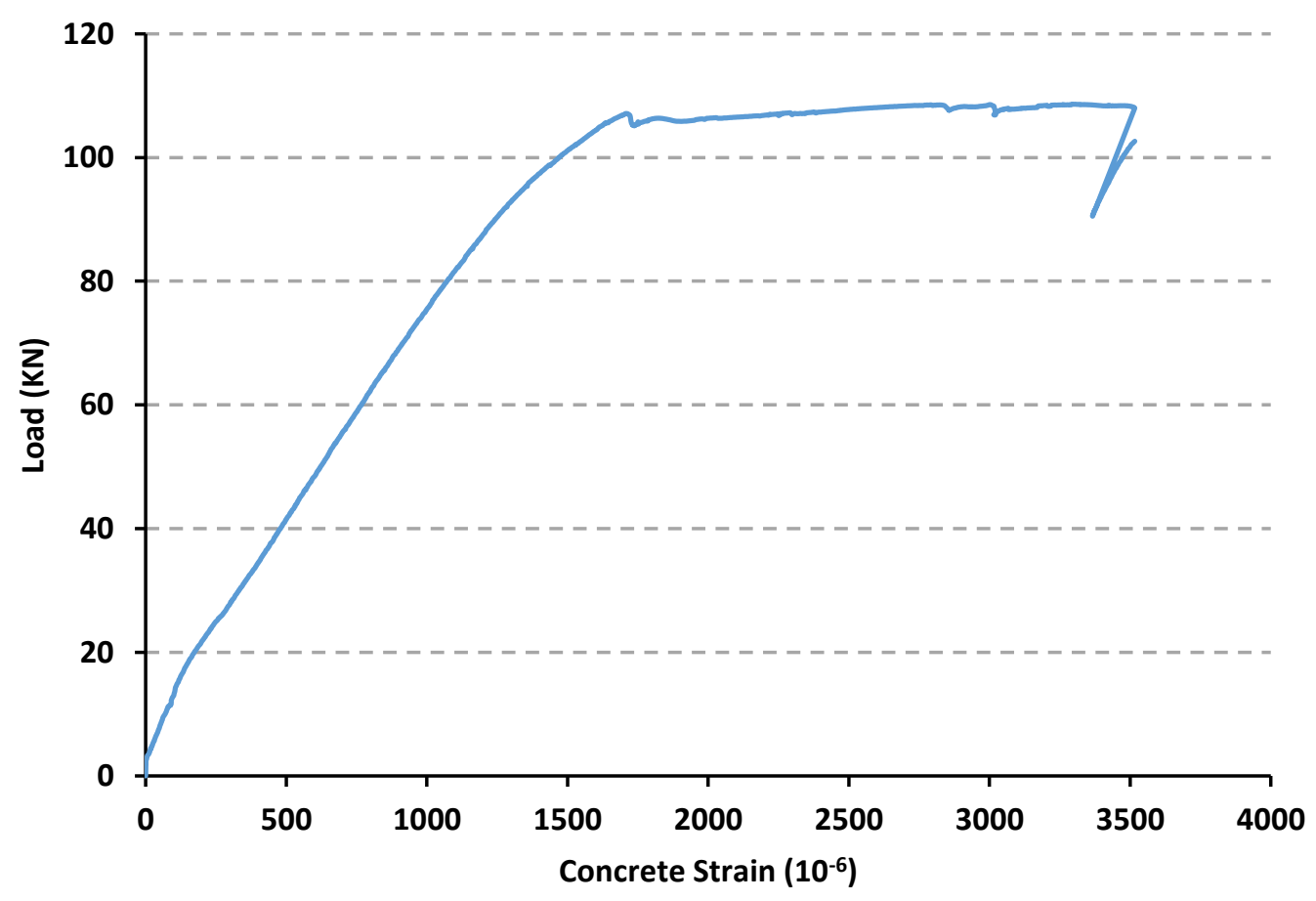

(b)

Figure 4.26 Test Results for Beam A7. a) Load vs. Deflection, b) Load vs. Concrete Strain, 


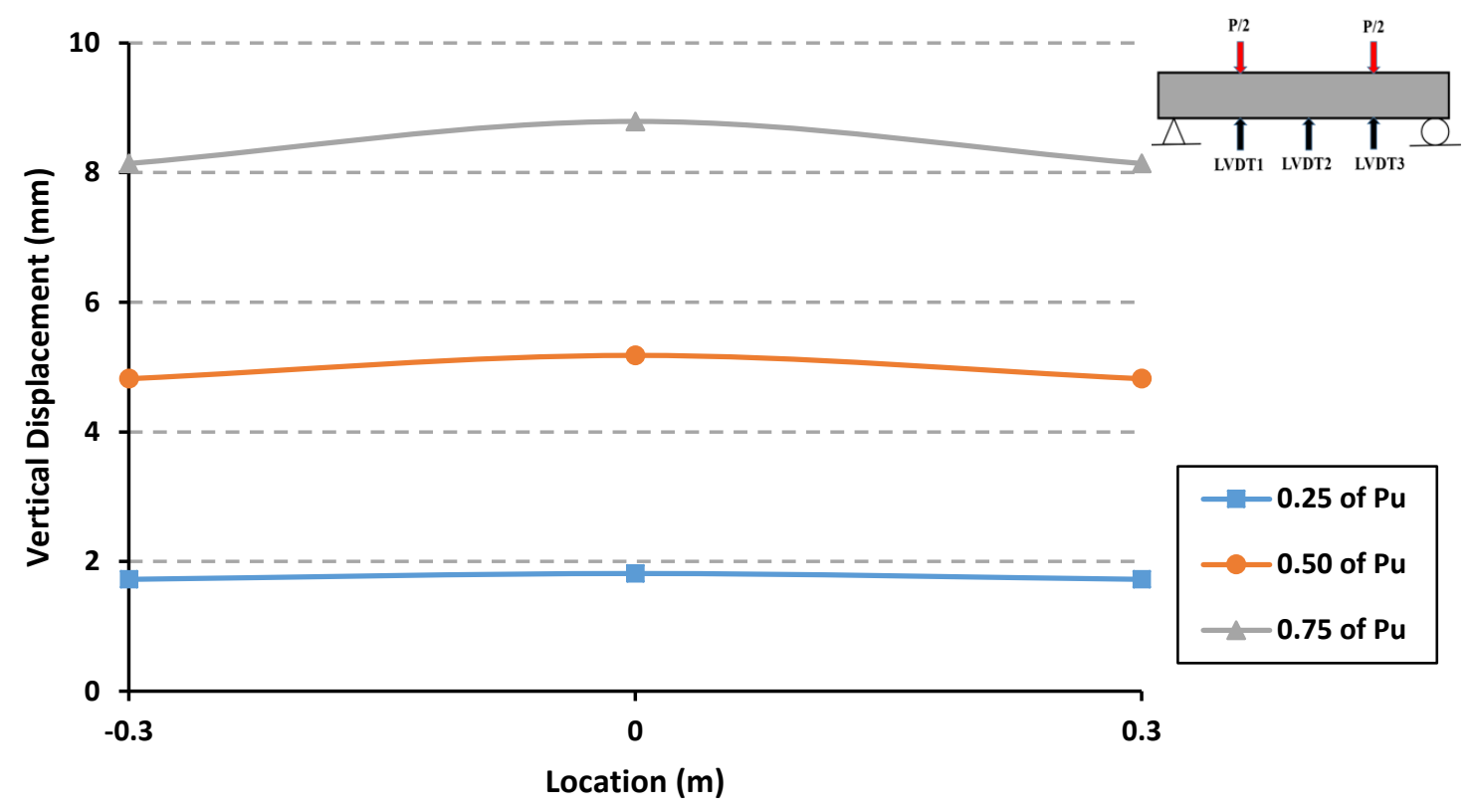

Figure 4.27 Deformed Shapes at Different Load Levels at the Bottom Surface

\subsubsection{Specimen A8 (100\% RCA+0.5\% BMF)}

Beam specimen A8 has $0 \%$ of NCA with $100 \%$ of RCA and added $0.5 \%$ of BMF. After applying the static load gradually, the first crack was observed within the constant moment region of beam specimen at the middle of the beam at a load of $21 \mathrm{kN}$. As the load was increased, additional flexural cracks spread consistently along the beam where the cracks moved further upward, with a visible increase in the deflection. The majority of the flexural cracks developed vertically and after that inclined flexural-shear cracks began to appear. Upon further increasing the applied load, the longitudinal steel yielded, and finally concrete crushed in compression zone and beam failed as it can be seen from Figure 4.28. Figure 4.29-a show the load-deflection relationships measured at the bottom surface at different locations of the specimen (refer to Figure 3.21 for measurement sensors locations). The load-deflection responses at mid-span presented in Figure 4.29-a show a linear elastic behavior before the initiation of the first flexural cracks (point A). When the load was increased beyond the cracking moment, the almost straight line slope was slightly declined because of the crack in the concrete in the tension zone. Then, the longitudinal 
steel reinforcement reached the yield point (point B) as shown in Figure 4.29-a. The recorded yielding load is $108.04 \mathrm{kN}$ (Yielding moment is $45.92 \mathrm{kN} . \mathrm{m}$ ). Finally, concrete crushed in the in compression zone with ultimate load of $108.52 \mathrm{kN}$, and maximum midspan deflection of $34 \mathrm{~mm}$.

Figure 4.29-b shows the load-concrete compressive strain relationship measured at top surface at mid-span of the specimen, the recorded maximum compressive strain was 0.00308 .

A deformed shape of the bottom surface of the specimen is shown in Figure 4.30. In this Figure, the vertical axis represents the vertical downward deflection; therefore, the actual deformed shapes should be up-side-down. It can be observed in Figure 4.30 that the largest deflection was observed at the mid-span of the beam.

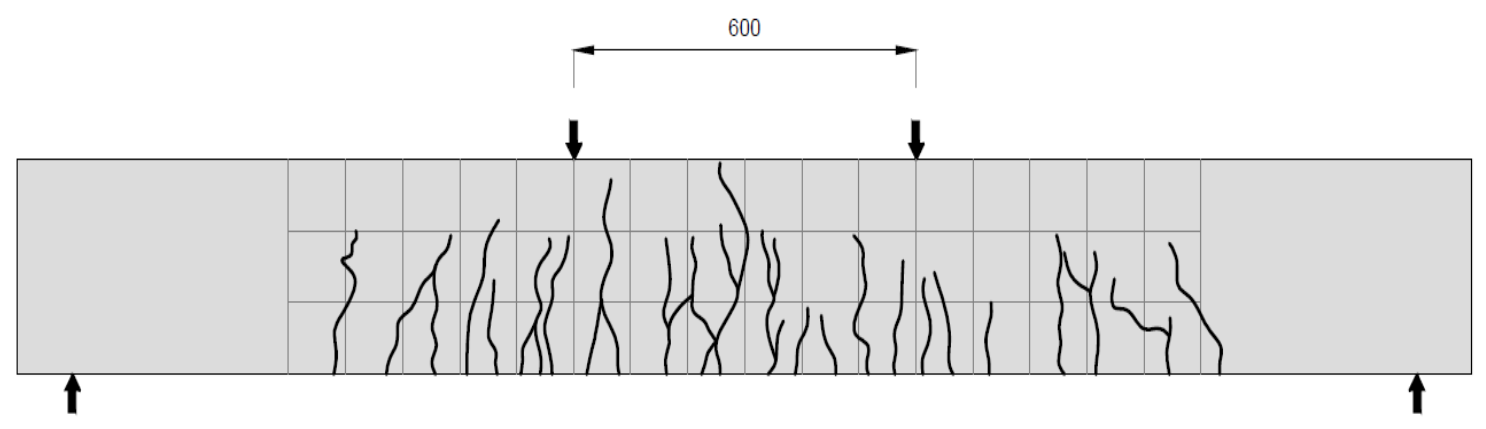

Figure 4.28 Cracking Pattern of Beam A8 


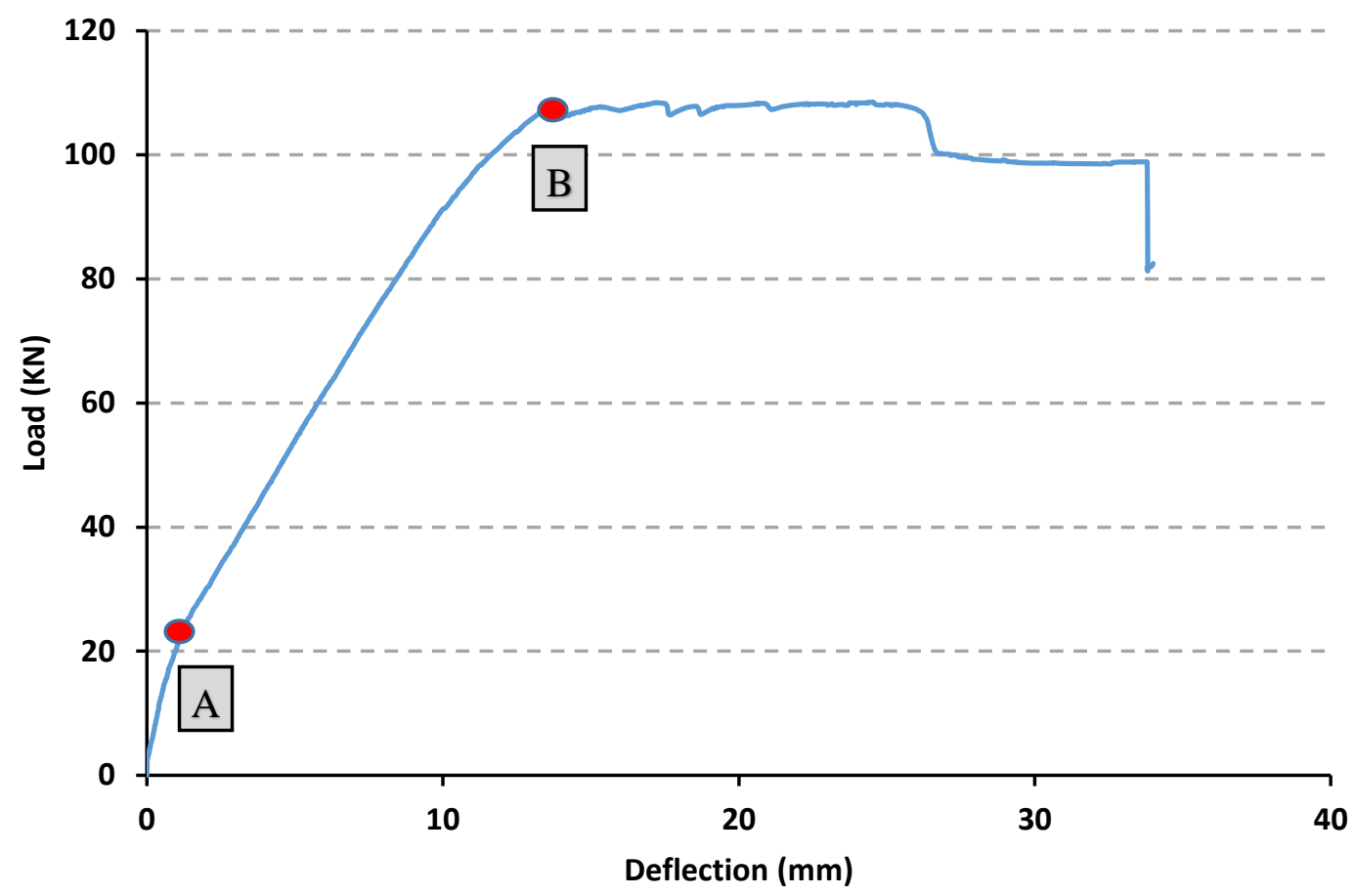

(a)

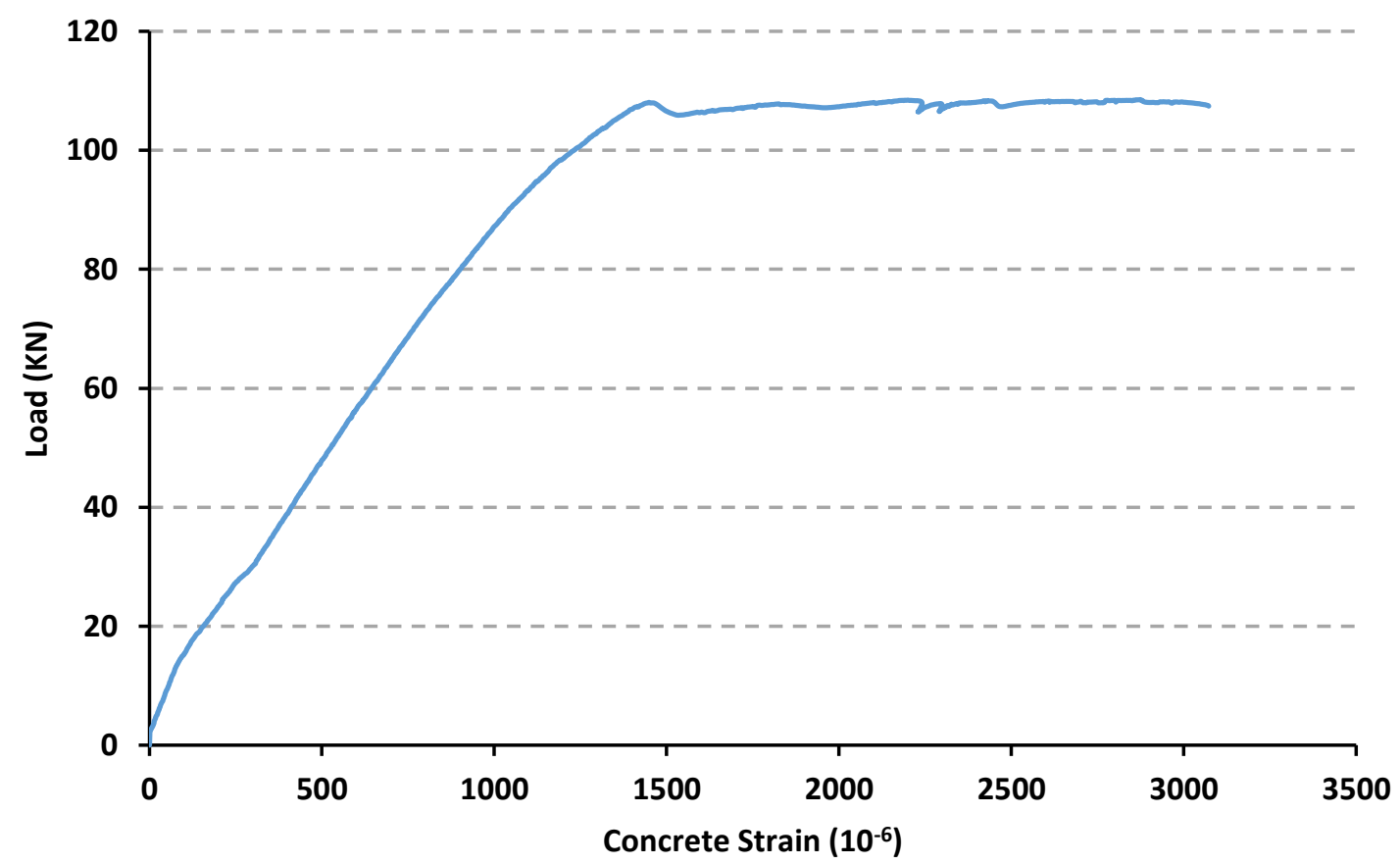

(b)

Figure 4.29 Test Results for Beam A8. a) Load vs. Deflection, b) Load vs. Concrete Strain 


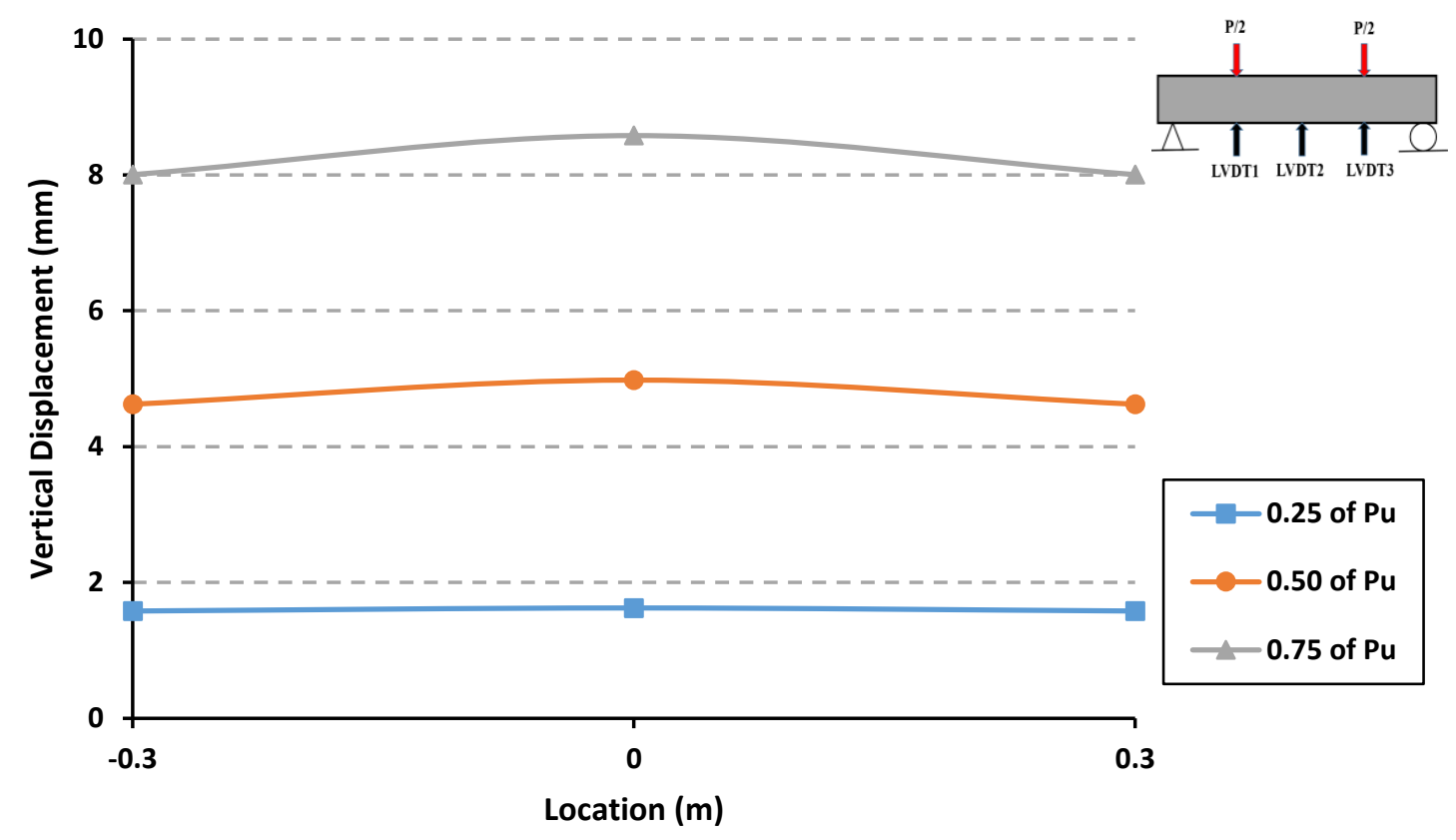

Figure 4.30 Deformed Shapes at Different Load Levels at the Bottom Surface

\subsubsection{Specimen A9 (0\% RCA+1.0\% BMF)}

Beam specimen A9 has $100 \%$ of NCA with $0 \%$ of RCA and added 1\% of BMF. This specimen was tested to serve as a control. The specimen was tested in flexure. After applying the static load gradually, the first crack was observed within the constant moment region of beam specimen at the middle of the beam at a load of $39 \mathrm{kN}$. As the load was increased, additional flexural cracks spread consistently along the beam where the cracks moved further upward, with a visible increase in the deflection. The majority of the flexural cracks developed vertically and after that inclined flexural-shear cracks began to appear. Upon further increasing the applied load, the longitudinal steel yielded, and finally concrete crushed in compression zone and beam failed as it can be seen from Figure 4.31.

Figure 4.32-a show the load-deflection relationships measured at the bottom surface at different locations of the specimen (refer to Figure 3.21 for measurement sensors locations). The load-deflection responses at mid-span presented in Figure 4.32-a show a linear elastic behavior before the initiation of the first flexural cracks (point A). When the load was increased beyond the cracking moment, the almost straight line slope was slightly 
declined because of the crack in the concrete in the tension zone. Then, the longitudinal steel reinforcement reached the yield point (point B) as shown in Figure 4.32-a. The recorded yielding load is $118.2 \mathrm{kN}$ (Yielding moment is $50.24 \mathrm{kN}$.m). Finally, concrete crushed in the in compression zone with ultimate load of $120.58 \mathrm{kN}$, and maximum midspan deflection of $45 \mathrm{~mm}$.

Figure 4.32-b shows the load-concrete compressive strain relationship measured at top surface at mid-span of the specimen, the recorded maximum compressive strain was 0.00262 .

A deformed shape of the bottom surface of the specimen is shown in Figure 4.33. In this Figure, the vertical axis represents the vertical downward deflection; therefore, the actual deformed shapes should be up-side-down. It can be observed in Figure 4.33 that the largest deflection was observed at the mid-span of the beam.

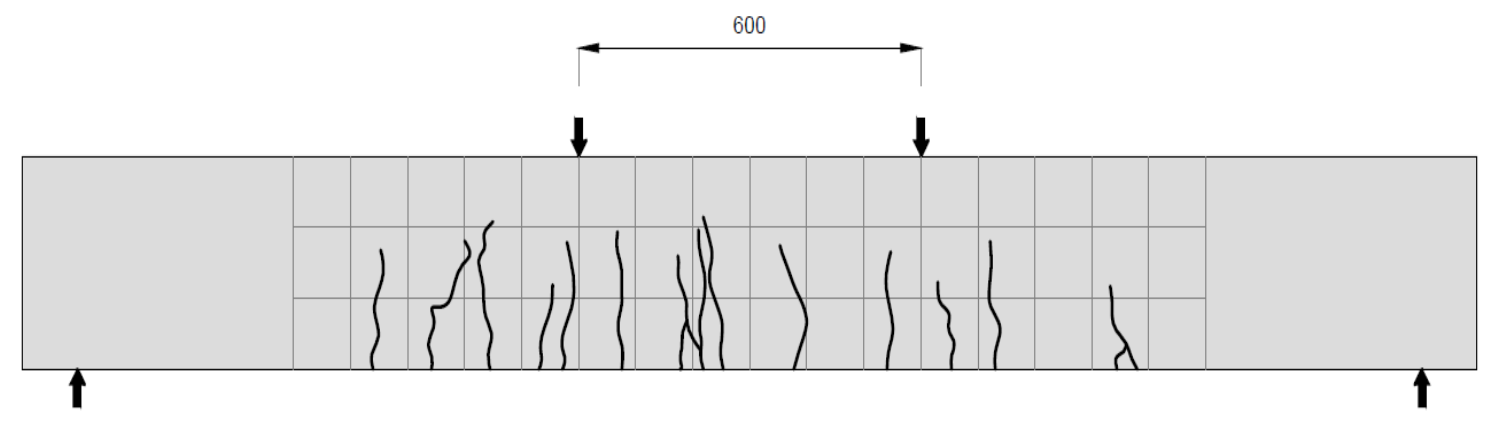

Figure 4.31 Cracking Pattern of Beam A9 


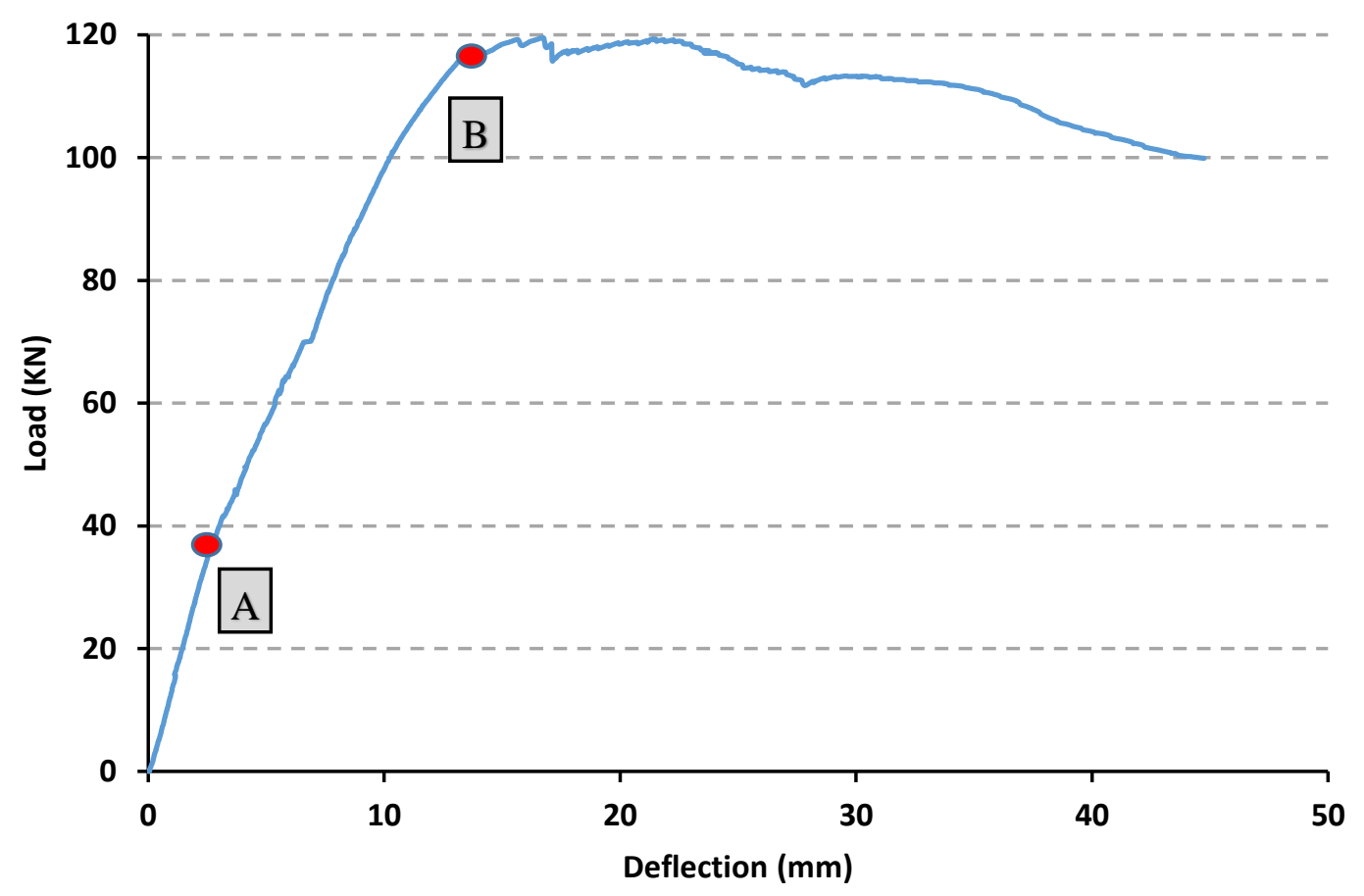

(a)

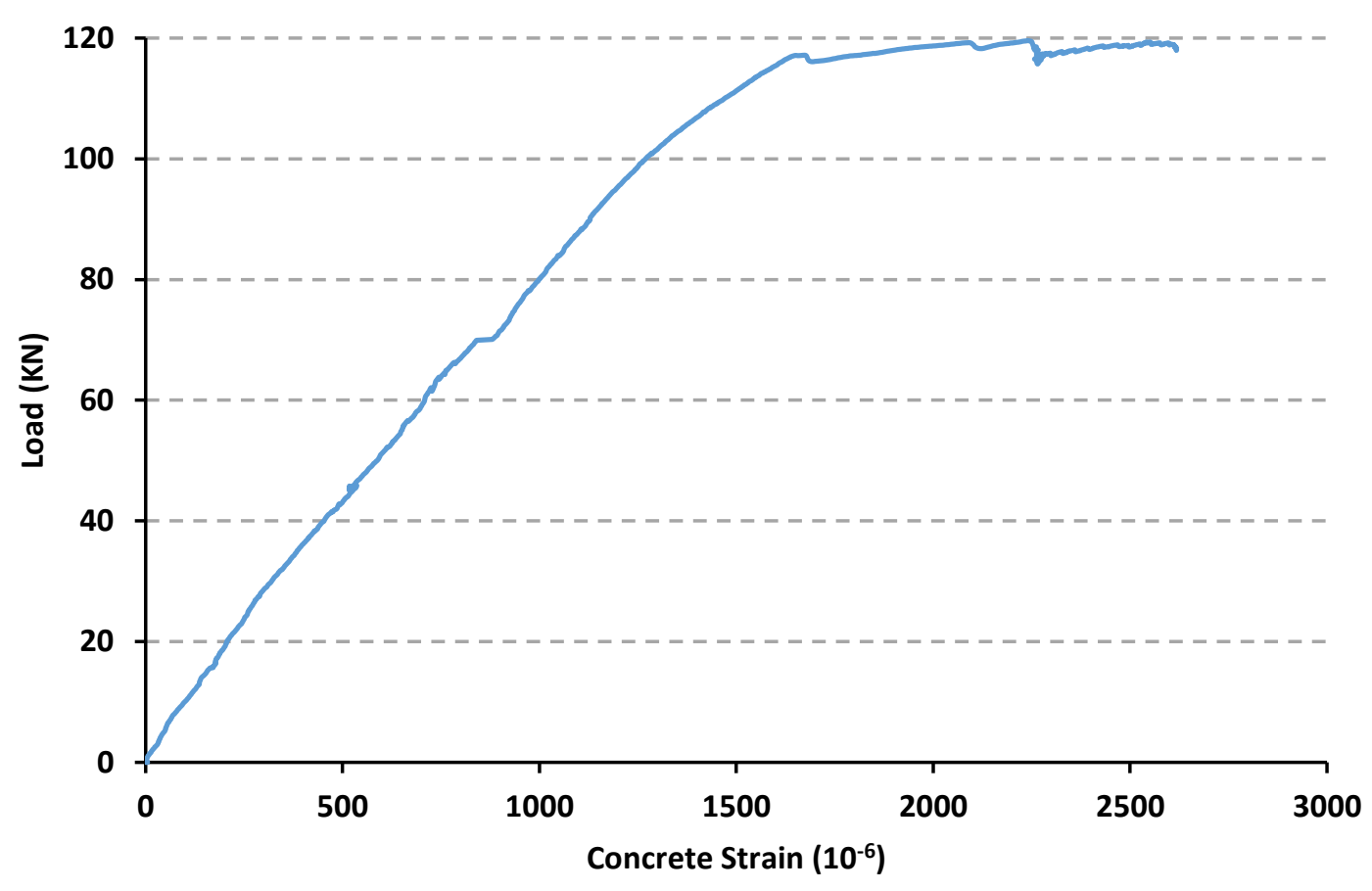

(b)

Figure 4.32 Test Results for Beam A9. a) Load vs. Deflection, b) Load vs. Concrete Strain 


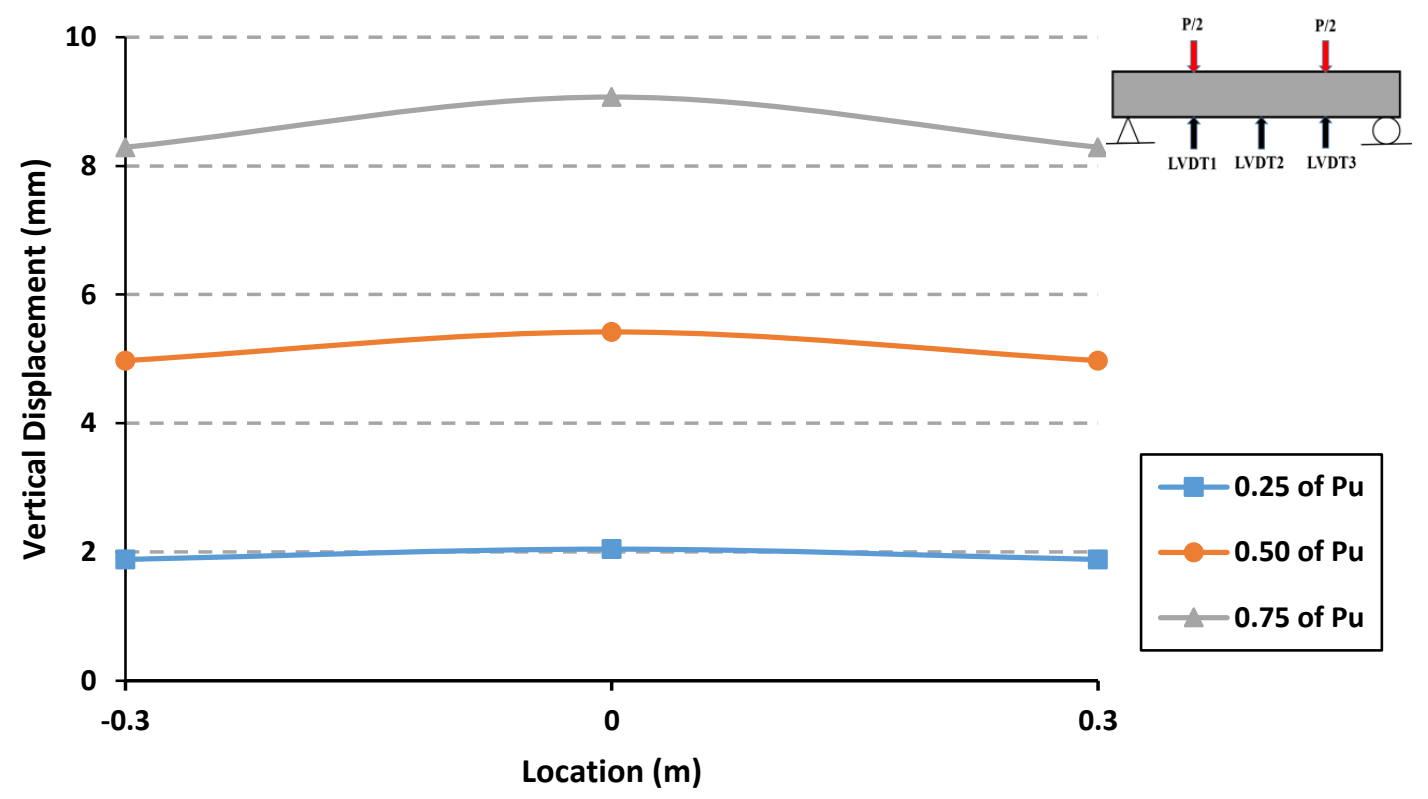

Figure 4.33 Deformed Shapes at Different Load Levels at the Bottom Surface

\subsubsection{Specimen A10 (25\% RCA+1.0\% BMF)}

Beam specimen A10 has $75 \%$ of NCA with $25 \%$ of RCA and added $1 \%$ of BMF. The specimen was tested in flexure. After applying the static load gradually, the first crack was observed within the constant moment region of beam specimen at the middle of the beam at a load of $30 \mathrm{kN}$. As the load was increased, additional flexural cracks spread consistently along the beam where the cracks moved further upward, with a visible increase in the deflection. The majority of the flexural cracks developed vertically and after that inclined flexural-shear cracks began to appear. Upon further increasing the applied load, the longitudinal steel yielded, and finally concrete crushed in compression zone and beam failed as it can be seen from Figure 4.34.

Figure 4.35-a show the load-deflection relationships measured at the bottom surface at different locations of the specimen (refer to Figure 3.21 for measurement sensors locations). The load-deflection responses at mid-span presented in Figure 4.35-a show a linear elastic behavior before the initiation of the first flexural cracks (point A). When the load was increased beyond the cracking moment, the almost straight line slope was slightly 
declined because of the crack in the concrete in the tension zone. Then, the longitudinal steel reinforcement reached the yield point (point B) as shown in Figure 4.35-a. The recorded yielding load is $103.1 \mathrm{kN}$ (Yielding moment is $43.82 \mathrm{kN}$.m). Finally, concrete crushed in the in compression zone with ultimate load of $105.75 \mathrm{kN}$, and maximum midspan deflection of $45 \mathrm{~mm}$.

Figure 4.35-b shows the load-concrete compressive strain relationship measured at top surface at mid-span of the specimen, the recorded maximum compressive strain was 0.00374 .

A deformed shape of the bottom surface of the specimen is shown in Figure 4.36. In this Figure, the vertical axis represents the vertical downward deflection; therefore, the actual deformed shapes should be up-side-down. It can be observed in Figure 4.36 that the deflection was largest at the mid-span of the beam.

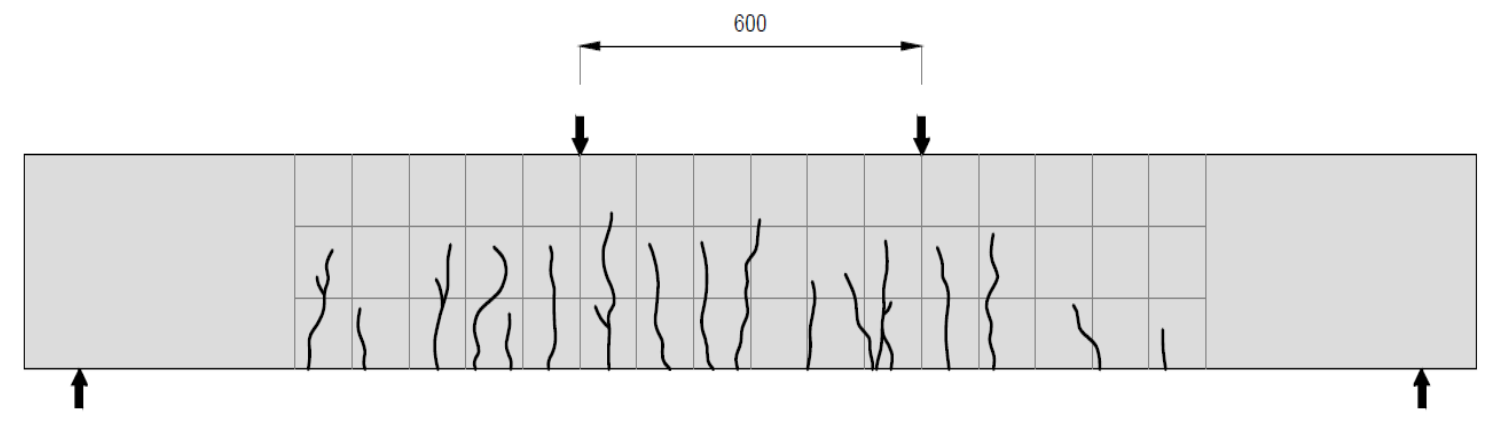

Figure 4.34 Cracking Pattern of Beam A10 


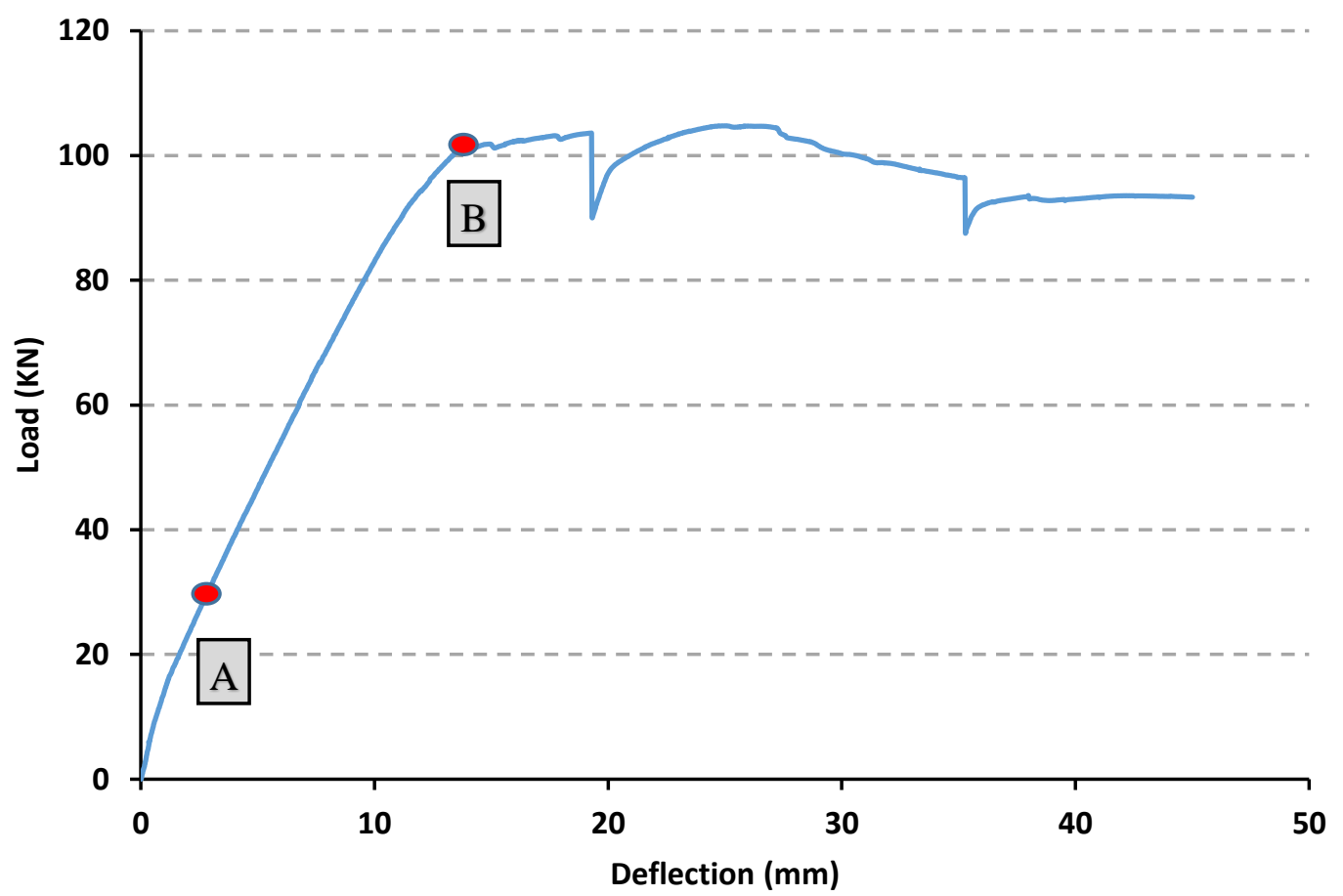

(a)

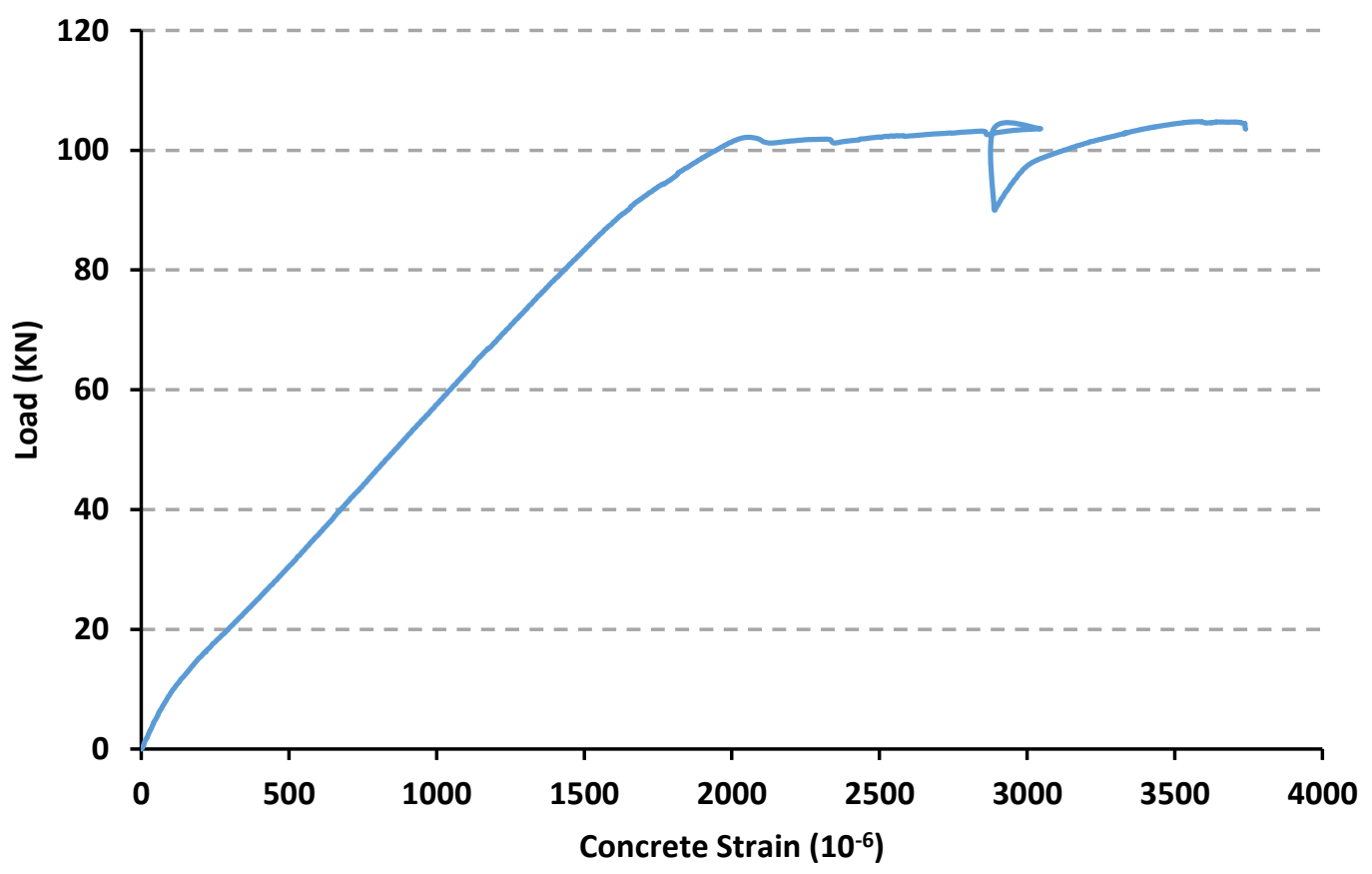

(b)

Figure 4.35 Test Results for Beam A10. a) Load vs. Deflection, b) Load vs. Concrete Strain 


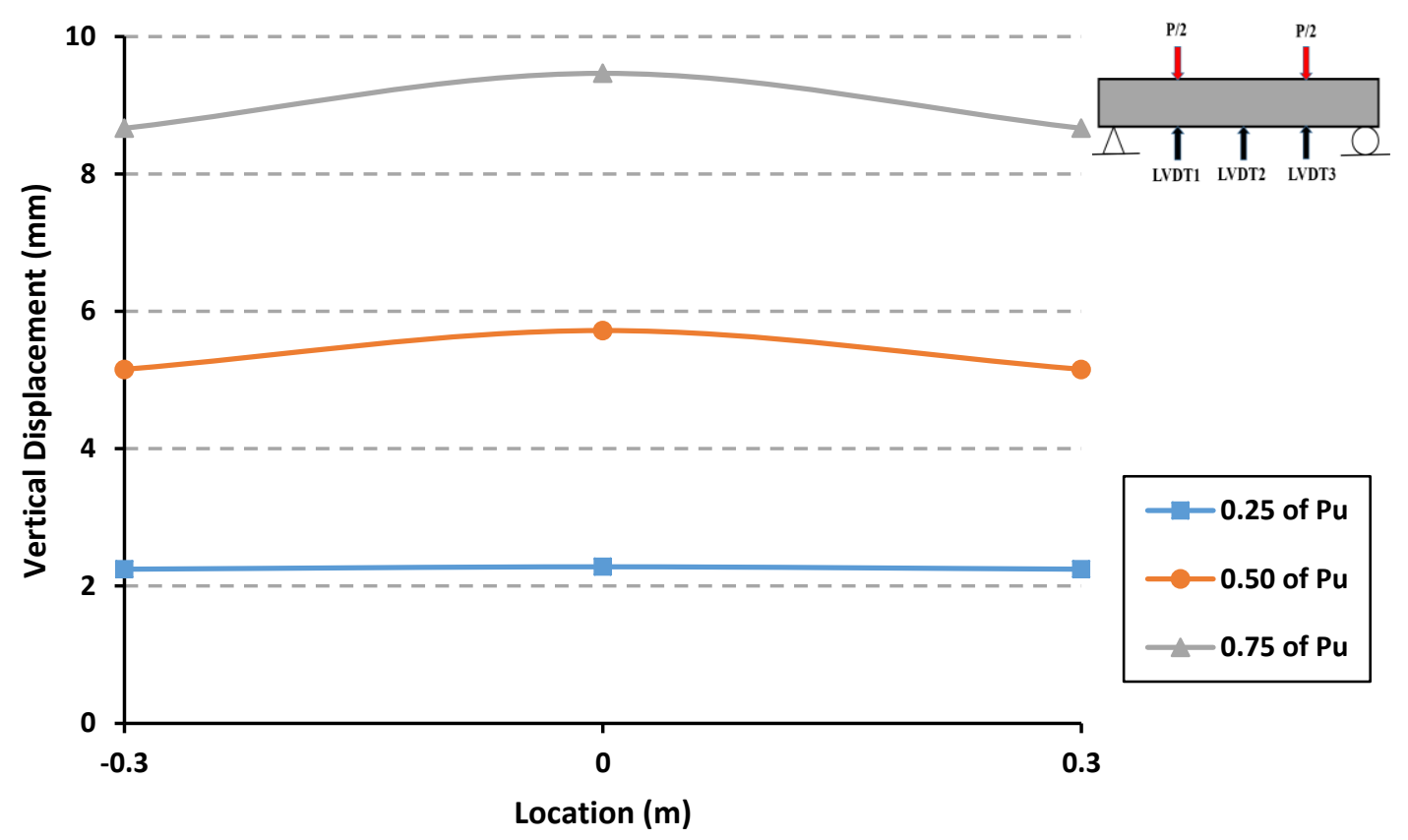

Figure 4.36 Deformed Shapes at Different Load Levels at the Bottom Surface

\subsubsection{Specimen A11 (50\% RCA+1.0\% BMF)}

Beam specimen A11 has 50\% of NCA with 50\% of RCA and added 1\% of BMF. The specimen was tested in flexure. After applying the static load gradually, the first crack was observed within the constant moment region of beam specimen at the middle of the beam at a load of $28 \mathrm{kN}$. As the load was increased, additional flexural cracks spread consistently along the beam where the cracks moved further upward, with a visible increase in the deflection. The majority of the flexural cracks developed vertically and after that inclined flexural-shear cracks began to appear. Upon further increasing the applied load, the longitudinal steel yielded, and finally concrete crushed in compression zone and beam failed as it can be seen from Figure 4.37.

Figure 4.38-a show the load-deflection relationships measured at the bottom surface at different locations of the specimen (refer to Figure 3.21 for measurement sensors locations). The load-deflection responses at mid-span presented in Figure 4.38-a show a linear elastic behavior before the initiation of the first flexural cracks (point A). When the load was increased beyond the cracking moment, the almost straight line slope was slightly 
declined because of the crack in the concrete in the tension zone. Then, the longitudinal steel reinforcement reached the yield point (point B) as shown in Figure 4.38-a. The recorded yielding load is $103.6 \mathrm{kN}$ (Yielding moment is $44.03 \mathrm{kN}$.m). Finally, concrete crushed in the in compression zone with ultimate load of $106.85 \mathrm{kN}$, and maximum midspan deflection of $46 \mathrm{~mm}$.

Figure 4.38-b shows the load-concrete compressive strain relationship measured at top surface at mid-span of the specimen, the recorded maximum compressive strain was0.00307.

A deformed shape of the bottom surface of the specimen is shown in Figure 4.39. In this Figure, the vertical axis represents the vertical downward deflection; therefore, the actual deformed shapes should be up-side-down. It can be observed in Figure 4.39 that the largest deflection was observed at the mid-span of the beam.

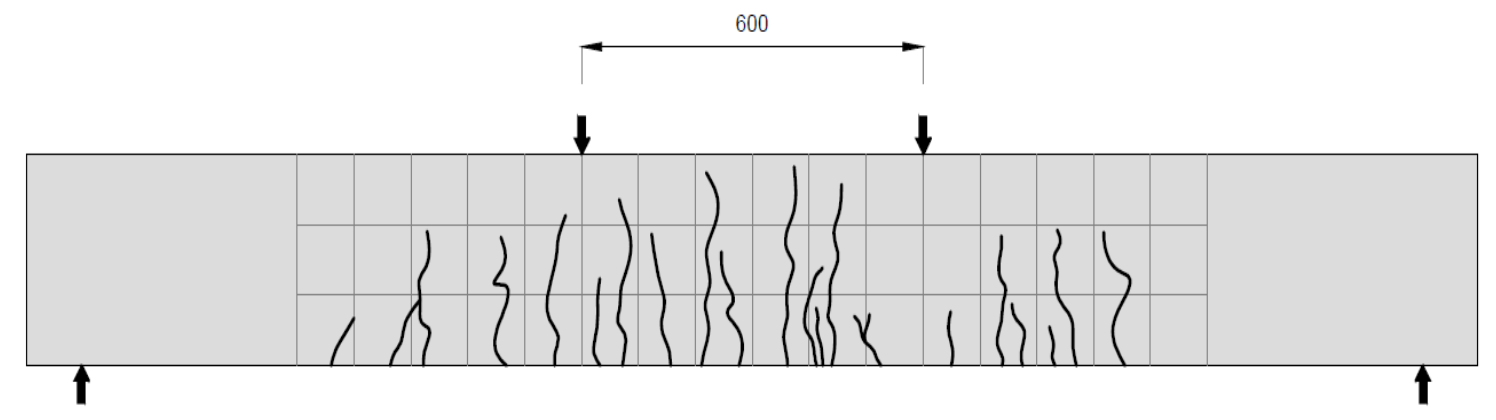

Figure 4.37 Cracking Pattern of Beam A11 


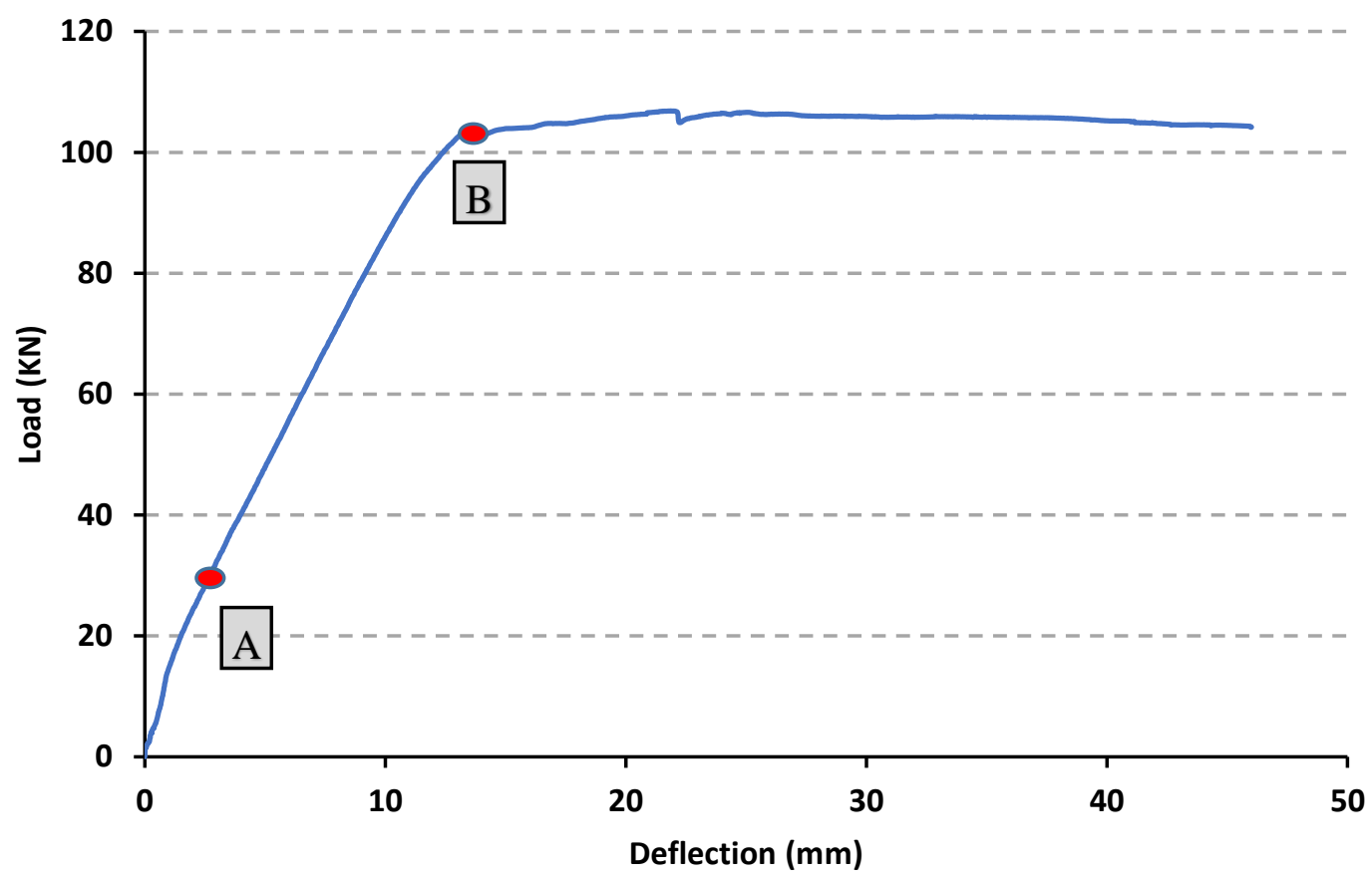

(a)

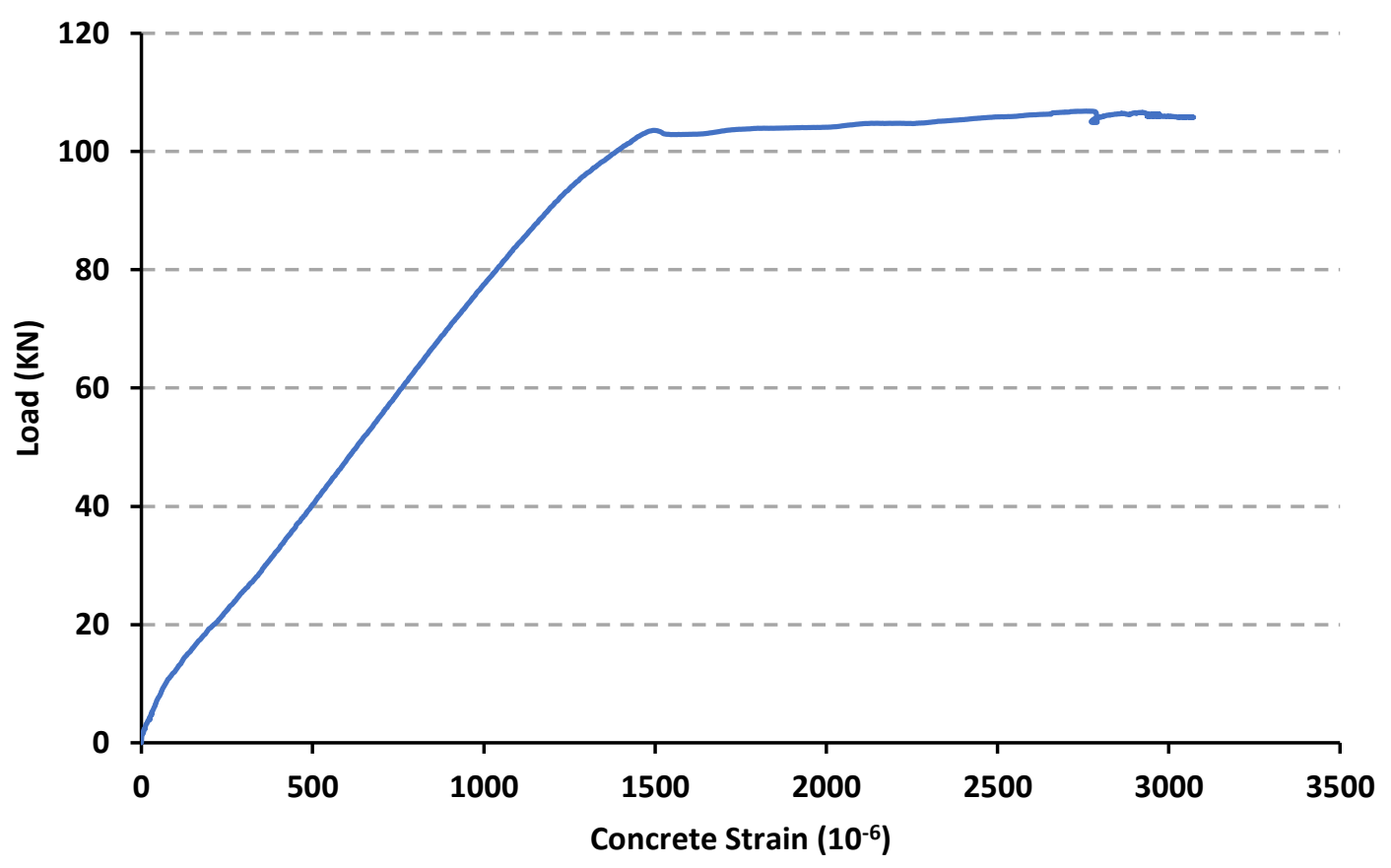

(b)

Figure 4.38 Test Results for Beam A11. a) Load vs. Deflection, b) Load vs. Concrete Strain 


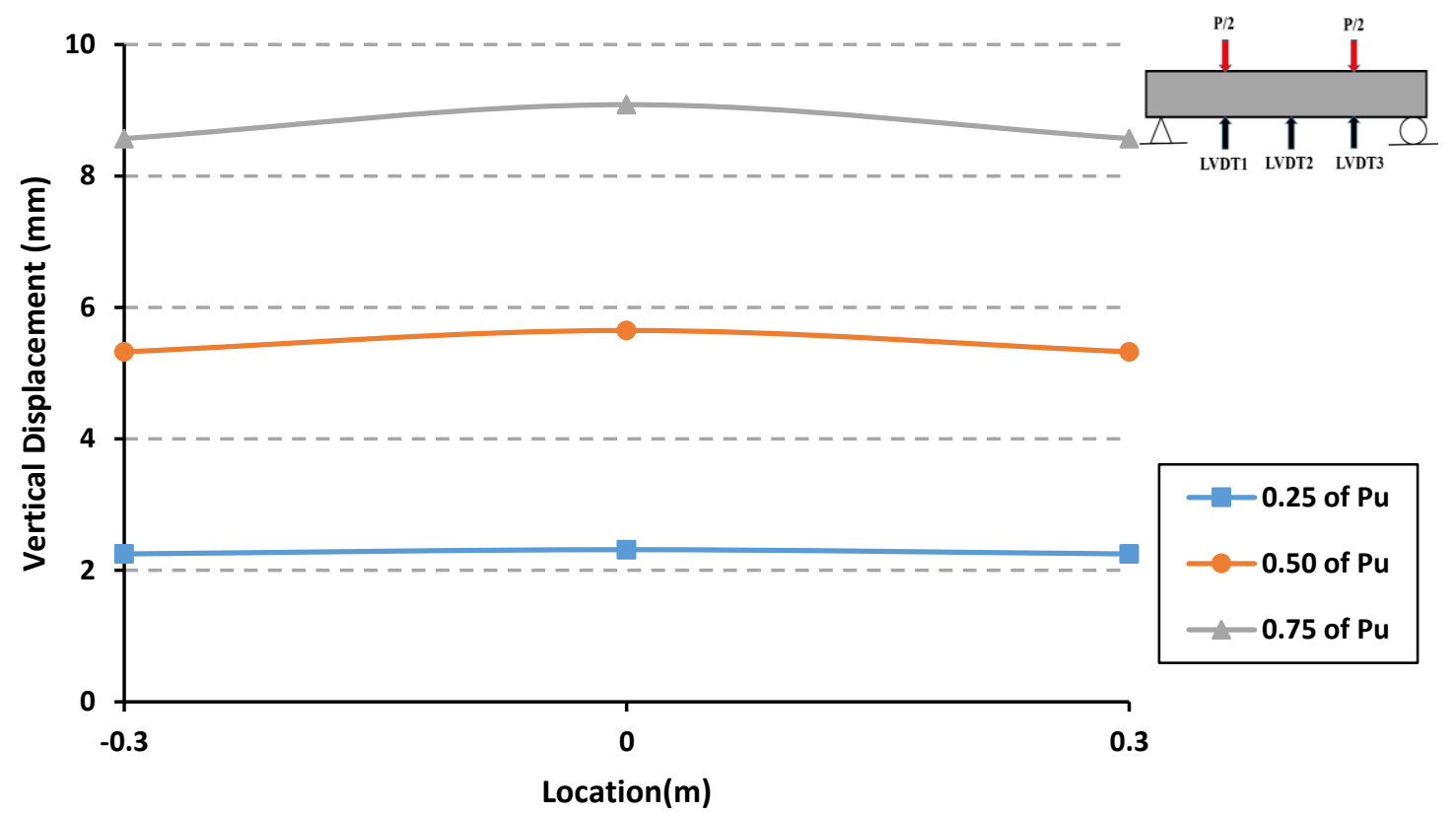

Figure 4.39 Deformed Shapes at Different Load Levels at the Bottom Surface

\subsubsection{Specimen A12 (100\% RCA+1.0\%BMF)}

Beam specimen A12 has $0 \%$ of NCA with $100 \%$ of RCA and added $1 \%$ of BMF. The specimen was tested in flexure. After applying the static load gradually, the first crack was observed within the constant moment region of beam specimen at the middle of the beam at a load of $31 \mathrm{kN}$. As the load was increased, additional flexural cracks spread consistently along the beam where the cracks moved further upward, with a visible increase in the deflection. The majority of the flexural cracks developed vertically and after that inclined flexural-shear cracks began to appear. Upon further increasing the applied load, the longitudinal steel yielded, and finally concrete crushed in compression zone and beam failed as it can be seen from Figure 4.40.

Figure 4.41-a show the load-deflection relationships measured at the bottom surface at different locations of the specimen (refer to Figure 3.21 for measurement sensors locations). The load-deflection responses at mid-span presented in Figure 4.41-a show a linear elastic behavior before the initiation of the first flexural cracks (point A). When the load was increased beyond the cracking moment, the almost straight line slope was slightly 
declined because of the crack in the concrete in the tension zone. Then, the longitudinal steel reinforcement reached the yield point (point B) as shown in Figure 4.41-a. The recorded yielding load is $105.4 \mathrm{kN}$ (Yielding moment is $44.8 \mathrm{kN} . \mathrm{m}$ ). Finally, concrete crushed in the in compression zone with ultimate load of $107.96 \mathrm{kN}$, and maximum midspan deflection of $46 \mathrm{~mm}$.

Figure 4.41-b shows the load-concrete compressive strain relationship measured at top surface at mid-span of the specimen, the recorded maximum compressive strain was 0.0035 .

A deformed shape of the bottom surface of the specimen is shown in Figure 4.42. In this Figure, the vertical axis represents the vertical downward deflection; therefore, the actual deformed shapes should be up-side-down. It can be observed in Figure 4.42 that the largest deflection was observed at the mid-span of the beam.

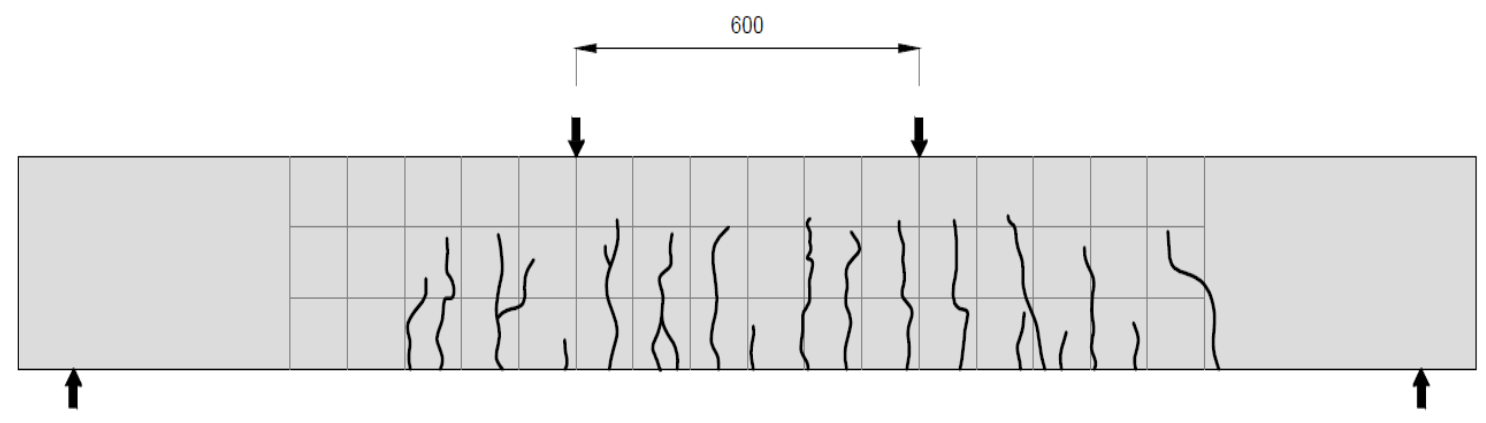

Figure 4.40 Cracking Pattern of Beam A12 


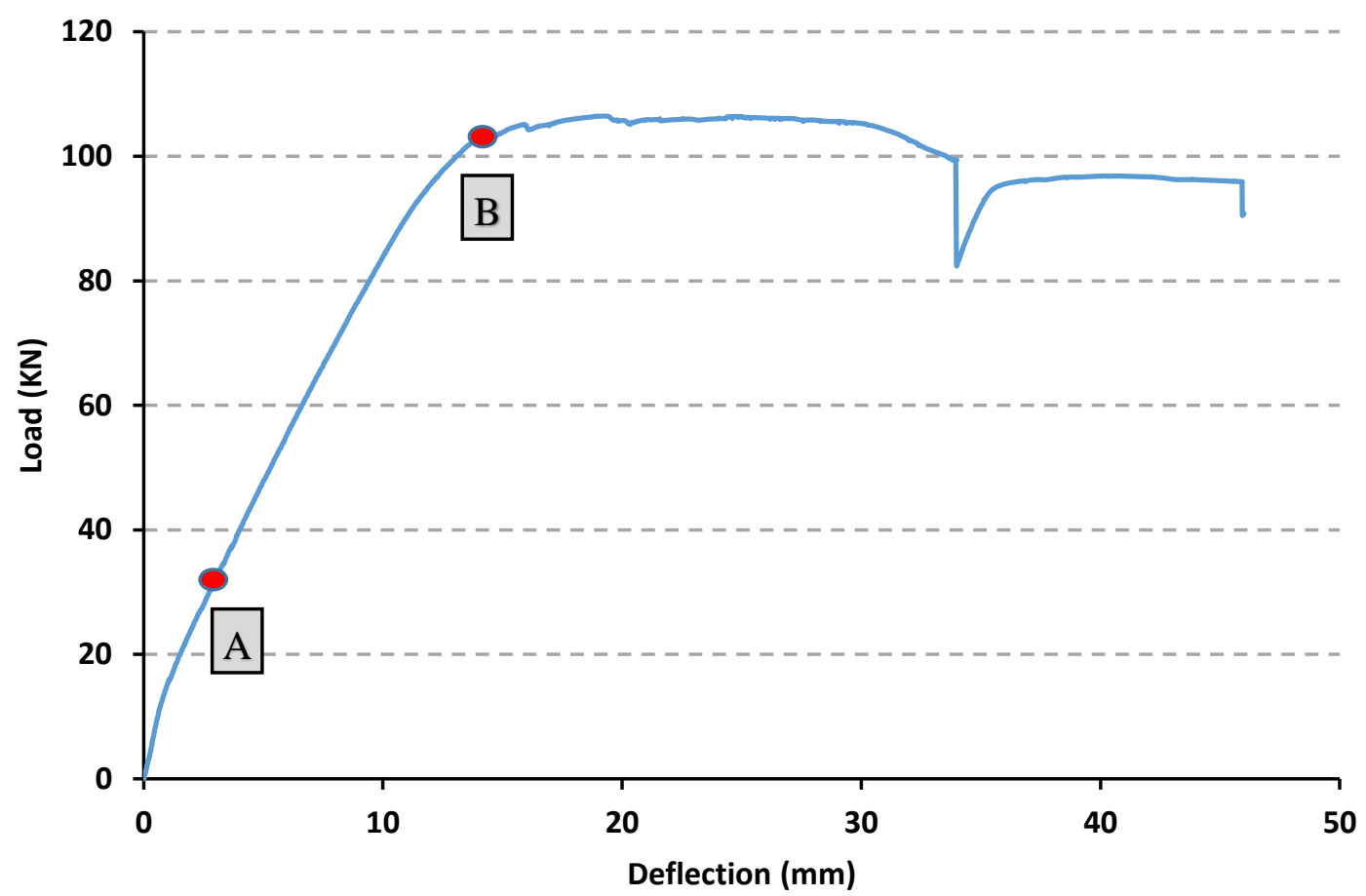

(a)

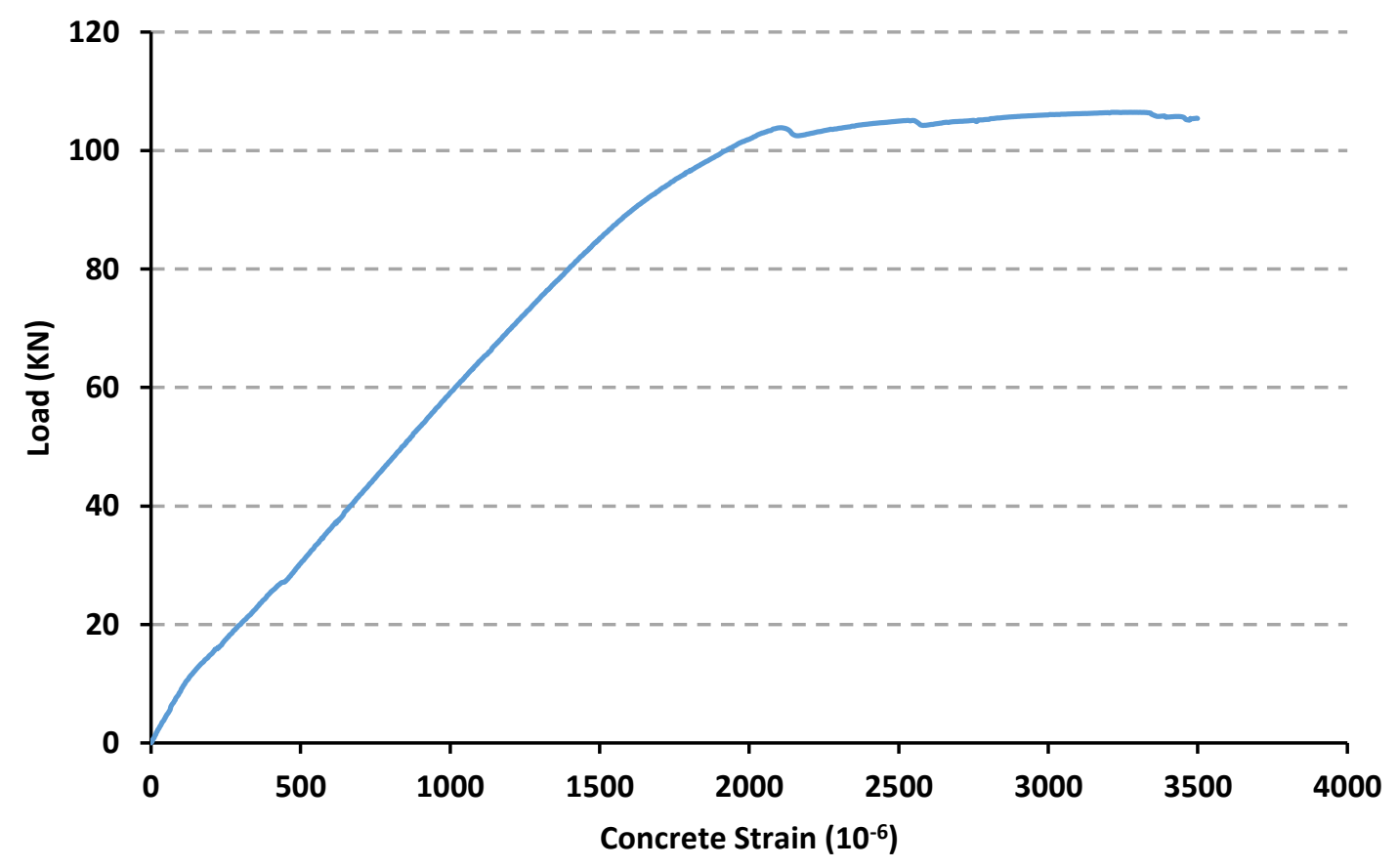

(b)

Figure 4.41 Test Results for Beam A12. a) Load vs. Deflection, b) Load vs. Concrete Strain 


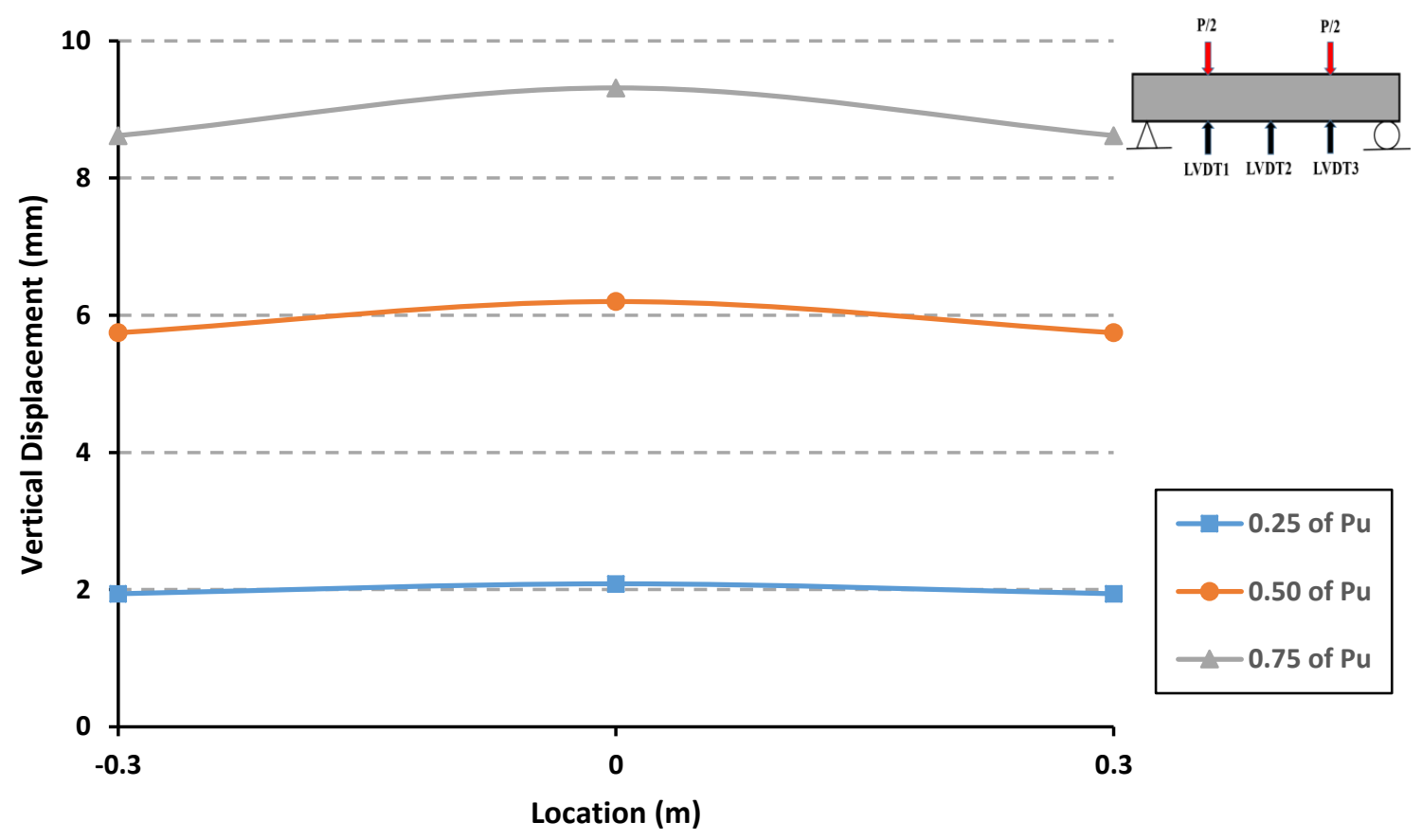

Figure 4.42 Deformed Shapes at Different Load Levels at the Bottom Surface

\subsubsection{Specimen A14 (25\% RCA+1.5\% BMF)}

Beam specimen A1 has $75 \%$ of NCA with $25 \%$ of RCA and added $1.5 \%$ of BMF. The specimen was tested in flexure. After applying the static load gradually, the first crack was observed within the constant moment region of beam specimen at the middle of the beam at a load of $31 \mathrm{kN}$. As the load was increased, additional flexural cracks spread consistently along the beam where the cracks moved further upward, with a visible increase in the deflection. The majority of the flexural cracks developed vertically and after that inclined flexural-shear cracks began to appear. Upon further increasing the applied load, the longitudinal steel yielded, and finally concrete crushed in compression zone and beam failed as it can be seen from Figure 4.46.

Figure 4.47-a show the load-deflection relationships measured at the bottom surface at different locations of the specimen (refer to Figure 3.21 for measurement sensors locations). The load-deflection responses at mid-span presented in Figure 4.47-a show a linear elastic behavior before the initiation of the first flexural cracks (point A). When the 
load was increased beyond the cracking moment, the almost straight line slope was slightly declined because of the crack in the concrete in the tension zone. Then, the longitudinal steel reinforcement reached the yield point (point B) as shown in Figure 4.47-a. The recorded yielding load is $112.9 \mathrm{kN}$ (Yielding moment is $47.99 \mathrm{kN} . \mathrm{m}$ ). Finally, concrete crushed in the in compression zone with ultimate load of $113.14 \mathrm{kN}$, and maximum midspan deflection of $49 \mathrm{~mm}$.

Figure 4.47-b shows the load-concrete compressive strain relationship measured at top surface at mid-span of the specimen, the recorded maximum compressive strain was 0.00217 .

A deformed shape of the bottom surface of the specimen is shown in Figure 4.48. In this Figure, the vertical axis represents the vertical downward deflection; therefore, the actual deformed shapes should be up-side-down. It can be observed in Figure 4.48 that the largest deflection was observed at the mid-span of the beam.

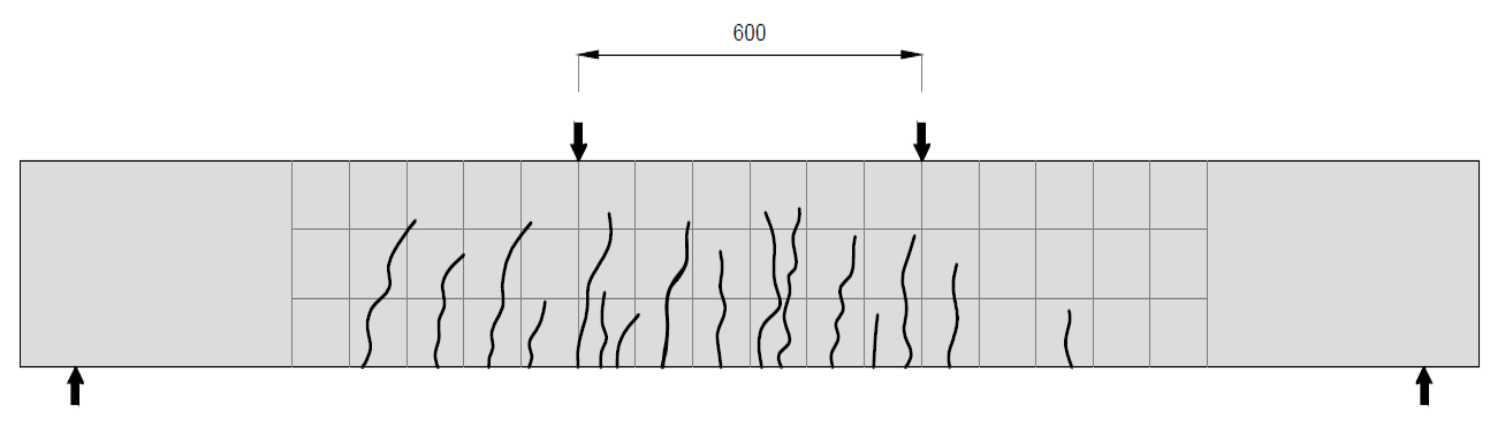

Figure 4.43 Cracking Pattern of Beam A14 


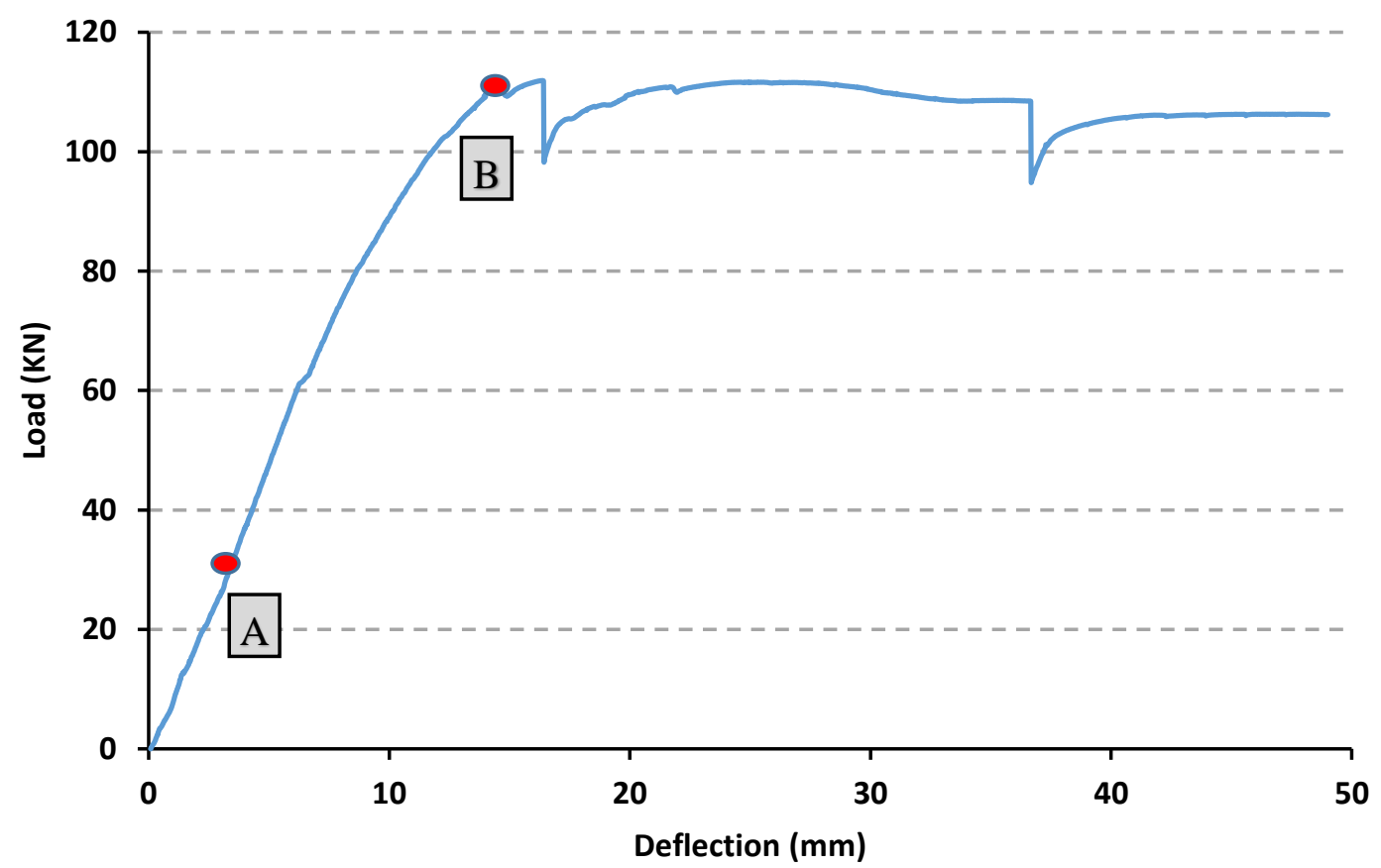

(a)

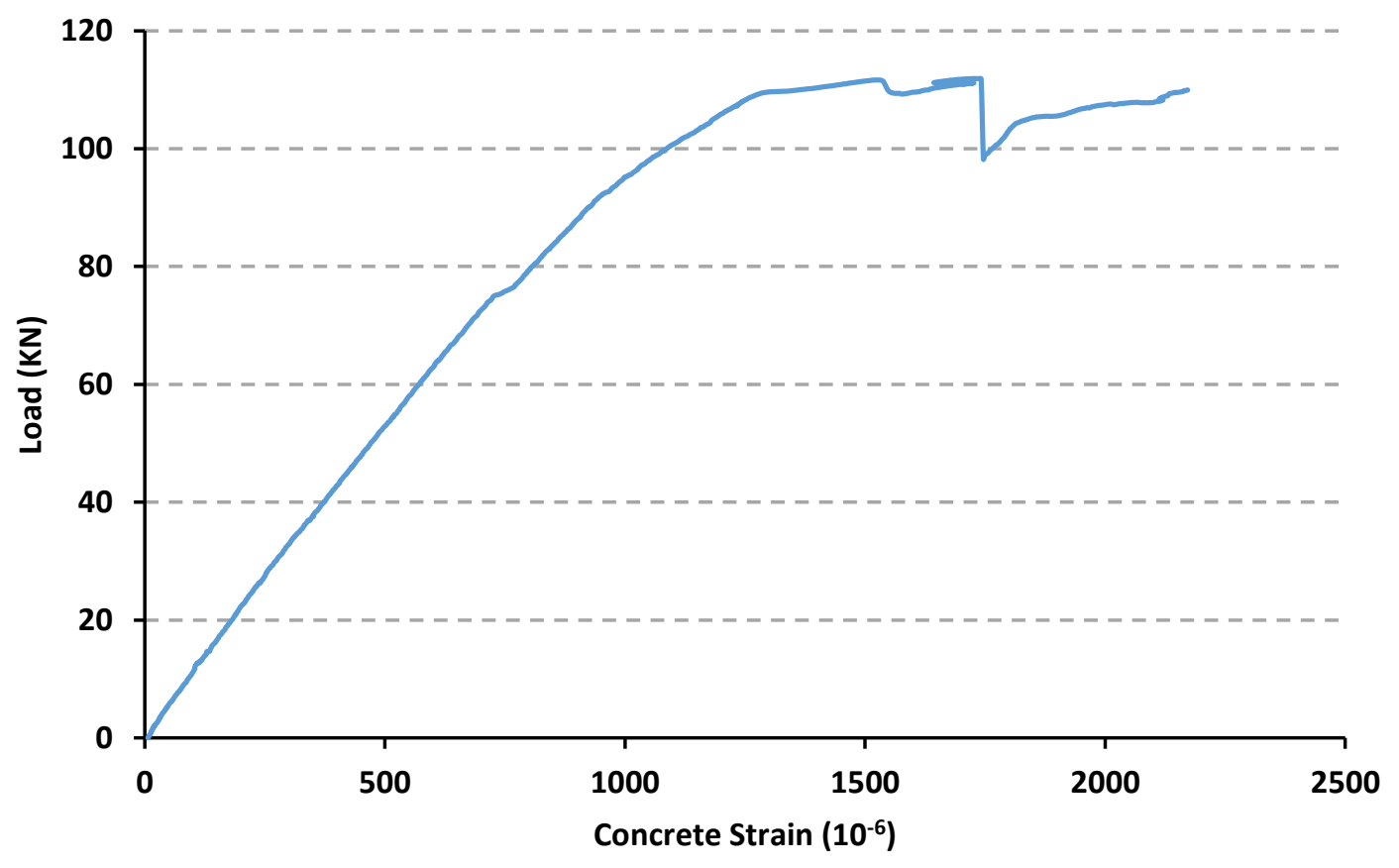

(b)

Figure 4.44 Test Results for Beam A14. a) Load vs. Deflection, b) Load vs. Concrete Strain 


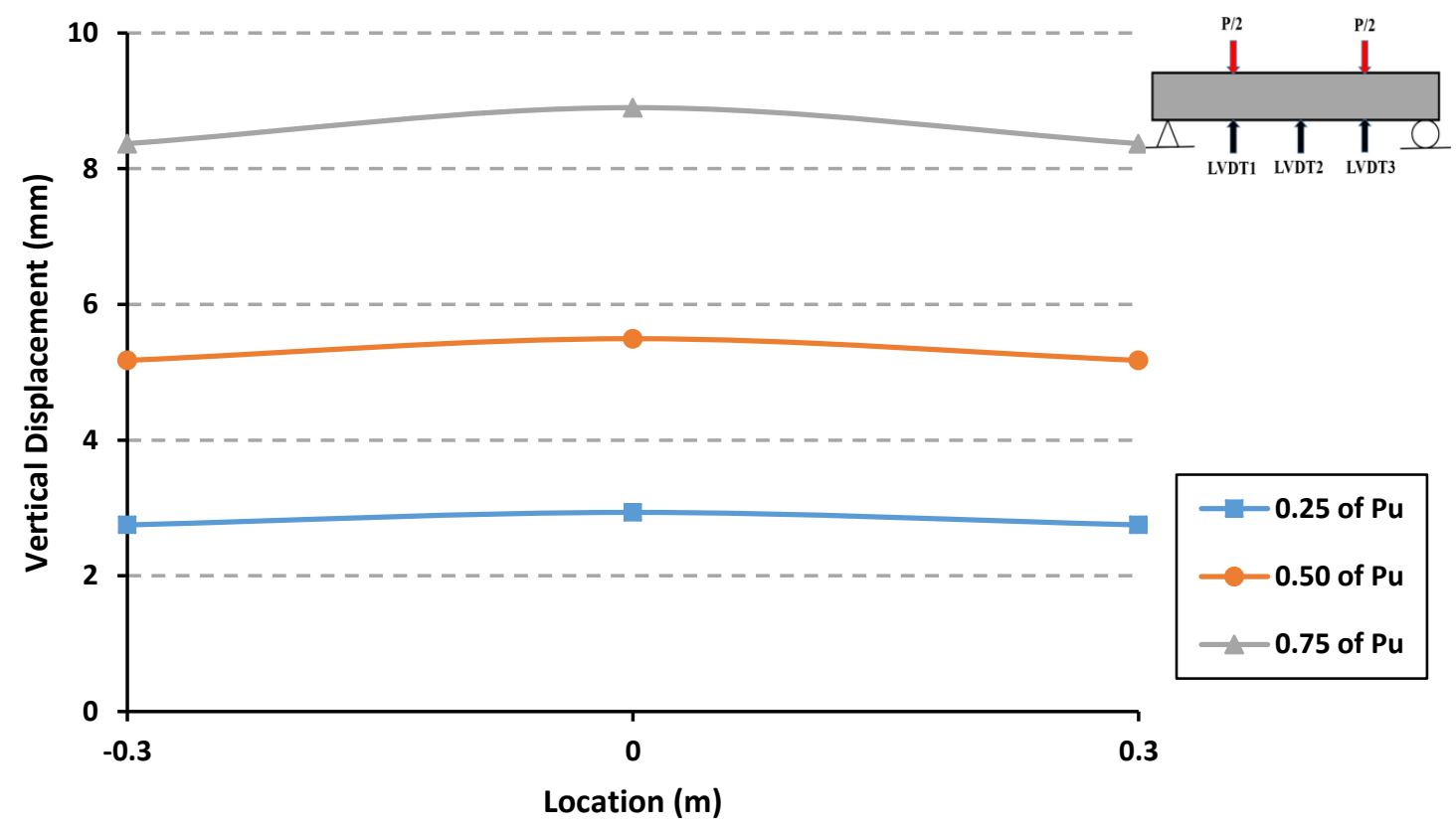

Figure 4.45 Deformed Shapes at Different Load Levels at the Bottom Surface

\subsubsection{Specimen A15 (50\% RCA+1.5\% BMF)}

Beam specimen A15 has 50\% of NCA with 50\% of RCA and added $1.5 \%$ of BMF. The specimen was tested in flexure. After applying the static load gradually, the first crack was observed within the constant moment region of beam specimen at the middle of the beam at a load of $33 \mathrm{kN}$. As the load was increased, additional flexural cracks spread consistently along the beam where the cracks moved further upward, with a visible increase in the deflection. The majority of the flexural cracks developed vertically and after that inclined flexural-shear cracks began to appear. Upon further increasing the applied load, the longitudinal steel yielded, and finally concrete crushed in compression zone and beam failed as it can be seen from Figure 4.49.

Figure 4.50-a show the load-deflection relationships measured at the bottom surface at different locations of the specimen (refer to Figure 3.21 for measurement sensors locations). The load-deflection responses at mid-span presented in Figure 4.50-a show a linear elastic behavior before the initiation of the first flexural cracks (point A). When the load was increased beyond the cracking moment, the almost straight line slope was slightly 
declined because of the crack in the concrete in the tension zone. Then, the longitudinal steel reinforcement reached the yield point (point B) as shown in Figure 4.50-a. The recorded yielding load is $108.2 \mathrm{kN}$ (Yielding moment is $45.99 \mathrm{kN}$.m). Finally, concrete crushed in the in compression zone with ultimate load of $109.13 \mathrm{kN}$, and maximum midspan deflection of $50 \mathrm{~mm}$.

Figure 4.50-b shows the load-concrete compressive strain relationship measured at top surface at mid-span of the specimen, the recorded maximum compressive strain was 0.00374 .

A deformed shape of the bottom surface of the specimen is shown in Figure 4.51. In this Figure, the vertical axis represents the vertical downward deflection; therefore, the actual deformed shapes should be up-side-down. It can be observed in Figure 4.51 that the largest deflection was observed at the mid-span of the beam.

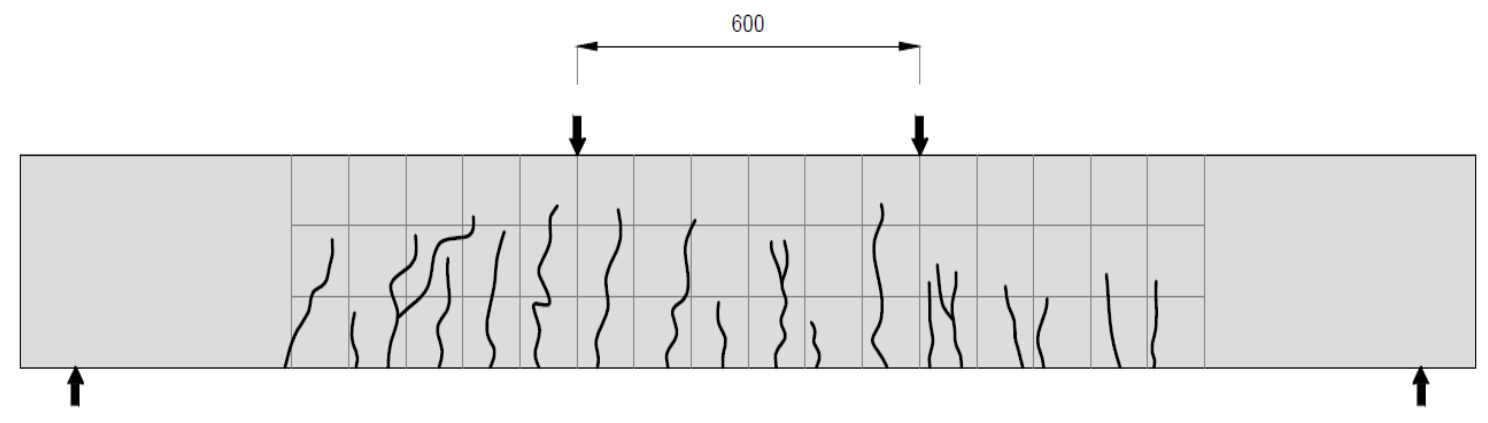

Figure 4.46 Cracking Pattern of Beam A15 


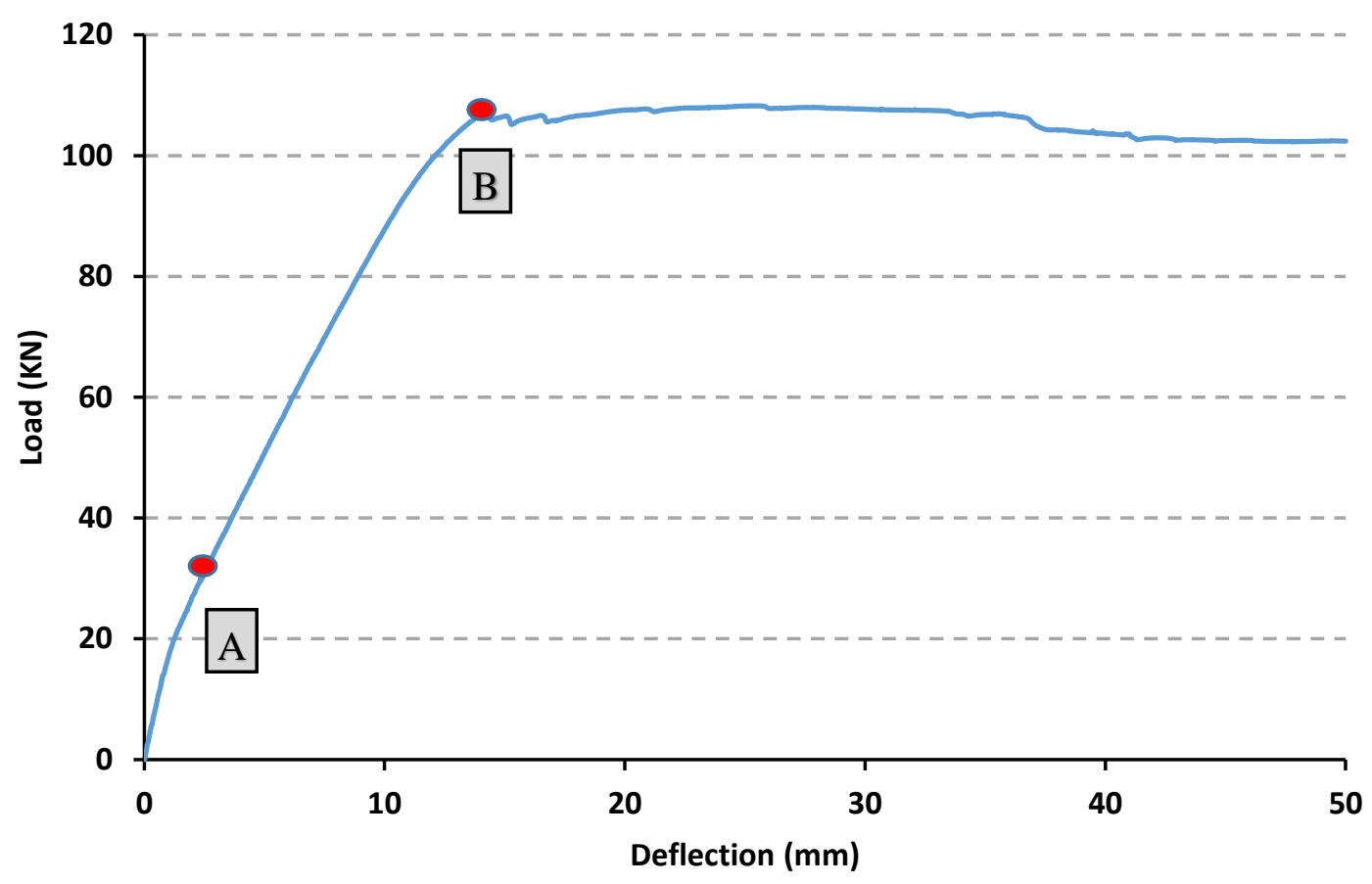

(a)

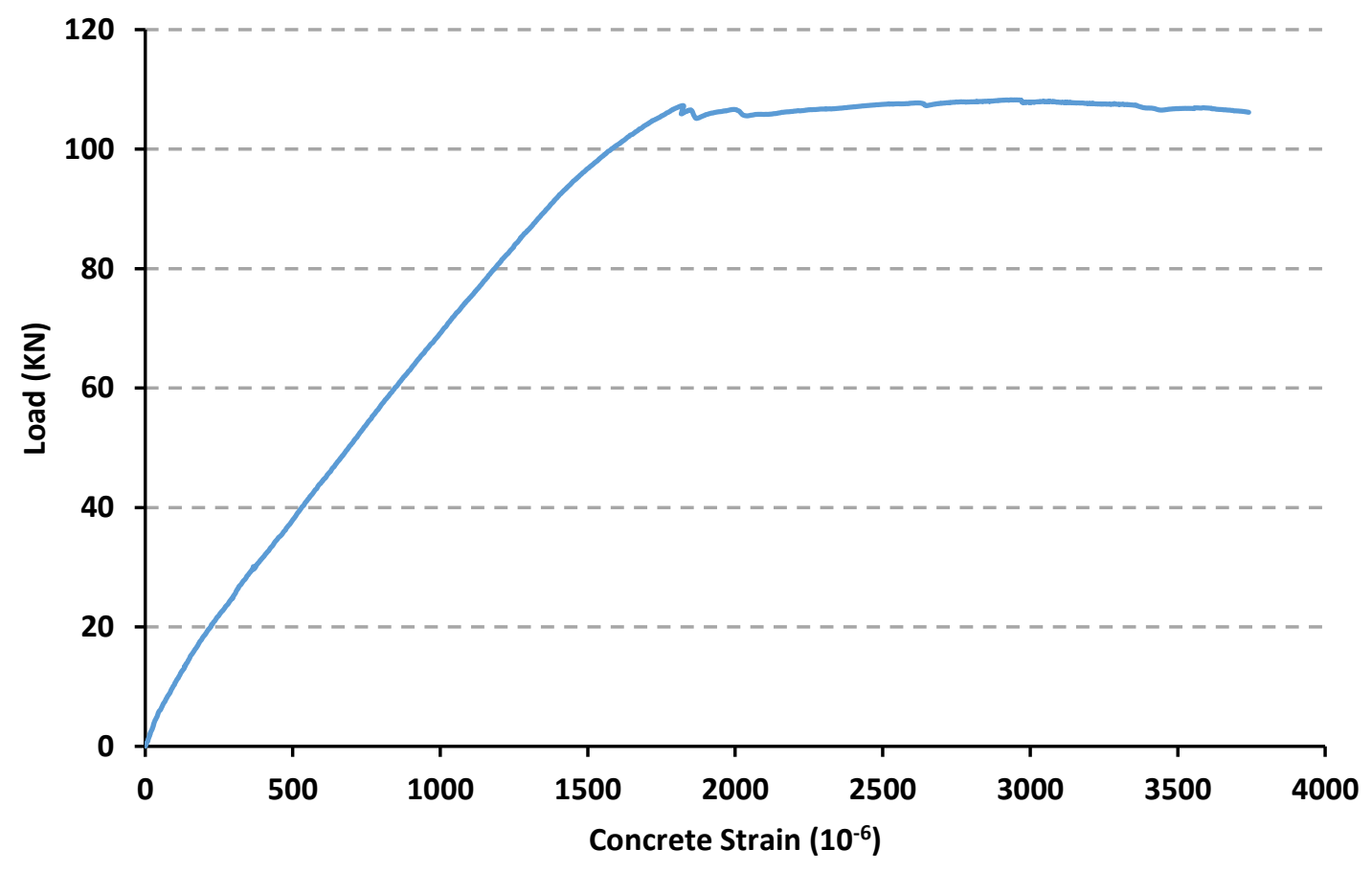

(b)

Figure 4.47 Test Results for Beam A15. a) Load vs. Deflection, b) Load vs. Concrete Strain 


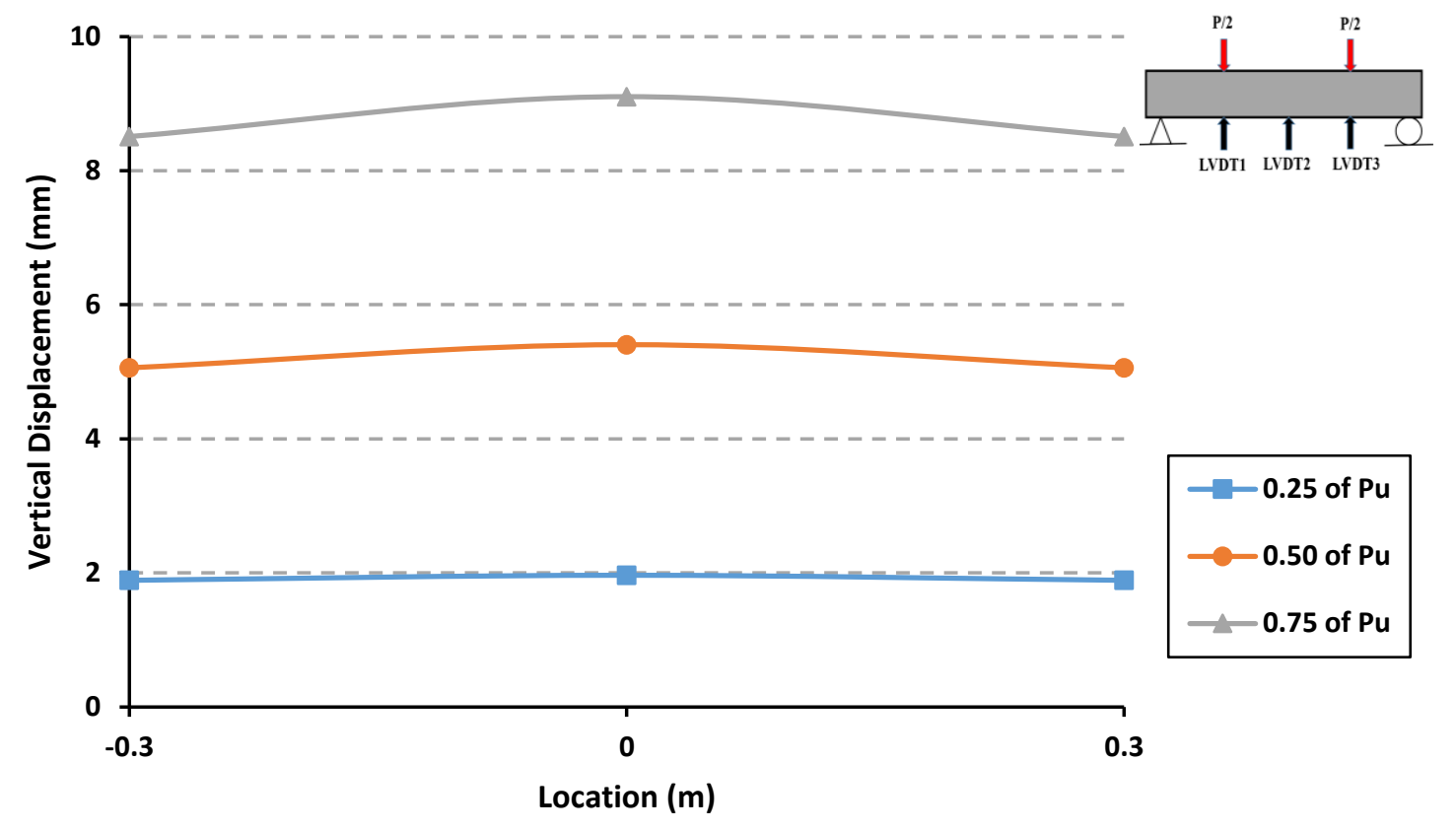

Figure 4.48 Deformed Shapes at Different Load Levels at the Bottom Surface

\subsubsection{Specimen A16 (100\% RCA+1.5\% BMF)}

Beam specimen A16 has $0 \%$ of NCA with $100 \%$ of RCA and added $1.5 \%$ of BMF. The specimen was tested in flexure. After applying the static load gradually, the first crack was observed within the constant moment region of beam specimen at the middle of the beam at a load of $25 \mathrm{kN}$. As the load was increased, additional flexural cracks spread consistently along the beam where the cracks moved further upward, with a visible increase in the deflection. The majority of the flexural cracks developed vertically and after that inclined flexural-shear cracks began to appear. Upon further increasing the applied load, the longitudinal steel yielded, and finally concrete crushed in compression zone and beam failed as it can be seen from Figure 4.52.

Figure 4.53-a show the load-deflection relationships measured at the bottom surface at different locations of the specimen (refer to Figure 3.21 for measurement sensors locations). The load-deflection responses at mid-span presented in Figure 4.53-a show a linear elastic behavior before the initiation of the first flexural cracks (point A). When the load was increased beyond the cracking moment, the almost straight line slope was slightly 
declined because of the crack in the concrete in the tension zone. Then, the longitudinal steel reinforcement reached the yield point (point B) as shown in Figure 4.53-a. The recorded yielding load is $114 \mathrm{kN}$ (Yielding moment is $48.3 \mathrm{kN}$.m). Finally, concrete crushed in the in compression zone with ultimate load of $116.05 \mathrm{kN}$, and maximum mid-span deflection of $54 \mathrm{~mm}$.

Figure 4.53-b shows the load-concrete compressive strain relationship measured at top surface at mid-span of the specimen, the recorded maximum compressive strain was 0.00372 .

A deformed shape of the bottom surface of the specimen is shown in Figure 4.54. In this Figure, the vertical axis represents the vertical downward deflection; therefore, the actual deformed shapes should be up-side-down. It can be observed in Figure 4.54 that the largest deflection was observed at the mid-span of the beam.

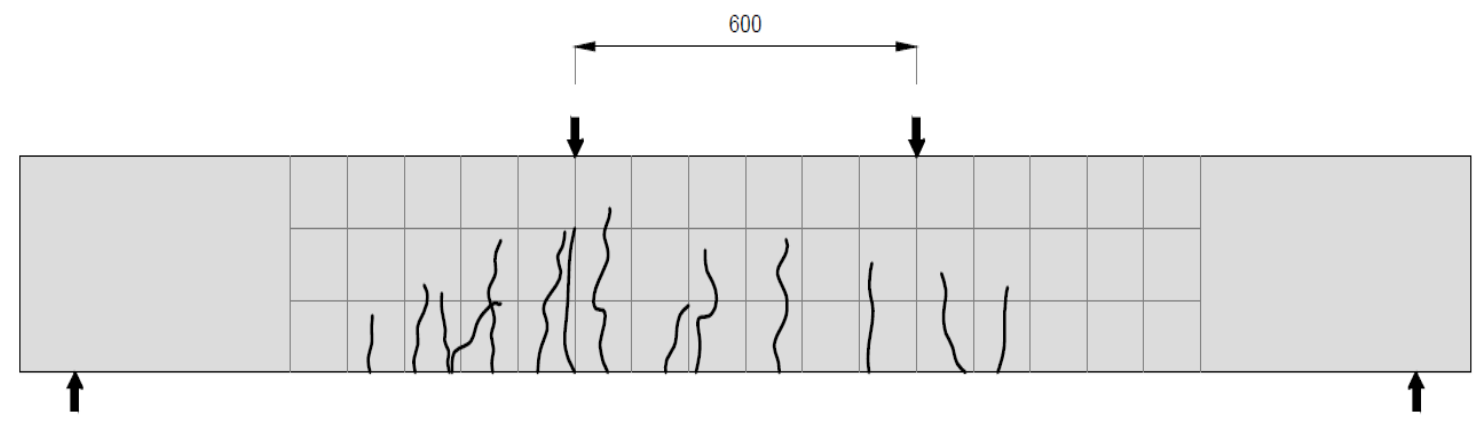

Figure 4.49 Cracking Pattern of Beam A16 


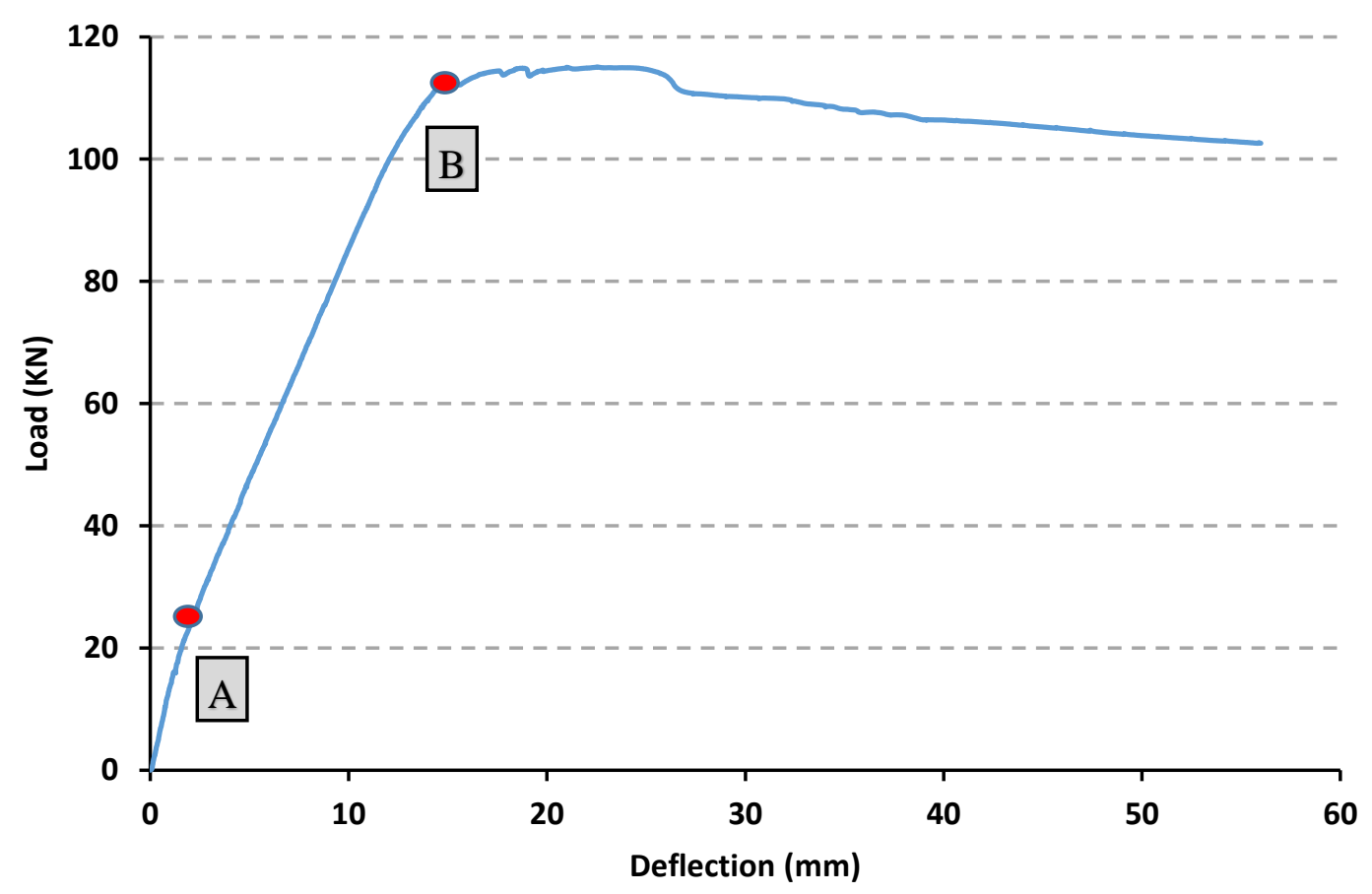

(a)

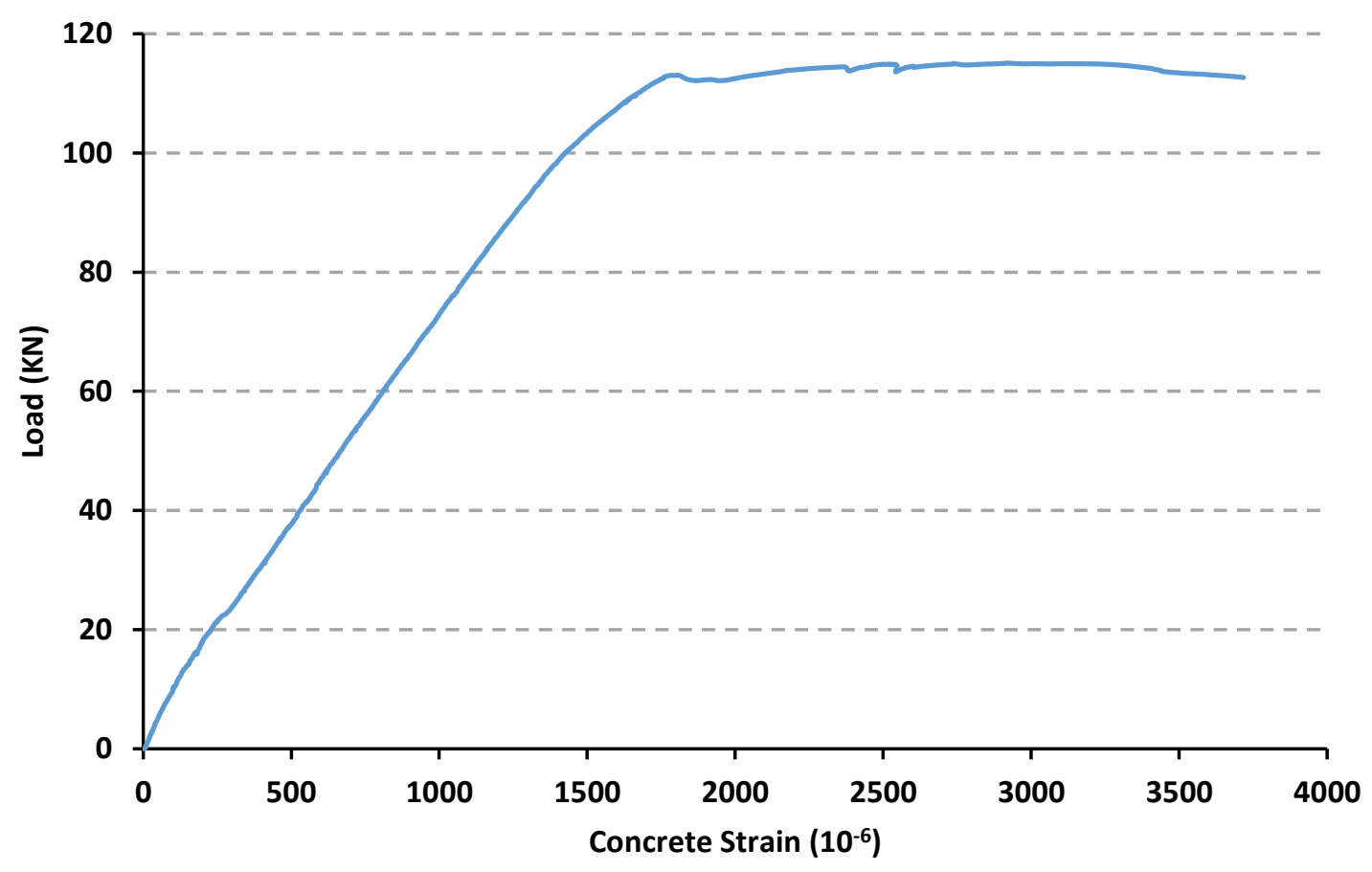

(b)

Figure 4.50 Test Results for Beam A16. a) Load vs. Deflection, b) Load vs. Concrete Strain 


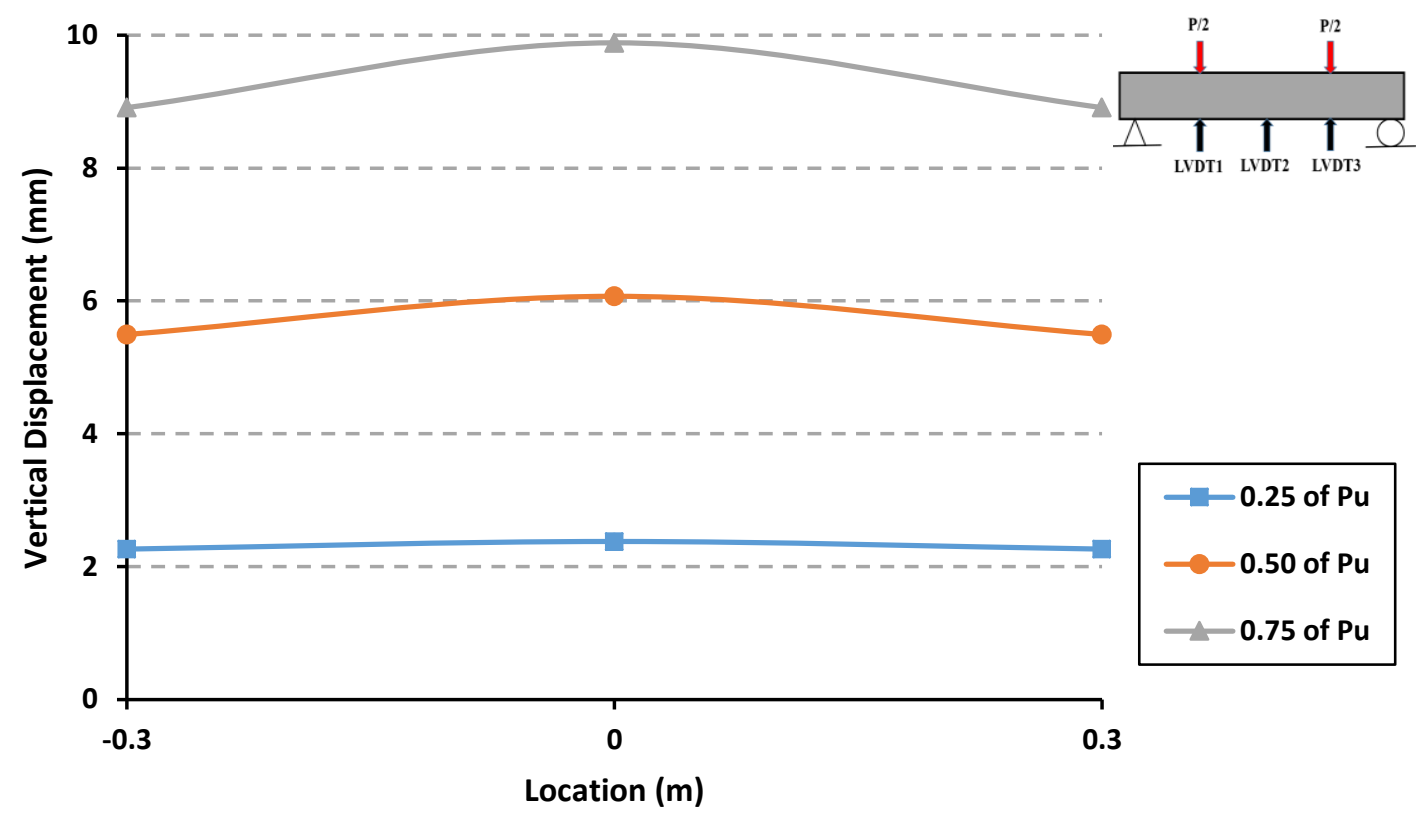

Figure 4.51 Deformed Shapes at Different Load Levels at the Bottom Surface

\subsection{DISCUSSION OF TEST RESULTS}

The main objective of the experimental part of this study is to reach for experimentallydriven conclusive remarks about the effect of following two parameters on the flexural behavior of RC beams: i.) Aggregate replacement ratio of the RCA and ii.) Volume fraction of the BMF. A detailed discussion about the effect of the above mentioned parameters is shown below. The observed service and ultimate loading capacities and the deformational characteristics in terms of the deflection and strain at mid-span between the different beams were used in the comparison. The cracking, yielding, and ultimate loads and moments, maximum mid-span deflection and ductility index (DI) for each beam are reported in Table 4.3. DI is defined as the ratio between the deflection at the ultimate load and that at yield load. 
Table 4.3 Summary of Tests Results

\begin{tabular}{ccccccccccc}
\hline Beam & RCA & BMF & $\boldsymbol{P c}$ & $\boldsymbol{P y}$ & $\boldsymbol{P u}$ & $\boldsymbol{M c}$ & $\boldsymbol{M y}$ & $\boldsymbol{M u}$ & $\Delta \mathbf{m a x}$ & $\boldsymbol{D I}$ \\
ID & $\boldsymbol{\%}$ & $\boldsymbol{\%}$ & $(\mathbf{K N})$ & $(\mathbf{K N})$ & $(\mathbf{K N})$ & $(\mathbf{K N . M})$ & $(\mathbf{K N . M})$ & $(\mathbf{K N . M})$ & $(\mathbf{m m})$ & \\
A1 & 0 & 0 & 25 & 110.2 & 113.05 & 10.63 & 46.84 & 48.05 & 35 & 2.57 \\
A2 & 25 & 0 & 21 & 100.17 & 103.08 & 8.93 & 42.57 & 43.81 & 32 & 2.52 \\
A3 & 50 & 0 & 19 & 99.31 & 105.19 & 8.08 & 42.21 & 44.71 & 31 & 2.46 \\
A4 & 100 & 0 & 18 & 104.6 & 107.58 & 7.65 & 44.46 & 45.72 & 30 & 2.17 \\
A5 & 0 & 0.5 & 27 & 113.7 & 115.08 & 11.48 & 48.33 & 48.91 & 42 & 2.73 \\
A6 & 25 & 0.5 & 24 & 116.75 & 117.77 & 10.20 & 49.62 & 50.05 & 39 & 2.67 \\
A7 & 50 & 0.5 & 22 & 107.12 & 108.63 & 9.35 & 45.53 & 46.17 & 36 & 2.71 \\
A8 & 100 & 0.5 & 21 & 108.04 & 108.52 & 8.93 & 45.92 & 46.12 & 34 & 2.46 \\
A9 & 0 & 1 & 39 & 118.2 & 120.58 & 16.58 & 50.24 & 51.25 & 45 & 3.26 \\
A10 & 25 & 1 & 30 & 103.1 & 105.75 & 12.75 & 43.82 & 44.94 & 45 & 3.19 \\
A11 & 50 & 1 & 28 & 103.6 & 106.85 & 11.90 & 44.03 & 45.41 & 46 & 3.38 \\
A12 & 100 & 1 & 31 & 105.4 & 107.96 & 13.18 & 44.80 & 45.88 & 46 & 3.22 \\
A14 & 25 & 1.5 & 31 & 112.9 & 113.14 & 13.18 & 47.99 & 48.08 & 49 & 3.33 \\
A15 & 50 & 1.5 & 33 & 108.2 & 109.13 & 14.03 & 45.99 & 46.38 & 50 & 3.47 \\
A16 & 100 & 1.5 & 25 & 114 & 116.05 & 10.63 & 48.30 & 49.32 & 54 & 3.58 \\
\hline
\end{tabular}

\subsubsection{Effect of Fiber Volume Fraction Ratio}

\subsubsection{Specimens A1, A5 and A9}

\section{Failure Mode and Load vs. Deflection}

All four beams specimens (A1, A5 and A9) have 0\% of RCA with 0\%, 0.5\%, and $1 \%$, of BMF respectively. Flexure failure at the mid-span was the main failure mode for all three tested beams, the failure occurred because of the tensile rupture of steel bars at the tension side of the beams. The ultimate loads along with maximum vertical deflection shown in Table 4.3. As expected, the addition of BMF to concrete tested caused increase in the ultimate load about $1.76 \%$ and $6.24 \%$ for beams A5 and A9 respectively. Hence, it can be observed that the BMF were efficient in strengthening the concrete and increasing the ultimate capacity of the RC beams. In addition, it can be noticed that the maximum deflection at failure increased about $16.67 \%$ and $22.22 \%$ for beams A5 and A9 respectively 
comparing with control beam A1. The largest maximum deflection at failure was observed in beam A9.

As BMF volume fraction increased, beams presented larger deflection before failure. The reason can be due to the effects of $\mathrm{BMF}$ and high bonding between $\mathrm{BMF}$ and concrete matrix. It can be concluded that the beams with BMF were stiffer than the control beam. In addition, the energy absorption and the ability to transfer the tensile forces under flexural loading were greatly enhanced by using BMF.

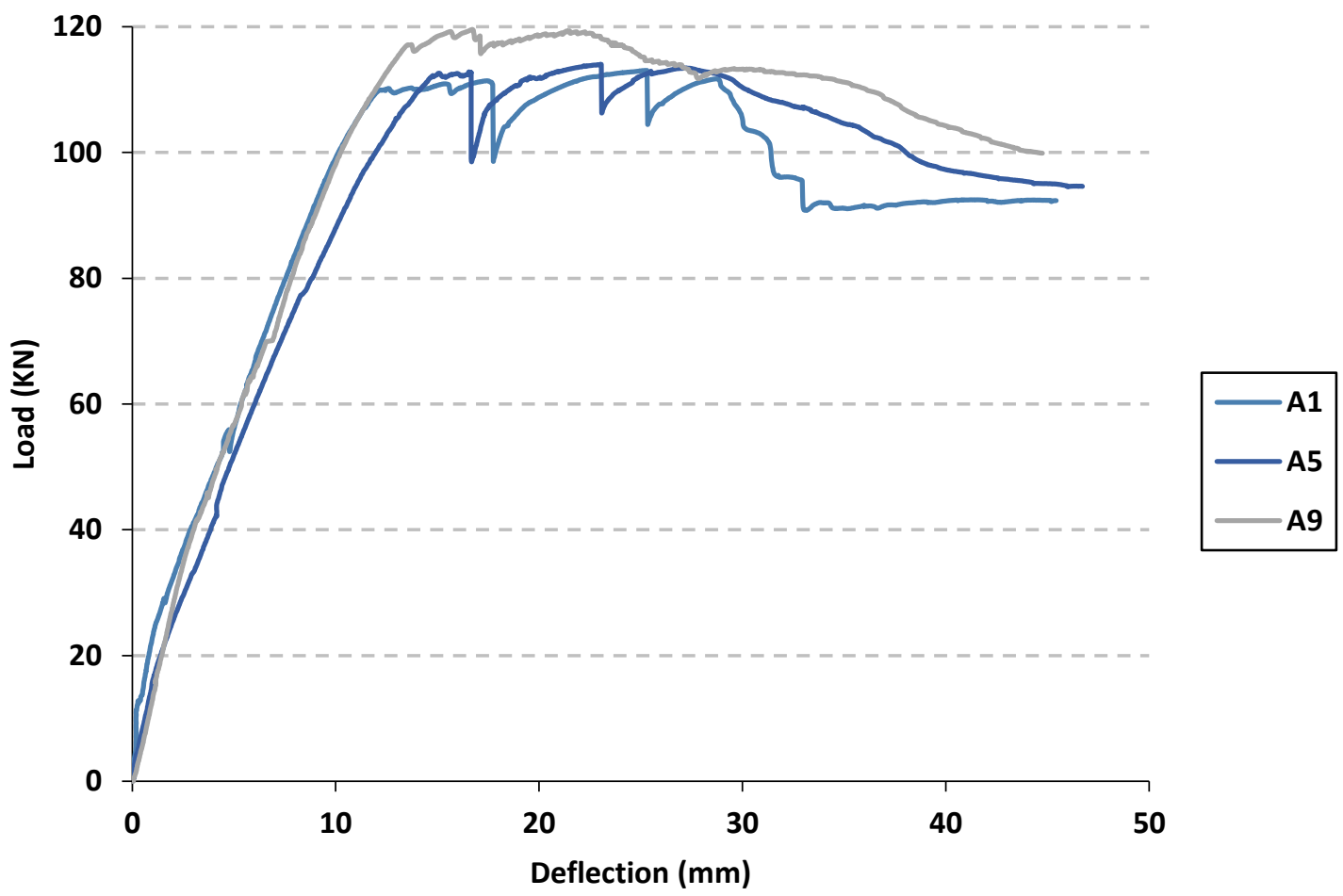

Figure 4.52 Load vs. Deflection for Specimens A1, A5 and A9 


\section{Crack Pattern}

Figure 4.56 illustrate the crack propagation and crack spacing at various loading stages from first crack up to failure for beams A5 and A9 and their corresponding control beam A1 photographically. The first flexural crack in beam specimen A1 was noticed at the mid-span at load of $25 \mathrm{kN}$, while the first crack in the specimens A5 and A9 were noticed at $27 \mathrm{kN}$ and $39 \mathrm{kN}$ respectively. In general, the $\mathrm{RC}$ beams made with $\mathrm{BMF}$ experienced slightly larger crack spacing, and exhibited a less number of flexural cracks as shown in Table 4.4. This is a clear indication that increasing the BMF content in concrete mix resulted in the redistribution of the tensile stresses. Unfortunately, due to the presence of technical issues with the crack transducers, crack widths measurements were not accurate, and were ignored. Though, visual observations showed significant difference among the crack widths of the 4 different beams.
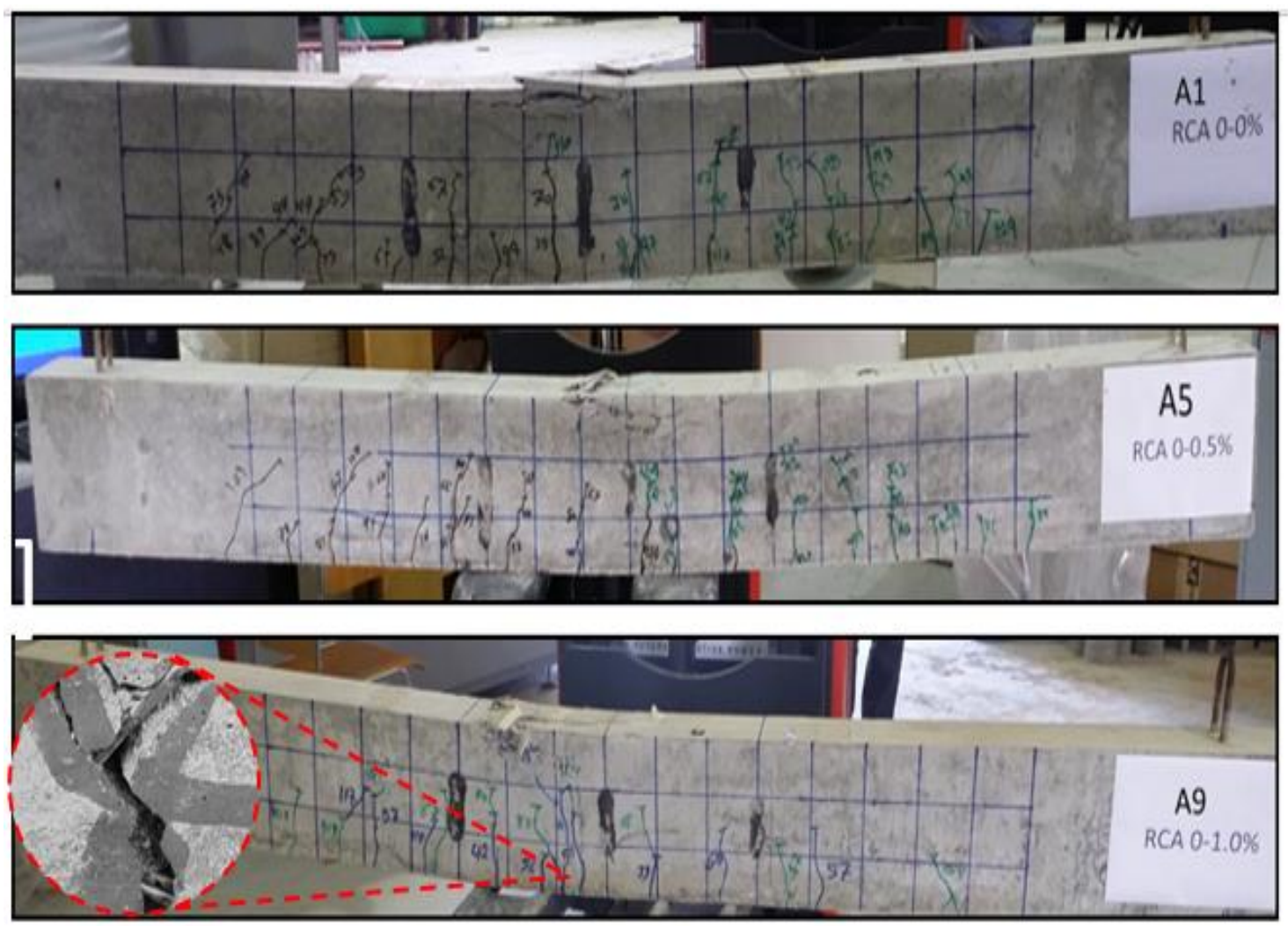

Figure 4.53 Crack Pattern in Test Beams A1, A5 and A9 
Table 4.4 Summary of Number of Cracks

\begin{tabular}{cccc}
\hline Beam ID & RCA \% & BMF \% & Number of Cracks \\
A1 & 0 & 0 & 19 \\
A5 & 0 & 0.5 & 18 \\
A9 & 0 & 1 & 16 \\
\hline
\end{tabular}

\section{Strain in Concrete}

The concrete compressive strains measured for beams (A1, A5 and A9) are presented in Figure 4.57. The maximum concrete strain values were 0.00283, 0.00285 and 0.00262 (break in strain gauges in beam A9) for beams A1, A5 and A9 respectively. The differences of the load-strain curves between the control beam and beams with BMF are significant. In control beam that has $0 \% \mathrm{BMF}$, once reaching the ultimate load, concrete failed by crushing and strain in reinforcement dropped suddenly. however, when the beams with BMF reached the ultimate load, concrete was held together and the strains in concrete and steel bars kept increasing gradually, this is due to the behavior of BMF, tensile loads can be transferred across the cracks by the bridging of fiber and increase in strain capacity of the concrete matrix in the pre-failure zone. 


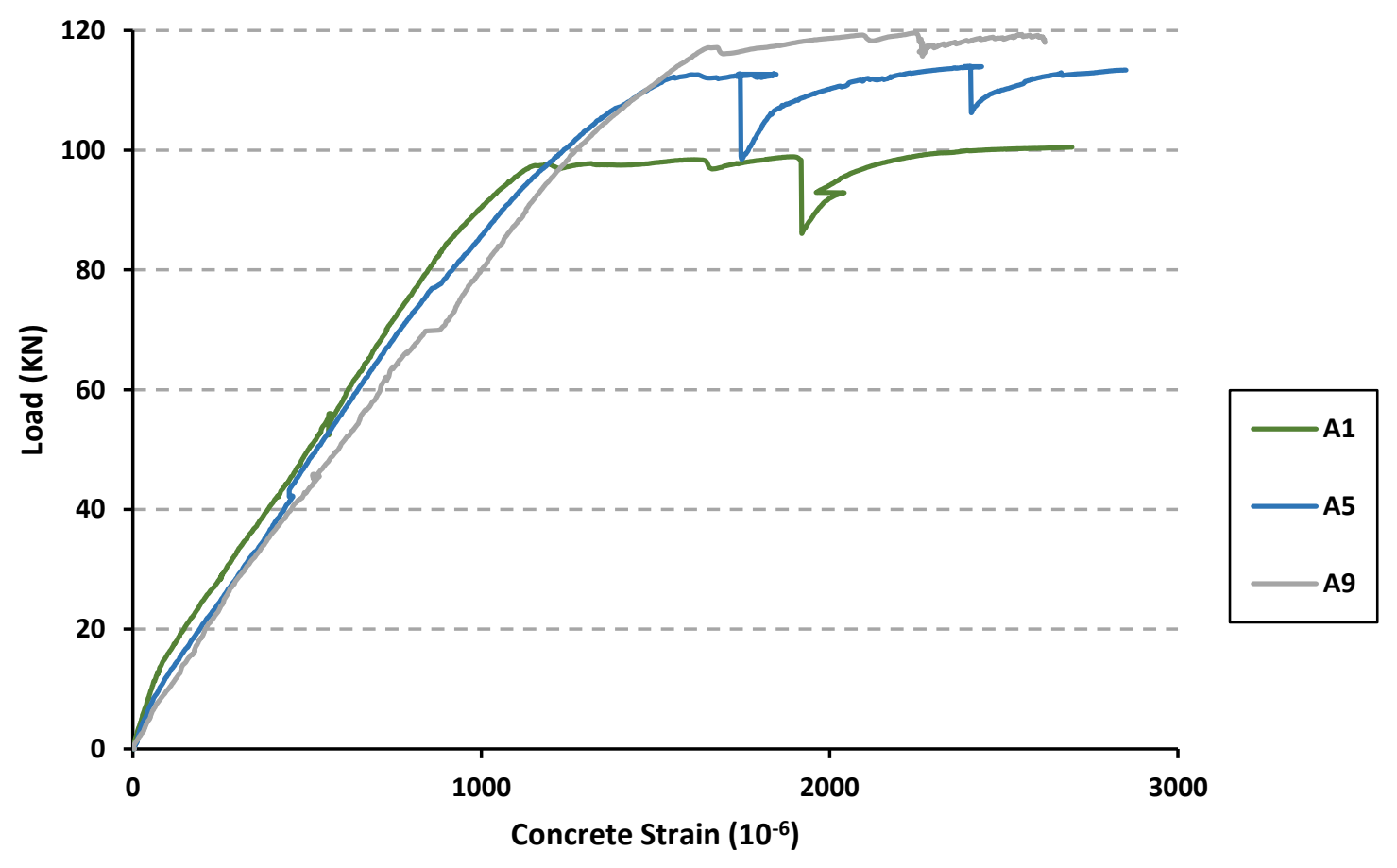

Figure 4.54 Concrete strain for test beams A1, A5 and A9

\section{Ductility Index (DI)}

The corresponding values of DI were 2.57, 2.73 and 3.26 for beams A1, A5 and A9 respectively. Figure 4.58 shows the relationship between the ductility index (DI) and volume fraction of BMF $\left(V_{f}\right)$. In general, ductile structures can provide an advanced warning prior to failure, while little or no warning can be observed before failure of the brittle structures. With the addition of BMF, the load capacity and deflection were increased. Therefore, higher energy absorption may ensure higher ductility, from this standpoint, the addition of BMF should significantly improve the system's ductility. 


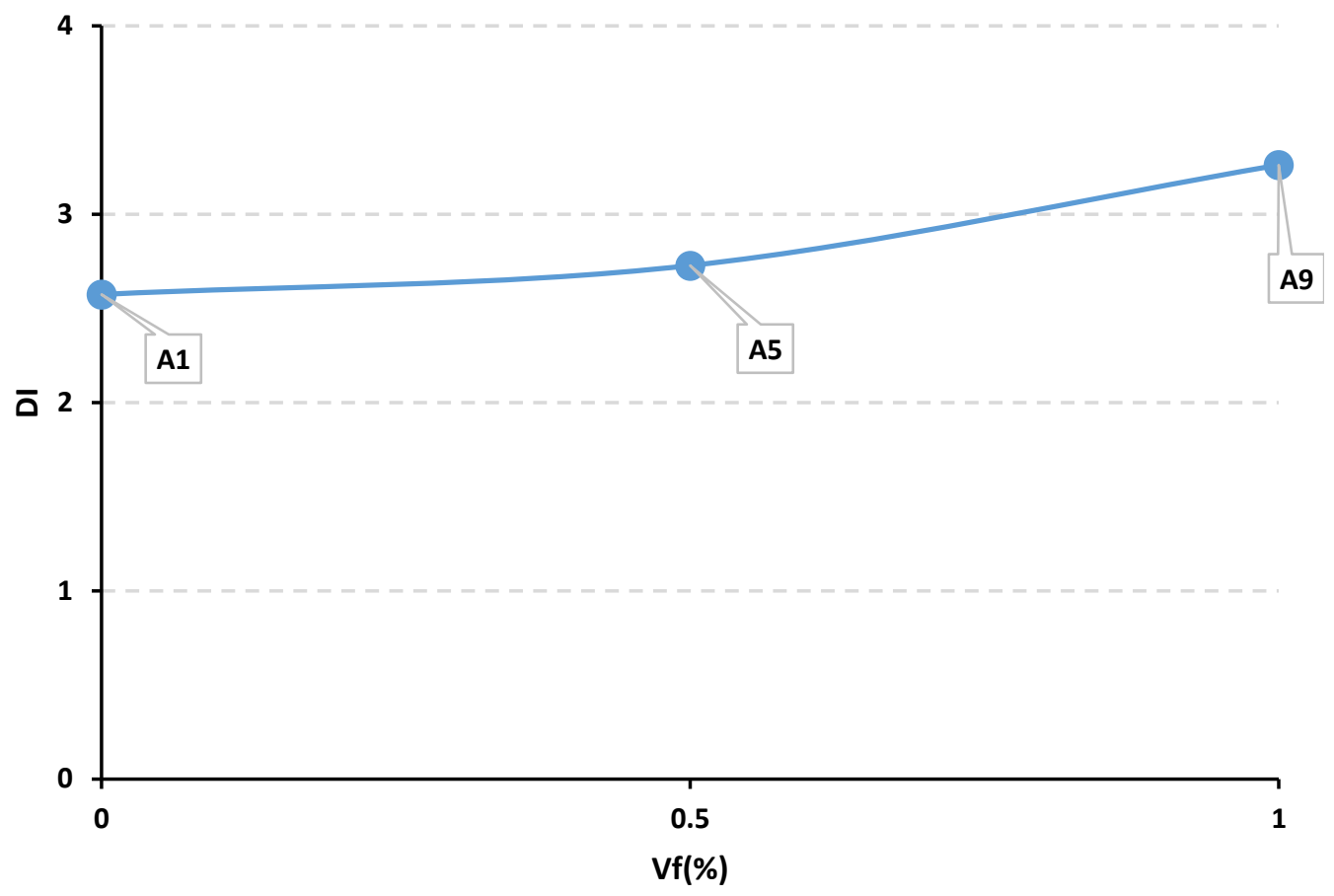

Figure 4.55 Ductility Index vs. Volume Fraction of Fiber for Beams A1, A5 and A9

\subsubsection{Specimens A2, A6, A10 and A14}

\section{Failure Mode and Load vs. Deflection}

All four beams specimens (A2, A6, A10, and A14) have 25\% of RCA with 0\%, $0.5 \%, 1 \%$, and $1.5 \%$ of BMF respectively. Flexure failure at the mid-span was the main failure mode for all four tested beams, the failure occurred because of the tensile rupture of steel bars at the tension side of the beams. The ultimate loads along with maximum vertical deflection shown in Table 4.3. As expected, the addition of BMF to concrete tested caused increase in the ultimate load about $12.47 \%, 2.52 \%$ and $8.89 \%$ for beams A6, A10, and A14 respectively. Hence, it can be observed that the BMF were efficient in strengthening the concrete and increasing the ultimate capacity of the RC beams. In addition, it can be noticed that the maximum deflection at failure increased about $17.95 \%$, $28.89 \%$ and $34.69 \%$ for beams A6, A10 and A14 respectively comparing with control beam A2. The largest maximum deflection at failure was observed in beam A14. As BMF 
volume fraction increased, beams presented larger deflection before failure. The reason can be due to the effects of BMF and high bonding between BMF and concrete matrix. It can be concluded that the beams with BMF were stiffer than the control beam. In addition, the energy absorption and the ability to transfer the tensile forces under flexural loading were greatly enhanced by using BMF.

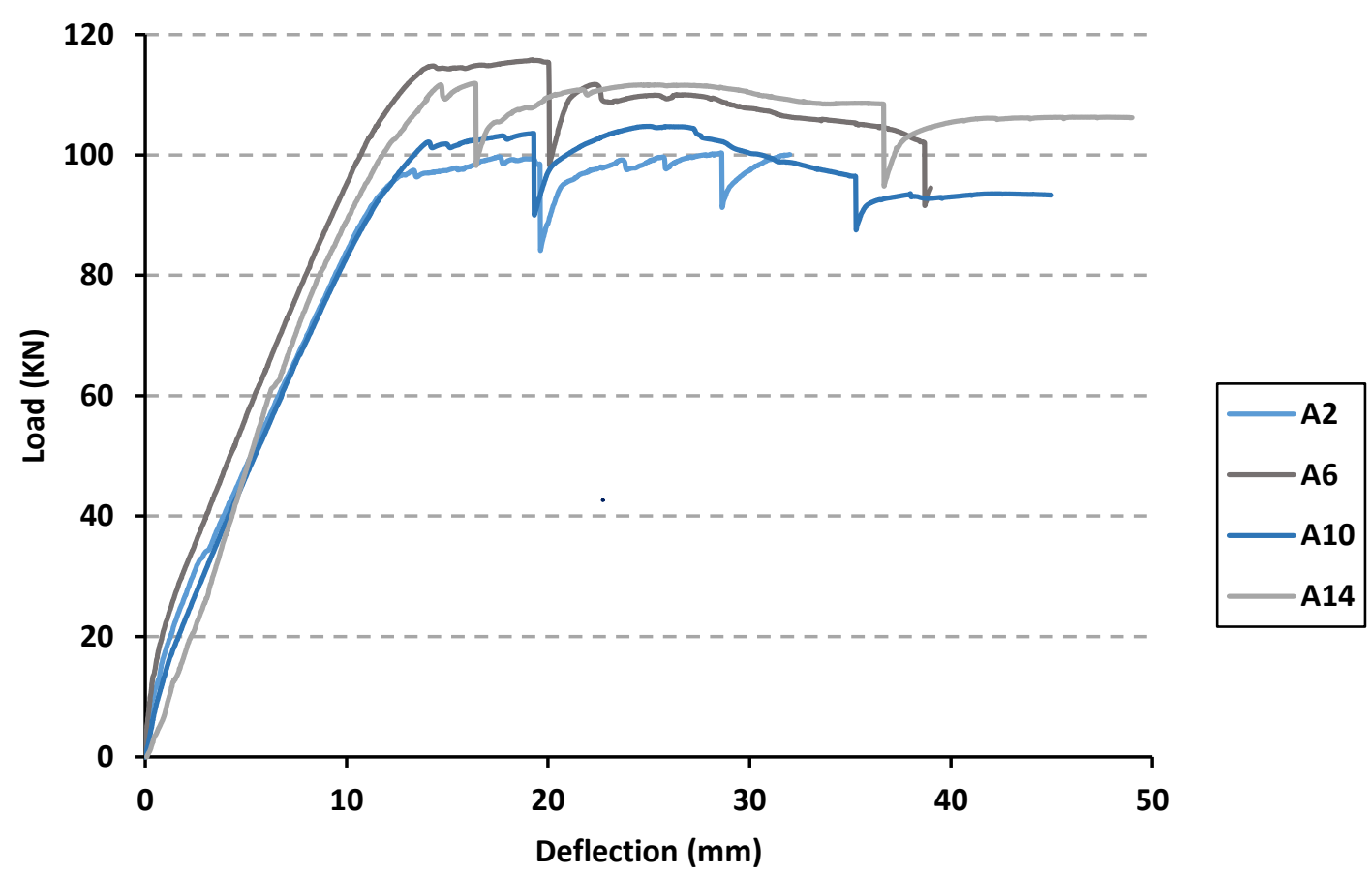

Figure 4.56 Load vs. Deflection for Specimens A2, A6, A10 and A14

\section{Crack Pattern}

Figure 4.60 illustrate the crack propagation and crack spacing at various loading stages from first crack up to failure for beams A6, A10, and A14 and their corresponding control beam A2 photographically. The first flexural crack in beam specimen A2 was noticed at the mid-span at load of $21 \mathrm{kN}$, while the first crack in the specimens A6, A10 and $\mathrm{A} 14$ were noticed at $24 \mathrm{kN}, 30 \mathrm{kN}$ and $31 \mathrm{kN}$ respectively. In general, the RC beams made with BMF experienced slightly larger crack spacing, and exhibited a less number of flexural cracks as shown in Table 4.5. This is a clear indication that increasing the BMF 
content in concrete mix resulted in the redistribution of the tensile stresses. Unfortunately, due to the presence of technical issues with the crack transducers, crack widths measurements were not accurate, and were ignored. Though, visual observations showed significant difference among the crack widths of the 4 different beams.
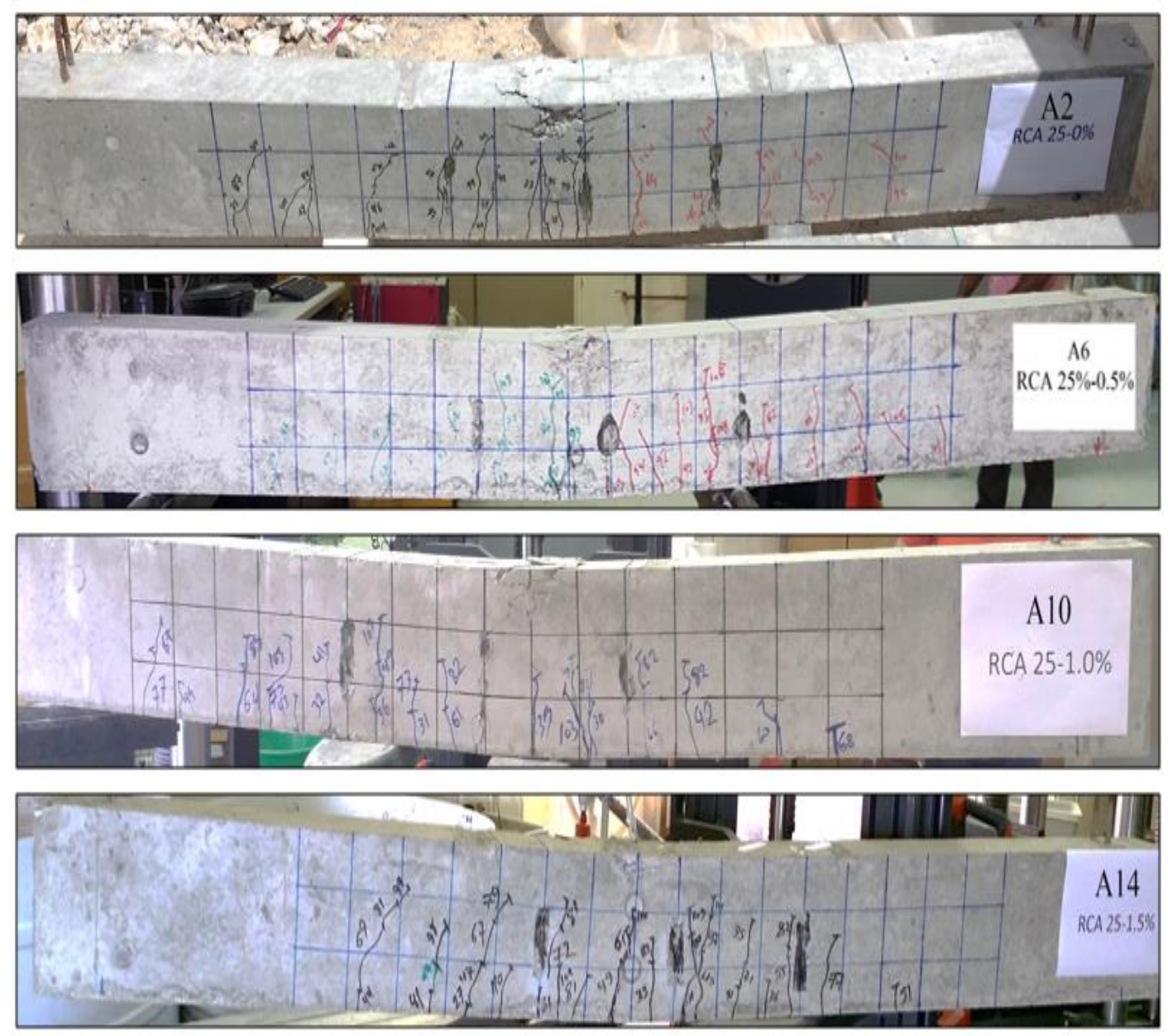

Figure 4.57 Crack Pattern in Test Beams A2, A6, A10 and A14 
Table 4.5 Summary of Number of Cracks

\begin{tabular}{cccc}
\hline Beam ID & RCA \% & BMF \% & Number of Cracks \\
A2 & 25 & 0 & 18 \\
A6 & 25 & 0.5 & 19 \\
A10 & 25 & 1 & 17 \\
A14 & 25 & 1.5 & 16 \\
\hline
\end{tabular}

\section{Strain in Concrete}

The concrete compressive strains measured for beams (A2, A6, A10, and A14) are presented in Figure 4.61. The maximum concrete strain values were 0.00285, 0.00228, 0.00374 and 0.00217 (break in strain gauges in beams A6 and A14) for beams A2, A6, A10, and A14 respectively. The differences of the load-strain curves between the control beam and beams with $\mathrm{BMF}$ are significant. In control beam that has $0 \% \mathrm{BMF}$, once reaching the ultimate load, concrete failed by crushing and strain in reinforcement dropped suddenly. however, when the beams with BMF reached the ultimate load, concrete was held together and the strains in concrete and steel bars kept increasing gradually, this is due to the behavior of BMF, tensile loads can be transferred across the cracks by the bridging of fiber and increase in strain capacity of the concrete matrix in the pre-failure zone. 


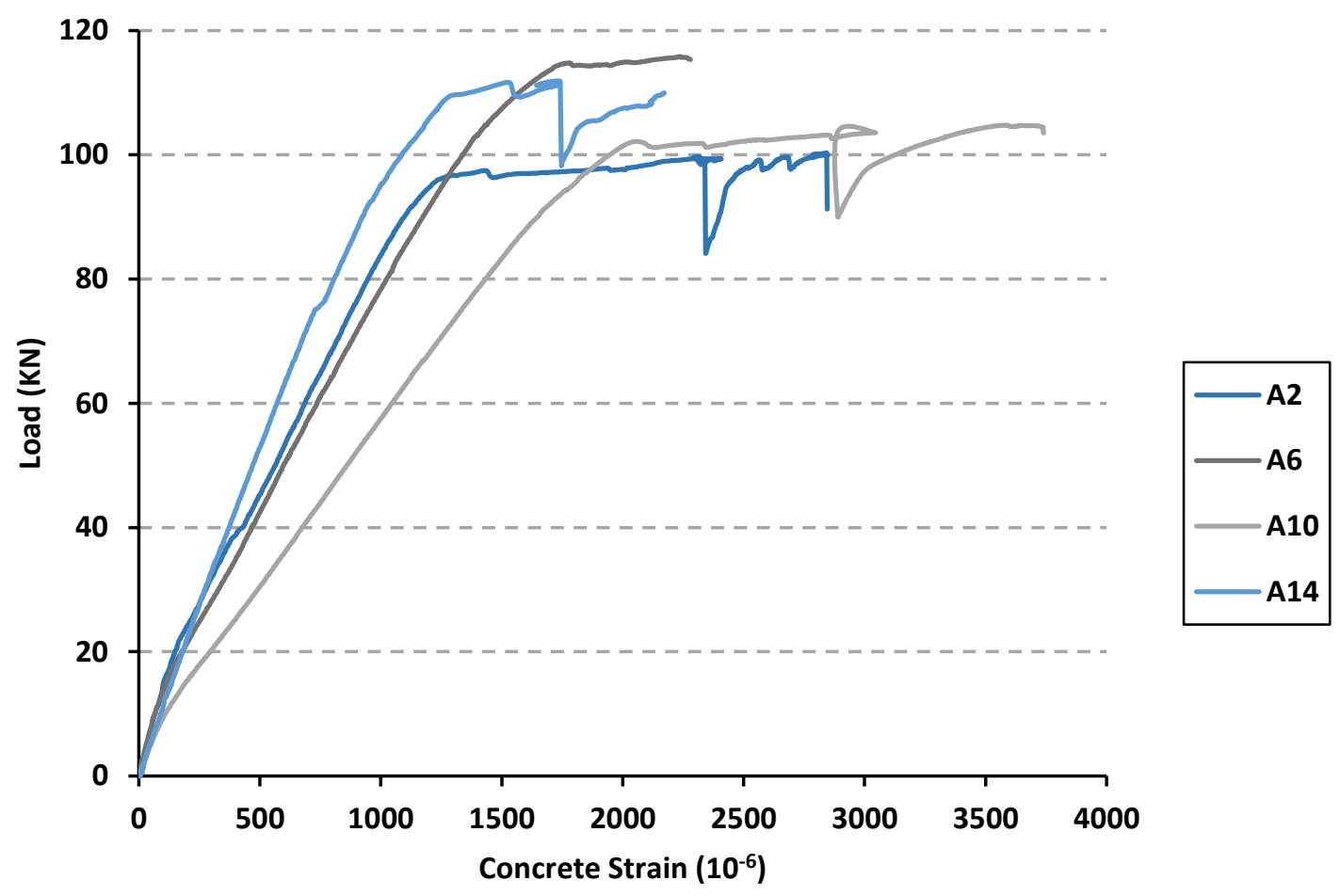

Figure 4.58 Concrete strain for test beams A2, A6, A10 and A14

\section{Ductility Index (DI)}

The corresponding values of DI were 2.52, 2.67, 3.19 and 3.33 for beams A2, A6, A10 and A14 respectively. Figure 4.62 shows the relationship between the ductility index (DI) and volume fraction of $\mathrm{BMF}\left(V_{f}\right)$. In general, ductile structures can provide an advanced warning prior to failure, while little or no warning can be observed before failure of the brittle structures. With the addition of BMF, the load capacity and deflection were increased. Therefore, higher energy absorption may ensure higher ductility, from this standpoint, the addition of BMF should significantly improve the system's ductility. 


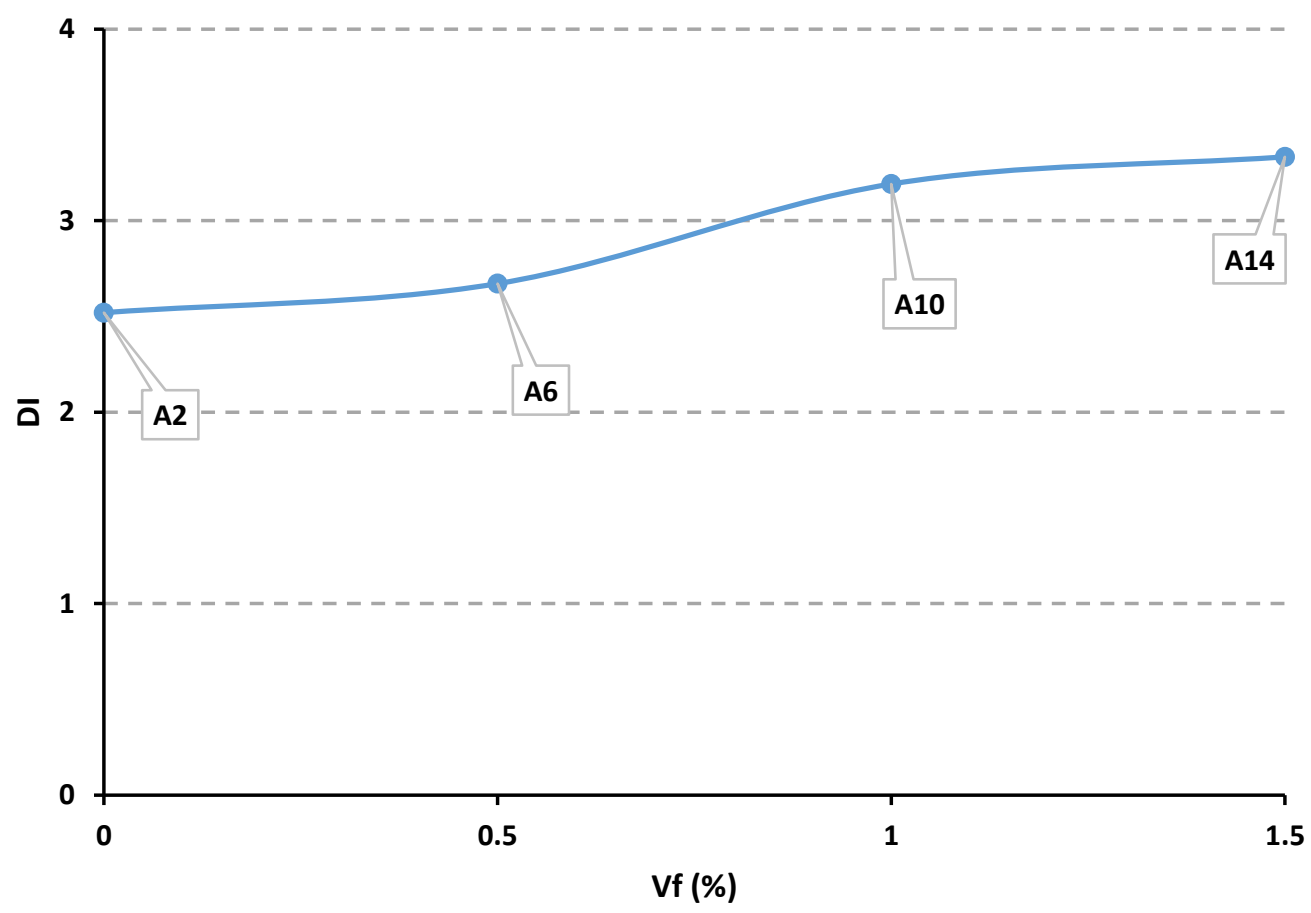

Figure 4.59 Ductility Index vs. Volume Fraction of Fiber for Beams A2, A6, A10 and A14

\section{Tensile Strain in Main Steel Reinforcement}

The tensile strain of the longitudinal steel reinforcement was measured at mid-span of beams (A2, A6, A10 and A14) to investigate the effect of adding the BMF to the concrete mix. When the first flexure crack reached the position of the steel bars, a change in the steel bars response was recorded. It can be observed from Figure 4.63, that adding a volume fraction of $0.5 \%$ to the concrete resulted in a decrease of $20.3 \%$ in the maximum steel tensile strain. The gain in flexural strength further increased to $49.8 \%$ when the volume fraction of the BMF increased to $1.5 \%$. This can be because BMF prevents the sharp and sudden increase of the strain. In addition, BMF controls the crack openings and transfers the tensile stress through the crack which resulted in a decrease in the tensile stress in the steel bars. There is a good agreement between the aforementioned results and a study conducted by Fritih et al. (Fritih et al. 2013). 


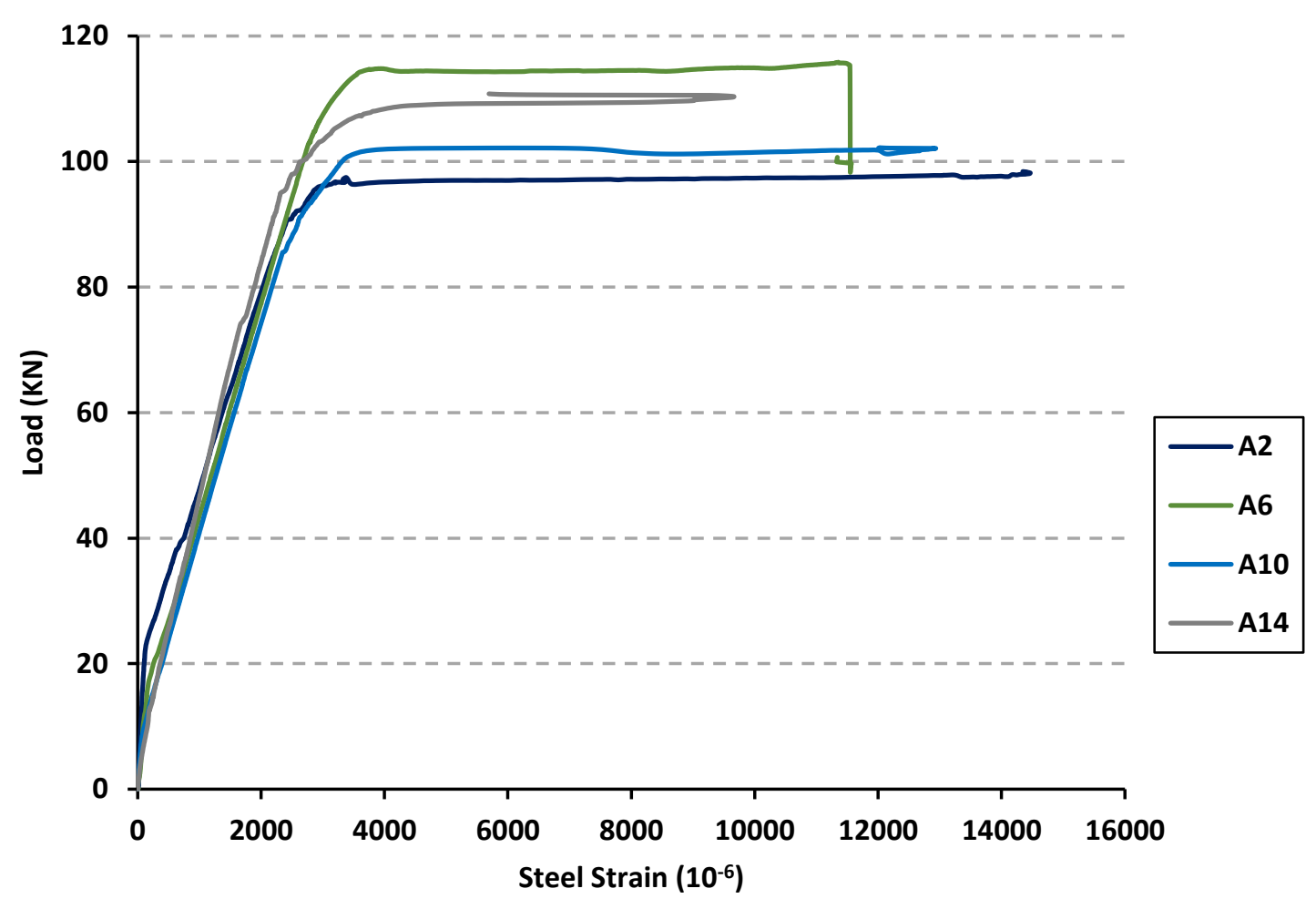

Figure 4.60 Steel Strain for test beams A2, A6, A10 and A14

\subsubsection{Specimens A3, A7, A11 and A15}

\section{Failure Mode and Load vs. Deflection}

All four beams specimens (A3, A7, A11, and A15) have 50\% of RCA with $0 \%$, $0.5 \%, 1 \%$, and $1.5 \%$ of BMF respectively. Flexure failure at the mid-span was the main failure mode for all four tested beams, the failure occurred because of the tensile rupture of steel bars at the tension side of the beams. The ultimate loads along with maximum vertical deflection shown in Table 4.3. As expected, the addition of BMF to concrete tested caused increase in the ultimate load about $3.17 \%, 1.55 \%$ and $3.61 \%$ for beams A7, A11, and A15 respectively. Hence, it can be observed that the BMF were efficient in strengthening the concrete and increasing the ultimate capacity of the RC beams. In addition, it can be noticed that the maximum deflection at failure increased about $13.89 \%$, $32.61 \%$ and $38 \%$ for beams A7, A11 and A15 respectively comparing with control beam A3. The largest maximum deflection at failure was observed in beam A15. As BMF 
volume fraction increased, beams presented larger deflection before failure. The reason can be due to the effects of BMF and high bonding between BMF and concrete matrix. It can be concluded that the beams with BMF were stiffer than the control beam. In addition, the energy absorption and the ability to transfer the tensile forces under flexural loading were greatly enhanced by using BMF.

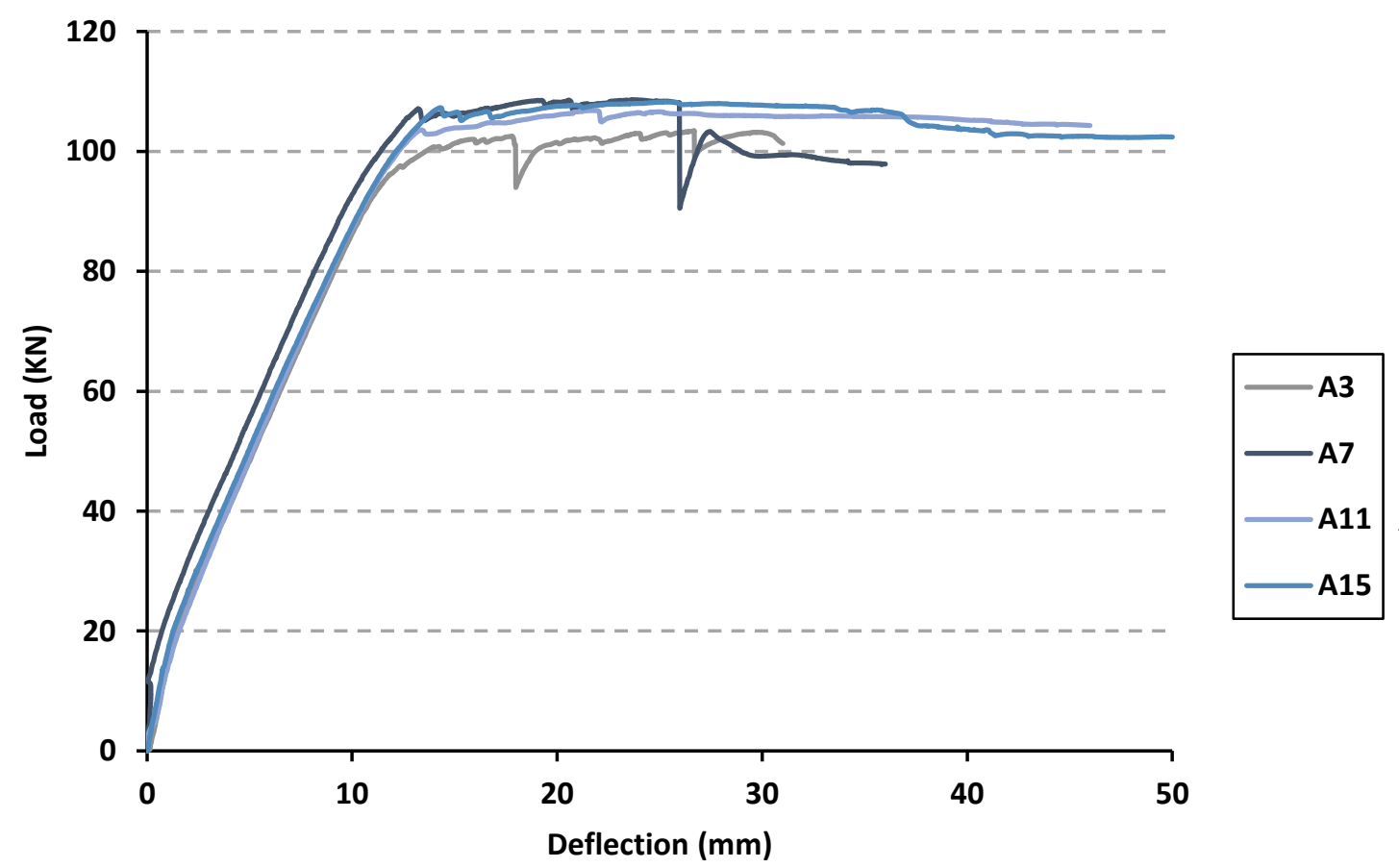

Figure 4.61 Load vs. Deflection for Specimens A3, A7, A11 and A15

\section{Crack Pattern}

Figure 4.65 illustrate the crack propagation and crack spacing at various loading stages from first crack up to failure for beams A7, A11, and A15 and their corresponding control beam A3 photographically. The first flexural crack in beam specimen A3 was noticed at the mid-span at load of $19 \mathrm{kN}$, while the first crack in the specimens A7, A11 and A15 were noticed at $22 \mathrm{kN}, 28 \mathrm{kN}$ and $33 \mathrm{kN}$ respectively. In general, the RC beams made with BMF experienced slightly larger crack spacing, and exhibited a less number of flexural cracks as shown in Table 4.6. This is a clear indication that increasing the BMF 
content in concrete mix resulted in the redistribution of the tensile stresses. Unfortunately, due to the presence of technical issues with the crack transducers, crack widths measurements were not accurate, and were ignored. Though, visual observations showed significant difference among the crack widths of the 4 different beams.
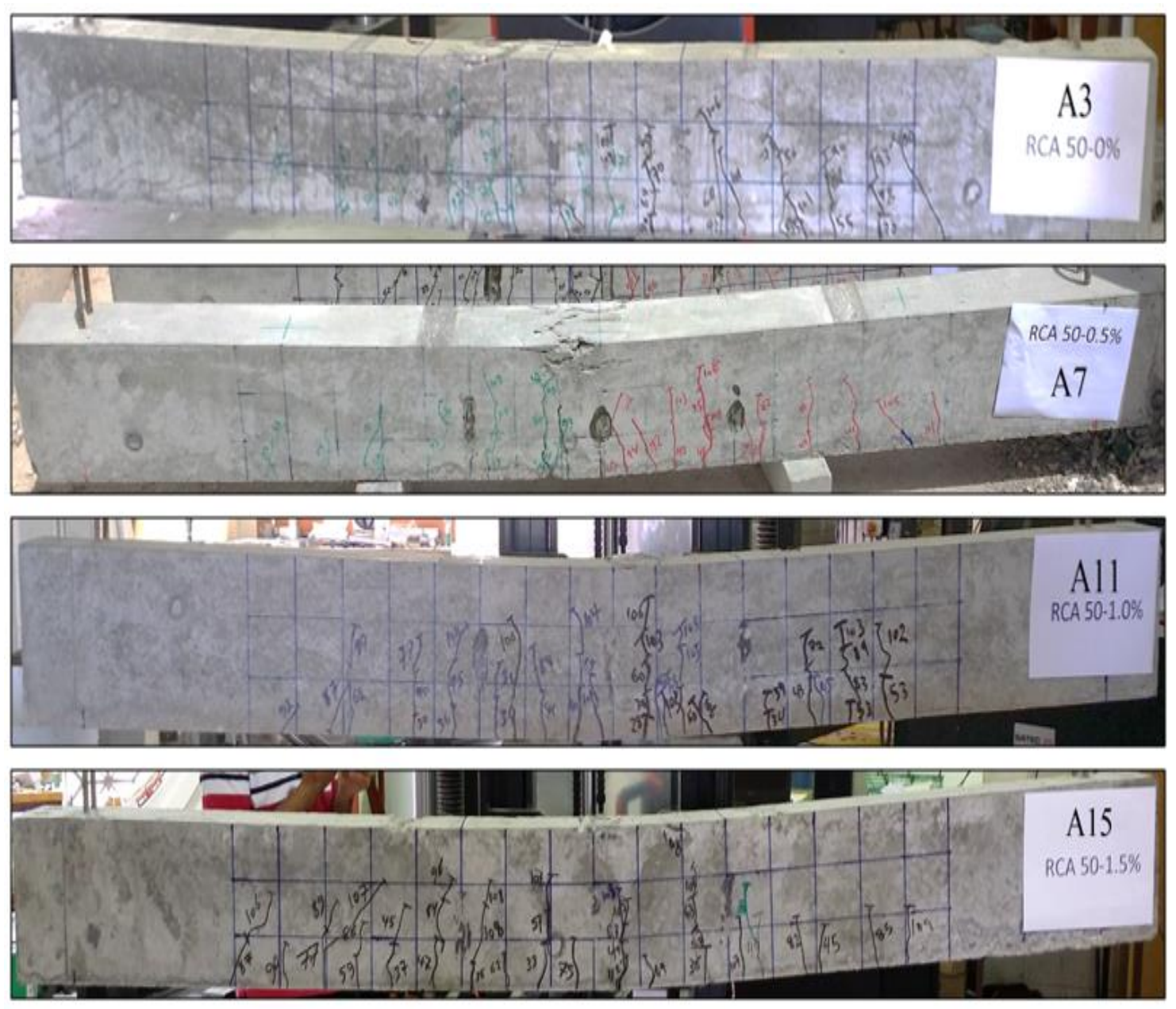

Figure 4.62 Crack Pattern in Test Beams A3, A7, A11 and A15 
Table 4.6 Summary of Number of Cracks

\begin{tabular}{cccc}
\hline Beam ID & RCA \% & BMF \% & Number of Cracks \\
A3 & 50 & 0 & 20 \\
A7 & 50 & 0.5 & 19 \\
A11 & 50 & 1 & 21 \\
A15 & 50 & 1.5 & 19 \\
\hline
\end{tabular}

\section{Strain in Concrete}

The concrete compressive strains measured for beams (A3, A7, A11, and A15) are presented in Figure 4.66. The maximum concrete strain values were 0.00283, 0.00352, 0.0031 and 0.00374 for beams A3, A7, A11, and A15 respectively. The differences of the load-strain curves between the control beam and beams with BMF are significant. In control beam that has $1 \% \mathrm{BMF}$, once reaching the ultimate load, concrete failed by crushing and strain in reinforcement dropped suddenly. however, when the beams with BMF reached the ultimate load, concrete was held together and the strains in concrete and steel bars kept increasing gradually, this is due to the behavior of BMF, tensile loads can be transferred across the cracks by the bridging of fiber and increase in strain capacity of the concrete matrix in the pre-failure zone. 


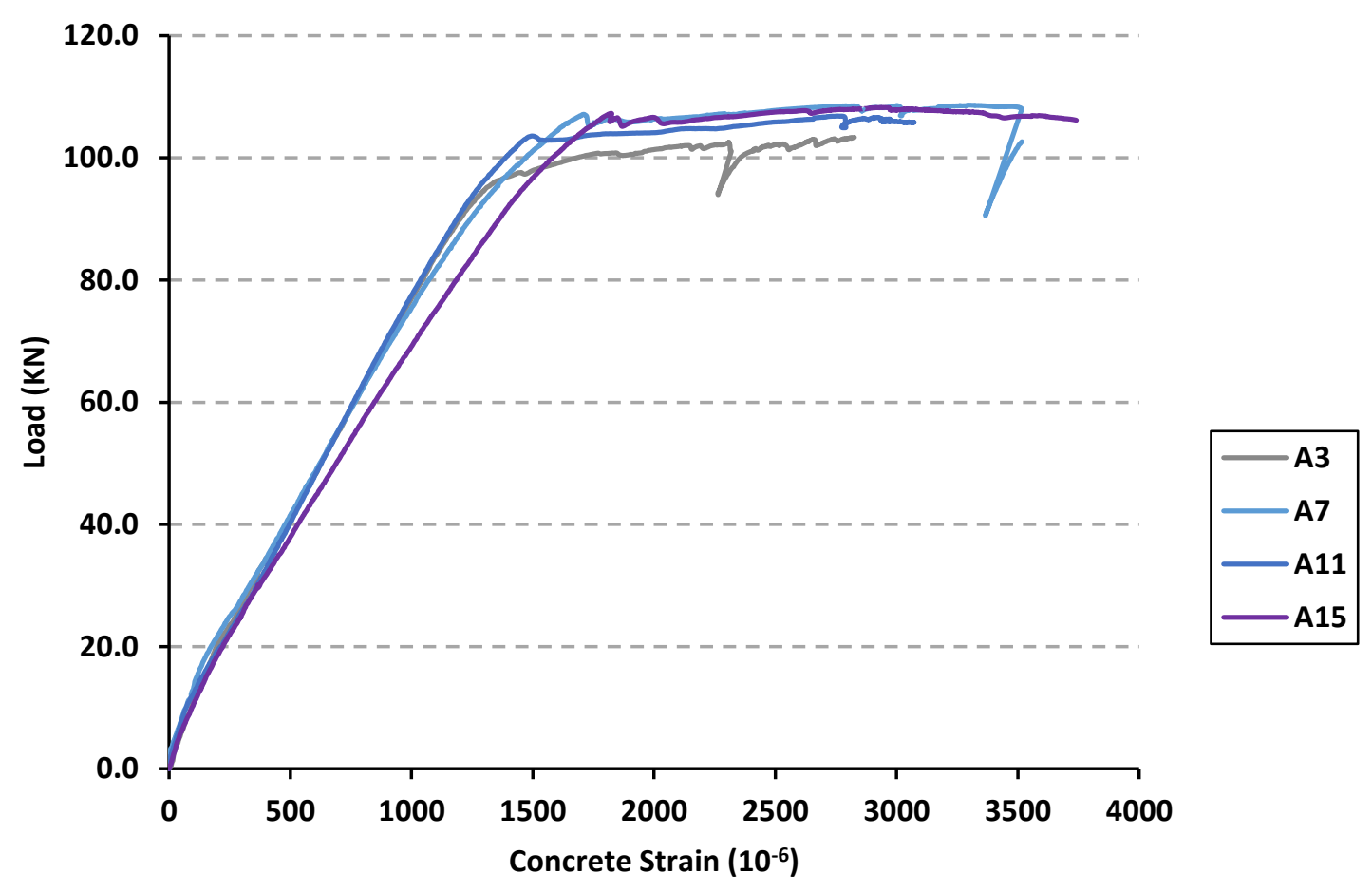

Figure 4.63 Concrete strain for test beams A3, A7, A11 and A15

\section{Ductility Index (DI)}

The corresponding values of DI were 2.46, 2.71, 3.38 and 3.47 for beams A3, A7, A11 and A15 respectively. Figure 4.67 shows the relationship between the ductility index (DI) and volume fraction of BMF $\left(V_{f}\right)$. In general, ductile structures can provide an advanced warning prior to failure, while little or no warning can be observed before failure of the brittle structures. With the addition of BMF, the load capacity and deflection increase. Therefore, higher energy absorption may ensure higher ductility, from this standpoint, the addition of BMF should significantly improve the system's ductility. 


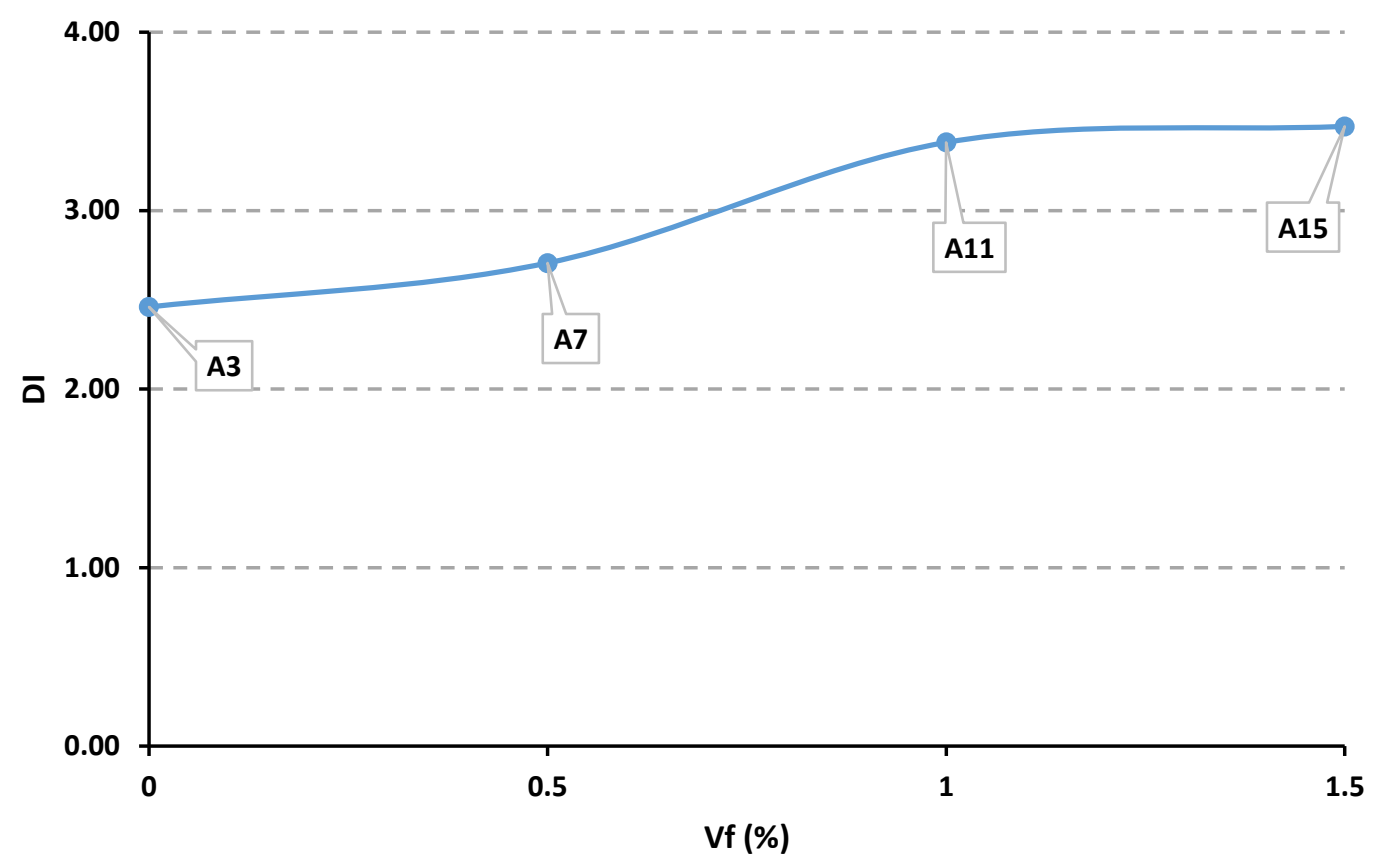

Figure 4.64 Ductility Index vs. Volume Fraction of Fiber for Beams A3, A7, A11and A15

\subsubsection{Specimens A4, A8, A12 and A16}

\section{Failure Mode and Load vs. Deflection}

All four beams specimens (A4, A8, A12, and A16) have 100\% of RCA with 0\%, $0.5 \%, 1 \%$, and $1.5 \%$ of BMF respectively. Flexure failure at the mid-span was the main failure mode for all four tested beams, the failure occurred because of the tensile rupture of steel bars at the tension side of the beams. The ultimate loads along with maximum vertical deflection shown in Table 4.3. As expected, the addition of BMF to concrete tested caused increase in the ultimate load about $0.87 \%, 0.35 \%$ and $4.71 \%$ for beams A8, A12, and A16 respectively. Hence, it can be observed that the BMF were efficient in strengthening the concrete and increasing the ultimate capacity of the RC beams. In addition, it can be noticed that the maximum deflection at failure increased about $11.76 \%$, $34.78 \%$ and $44.44 \%$ for beams A8, A12 and A16 respectively comparing with control beam A4. The largest maximum deflection at failure was observed in beam A16. As BMF volume fraction increased, beams presented larger deflection before failure. The reason can 
be due to the effects of BMF and high bonding between BMF and concrete matrix. It can be concluded that the beams with BMF were stiffer than the control beam. In addition, the energy absorption and the ability to transfer the tensile forces under flexural loading were greatly enhanced by using BMF.

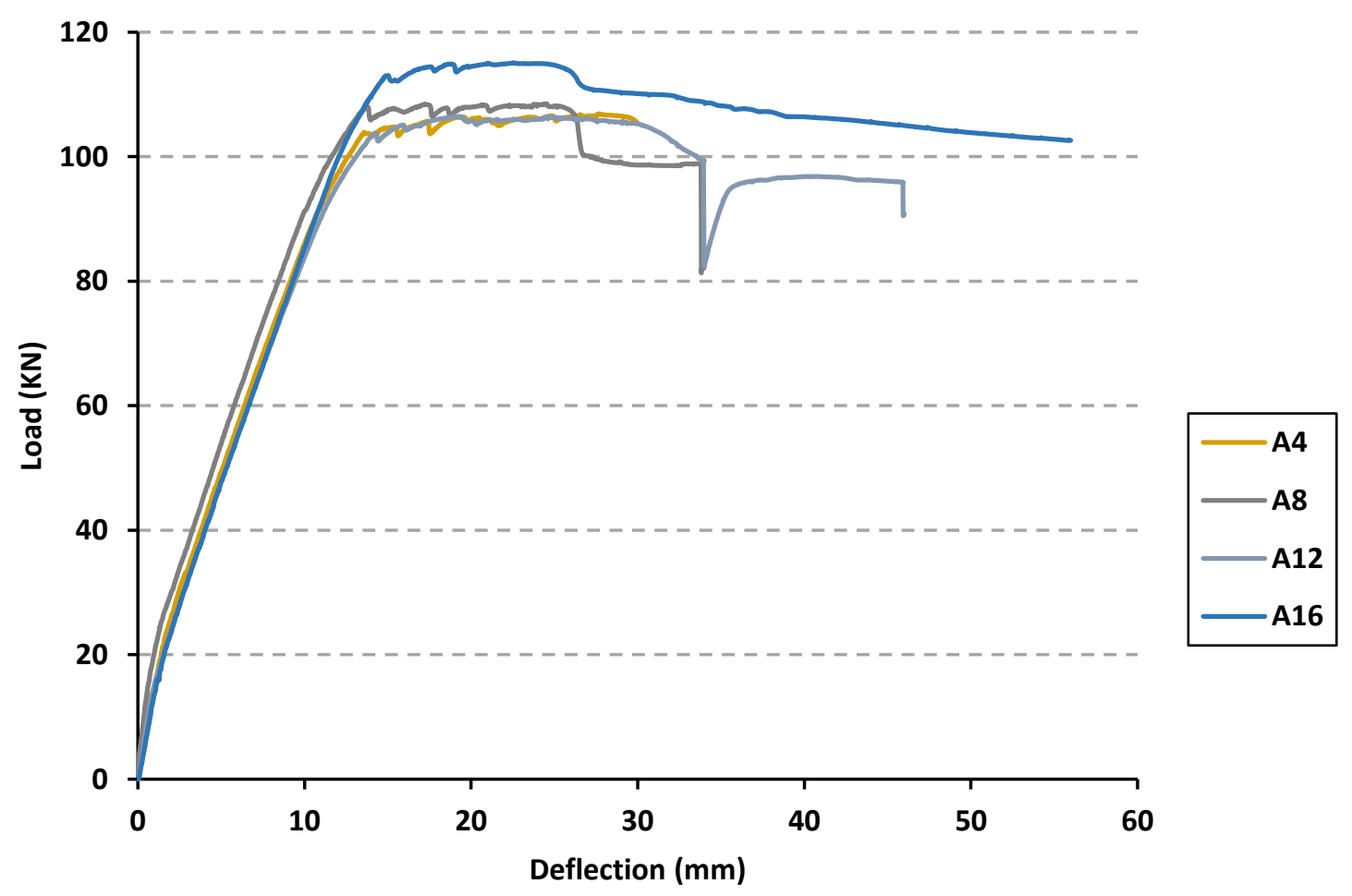

Figure 4.65 Load Vs. Deflection for Specimens A4, A9, A12 and A16

\section{Crack Pattern}

Figure 4.69 illustrate the crack propagation and crack spacing at various loading stages from first crack up to failure for beams A8, A12, and A16 and their corresponding control beam A4 photographically. The first flexural crack in beam specimen A4 was noticed at the mid-span at load of $18 \mathrm{kN}$, while the first crack in the specimens A8, A12 and $\mathrm{A} 16$ were noticed at $21 \mathrm{kN}, 31 \mathrm{kN}$ and $25 \mathrm{kN}$ respectively. In general, the RC beams made with BMF experienced slightly larger crack spacing, and exhibited a less number of flexural cracks as shown in Table 4.7. This is a clear indication that increasing the BMF 
content in concrete mix resulted in the redistribution of the tensile stresses. Unfortunately, due to the presence of technical issues with the crack transducers, crack widths measurements were not accurate, and were ignored. Though, visual observations showed significant difference among the crack widths of the 4 different beams.
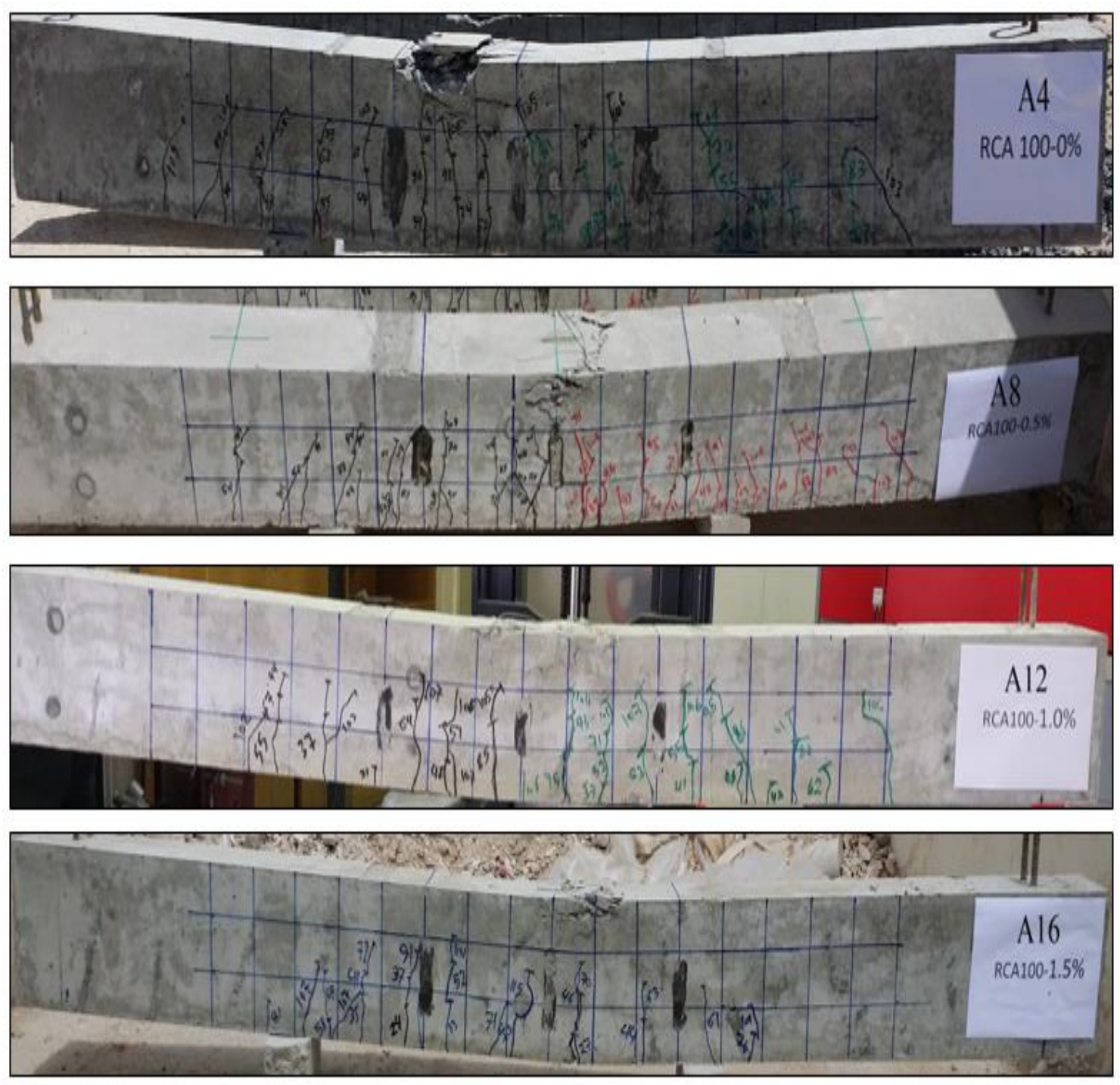

Figure 4.66 Crack Pattern in Test Beams A4, A9, A12 and A16 
Table 4.7 Summary of Number of Cracks

\begin{tabular}{cccc}
\hline Beam ID & RCA \% & BMF \% & Number of Cracks \\
A4 & 100 & 0 & 20 \\
A8 & 100 & 0.5 & 16 \\
A12 & 100 & 1 & 19 \\
A16 & 100 & 1.5 & 14 \\
\hline
\end{tabular}

\section{Strain in Concrete}

The concrete compressive strains measured for beams (A4, A8, A12, and A16) are presented in Figure 4.70. The maximum concrete strain values were 0.00292, 0.00308, 0.0035 and 0.00372 for beams A4, A8, A12, and A16 respectively. The differences of the load-strain curves between the control beam and beams with BMF are significant. In control beam that has $1.5 \% \mathrm{BMF}$, once reaching the ultimate load, concrete failed by crushing and strain in reinforcement dropped suddenly. however, when the beams with BMF reached the ultimate load, concrete was held together and the strains in concrete and steel bars kept increasing gradually, this is due to the behavior of BMF, tensile loads can be transferred across the cracks by the bridging of fiber and increase in strain capacity of the concrete matrix in the pre-failure zone. 


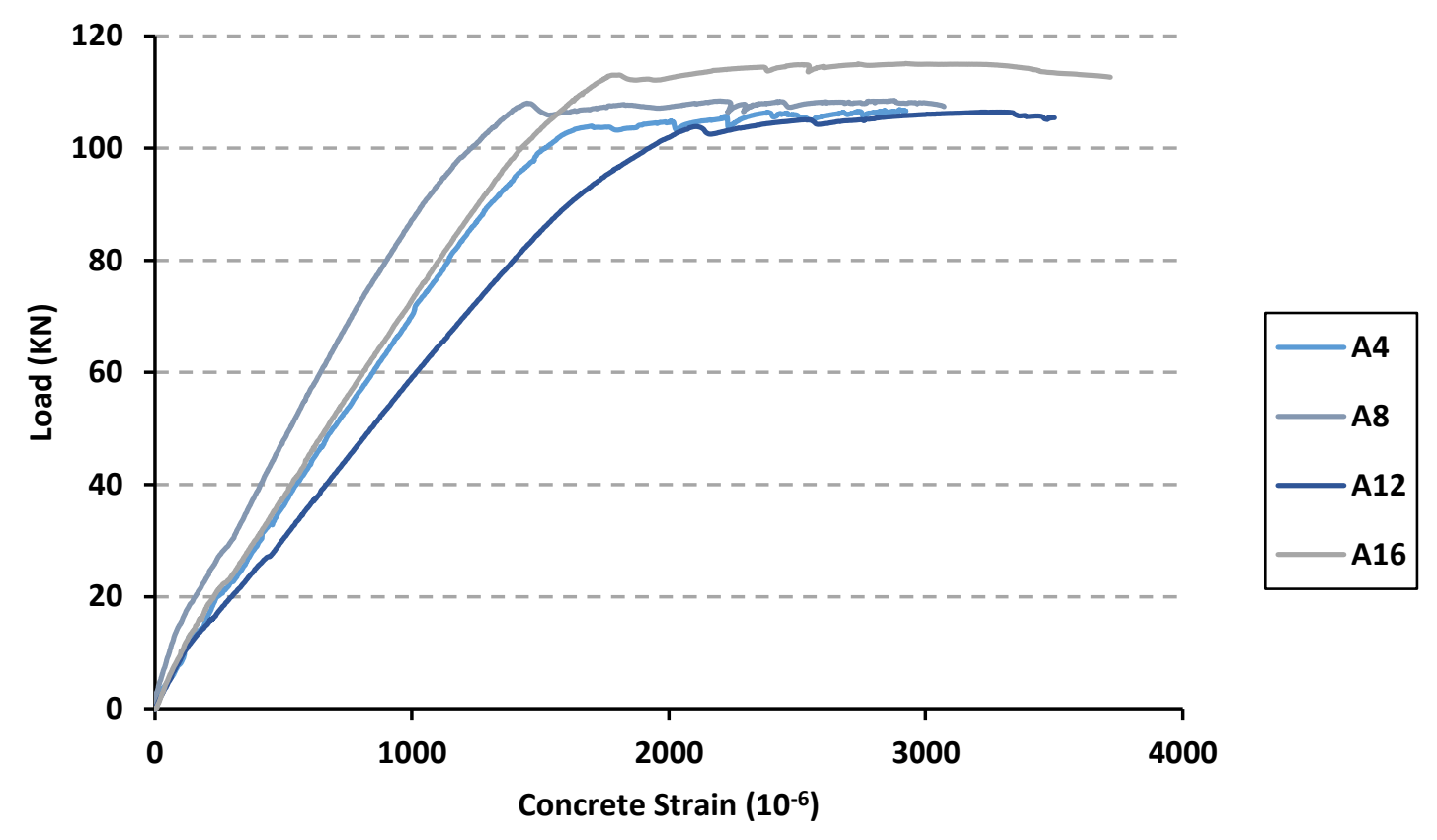

Figure 4.67 Concrete strain for test beams A4, A9, A12 and A16

\section{Ductility Index (DI)}

The corresponding values of DI were 2.17, 2.46, 3.22 and 3.58 for beams A4, A8, A12 and A16 respectively. Figure 4.71 shows the relationship between the ductility index (DI) and volume fraction of BMF $\left(V_{f}\right)$. In general, ductile structures can provide an advanced warning prior to failure, while little or no warning can be observed before failure of the brittle structures. With the addition of BMF, the load capacity and deflection increase. Therefore, higher energy absorption may ensure higher ductility, from this standpoint, the addition of BMF should significantly improve the system's ductility. 


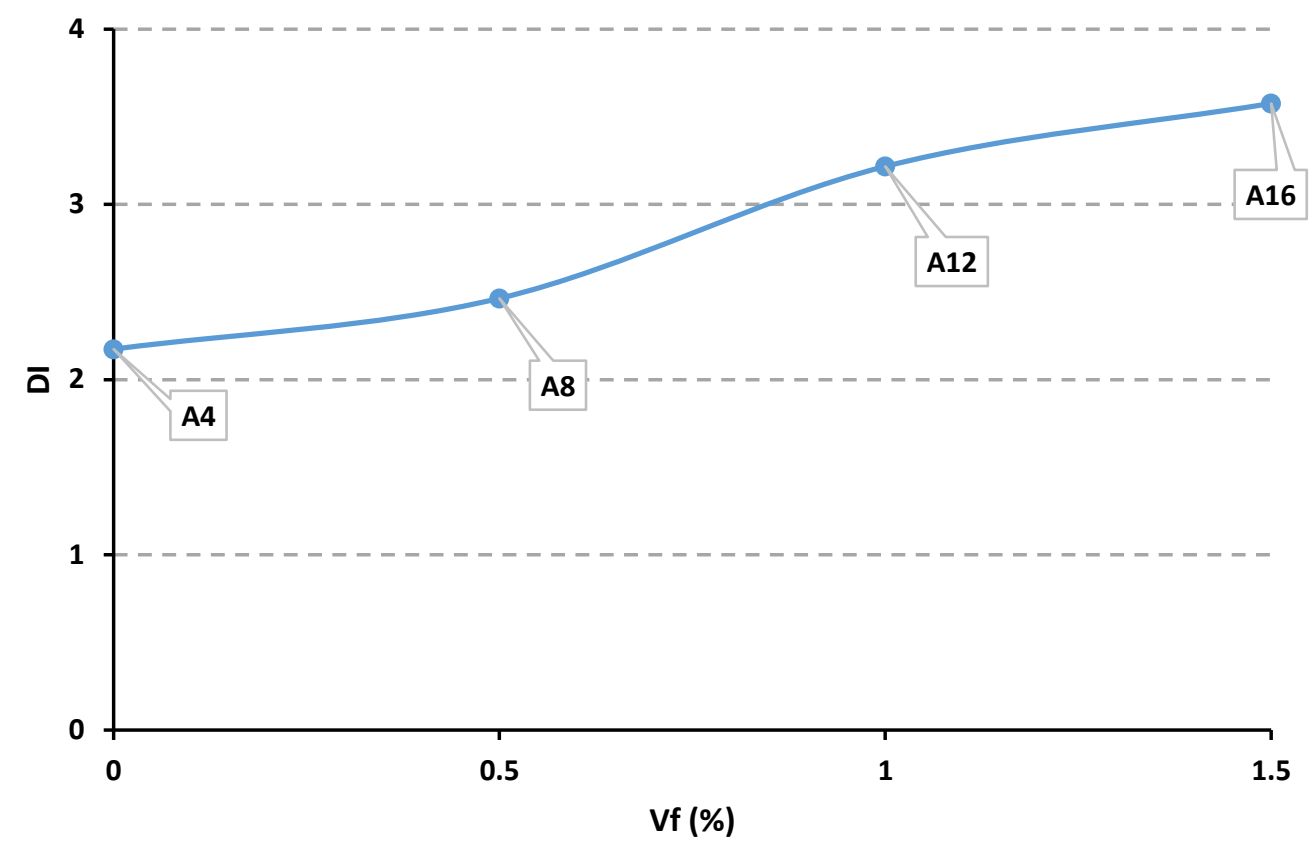

Figure 4.68 Ductility Index vs. Volume Fraction of Fiber for Beams A4, A8, A12and A16

\subsubsection{Effect of Aggregate Replacement Ratio of the RCA}

\subsubsection{Specimens A1, A2, A3, and A4}

\section{Failure Mode and Load vs. Deflection}

All four beams specimens (A1, A2, A3, and A4) have 0\% of BMF with 0\%, 25\%, $50 \%$, and $100 \%$ of RCA respectively. Flexure failure at the mid-span was the main failure mode for all four tested beams, the failure occurred because of the tensile rupture of steel bars at the tension side of the beams. The ultimate loads along with maximum vertical deflection shown in Table 4.3. As expected, the effect of using RCA on the flexural strength of the beams was relatively small, the replacement caused a slight decrease in the ultimate load about $8.82 \%, 6.95 \%$ and $5.18 \%$ for beams A2, A3, and A4 respectively, comparing to the control beam A1. This is because of using saturated surface dry RCA in concrete mix design, which partially compensated the negative effect related to the weakness of the old interfacial transition zone in RCA as the flexural strength is mainly dependent on the bond strength between aggregate and cement matrix. In addition, it can be noticed that the 
deflection slightly decreased by about $8.57 \%, 11.43 \%$ and $14.29 \%$ for beams A2, A3 and A4 respectively, comparing with control beam A1. As the aggregate replacement ration increased, beams presented a slightly smaller deflection before failure. This is primarily due to the presence of the attached old mortar.

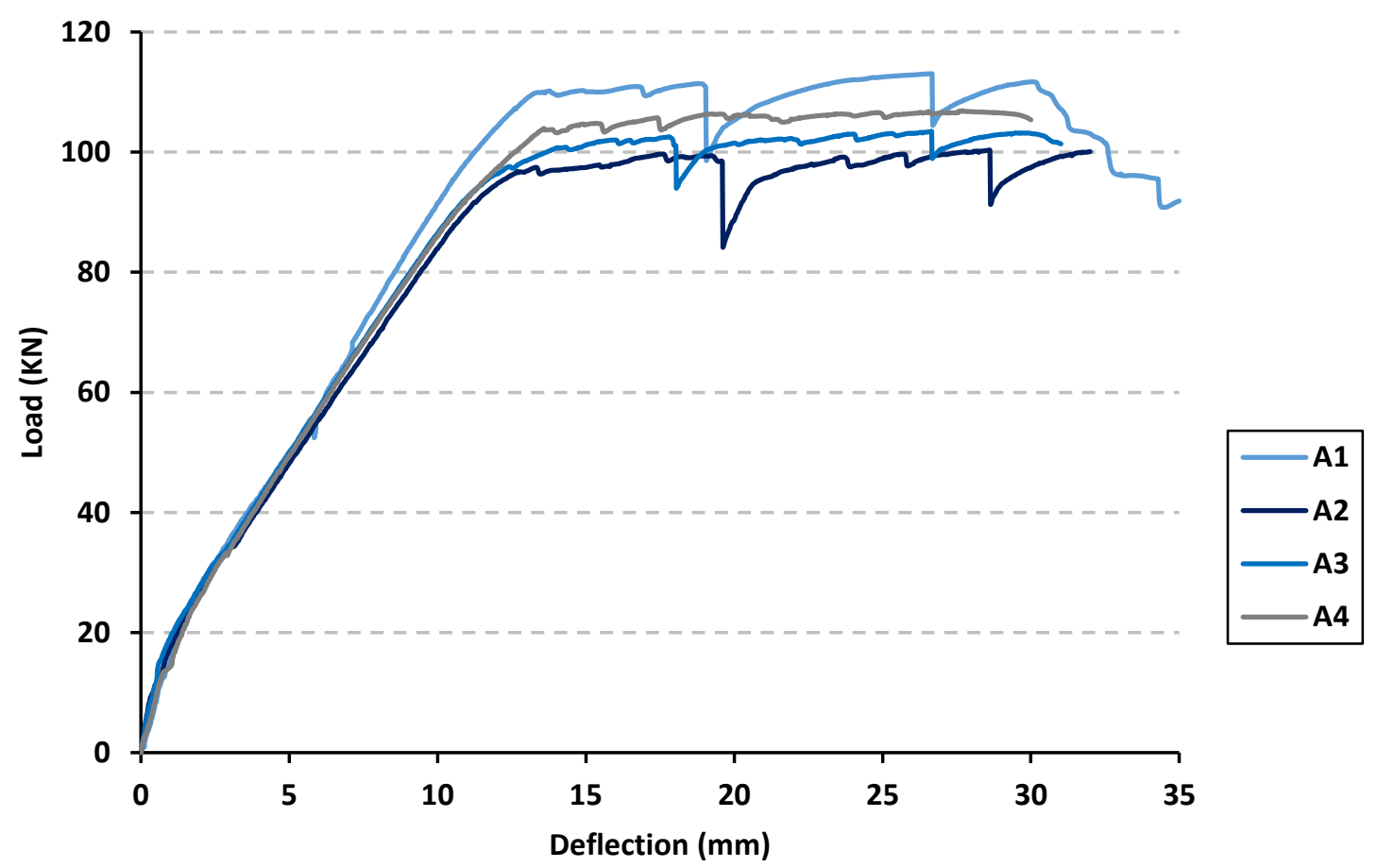

Figure 4.69 Load Vs. Deflection for Specimens A1, A2, A3 and A4

\section{Crack Pattern}

Figure 4.73 illustrate the crack propagation and crack spacing at various loading stages from first crack up to failure for beams A2, A3, and A4 and their corresponding control beam A1 photographically. The first flexural crack in beam specimen A1 was noticed at the mid-span at load of $25 \mathrm{kN}$, while the first crack in the specimens A2, A3 and A4 were noticed at $21 \mathrm{kN}, 19 \mathrm{kN}$ and $18 \mathrm{kN}$ respectively. In general, the numbers of cracks for beams containing RCA were almost similar to the number of cracks observed in the control beam. This improvement is due to using saturated surface dry RCA in the concrete mix design, that enhances the bond behavior of RCA during the hardening stage. 
Unfortunately, due to the presence of technical issues with the crack transducers, crack widths measurements were not accurate, and were ignored. Though, visual observations showed no significant difference among the crack widths of the 4 different beams.
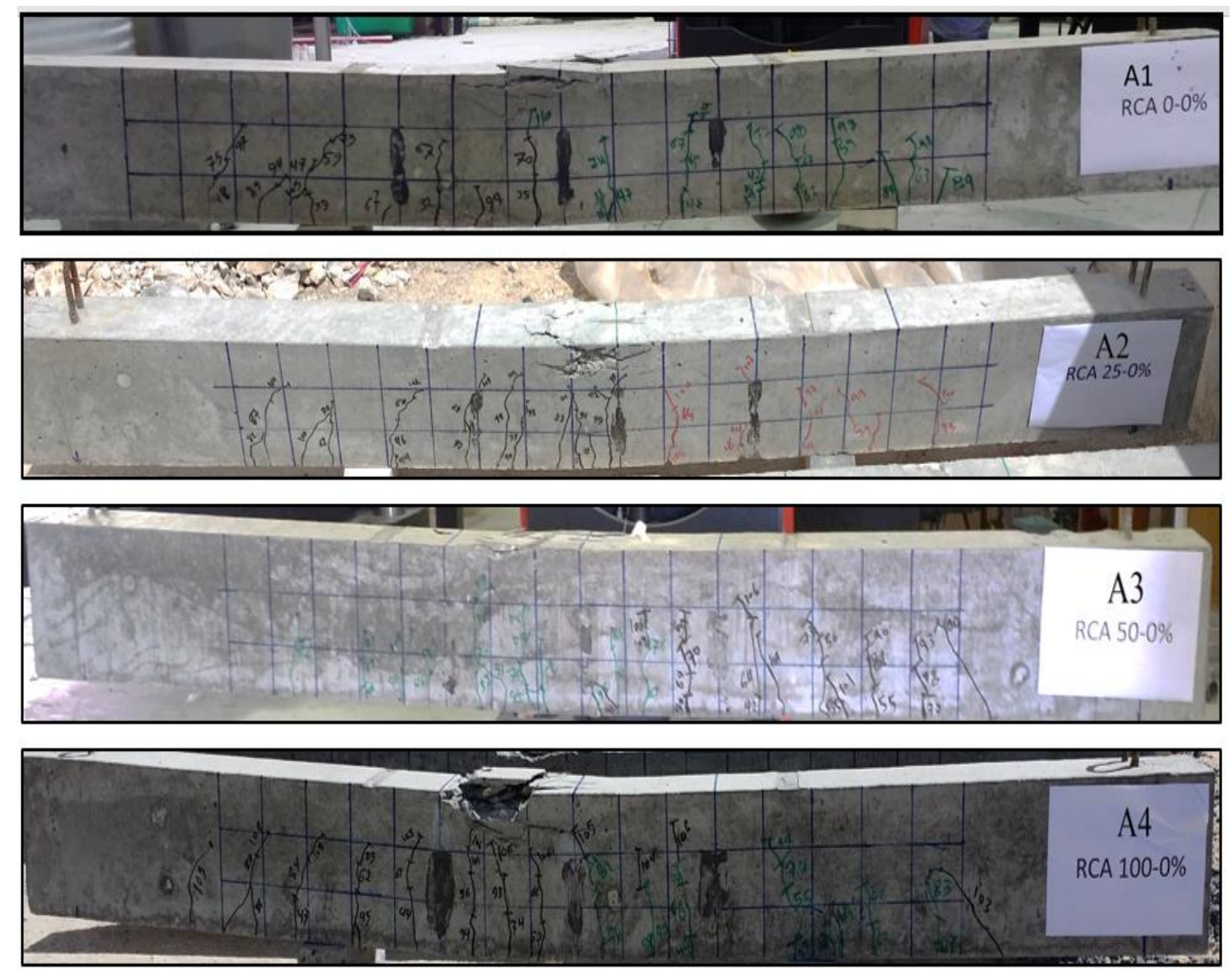

Figure 4.70 Crack Pattern in Test Beams A1, A2, A3 and A4 
Table 4.8 Summary of Number of Cracks

\begin{tabular}{cccc}
\hline Beam ID & RCA \% & BMF \% & Number of Cracks \\
A1 & 0 & 0 & 19 \\
A2 & 25 & 0 & 18 \\
A3 & 50 & 0 & 20 \\
A4 & 100 & 0 & 20 \\
\hline
\end{tabular}

\section{Strain in Concrete}

The concrete compressive strains measured for beams (A1, A2, A3, and A4) are presented in Figure 4.74. The maximum concrete strain values were 0.00282, 0.00284 ,0.00283 and 0.00292 for beams A1, A2, A3, and A4 respectively. The load-strain curves for each replacement ratio of RCA beams seem to follow a similar trend to the control beam that has $0 \%$ RCA. In general, the RCA follow same behavior of NCA. This is due to concrete mix design that enhanced by using saturated surface dry RCA.

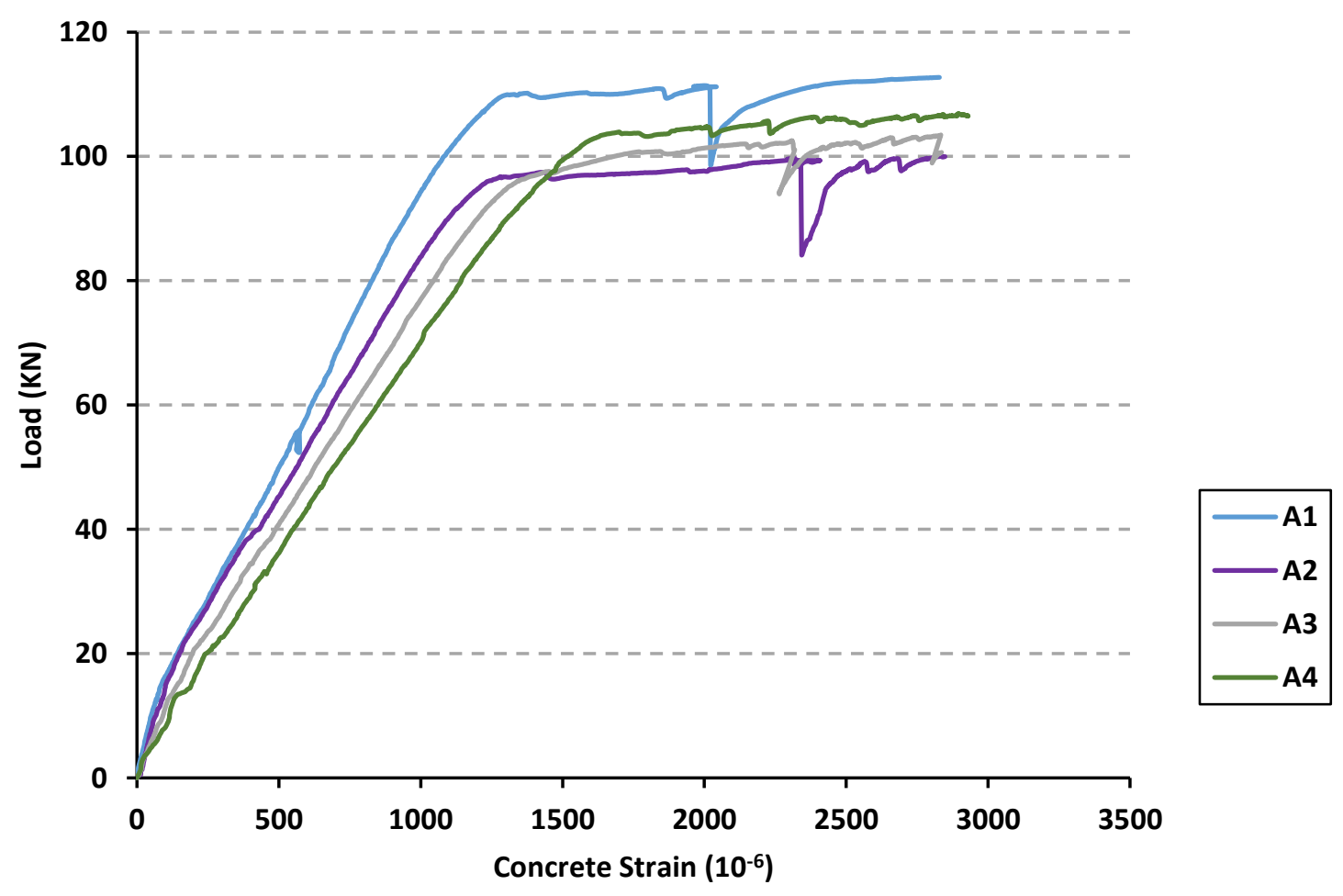

Figure 4.71 Concrete strain for test beams A1, A2, A3 and A4 


\section{Tensile Strain in Main Steel Reinforcement}

The tensile strain of the longitudinal steel reinforcement was measured at mid-span of beams (A1, A2, A3 and A4) to investigate the effect of using different replacement rations of RCA to the concrete mix. When the first flexure crack reached the position of the steel bars, a change in the steel bars response was recorded. It can be observed from Figure 4.75, that replacing ratios of $25 \%, 50 \%$ and $100 \%$ RCA to the concrete resulted in a decrease of $21.61 \%, 21.5 \%$ and $37.77 \%$ respectively in the maximum steel tensile strain. Indicating that the steel bar strain tended to decreases as the RCA replacement ratio increased. There is a good agreement between the aforementioned results and a study conducted by Kang et al. (Kang et al. 2014).

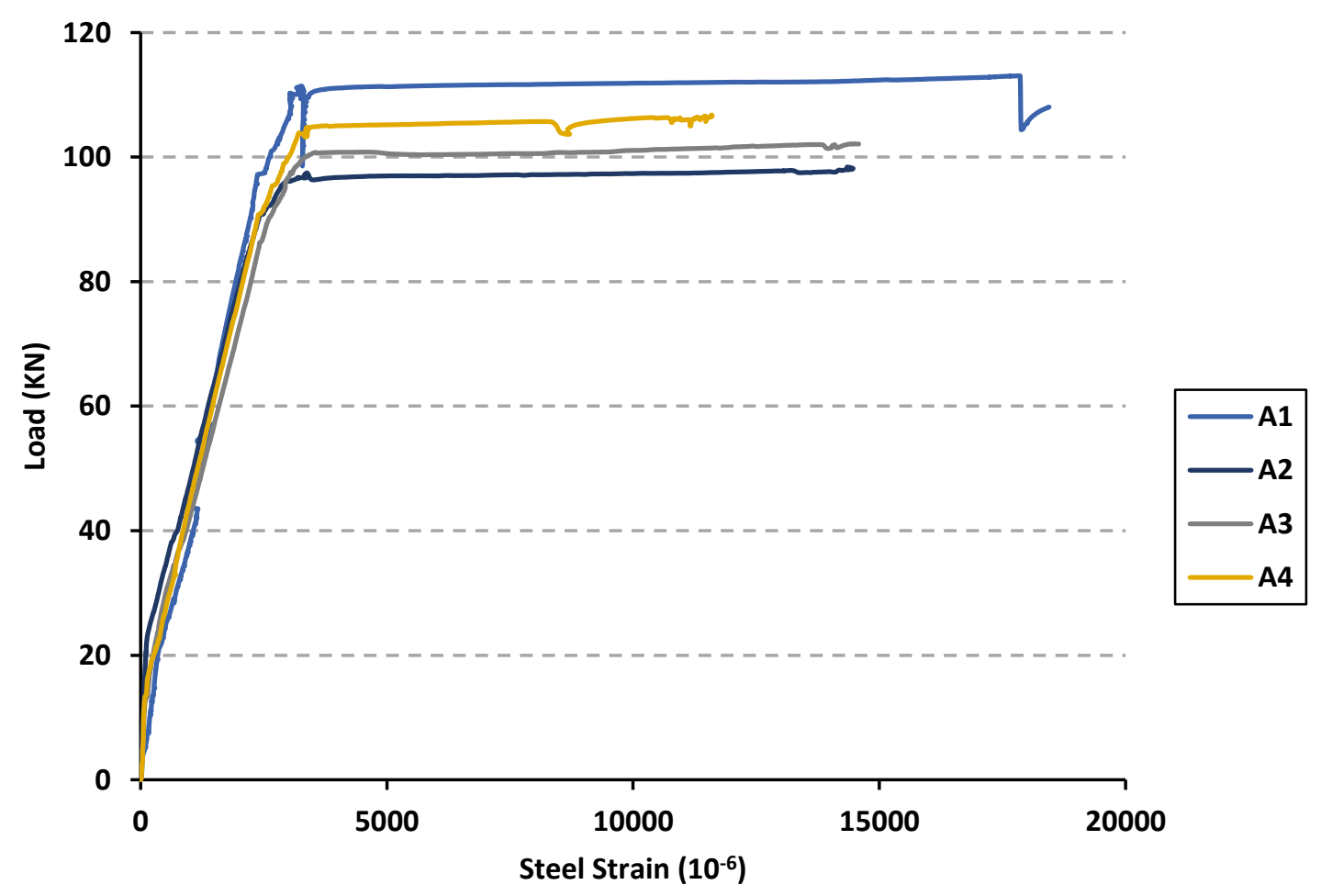

Figure 4.72 Steel Strain for test beams A1, A2, A3 and A4 


\section{Ductility Index (DI)}

The corresponding values of DI were 2.57, 2.52, 2.46 and 2.17 for beams A1, A2, A3 and A4 respectively. Figure 4.76 shows the relationship between the ductility index (DI) and replacement ratio of RCA (RCA \%). It can be noticed that the concrete beams made with saturated surface dry RCA normally have slightly lower ductility performance compared with the control beam. This is primarily due to the presence of the attached old mortar.

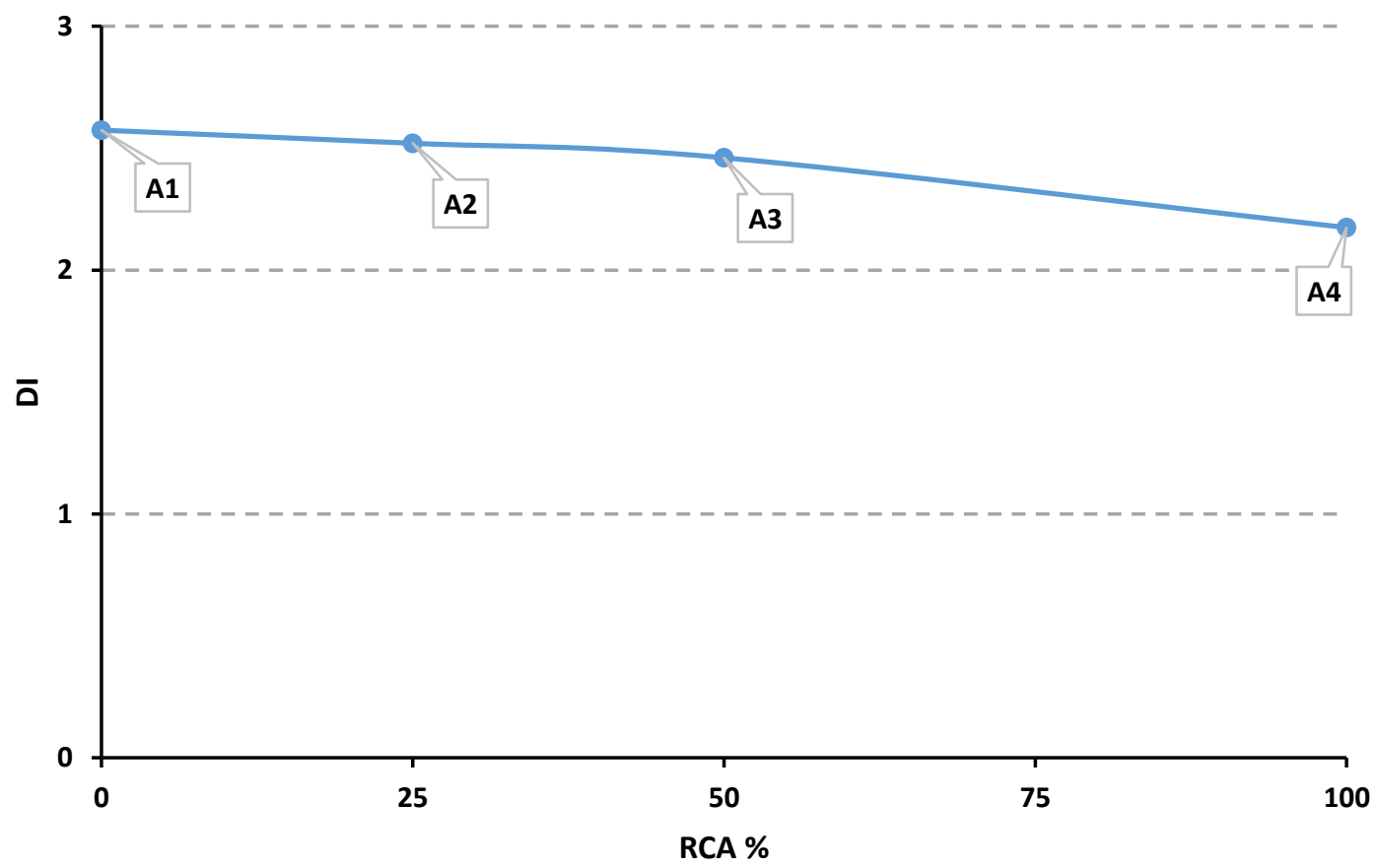

Figure 4.73 Ductility Index vs. Replacement Ratio of RCA for Specimens A1, A2, A3 and A4 


\subsubsection{Specimens A5, A6, A7, and A8}

\section{Failure Mode and Load vs. Deflection}

All four beams specimens (A5, A6, A7, and A8) have 0.5\% of BMF with 0\%, 25\%, $50 \%$, and $100 \%$ of RCA respectively. Flexure failure at the mid-span was the main failure mode for all four tested beams, the failure occurred because of the tensile rupture of steel bars at the tension side of the beams. The ultimate loads along with maximum vertical deflection shown in Table 4.3. As expected, the effect of using RCA on the flexural strength of the beams was relatively small, the replacement caused a slight decrease in the ultimate load about 5.6\%, 5.7\% and a slight increase 2.28\% for beams A7, A8, and A6 respectively, comparing to the control beam A5. This is because of using saturated surface dry RCA in concrete mix design, which partially compensated the negative effect related to the weakness of the old interfacial transition zone in RCA as the flexural strength is mainly dependent on the bond strength between aggregate and cement matrix. In addition, it can be noticed that the deflection slightly decreased by about $7.14 \%, 14.29 \%$ and $19.05 \%$ for beams A6, A7 and A8 respectively, comparing with control beam A5. As the aggregate replacement ration increased, beams presented a slightly smaller deflection before failure. This is primarily due to the presence of the attached old mortar. 


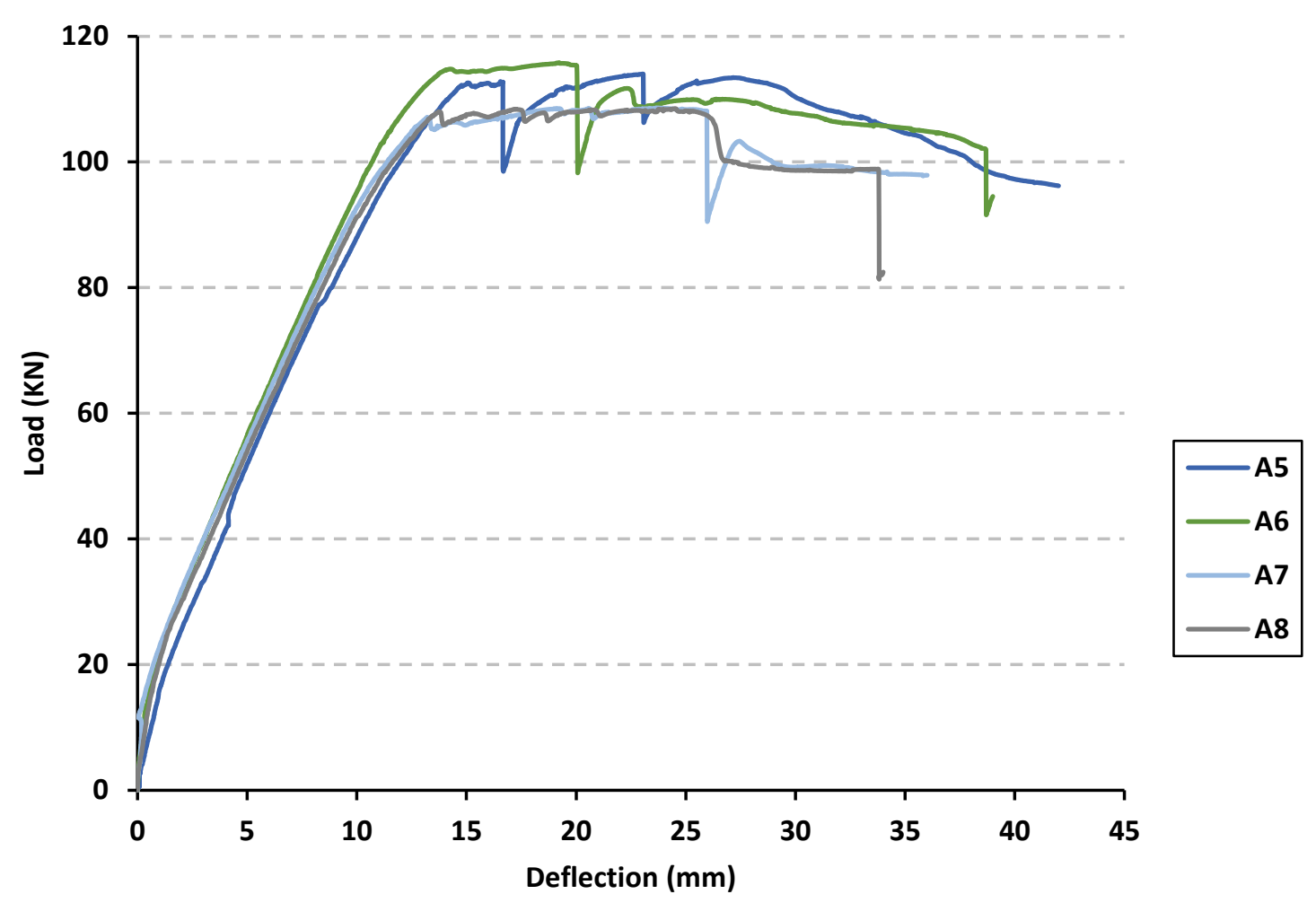

Figure 4.74 Load Vs. Deflection for Specimens A5, A6, A7 and A8

\section{Crack Pattern}

Figure 4.78 illustrate the crack propagation and crack spacing at various loading stages from first crack up to failure for beams A6, A7, and A8 and their corresponding control beam A5 photographically. The first flexural crack in beam specimen A5 was noticed at the mid-span at load of $27 \mathrm{kN}$, while the first crack in the specimens A6, A7 and A8 were noticed at $24 \mathrm{kN}, 22 \mathrm{kN}$ and $21 \mathrm{kN}$ respectively. In general, the numbers of cracks for beams containing RCA were almost similar to the number of cracks observed in the control beam. This improvement is due to using saturated surface dry RCA in the concrete mix design, that enhances the bond behavior of RCA during the hardening stage. Unfortunately, due to the presence of technical issues with the crack transducers, crack widths measurements were not accurate, and were ignored. Though, visual observations showed no significant difference among the crack widths of the 4 different beams. 

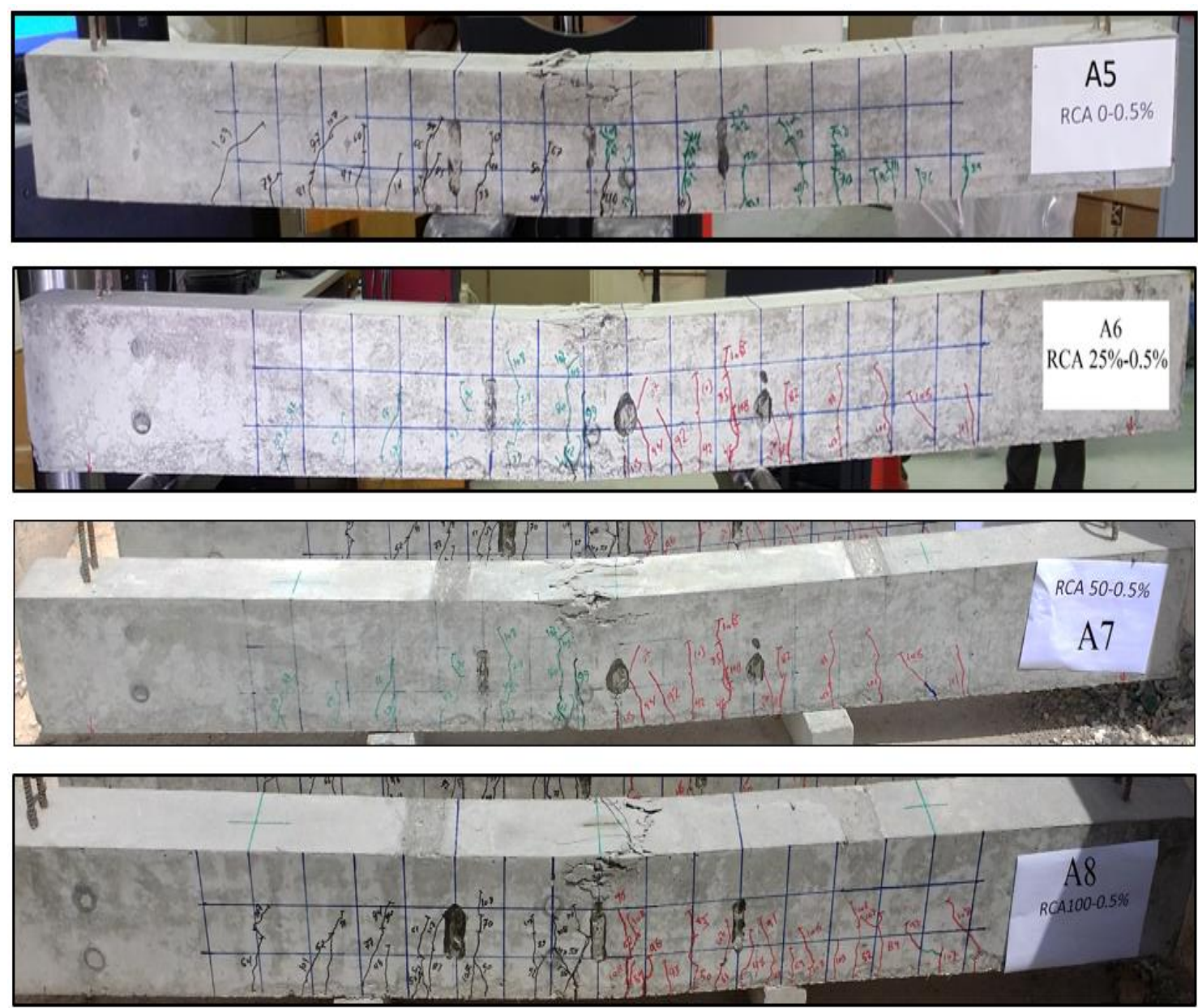

Figure 4.75 Crack Pattern in Test Beams A5, A6, A7 and A8

Table 4.9 Summary of Number of Cracks

\begin{tabular}{cccc}
\hline Beam ID & RCA \% & BMF \% & Number of Cracks \\
A5 & 0 & 0.5 & 18 \\
A6 & 25 & 0.5 & 19 \\
A7 & 50 & 0.5 & 19 \\
A8 & 100 & 0.5 & 16 \\
\hline
\end{tabular}




\section{Strain in Concrete}

The concrete compressive strains measured for beams (A5, A6, A7, and A8) are presented in Figure 4.79. The maximum concrete strain values were 0.00285, 0.00228 (break in strain gauges in beam A6),0.00352 and 0.00292 for beams A5, A6, A7, and A8 respectively. The load-strain curves for each replacement ratio of RCA beams seem to follow a similar trend to the control beam that has $0 \%$ RCA. In general, the RCA follow same behavior of NCA. This is due to concrete mix design that enhanced by using saturated surface dry RCA.

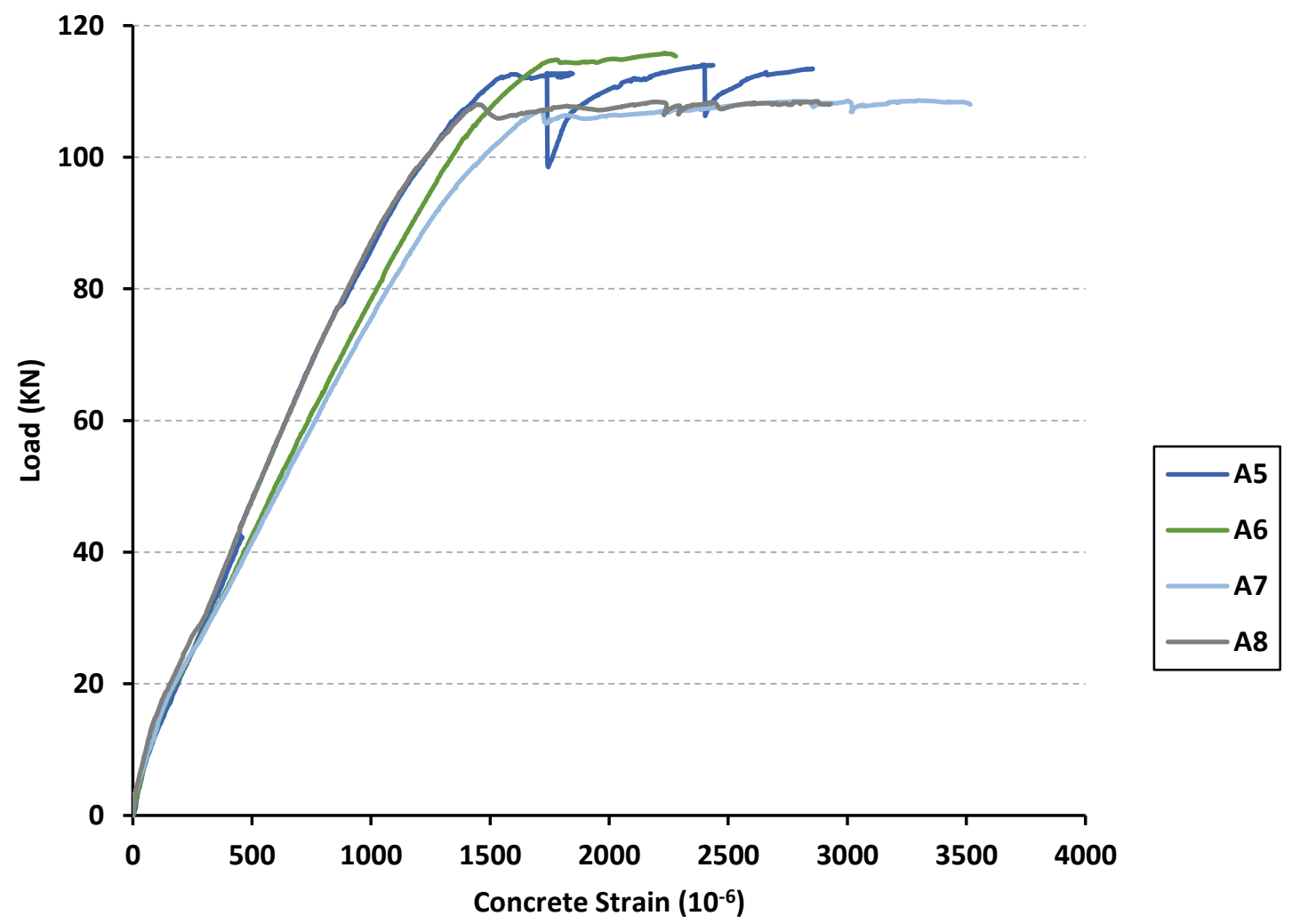

Figure 4.76 Concrete strain for test beams A5, A6, A7 and A8 


\section{Ductility Index (DI)}

The corresponding values of DI were 2.73, 2.67, 2.71 and 2.46 for beams A5, A6, A7 and A8 respectively. Figure 4.80 shows the relationship between the ductility index (DI) and replacement ratio of RCA (RCA \%). It can be noticed that the concrete beams made with saturated surface dry RCA normally have slightly lower ductility performance compared with the control beam. This is primarily due to the presence of the attached old mortar.

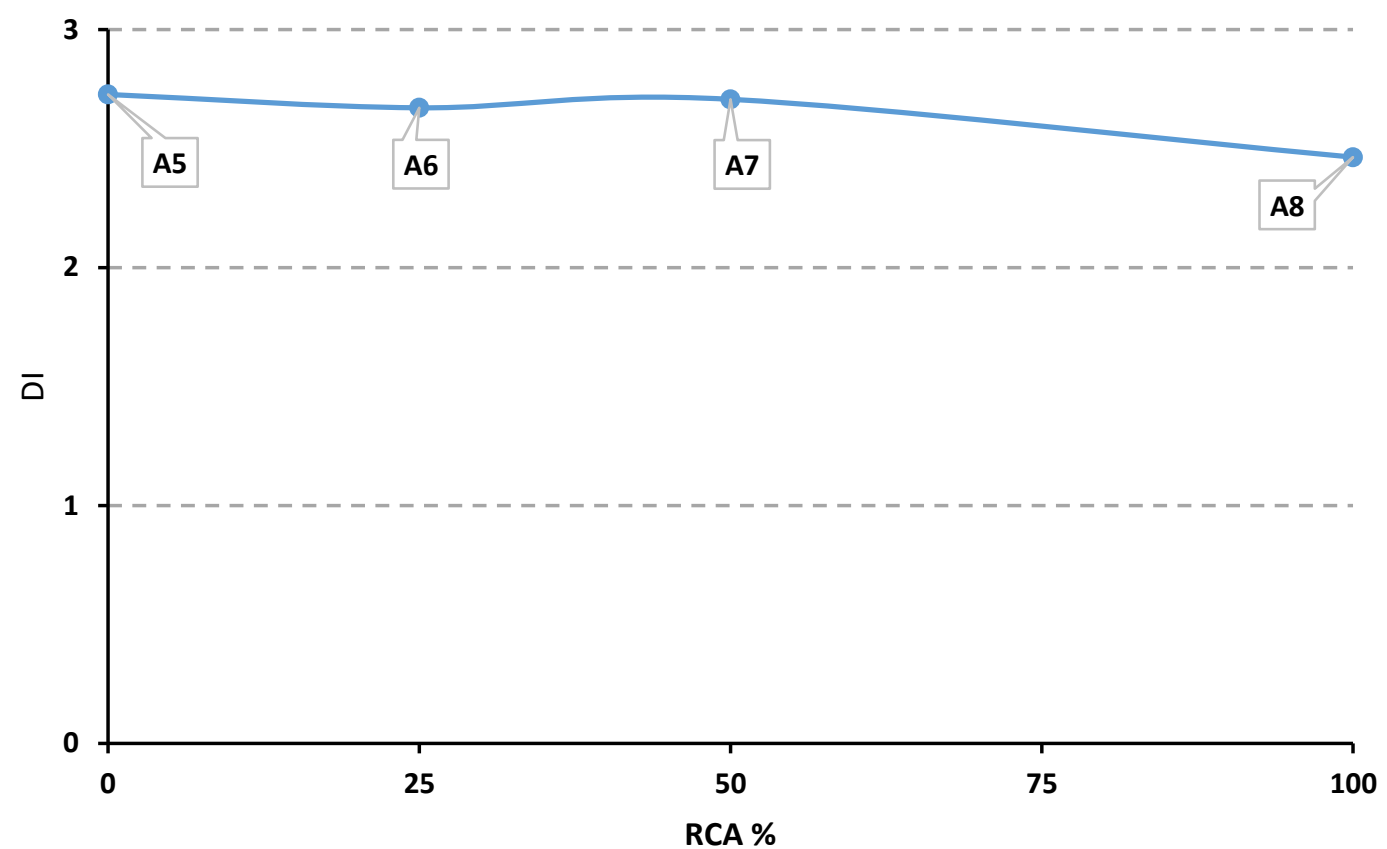

Figure 4.77 Ductility Index vs. Replacement Ratio of RCA for Specimens A5, A6, A7 and $\mathrm{A} 8$ 


\subsubsection{Specimens A9, A10, A11, and A12}

\section{Failure Mode and Load vs. Deflection}

All four beams specimens (A9, A10, A11, and A12) have 1\% of BMF with $0 \%$, $25 \%, 50 \%$, and $100 \%$ of RCA respectively. Flexure failure at the mid-span was the main failure mode for all four tested beams, the failure occurred because of the tensile rupture of steel bars at the tension side of the beams. The ultimate loads along with maximum vertical deflection shown in Table 4.3. As expected, the effect of using RCA on the flexural strength of the beams was relatively small, the replacement caused a slight decrease in the ultimate load about 12.3\%, $11.39 \%$ and $10.47 \%$ for beams A10, A11, and A12 respectively, comparing to the control beam A9. This is because of using saturated surface dry RCA in concrete mix design, which partially compensated the negative effect related to the weakness of the old interfacial transition zone in RCA as the flexural strength is mainly dependent on the bond strength between aggregate and cement matrix. In addition, it can be noticed that the deflection of beams A10, A11 and A12 are almost similar to the control beam A9. As the aggregate replacement ration increased, beams presented a slightly smaller deflection before failure. This is primarily due to the presence of the attached old mortar. 


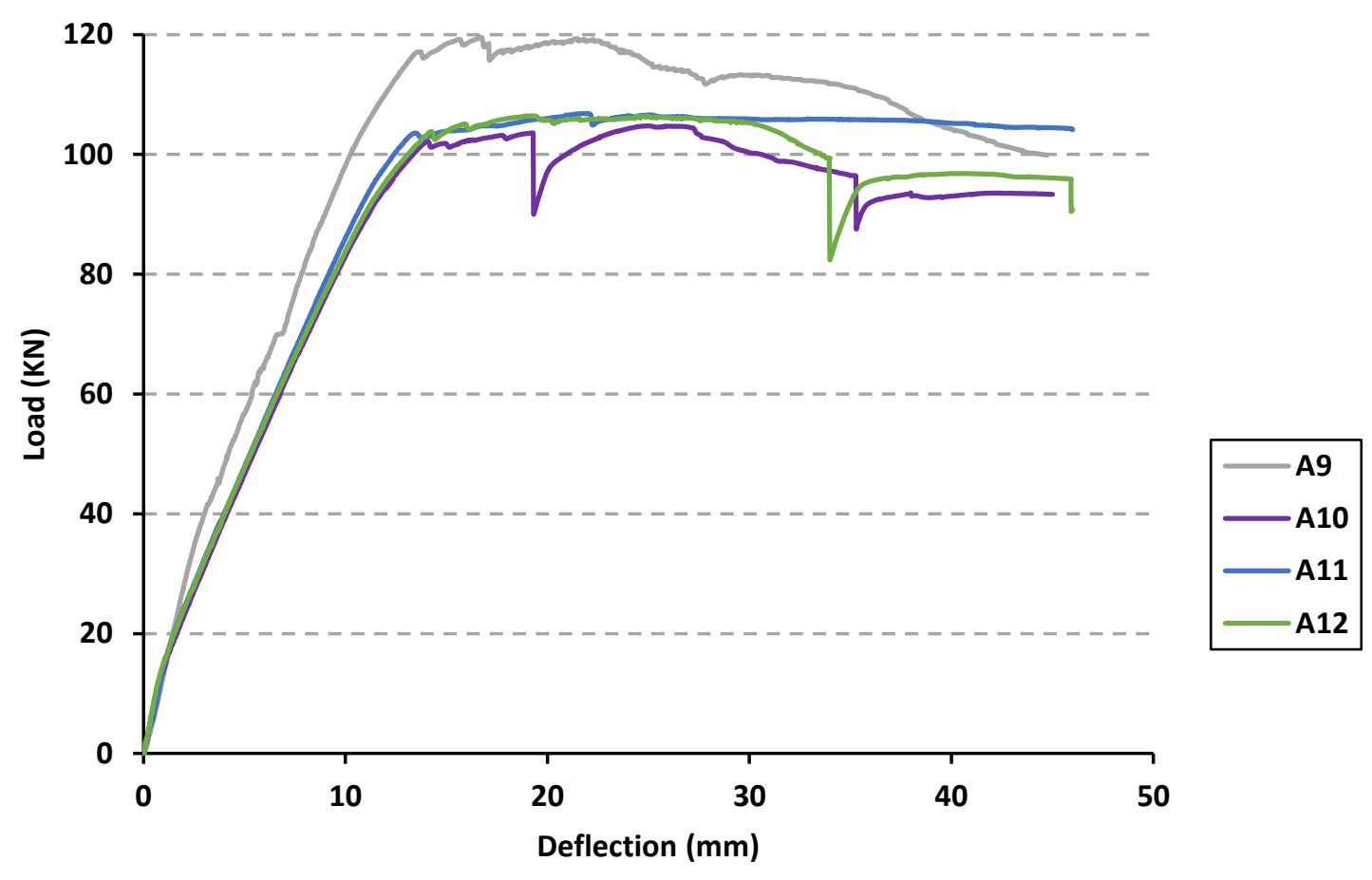

Figure 4.78 Load Vs. Deflection for Specimens A9, A10, A11 and A12

\section{Crack Pattern}

Figure 4.82 illustrate the crack propagation and crack spacing at various loading stages from first crack up to failure for beams A10, A11, and A12 and their corresponding control beam A9 photographically. The first flexural crack in beam specimen A9 was noticed at the mid-span at load of $39 \mathrm{kN}$, while the first crack in the specimens A10, A11 and A12 were noticed at $30 \mathrm{kN}, 28 \mathrm{kN}$ and $31 \mathrm{kN}$ respectively. In general, the numbers of cracks for beams containing RCA were almost similar to the number of cracks observed in the control beam. This improvement is due to using saturated surface dry RCA in the concrete mix design, that enhances the bond behavior of RCA during the hardening stage. Unfortunately, due to the presence of technical issues with the crack transducers, crack widths measurements were not accurate, and were ignored. Though, visual observations showed no significant difference among the crack widths of the 4 different beams. 

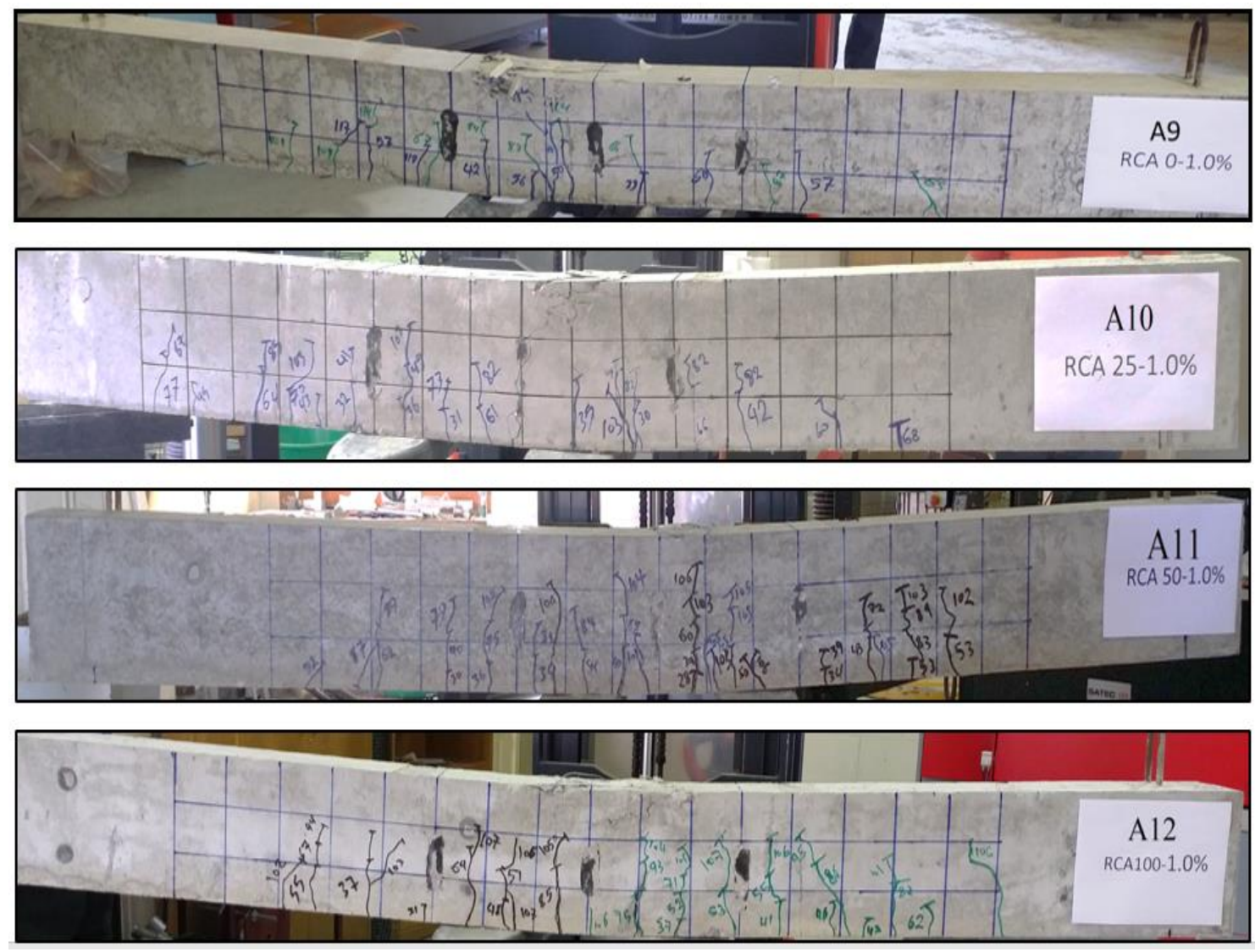

Figure 4.79 Crack Pattern in Test Beams A9, A10, A11 and A12

Table 4.10 Summary of Number of Cracks

\begin{tabular}{cccc}
\hline Beam ID & RCA \% & BMF \% & Number of Cracks \\
A9 & 0 & 1 & 16 \\
A10 & 25 & 1 & 17 \\
A11 & 50 & 1 & 21 \\
A12 & 100 & 1 & 19 \\
\hline
\end{tabular}




\section{Strain in Concrete}

The concrete compressive strains measured for beams (A9, A10, A11, and A12) are presented in Figure 4.83. The maximum concrete strain values were 0.00262 (break in strain gauges in beam A9), $0.00374,0.0031$ and 0.0035 for beams A9, A10, A11, and A12 respectively. The load-strain curves for each replacement ratio of RCA beams seem to follow a similar trend to the control beam that has $0 \%$ RCA. In general, the RCA follow same behavior of NCA. This is due to concrete mix design that enhanced by using saturated surface dry RCA.

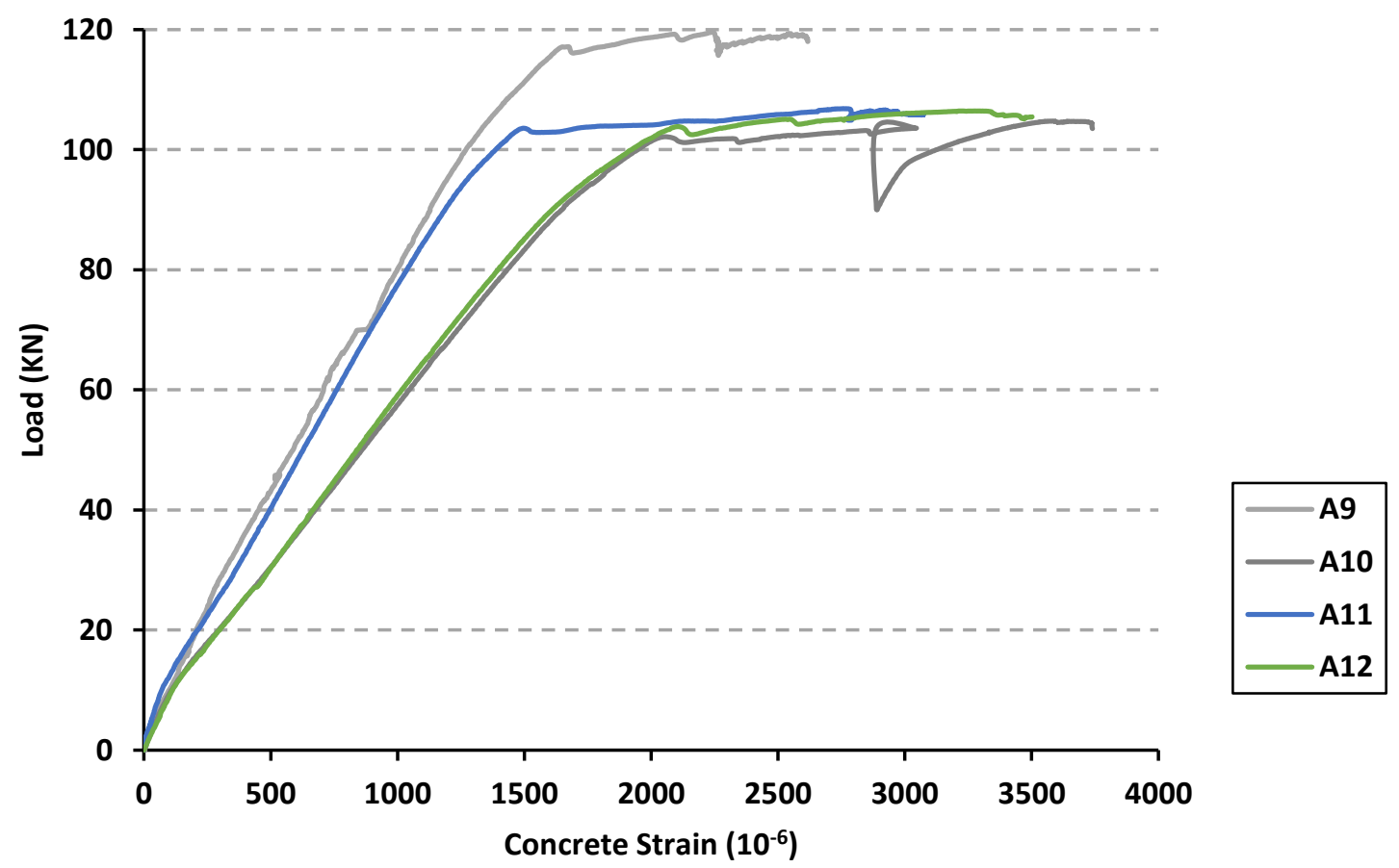

Figure 4.80 Concrete strain for test beams A9, A10, A11 and A12 


\section{Ductility Index (DI)}

The corresponding values of DI were 3.26, 3.19, 3.38 and 3.22 for beams A9, A10, A11 and A12 respectively. Figure 4.80 shows the relationship between the ductility index (DI) and replacement ratio of RCA (RCA \%). It can be noticed that the concrete beams made with saturated surface dry RCA normally have slightly lower ductility performance compared with the control beam. This is primarily due to the presence of the attached old mortar.

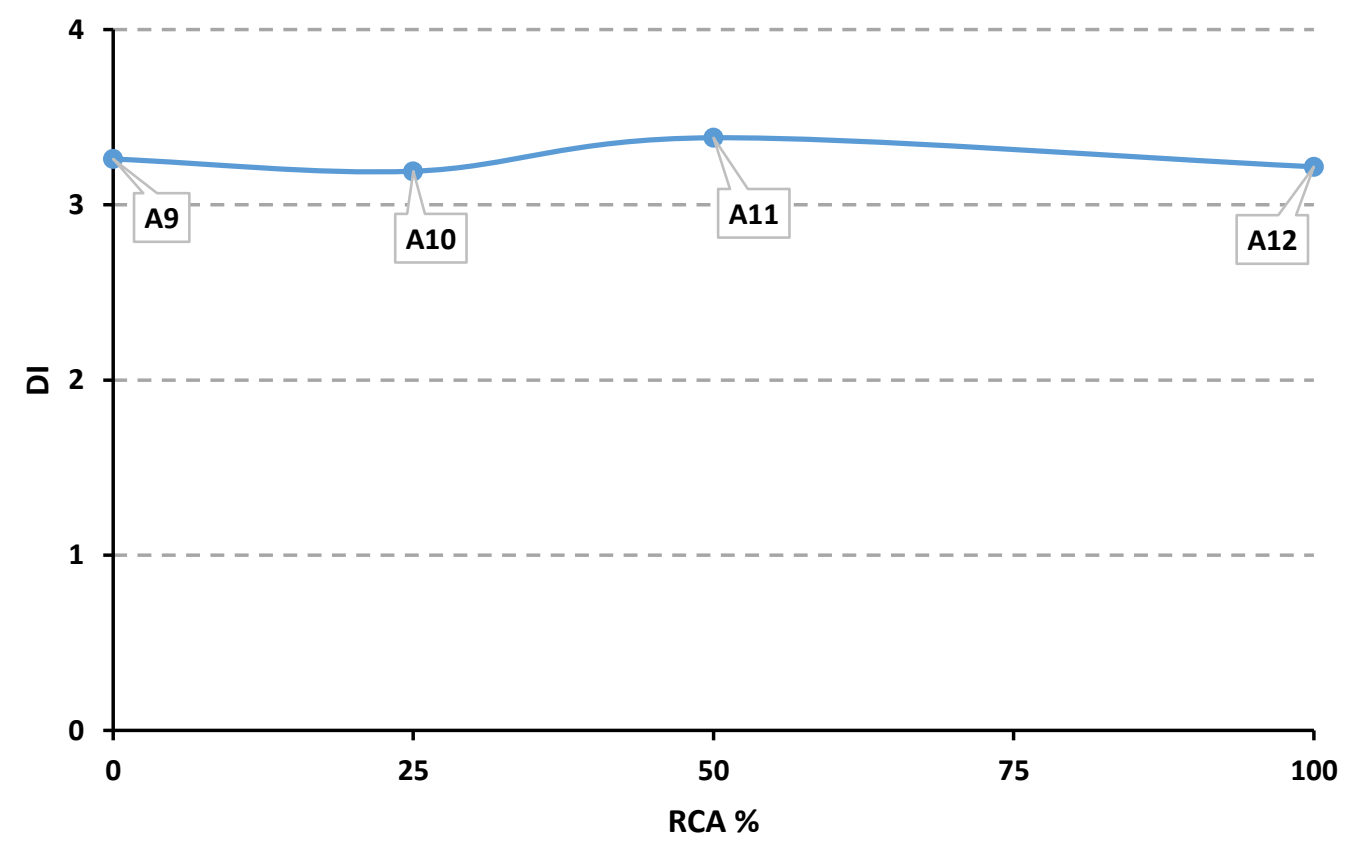

Figure 4.81 Ductility Index vs. Replacement Ratio of RCA for Specimens A9, A10, A11 and $\mathrm{A} 12$

\subsubsection{Specimens A14, A15, and A16}

\section{Failure Mode and Load vs. Deflection}

All four beams specimens (A14, A15, and A16) have 1.5\% of BMF with 25\%, 50\%, and $100 \%$ of RCA respectively. Flexure failure at the mid-span was the main failure mode for all four tested beams, the failure occurred because of the tensile rupture of steel bars at the tension side of the beams. The ultimate loads along with maximum vertical deflection 
shown in Table 4.3. As expected, the effect of using RCA on the flexural strength of the beams was relatively small. This is because of using saturated surface dry RCA in concrete mix design, which partially compensated the negative effect related to the weakness of the old interfacial transition zone in RCA as the flexural strength is mainly dependent on the bond strength between aggregate and cement matrix. In addition, it can be noticed that the deflection slightly increased by about $2.04 \%$, and $9.26 \%$ for beams A15, A16 respectively comparing with beam A14. As the aggregate replacement ration increased, beams presented a slightly smaller deflection before failure. This is primarily due to the presence of the attached old mortar.

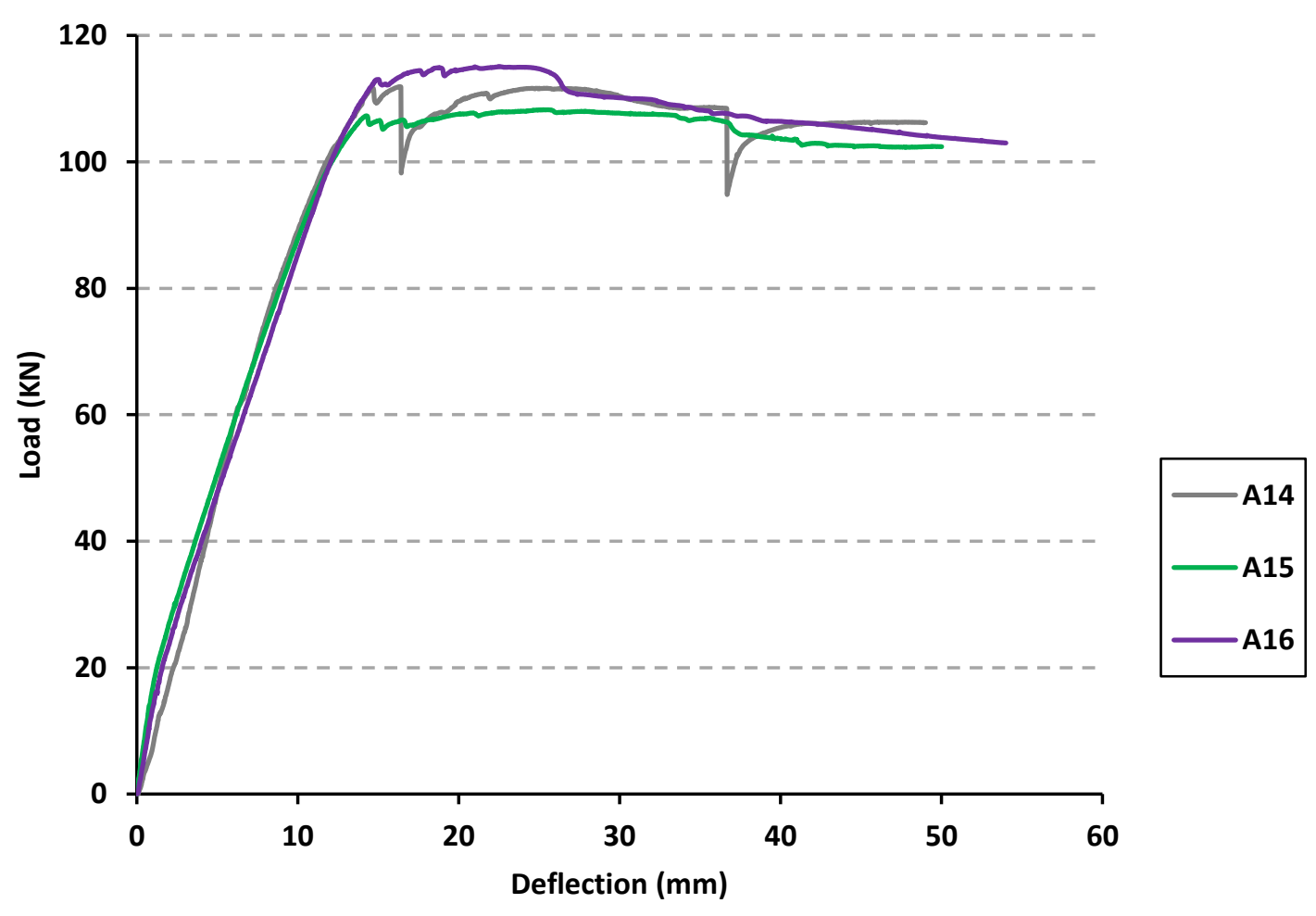

Figure 4.82 Load Vs. Deflection for Specimens A14, A15 and A16 


\section{Crack Pattern}

Figure 4.86 illustrate the crack propagation and crack spacing at various loading stages from first crack up to failure for beams A14, A15, and A16 photographically. The first flexural crack in beam specimen A14 was noticed at the mid-span at load of $31 \mathrm{kN}$, while the first crack in the specimens A15 and A16 were noticed at $33 \mathrm{kN}$ and $25 \mathrm{kN}$ respectively. In general, the numbers of cracks for beams containing RCA were almost similar to the number of cracks observed in the control beam. This improvement is due to using saturated surface dry RCA in the concrete mix design, that enhances the bond behavior of RCA during the hardening stage. Unfortunately, due to the presence of technical issues with the crack transducers, crack widths measurements were not accurate, and were ignored. Though, visual observations showed no significant difference among the crack widths of the 4 different beams.
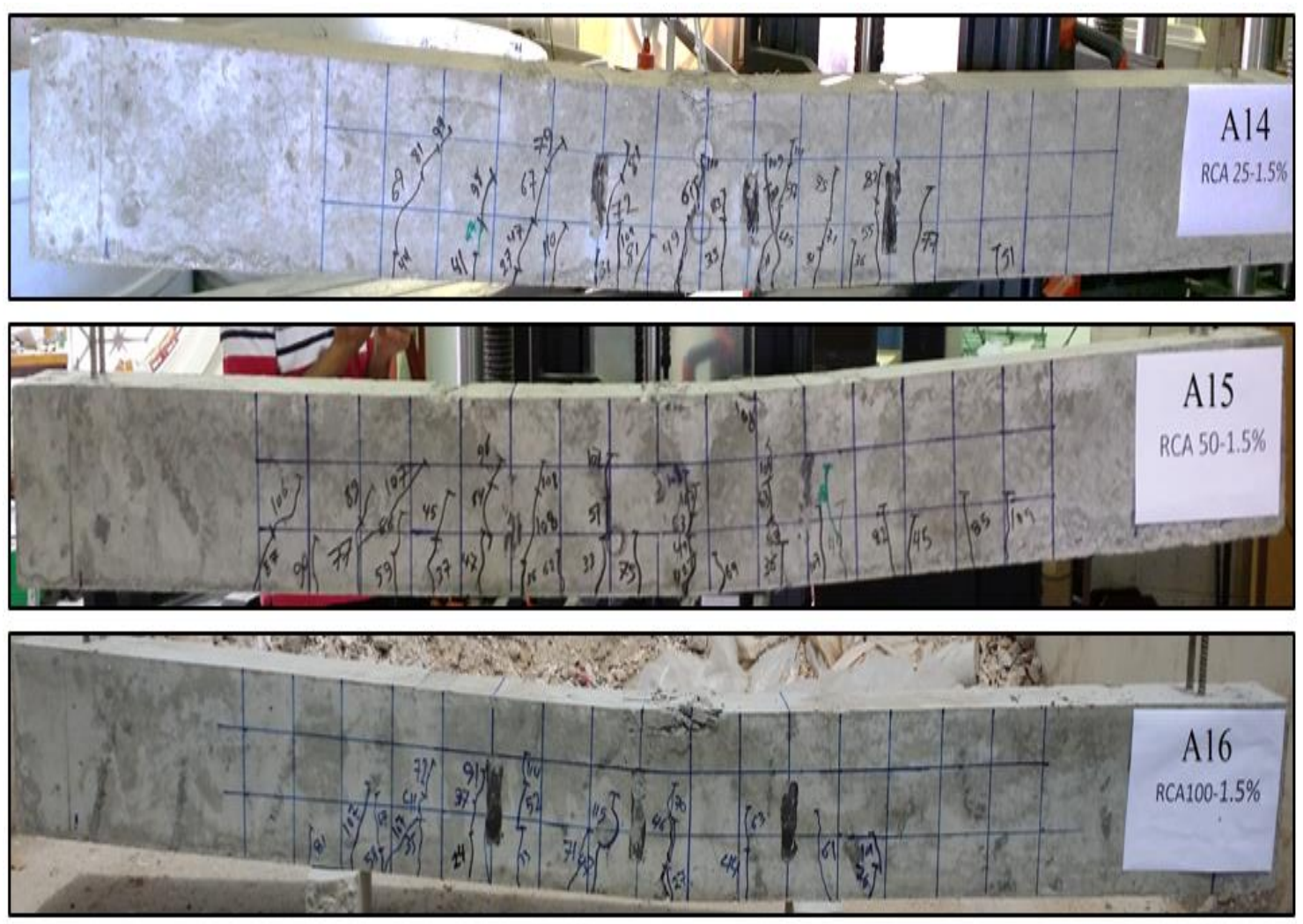

Figure 4.83 Crack Pattern in Test Beams A14, A15 and A16 
Table 4.11Summary of Number of Cracks

\begin{tabular}{cccc}
\hline Beam ID & RCA \% & BMF \% & Number of Cracks \\
A14 & 25 & 1.5 & 16 \\
A15 & 50 & 1.5 & 19 \\
A16 & 100 & 1.5 & 14 \\
\hline
\end{tabular}

\section{Strain in Concrete}

The concrete compressive strains measured for beams (A14, A15, and A16) are presented in Figure 4.87. The maximum concrete strain values were $0.00217,0.00374$ and 0.00372 for beams A14, A15, and A16 respectively. The load-strain curves for each replacement ratio of RCA beams seem to follow a similar trend to the beam that has $25 \%$ RCA. In general, the RCA follow same behavior of NCA. This is due to concrete mix design that enhanced by using saturated surface dry RCA.

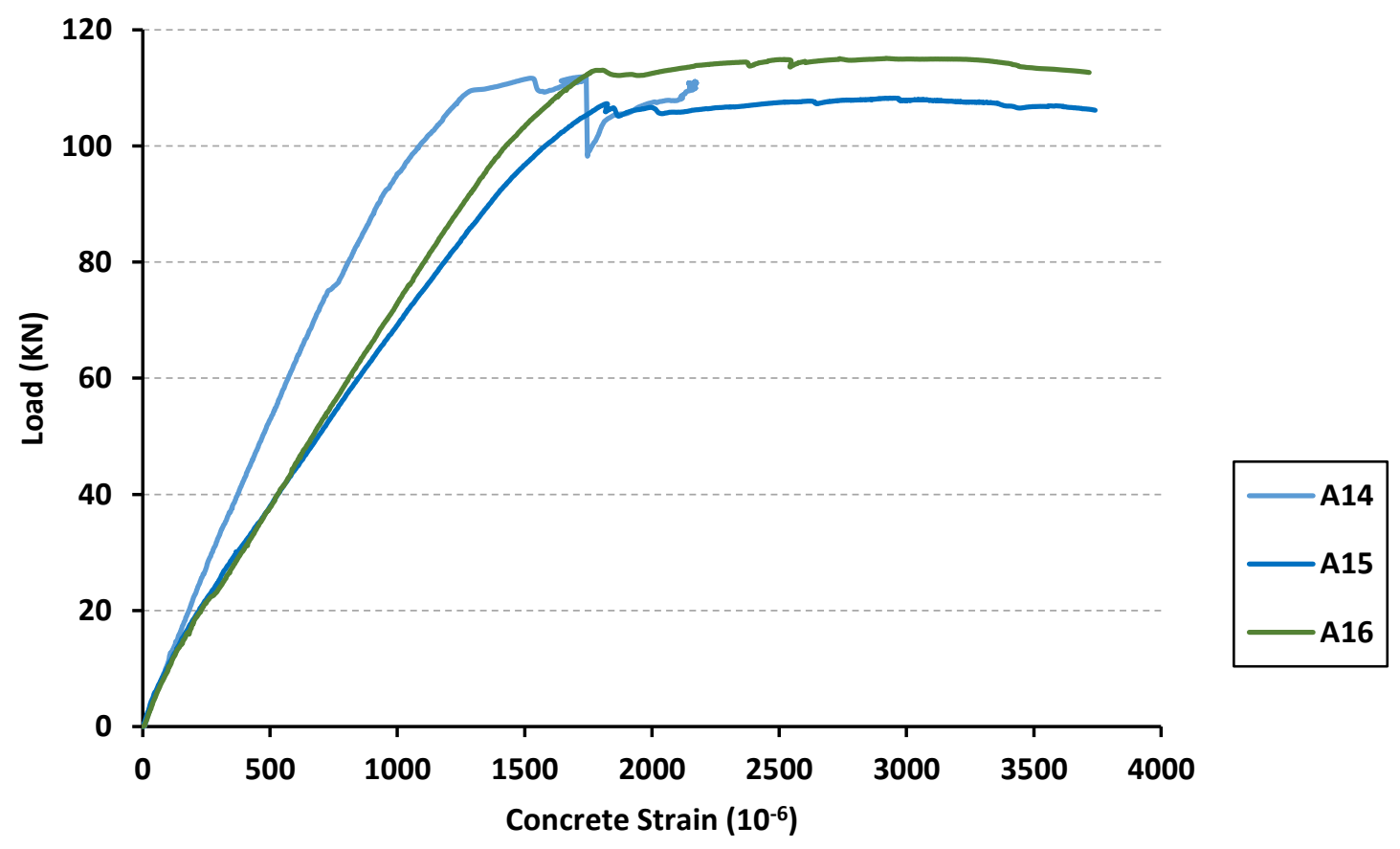

Figure 4.84 Concrete strain for test beams A14, A15 and A16 


\section{Ductility Index (DI)}

The corresponding values of DI were 3.33, 3.47 and 3.58 for beams A14, A15 and A16 respectively. Figure 4.80 shows the relationship between the ductility index (DI) and replacement ratio of RCA (RCA \%). It can be noticed that the concrete beams made with saturated surface dry RCA normally have slightly lower ductility performance compared with the control beam. This is primarily due to the presence of the attached old mortar.

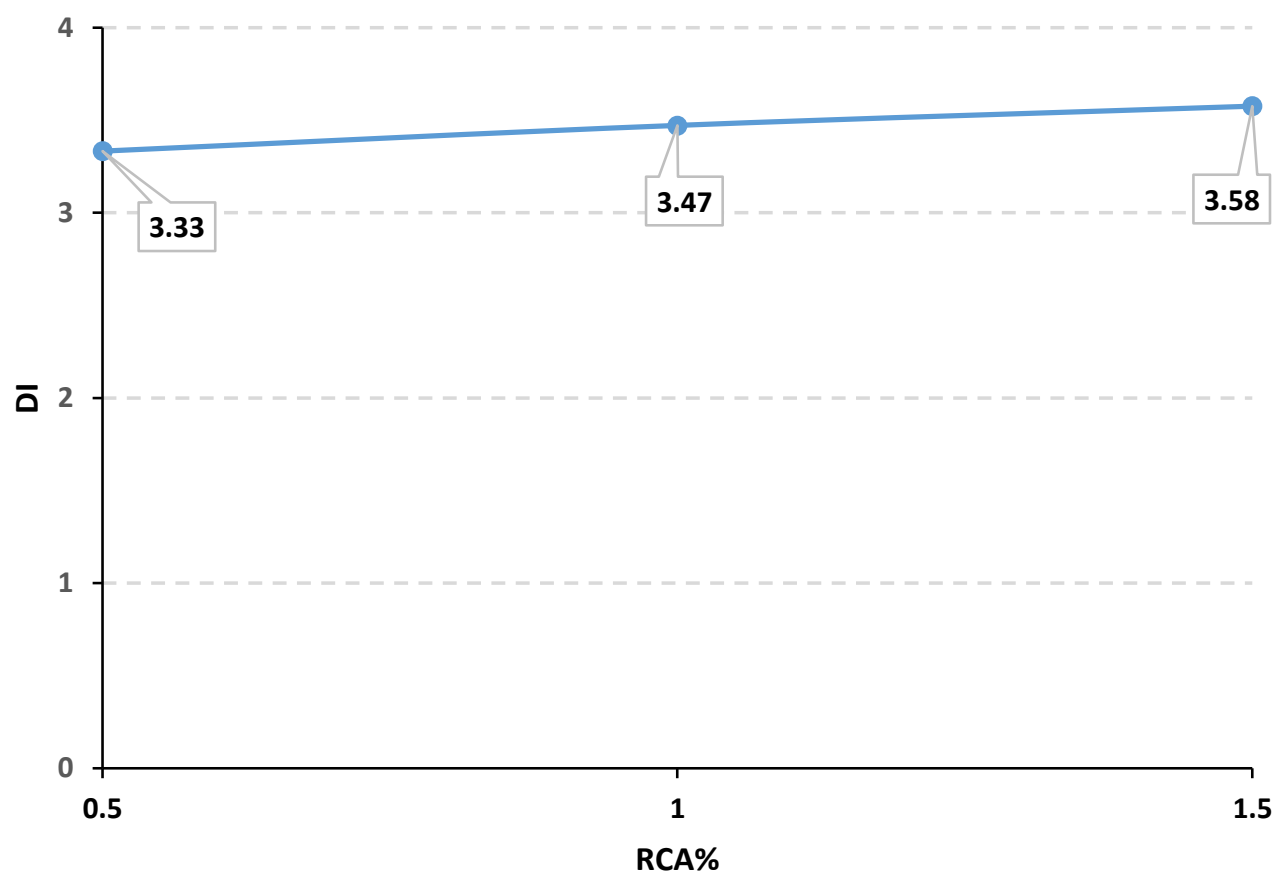

Figure 4.85 Ductility Index vs. Replacement Ratio of RCA for Specimens A14, A15 and A16 


\section{CHAPTER 5}

\section{THEORETICAL DEFLECTION AND FLEXURAL CALCULATIONS}

Currently, there are no specific provisions in any national or international guidelines for the design or calculating the flexural strength and the deflection of the FRC beams made with RCA. In this chapter, a critical comparison study was carried out between the experimental findings of this research and the analytical formulations based on the existing code-based analytical models. In addition, an improved code-based analytical model for evaluating the deflection of the FRC beams made with RCA was proposed. The values of the cracking moment, the flexural strength, and the mid-span deflection were analytically calculated and compared with the experimentally observed values, as follows:

1. Predicting the cracking moment $\left(M_{c r}\right)$, ultimate moment $\left(M_{u}\right)$ and moment of inertia of gross section $\left(I_{e}\right)$.by the recommended equations of (ACI 318 2014) for beams without BMF and (ACI 544.4R-88) for beams with BMF, the obtain results are compared with the corresponding experimental results for all RC beams.

2. Predicting the instantaneous deflection $\left(\Delta_{i}\right)$ for RC beams without BMF at $40 \%$ of their ultimate load $\left(P_{u}\right)$ by using the recommended equations of (ACI 318 2014), and the obtain results are compared with the corresponding experimental results.

3. Evaluating the applicability of the recommended equations that proposed by (Tan et al 1994) for calculating the moment of inertia of cracked section and instantaneous deflection $\left(\Delta_{i}\right)$ of RC beams with BMF at $40 \%$ of their ultimate load $\left(P_{u}\right)$. and the obtain results are compared with the corresponding experimental results.

The following sections present step-by-step formulations adopted for calculating the instantaneous deflection and ultimate flexural strength for all types of RC beams. 


\subsection{FLEXURAL CALCULATIONS}

\subsubsection{Prediction of the Cracking Moment $\left(M_{c r}\right)$}

The cracking moment $\left(M_{c r}\right)$ was calculated based on ACI 318-14 code (ACI 318 2014). Table 5.1 presents the predicted and experimentally evaluated cracking moments of the tested beams. The cracking moment $\left(M_{c r}\right)$ was predicted as follow:

- Use modulus of rupture $\left(f_{r}\right)$ obtained from experimental testing results, as shown in chapter four.

- Determine the gross moment of inertia $\left(I_{g}\right)$ by using the equation (5-1):

$$
I_{g}=\frac{b h^{3}}{12}
$$

- Determine the centroidal axis for uncracked section $(y t)$

- Determine the cracking moment $\left(M_{c r}\right)$ by using the equation (5-2)

$$
M_{c r}=\frac{f_{r} I_{g}}{y_{t}}
$$

Where $b$ is the width of beam, $h$ is the height of beam. The experimental cracking moment was calculated using the observed cracking load based on visual inspection during the test. 
Table 5.1 Theoretical and Experimental cracking moments

\begin{tabular}{|c|c|c|c|c|c|}
\hline Beam ID & RCA\% & BMF\% & $M_{c r \text { theo. }}(\mathrm{kN} . \mathrm{m})$ & $M_{c r, \text { exp. }}(\mathbf{k N} . \mathbf{m})$ & $M_{c r . \text { theo. }} / M_{c r, \exp }$ \\
\hline A1 & 0 & 0 & 6.83 & 10.63 & 0.64 \\
\hline $\mathbf{A 2}$ & 25 & 0 & 7.03 & 8.93 & 0.79 \\
\hline A3 & 50 & 0 & 6.92 & 8.08 & 0.86 \\
\hline A4 & 100 & 0 & 6.7 & 7.65 & 0.88 \\
\hline A5 & 0 & 0.5 & 7.41 & 11.48 & 0.65 \\
\hline A6 & 25 & 0.5 & 7.72 & 10.2 & 0.76 \\
\hline A7 & 50 & 0.5 & 7.33 & 9.35 & 0.78 \\
\hline A8 & 100 & 0.5 & 7.84 & 8.93 & 0.88 \\
\hline A9 & 0 & 1 & 9.09 & 16.58 & 0.55 \\
\hline A10 & 25 & 1 & 8.94 & 12.75 & 0.70 \\
\hline A11 & 50 & 1 & 8.69 & 11.9 & 0.73 \\
\hline A12 & 100 & 1 & 8.97 & 13.18 & 0.68 \\
\hline A14 & 25 & 1.5 & 9.67 & 13.18 & 0.73 \\
\hline A15 & 50 & 1.5 & 9.44 & 14.03 & 0.67 \\
\hline A16 & 100 & 1.5 & 9.5 & 10.63 & 0.89 \\
\hline
\end{tabular}

Based on the theoretical and experimental results shown in Table5.1, the theoretical results are reasonably close to the experimental trends, indicating that existing theoretical models and code based procedures for conventional reinforced concrete beams can also be applied to beams with different replacement ratios of RCA and volume fraction of BMF within similar variability for conventional concrete beam. According to Fathifazl et al.(Fathifazl et al. 2010), the ACI 318 method is known to be accurate within $\pm 20 \%$ for conventional RC beams. However, the $M_{c r \text {.theo. }} / M_{c r \text {,exp. }}$ ratio for some beams are slightly higher than this range. In addition, it is observed that adding more RCA into the concrete mix resulted in a slight decrease in the recorded cracking. This is because of the existence of two interfacial transition zones (ITZ) in the RCA beams compared with only one ITZ in the NCA beams. However, the effect of RCA on the cracking moment was less effective $1 \%$ and more. 


\subsubsection{Prediction of the ultimate moment $\left(M_{u}\right)$}

In this section, the ultimate flexural strength of beams specimens with and without BMF was calculated using the code-based equations of (ACI 544.4R-88) and (ACI 318 2014) respectively. The stress and strain distribution of RC beam with BMF is shown in Figure5.1.

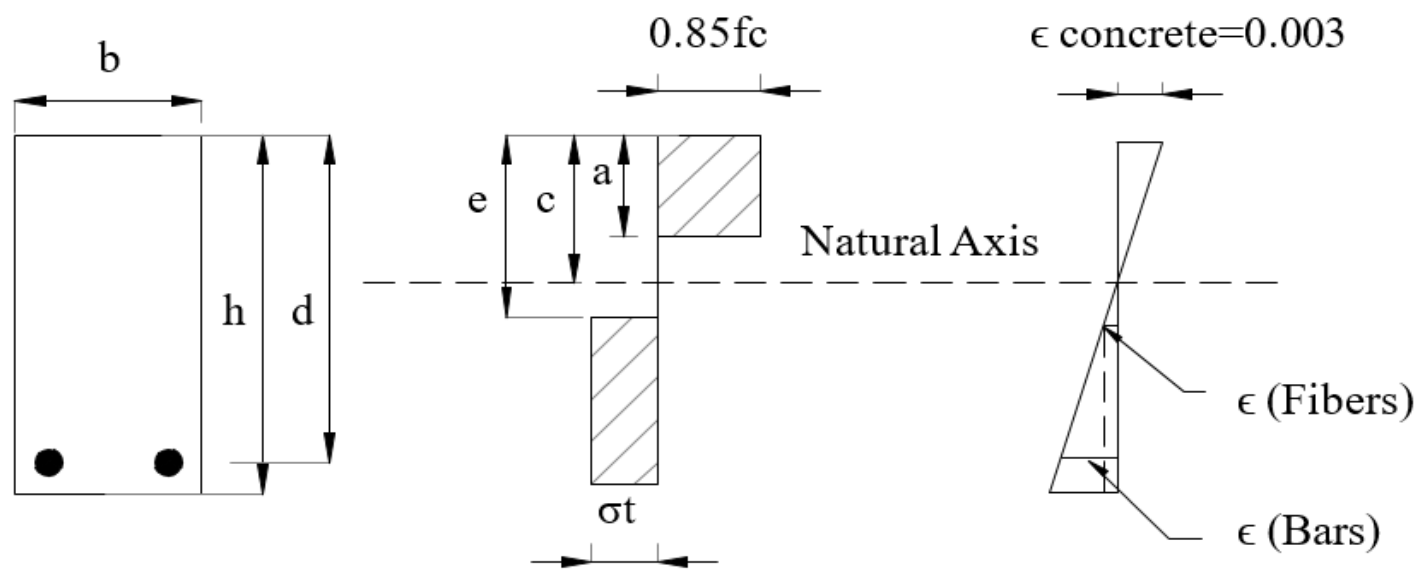

Figure 5.1Stress and Strain for RC beam with BMF

The calculation was carried out to determine the effect of volume fraction of fiber on the ultimate flexural strength using the following equations (ACI 544.4R-88):

$$
\begin{aligned}
& M_{n}=A_{s} f_{y}\left(d-\frac{a}{2}\right)+\sigma_{t} b(h-e)\left(\frac{h}{2}+\frac{e}{2}-\frac{a}{2}\right) \\
& a=\frac{\sigma_{t} b(h-e)+A_{s} f_{y}}{0.85 f_{c} b} \\
& e=\left[\varepsilon_{f}+0.003\right]^{c} / 0.003 \\
& \sigma_{t}=0.00772 l / d_{f} V_{f} F_{b e}
\end{aligned}
$$

The ultimate flexural strength for beams without BMF was calculated as follow (ACI 318 2014):

$$
a=\frac{A_{s} f_{y}}{0.85 f_{c} b}
$$




$$
M_{u}=A_{s} f_{y}\left(d-\frac{a}{2}\right)
$$

Where $A_{s}$ and $f_{y}$ are the area and the yield strength of longitudinal reinforcement respectively, $d$ is the effective depth of the beam section, $a$ is the depth of compressive stress block, $\sigma_{t}$ is the tensile stress in fibrous concrete, $b$ is width of beam, $e$ is the distance from extreme compression fiber to top of tensile stress block in fibrous concrete, $\epsilon_{f}$ is the tensile strain of fiber, $c$ is the distance from extreme compression fiber to neutral axis, $V_{f}$ is the volume fraction of BMF (\%) and $F_{b e}$ is the bond efficiency of BMF. The theoretical predicted and experimentally observed values of the ultimate strength of the tested beams specimens are compared in Table 5.2.

Table 5.2 Theoretical and Experimental Ultimate Flexural Moments

\begin{tabular}{cccccc}
\hline Beam ID & RCA\% & BMF\% & $M_{u \text {. theo. }}(\mathbf{k N . m})$ & $M_{u . \text { exp. }}(\mathbf{K N . M})$ & $M_{u \text {. theo }} / \boldsymbol{M}_{u \text {. exp }}$ \\
A1 & 0 & 0 & 32.5 & 48.05 & 0.68 \\
A2 & 25 & 0 & 32.3 & 43.81 & 0.74 \\
A3 & 50 & 0 & 32.2 & 44.71 & 0.72 \\
A4 & 100 & 0 & 32.3 & 45.72 & 0.71 \\
A5 & 0 & 0.5 & 33.02 & 48.91 & 0.68 \\
A6 & 25 & 0.5 & 33.1 & 50.05 & 0.66 \\
A7 & 50 & 0.5 & 32.34 & 46.17 & 0.70 \\
A8 & 100 & 0.5 & 33.05 & 46.12 & 0.72 \\
A9 & 0 & 1 & 33.11 & 51.25 & 0.65 \\
A10 & 25 & 1 & 32.63 & 44.94 & 0.73 \\
A11 & 50 & 1 & 32.94 & 45.41 & 0.72 \\
A12 & 100 & 1 & 32.66 & 45.88 & 0.71 \\
A14 & 25 & 1.5 & 33.42 & 48.08 & 0.69 \\
A15 & 50 & 1.5 & 33.61 & 46.38 & 0.72 \\
A16 & 100 & 1.5 & 33.28 & 49.32 & 0.67 \\
\hline
\end{tabular}

It is observed from Table 5.2 that the calculated ultimate flexural moment of beams specimens with and without BMF using the code-based equations of (ACI 544.4R-88) and (ACI 318 2014) respectively are slightly less than the experimentally recorded values 
.Based on these ratios, it can be observed that the (ACI 318 2014) flexural design provisions of conventional reinforced concrete beams are applicable to reinforced RCA concrete beams, and (ACI 544.4R-88) flexural design provisions are applicable to reinforced RCA concrete beams with BMF.

\subsection{ANALYTICAL MODELS FOR DEFLECTION CALCULATION}

All simply supported tested beams specimens of span "L" were subjected to two equal concentrated loads symmetrically placed about the beam center line at a distance "a" from the supports as shown in Figure 5.2.

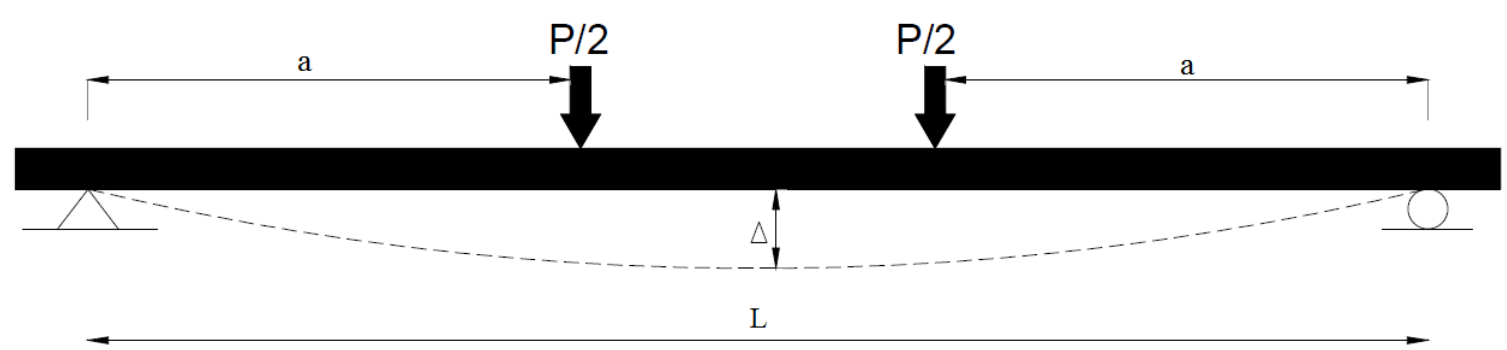

Figure 5.2 The simply-supported beam subjected to two equal concentrated loads symmetrically placed about the beam centerline

The instantaneous deflection $(\Delta \mathrm{i})$ computed at the mid-span of the beam is calculated as follow:

$$
\Delta i=\frac{P_{a}}{48 E_{c} I_{c}}\left(3 L^{2}-4 a^{2}\right)
$$

Where $P$ is the total applied concentrated load divided into two concentrated loads, $E c$ is the modulus of elasticity of concrete, and $I_{e}$ is the effective moment of inertia.

According to (ACI 318 2014), the effective moment of inertia, $I_{e}$ and $I_{c r}$ for beams without $\mathrm{BMF}$ is calculated as follows:

$$
\begin{aligned}
I_{e} & =\left(\frac{M_{c r}}{M_{a}}\right)^{3} I_{g}+\left[1-\left(\frac{M_{c r}}{M_{a}}\right)^{3}\right] I_{c r} \leq I_{g} \\
I_{c r} & =\frac{b X^{3}}{3}+n A_{s}(d-X)
\end{aligned}
$$


Where $M_{c r}$ is cracking moment, $M_{a}$ is the applied moment, $I_{c r}$ is the moment of inertia of the cracked transformed section, and $I_{g}$ is the moment of inertia of the uncracked section, $b$ is the beam width, $X$ is the distance from compression surface of the beam to the natural axis, $\mathrm{n}$ is the modular ratio, $A_{s}$ is the area of the steel, and $d$ is the effective depth of beam. According to (Tan et al 1994) the effective moment of inertia, $I_{e}$ can be calculated using equation (5.10). However, the moment of inertia of the transformed cracked section $I_{c r}$ for beams with BMF is determined as follows:

$$
I_{c r}=\frac{b X^{3}}{3}+n A_{s}(d-X)^{2}+n_{f} A_{f} \frac{(h-X)^{2}}{3}+\left(n_{f}-1\right) A_{f}^{\prime} \frac{X^{3}}{3}
$$

Where $n_{f}=E_{f} / E_{c f}, A f$ and $A_{f}^{\prime}$ are the area of BMF in tensile and compression zones respectively. $A f$ and $A_{f}^{\prime}$ are calculated as follow:

$$
\begin{aligned}
& A_{f}=\eta_{l} \eta^{\prime}{ }_{0} V_{f} b(h-X) \\
& A_{f}^{\prime}=\eta_{l} \eta_{0} V_{f} b X
\end{aligned}
$$

Where $\eta_{l}$ is the length efficiency factor, $\eta_{0}$ and $\eta^{\prime}{ }_{0}$ are the orientation factor before and after cracking of the composite material respectively, and $V_{f}$ is the fiber volume fraction of BMF.

The theoretical mid-span deflection results at service load (40\% of ultimate load) for the 16 tested beams in this project are compared with the experimentally measured values using the LVDTs in Table 5.3 and Figure 5.3. 
Table 5.3 Theoretical and Experimental Mid-Span Deflection of the Tested Beams

\begin{tabular}{cccccc}
\hline Beam & RCA & BMF & $\Delta$ theoretical & $\Delta$ Experimental & $\Delta$. exp. $/ \Delta$. theo. \\
ID & \% & $\%$ & $\begin{array}{c}\text { \% 40Pu } \\
(\mathbf{m m})\end{array}$ & $\begin{array}{c}\text { @ 40Pu } \\
(\mathbf{m m})\end{array}$ & \\
& & & 6.12 & 3.95 & 0.65 \\
A1 & 0 & 0 & 5.80 & 3.70 & 0.64 \\
A2 & 25 & 0 & 6.01 & 3.84 & 0.64 \\
A3 & 50 & 0 & 6.10 & 3.93 & 0.64 \\
A4 & 100 & 0 & 5.99 & 5.31 & 0.89 \\
A5 & 0 & 0.5 & 6.71 & 3.78 & 0.56 \\
A6 & 25 & 0.5 & 6.32 & 3.79 & 0.60 \\
A7 & 50 & 0.5 & 6.24 & 3.61 & 0.58 \\
A8 & 100 & 0.5 & 6.41 & 3.94 & 0.61 \\
A9 & 0 & 1 & 6.04 & 4.33 & 0.72 \\
A10 & 25 & 1 & 5.86 & 4.31 & 0.73 \\
A11 & 50 & 1 & 6.14 & 4.16 & 0.68 \\
A12 & 100 & 1 & 5.95 & 4.47 & 0.75 \\
A14 & 25 & 1.5 & 5.59 & 4.01 & 0.72 \\
A15 & 50 & 1.5 & 6.24 & 4.55 & 0.73 \\
A16 & 100 & 1.5 & & & \\
\hline
\end{tabular}



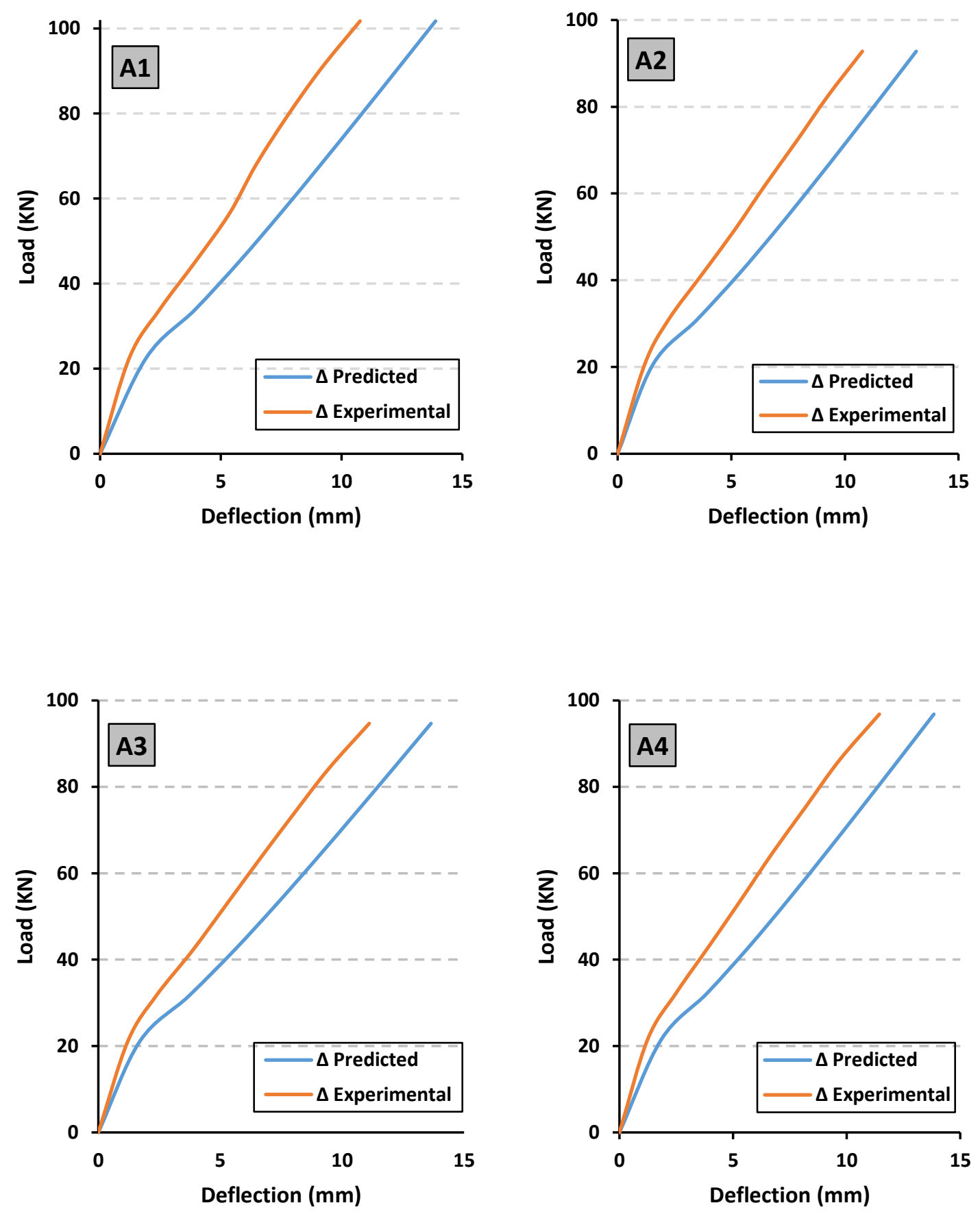

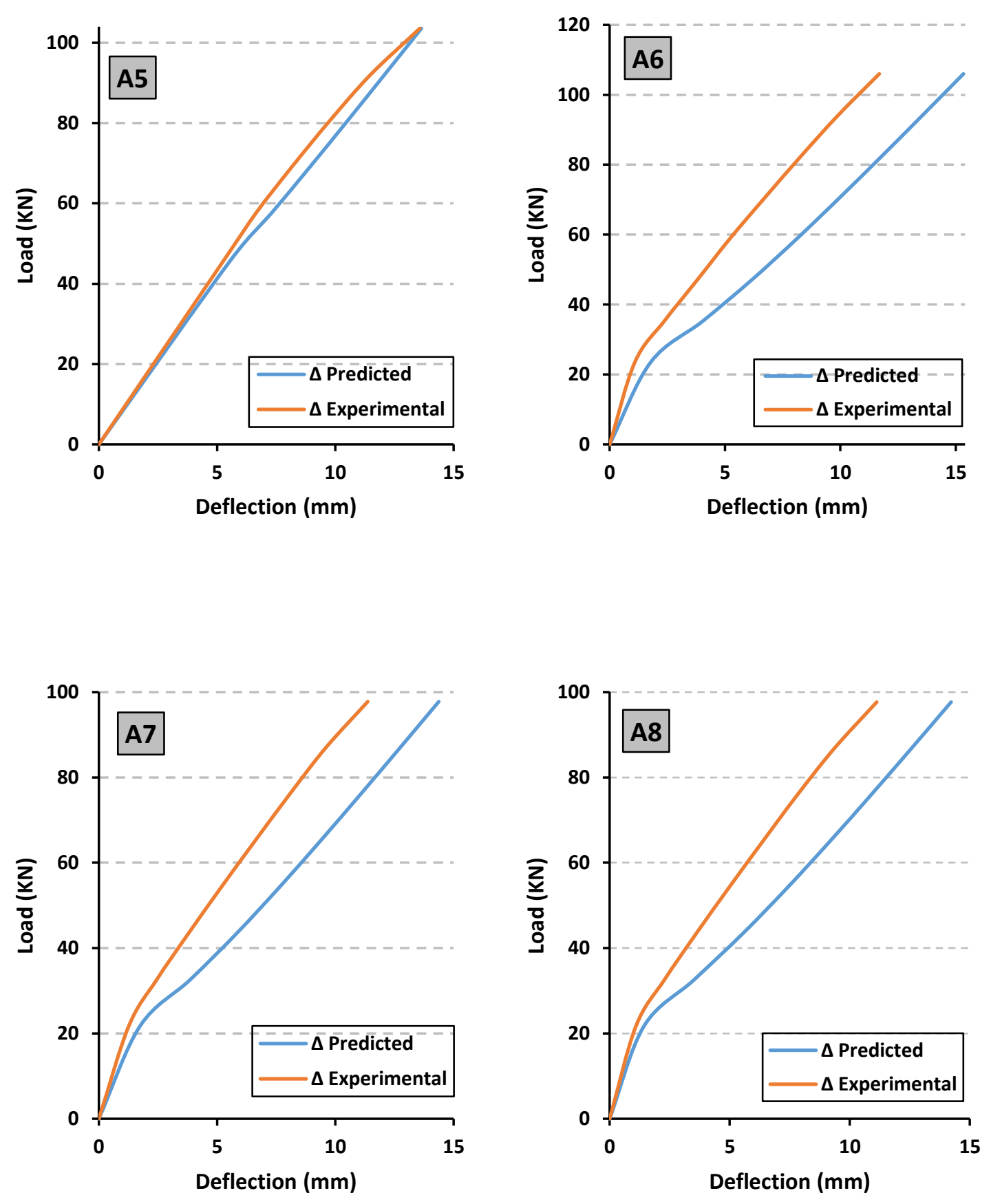

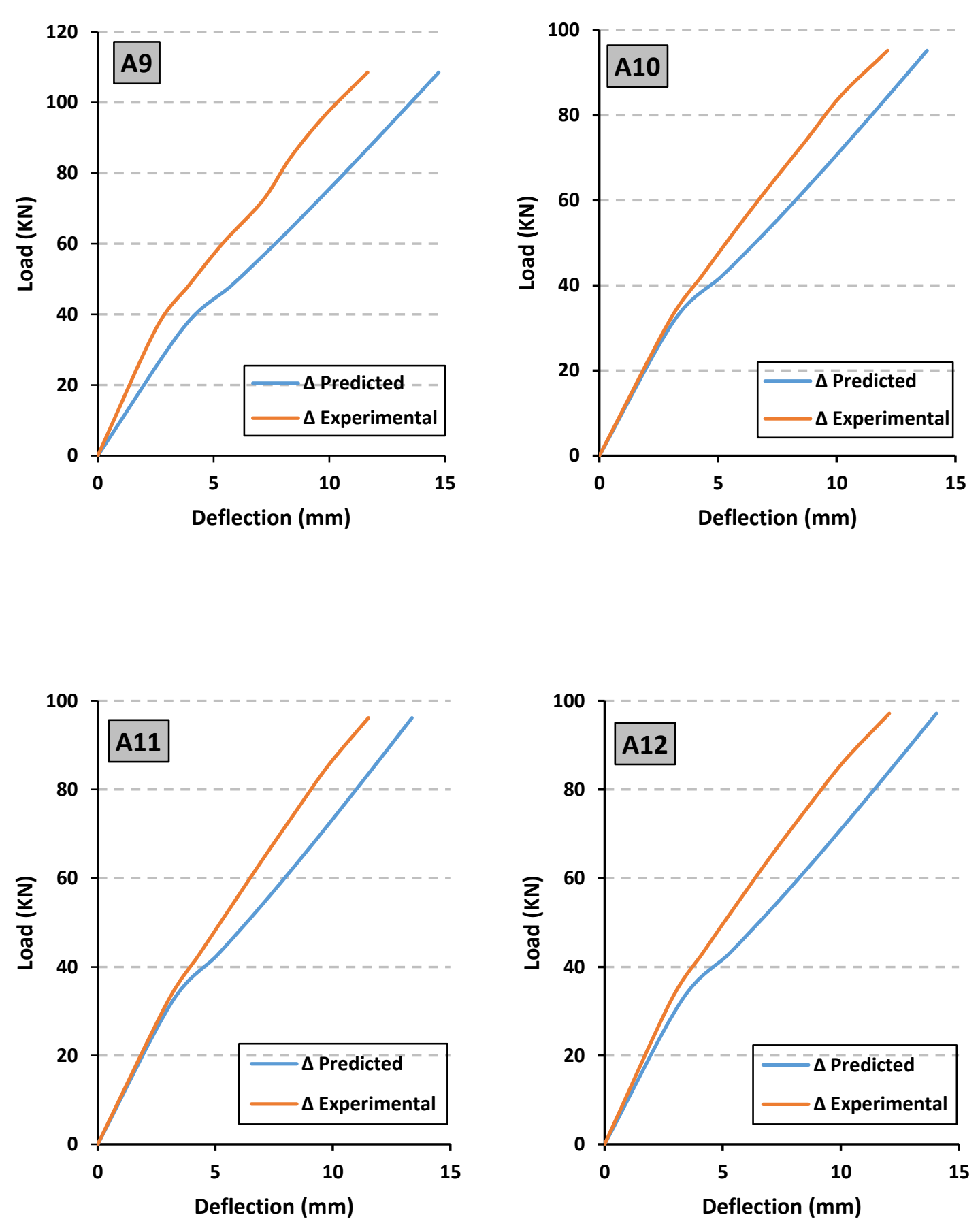

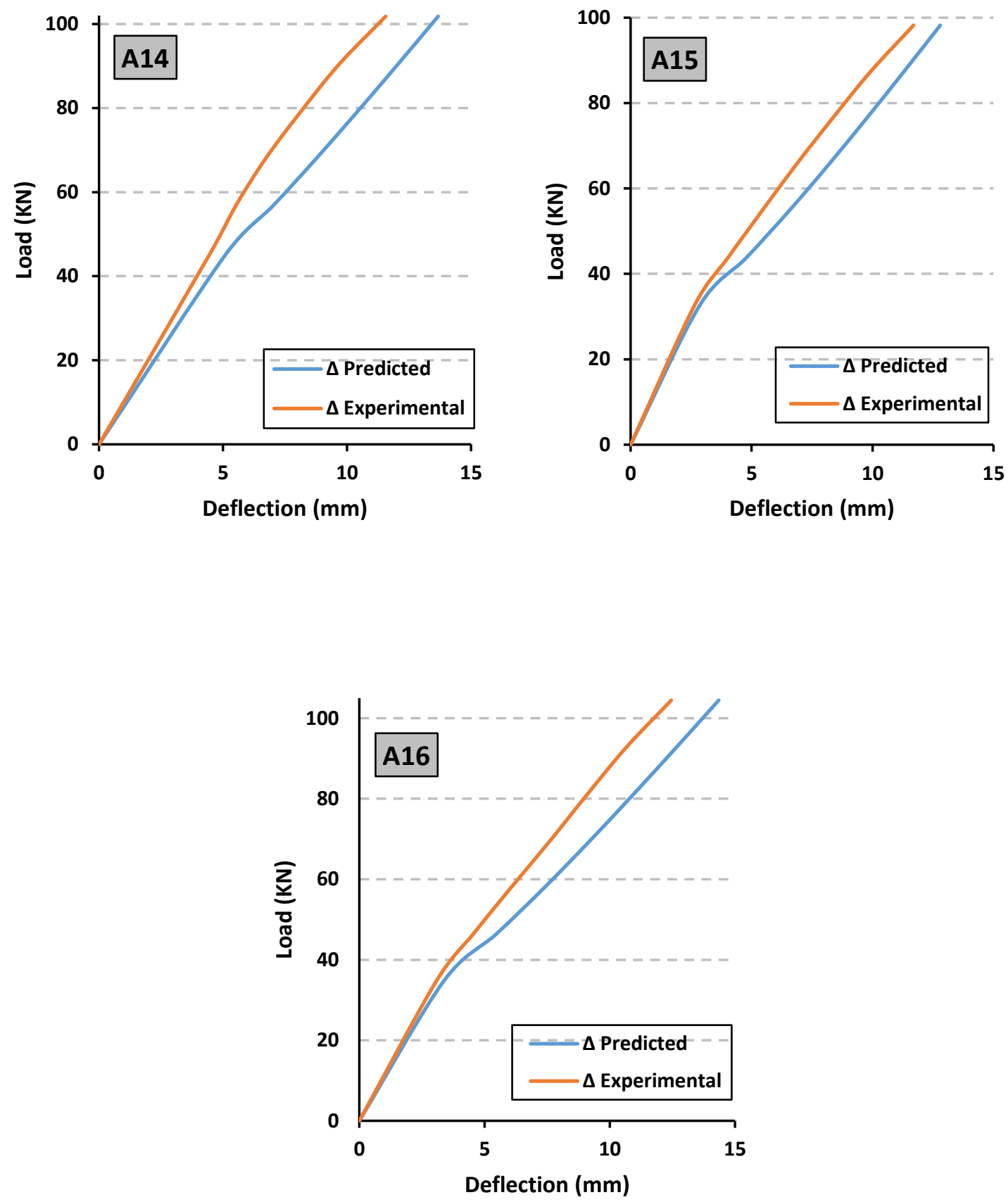

Figure 5.3 Comparison of Predicted and Experimental Deflection 
The immediate mid-span deflection of reinforced RCA concrete beams at $40 \%$ of their corresponding ultimate load were predicted based on (ACI 318 2014), and the immediate mid-span deflection of reinforced RCA concrete beams with BMF were predicted based on proposed method by (Tan et al 1994). According to Table 5.3, there is no major difference observed between the $\Delta_{\text {.exp. }} / \Delta_{\text {.theo. }}$. values of conventional reinforced concrete beam and RCA concrete beams with or without BMF. This verifies the applicability of both deflection calculations methods to reinforced RCA concrete beams with or without BMF. 


\section{CHAPTER 6}

\section{SUMMARY, CONCLUSION AND RECOMMENDATIONS}

\subsection{SUMMARY}

The summary of this study that includes coordinated experimental and theoretical studies that were performed on 16 large-scale beams were casted to investigate the influence of different replacement ratio of recycled concrete aggregates (RCA) and different volume fraction of basalt macro fiber (BMF) on the flexural behavior of the beams. All 16 beams were tested under four point bending until failure. The deflection, compressive concrete strain, tensile steel strain, and ductility of the tested beams were measured and recorded. The testing results of the specimens were compared to the control beam specimen with NCA, without BMF. The theoretical and experimental results showed improvement in the flexural capacity of the beam specimens with the addition of BMF, while there are no remarkable effects of RCA on flexural strength of the tested beams. Test results clearly showed that both RCA and BMF can be used as sustainable and eco-friendly alternative materials in concrete structures.

\subsection{CONCLUSION}

The following conclusion can be drawn based on the finding of the experimental and analytical investigation:

1. The RCA show higher water absorption ratio compared with NCA due to the residual mortar, that remains attached to the surface of the RCA. RCA has a relatively lower specific gravity and higher L.A abrasion ratio compared with NCA.

2. Adding macro fibers to the concrete mix may create pouring and workability problems depending on the volume fraction of $\mathrm{BMF}$, the proper mix design, and the percentage of chemical additives. Based on the experimental results of this research, it was found that the optimum volume fraction of BMF and chemical additive dosages is recommended as $1 \%$ and $400 \mathrm{ml} / \mathrm{m}^{3}$ respectively.

3. The addition of RCA into concrete has little-to-no effect on the compressive strength of the concrete mix. This is mainly due to the use of the absolute volume 
concrete mixture method with saturated surface dry RCA, which imposed the largest positive effect on the concrete compressive strength.

4. The addition of different volume of BMF into concrete has little-to-no effect on the compressive strength of the concrete mix. That is because there is no clear correlation between the two parameters.

5. It was observed that the addition of BMF resulted in an increase in the flexural tensile strength of the concrete mix. BMF acts as a proactive reinforcement that provides the immediate tensile load carrying capacity when micro cracks develop in concrete.

6. The addition of RCA into concrete has little effect on the flexural tensile strength of the concrete mix. This is because the negative effect related to the weakness of the old interfacial transition zone in RCA as the flexural strength is mainly dependent on the bond strength between aggregate and cement matrix.

7. There is an improvement in ductility of the beams with BMF, with same replacement ratio of RCA as compared to concrete beams without fibers. The improvement on the ductility of the concrete with the addition of BMF is encouraging, particularly for the large-scale beams, due to the impact it can have on the overall serviceability limit states of fiber reinforced concrete structures. The observed high compressive strain in concrete indicated that the beams with BMF are ductile enough to allow moment redistribution in beam.

8. The beams with BMF showed higher cracking and ultimate moment capacity compared to the beams without BMF. The ultimate load values were slightly greater for beams with BMF than the companion beams without BMF for all replacement ratios of RCA.

9. In terms of crack pattern, the beams with BMF experienced a lower number of cracks, because the BMF redistribute the tensile stress in $\mathrm{RC}$ beam.

10. The evaluation of the strain in the longitudinal reinforcement shows that, by controlling the crack opening fibers make a tensile mechanical contribution that induces relaxation in steel bars. 
11. The mid-span deflections of reinforced RCA concrete beams with BMF showed higher deflection, than the control beam without BMF, and the effect of RCA has been reduced by using BMF and there is no effect by adding $1 \%$ and more of BMF.

12. The theoretical calculation values of cracking moment $\left(M_{c r}\right)$ and ultimate flexural moment $\left(M_{u}\right)$ based on the code-based equations are reasonably close to the experimental results for all beams.

13. The theoretical calculation values of instantaneous deflection $(\Delta \mathrm{i})$ based on the code-based equations and proposed equations are satisfactory, and give accurate prediction over the range of variables and tested parameters.

\subsection{RECOMMENDATIONS}

The results of this research project show that it is possible to use recycled concrete aggregates produced from construction and demolition wastes in constructing structural concrete elements. However, the quality of the concrete made with RCA depends on the material properties and the quality of the demolished structures. In order to overcome this obstacle, it is recommended to use MBF in order to improve the concrete mechanical properties. BMF reduces the micro-cracks and provides ductility to concrete which improve concrete durability and help structural members to function after cracks. It also increases the bond between RCA and concrete matrix. This research project will inspire the acceptance of using of fiber reinforced concrete with recycled concrete aggregates.

\subsection{FUTURE WORK}

Overall, further research work is still required in order to understand and quantify the effects of using different types of fibers on the behavior of concrete made with RCA. Additional research work is essential to study the durability and long term performance of concrete with RCA and BMF in a service environment. In addition, the shear behavior of Basalt FRC beams with RCA is necessary. Replacement of fine aggregates with recycled fine aggregates was not included in the scope of this study, and it is important to be explored in a future research work. Research studies to evaluate the effects of using self- 
compacting concrete(SCC) with RCA and BMF could also be performed. Further research is needed on the influence of elevated temperature on the strength of basalt FRC beams. 


\section{REFERENCES}

Abbas, A. et al., 2007. Environmental benefits of green concrete. 2006 IEEE EIC Climate Change Technology Conference, EICCCC 2006.

Abdulla, N.A., 2012. Effect of Recycled Coarse Aggregate Type on Concrete. Asce, 150(Astm), pp.1-9.

ACI 315-99, 1999. Details and Detailing of Concrete Reinforcement Reported by ACI Committee 315, Farmington Hills,MI.

ACI 318M-14, 2014. Building Code Requirements for Structural Concrete, Farmington Hills,MI.

ACI Comite 544, 2002. State of the Art Report on Fiber Reinforced Concrete Reported (ACI 544.1R-96 Reapproved 2002). ACI Structural Journal, 96(Reapproved), p.66.

Al-Ansary, M. \& Iyengar, S.R., 2013. Physiochemical characterization of coarse aggregates in Qatar for construction industry. International Journal of Sustainable Built Environment, 2(1), pp.27-40.

Anil, P., Len, M. \& Sudeep, A., 2013. Basalt Frp Minibar Reinforced Concrete. In pp. 5152.

Arezoumandi, M. et al., 2015. An experimental study on flexural strength of reinforced concrete beams with $100 \%$ recycled concrete aggregate. Engineering Structures, 88, pp.154-162.

ASTM C127, 2015. Standard Test Method for Relative Density (Specific Gravity) and Absorption of Coarse Aggregate, American Society for Testing and Materials, West Conshohocken,PA,USA.

ASTM C131, 2015. Standard Test Method for Resistance to Degradation of Small-Size

Coarse Aggregate by Abrasion and Impact in the Los Angeles Machine, American Society for Testing and Materials, West Conshohocken,PA,USA.

ASTM C136, 2015. Standard Test Method for Sieve Analysis of Fine and Coarse Aggregates 1, American Society for Testing and Materials,West Conshohocken,PA,USA.

ASTM C150, 2007. Standard Specification for Portland Cement, American Society for Testing and Materials,West Conshohocken,PA,USA. 
ASTM C192, 2016. Standard Practice for Making and Curing Concrete Test Specimens in the Laboratory, American Society for Testing and Materials, West Conshohocken,PA,USA.

ASTM C39, 2016. Standard Test Method for Compressive Strength of Cylindrical Concrete Specimens, American Society for Testing and Materials,West Conshohocken,PA,USA.

ASTM C78, 2010. Standard Test Method for Flexural Strength of Concrete (Using Simple Beam with Third-Point Loading ) 1, American Society for Testing and Materials,West Conshohocken,PA,USA.

Bajaj, S., 2012. Effect of Corrosion on Physical and Mechanical Properties of Reinforced Concrete (Theses).

Banibayat, P. \& Patnaik, A., 2014. Variability of mechanical properties of basalt fiber reinforced polymer bars manufactured by wet-layup method. Materials and Design, 56, pp.898-906.

Byung, B. \& Oh, H., 1993. FLEXURAL ANALYSIS O F REINFORCED CONCRETE by volume. The various properties were measured during the tests in order to explore the mechanical characteristics of fiber-reinforced concrete beams. Size effects were not investigated nor considered in develo. , 118(10), pp.2821-2835.

Çakir, O., 2014. Experimental analysis of properties of recycled coarse aggregate (RCA) concrete with mineral additives. Construction and Building Materials, 68, pp.17-25.

Choi, W.-C. \& Yun, H.-D., 2013. Long-term deflection and flexural behavior of reinforced concrete beams with recycled aggregate. Materials \& Design, 51, pp.742-750.

Das, W., 2005. Der Einfluss von Basaltfasern auf aus- gewählte physische und mechanische Eigenschaften von Zementmörtel The impact of basaltic fibre on selected physi- cal and mechanical properties of cement mortar. , pp.28-33.

Dias, D.P. \& Thaumaturgo, C., 2005. Fracture toughness of geopolymeric concretes reinforced with basalt fibers. Cement and Concrete Composites, 27(1), pp.49-54.

Dilbas, H., Şimşek, M. \& Çakır, Ö., 2014. An investigation on mechanical and physical properties of recycled aggregate concrete (RAC) with and without silica fume. Construction and Building Materials, 61(March 2006), pp.50-59.

Dong, J.F., Wang, Q.Y. \& Guan, Z.W., 2017. Material properties of basalt fibre reinforced 
concrete made with recycled earthquake waste. Construction and Building Materials, 130, pp.241-251.

Emmanuelle Landais, 2008. Construction waste "needs attention" | GulfNews.com. Gulf News.

Fathifazl, G. et al., 2010. Flexural Performance of Steel-Reinforced Recycled Concrete Beams. , (106).

Fritih, Y. et al., 2013. Flexural and shear behavior of steel fiber reinforced SCC beams. KSCE Journal of Civil Engineering, 17(6), pp.1383-1393.

Grdic, Z.J. et al., 2010. Properties of self-compacting concrete prepared with coarse recycled concrete aggregate. Construction and Building Materials, 24(7), pp.11291133.

Güneyisi, E. et al., 2014. Effect of surface treatment methods on the properties of selfcompacting concrete with recycled aggregates. Construction and Building Materials, 64, pp.172-183.

High, C. et al., 2015. Use of basalt fibers for concrete structures. Construction and Building Materials, 96, pp.37-46.

Holschemacher, K., Mueller, T. \& Ribakov, Y., 2010. Effect of steel fibres on mechanical properties of high-strength concrete. Materials and Design, 31(5), pp.2604-2615.

Huda, S.B. \& Alam, M.S., 2014. Mechanical behavior of three generations of $100 \%$ repeated recycled coarse aggregate concrete. Construction and Building Materials, 65, pp.574-582.

Jiang, C. et al., 2014. Experimental study on the mechanical properties and microstructure of chopped basalt fibre reinforced concrete. Materials \& Design, 58, pp.187-193.

Kang, T.H.-K. et al., 2014. Flexural Testing of Reinforced Concrete Beams with Recycled Concrete Aggregates (with Appendix). Structural Journal, 111(3), pp.607-616.

Katz, A., 2004. Treatments for the Improvement of Recycled Aggregate. Journal of Materials in Civil Engineering, 16(6), pp.597-603.

Katzer, J. \& Domski, J., 2012. Quality and mechanical properties of engineered steel fibres used as reinforcement for concrete. Construction and Building Materials, 34, pp.243248.

Kiang-Hwee Tan, P. Paramasivam, \& K.-C.T., 1994. Creep and Shrinkage Deflections of 
RC Beams With Steel Fibers. , 6(4), pp.474-494.

Knaack, A.M. \& Kurama, Y.C., 2014. Behavior of Reinforced Concrete Beams with Recycled Concrete Coarse Aggregates. ASCE Journal of Structural Engineering, 141(Special Issue: Sustainable Building Structures), pp.1-12.

Kou, S.C. \& Poon, C.S., 2009. Properties of self-compacting concrete prepared with coarse and fine recycled concrete aggregates. Cement and Concrete Composites, 31(9), pp.622-627.

Kutalmıs Recep Akça a, Özgür Çakır b, M. Ipek a, 2015. Properties of fiber reinforced concrete using recycled aggregates. European Conference of Chemical Engineering, 98, pp.620-630.

Liang, Y.-C. et al., 2013. Development of Processing Methods to Improve Strength of Concrete with 100\% Recycled Coarse Aggregate. Journal of Materials in Civil Engineering, 27(5), p.130801045339002.

McNeil, K. \& Kang, T.H.K., 2013. Recycled Concrete Aggregates: A Review. International Journal of Concrete Structures and Materials, 7(1), pp.61-69.

Mertol, H.C., Baran, E. \& Bello, H.J., 2015. Flexural behavior of lightly and heavily reinforced steel fiber concrete beams. Construction and Building Materials, 98, pp.185-193.

Mohammadi, Y. et al., 2009. Impact resistance of steel fibrous concrete containing fibres of mixed aspect ratio. Construction and Building Materials, 23(1), pp.183-189.

Panda, K.C. \& Bal, P.K., 2013. Properties of self compacting concrete using recycled coarse aggregate. Procedia Engineering, 51(NUiCONE 2012), pp.159-164.

Pereira-De-Oliveira, L.A. et al., 2014. Permeability properties of self-Compacting concrete with coarse recycled aggregates. Construction and Building Materials, 51, pp.113120.

Poon, C.S. \& Chan, D., 2007. The use of recycled aggregate in concrete in Hong Kong. Resources, Conservation and Recycling, 50(3), pp.293-305.

Project, I., 1997. Basalt Fiber Composite Reinforcement for Concrete, Madison, Wisconsin.

Purushothaman, R., Amirthavalli, R.R. \& Karan, L., 2000. Influence of Treatment Methods on the Strength and Performance Characteristics of Recycled Aggregate Concrete. 
Journal of Materials in Civil Engineering, 27(5).

Qatar 2022 bidding committee official website, 2011. Qatar 2022. Available at: www.qatar2022bid.com.

Qatar Customs, 2010. Qatar Customs Database. Available at: http://www.qsa.gov.qa/Eng/\%0ALatestPublications.htm.

Qatar Steel, 2016. Product Specification - Deformed Bars. Available at: http://www.qatarsteel.com.qa/Products/Specification/SitePages/bars.aspx.

QCS, 2014. Qatar Construction Specifications, State of Qatar.

ReforceTech, 2016. Chopped Basalt Fiber, Republic of Ireland.

Shah, S.P. et al., 1999. Design Considerations for Steel Fiber Reinforced Concrete. , 88(Reapproved).

Silva, R. V., De Brito, J. \& Dhir, R.K., 2014. Properties and composition of recycled aggregates from construction and demolition waste suitable for concrete production. Construction and Building Materials, 65, pp.201-217.

Subramanian, N. \& Engineer, C., 2010. Sustainability of RCC Structures. , 1(September), pp.1-6.

Sudeep Adhikari, 2013. MECHANICAL AND STRUCTURAL CHARACTERIZATION OF MINI-BAR REINFORCED CONCRETE BEAMS A Dissertation Presented to The Graduate Faculty of The University of Akron In Partial Fulfillment of the Requirements for the Degree Doctor of Philosophy Sudeep Adhikari.

Tumadhir, M., 2013. Thermal and Mechanical Properties of Basalt Fibre Reinforced Concrete. , 7(4), pp.712-715.

Urbanski, M., Lapko, A. \& Garbacz, A., 2013. Investigation on concrete beams reinforced with basalt rebars as an effective alternative of conventional R/C structures. Procedia Engineering, 57, pp.1183-1191. Available at: http://dx.doi.org/10.1016/j.proeng.2013.04.149.

Zhang, W.T. \& Ingham, J.M., 2010. Using Recycled Concrete Aggregates in New Zealand Ready-Mix Concrete Production. Journal of Materials in Civil Engineering, 22(5), pp.443-450. 